VANESCA SARTORELLI MEDEIROS

\title{
ANÁLISE ESTATÍSTICA DE EVENTOS CRÍTICOS DE PRECIPITAÇÃO RELACIONADOS A DESASTRES NATURAIS EM DIFERENTES REGIÕES DO BRASIL
}




\section{ANÁLISE ESTATÍSTICA DE EVENTOS CRÍTICOS DE PRECIPITAÇÃO RELACIONADOS A DESASTRES NATURAIS EM DIFERENTES REGIÕES DO BRASIL}

Dissertação apresentada à Escola Politécnica da Universidade de São Paulo para obtenção do título de Mestre em Engenharia

Área de concentração:

Engenharia Hidráulica

Orientador:

Mario Thadeu Leme de Barros

\section{São Paulo}


Este exemplar foi revisado e corrigido em relação à versão original, sob responsabilidade única do autor e com a anuência de seu orientador.

São Paulo, 13 de maio de 2013.

Assinatura do autor

Assinatura do orientador

FICHA CATALOGRÁFICA

Medeiros, Vanesca Sartorelli

Análise estatística de eventos críticos de precipitação relacionados a desastres naturais em diferentes regiões do Brasil / V.S. Medeiros. -- versão corr. -- São Paulo, 2013.

$207 \mathrm{p}$.

Dissertação (Mestrado) - Escola Politécnica da Universidade de São Paulo. Departamento de Engenharia Hidráulica e Ambiental.

1. Chuva 2. Inundações 3. Desastres ambientais 4. Deslizamento de terra I. Universidade de São Paulo. Escola Politécnica. Departamento de Engenharia Hidráulica e Ambiental II. t. 


\section{DEDICATÓRIA}

Aos meus pais, pelo amor, dedicação, carinho e educação, a minha amada irmã e ao meu querido namorado. 


\section{AGRADECIMENTOS}

Ao amigo e orientador Mario Thadeu Leme de Barros, pela orientação, confiança e amizade, a quem serei eternamente grata pelos ensinamentos e sabedoria compartilhados durante a elaboração desta dissertação.

Ao meu pai, Paulo Medeiros, in memoriam, a minha mãe, Geni Aparecida Sartorelli e a minha irmã Verusca Sartorelli Medeiros, pelo amor incondicional e por me apoiarem nos momentos mais importantes de minha vida.

Ao meu querido namorado, Luiz Fernando Medeiros Xavier, pelo amor, carinho, admiração, cuidado, companheirismo, incentivo e compreensão.

À minha prima Daniela Saes Sartorelli, pelo exemplo de amor e dedicação à pesquisa.

Ao Departamento de Engenharia Hidráulica e Ambiental da Escola Politécnica da USP, em especial aos professores Renato Carlos Zambon, Monica Ferreira do Amaral Porto e Rubem La Laina Porto.

Aos professores José Rodolfo Scarati Martins e João Luiz Boccia Brandão, pela valiosa contribuição na qualificação e na defesa desta dissertação.

Aos professores José Augusto de Lollo e Pérsio Marconi pelo incentivo no início desta pesquisa.

À CPRM - Companhia de Pesquisa de Recursos Minerais, em especial aos amigos Eber José de Andrade Pinto, Carlos Eduardo de Oliveira Dantas, Karine Pickbrenner, Ana Carolina Costi Zoppas, Angela Maria de Godoy Theodorovcs, Lauro Gracindo Pizzatto e José Carlos Garcia Ferreira pelo incentivo e contribuição.

A todos os meus amigos, a Cristina Maria Pereira, Cristiane Bettini de Souza, Alexandra Bortoluzzo, Ana Claudia Gonçalves Rossi, Alexandre Rodrigues de Castro, Richard Calanca e William Nakamura pela amizade e por compartilharem momentos especiais de minha vida.

A todos que, direta ou indiretamente, contribuíram para a realização deste estudo. 
Chove. Há Silêncio.

Chove. Há silêncio, porque a mesma chuva Não faz ruído senão com sossego. Chove. O céu dorme. Quando a alma é viúva Do que não sabe, o sentimento é cego. Chove. Meu ser (quem sou) renego...

Tão calma é a chuva que se solta no ar (Nem parece de nuvens) que parece Que não é chuva, mas um sussurrar Que de si mesmo, ao sussurrar, se esquece.

Chove. Nada apetece...

Não paira vento, não há céu que eu sinta. Chove longínqua e indistintamente, Como uma coisa certa que nos minta, Como um grande desejo que nos mente.

Chove. Nada em mim sente...

Fernando Pessoa, "Cancioneiro" 


\section{RESUMO}

A dissertação apresenta um estudo das chuvas extremas relacionadas a quatro desastres naturais ocorridos no Brasil: as inundações do Vale do Itajaí - SC, em novembro de 2008, a inundação histórica de São Luís do Paraitinga - SP, em janeiro de 2010, as inundações ocorridas no Vale do Mundaú - AL, em junho de 2010 e as inundações e escorregamentos da Região Serrana - RJ, em janeiro de 2011. As chuvas catastróficas foram analisadas através de estatísticas básicas dos dados dos pluviômetros localizados nas regiões. No Vale do Itajaí, as chuvas registradas nos dias 23 e 24 de novembro foram elevadas, atingindo valores acima de $250 \mathrm{~mm}$. Na estação Blumenau, choveu $243,5 \mathrm{~mm}$ e $250,9 \mathrm{~mm}$ nesses. $\mathrm{Na}$ estação localizada em São Luís do Paraitinga, choveu apenas $64,7 \mathrm{~mm}$ no dia 1 de janeiro de 2010, quando ocorreu a inundação. Porém, foram observados 205,7 mm em uma das estações localizadas em Cunha. Nesse caso, o elevado volume precipitado na cabeceira da bacia deflagrou as inundações observadas nos dois municípios. No Vale do Mundaú e Paraíba, choveu cerca de $200 \mathrm{~mm}$ no dia 5 de junho, em duas das seis estações analisadas. $O$ elevado volume precipitado no dia 5 , combinado com as chuvas ocorridas no período de 17 a 19, pode ter causado as inundações observadas no dia 19 nessas bacias. Os dados indicaram que, na Região Serrana do RJ, as inundações e escorregamentos foram causados pela chuva extrema ocorrida nos dias 11 e 12 de janeiro de 2011, que ultrapassou 270 $\mathrm{mm}$ no intervalo de $24 \mathrm{~h}$ em uma das estações. As chuvas acumuladas nos meses que antecedem os eventos e a alta declividade contribuíram para a saturação do solo e posteriores escorregamentos. Os eventos pluviométricos, classificados através do SPI resultaram, na maioria das estações, chuvas severas ou chuvas extremas A vulnerabilidade das regiões, onde inúmeras habitações estão localizadas em áreas de risco, também foi determinante para que os desastres acontecessem. Outros eventos de magnitude elevada foram observados anteriormente, o que indica que estes eventos são característicos das regiões estudadas. Constatou-se que as regiões analisadas estão sujeitas a chuvas extremas com frequência relativamente alta, muito embora tenha sido observado, em alguns casos, certo grau de raridade nesses eventos. Portanto, nessas áreas devem ser adotadas medidas regionais no sentido de disciplinar o uso e ocupação do solo e reduzir os riscos dos desastres. É 
fundamental buscar medidas de adaptação da ocupação dessas áreas, considerando o regime hidrológico dessas regiões.

Palavras-chave: Eventos extremos, chuvas, desastres naturais, inundações, escorregamentos. 


\section{ABSTRACT}

The paper presents a study of extreme rainfall related to four natural disasters occurring in Brazil: the floods in Itajaí Valley, state of Santa Catarina, in November, 2008; the historic flood in São Luís do Paraitinga, state of São Paulo, in January, 2010; the floods in Mundaú Valley, state of Alagoas, in June, 2010; and the floods and landslides in the mountainous region of Rio de Janeiro in January, 2011. The catastrophic rains were analyzed through basic statistical data collected from rain gauges located in those regions. In Itajaí Valley, extremely high rainfalls exceeding $250 \mathrm{~mm}$ were recorded on November 23 and 24. In Blumenau, it rained $243.5 \mathrm{~mm}$ and $250.9 \mathrm{~mm}$ on the same days. At the station located in São Luís do Paraitinga, it rained just $64.7 \mathrm{~mm}$ on January 1, 2010, when the flood occurred. However, 205.7 $\mathrm{mm}$ were observed in one of the stations located in Cunha. In this case, the high volume of rainfall at the headwater of the basin triggered flooding observed in these two cities. In the valleys of Mundaú and Paraíba, it rained nearly $200 \mathrm{~mm}$ on June 5, in two of the six stations analyzed. The high volume of rainfall on June 5 , combined with the rains from the $17^{\text {th }}$ to the $19^{\text {th }}$, may have led to the floods in these basins on June 19. The data indicated that, in the mountainous region of Rio de Janeiro, the flooding and landslides were caused by massive rainfall on January 11 and 12, 2011, which exceeded $270 \mathrm{~mm}$ within a period of 24 hours in one of the stations. The rainfall accumulated in the months prior to the events and the high sloping land contributed to soil saturation and subsequent landslides. The rainfall events, sorted through the SPI, resulted in severe or extreme rains in most of the stations. The vulnerability of the regions, which include many homes located in hazardous areas, was also crucial for the disasters to happen. Other major events were previously observed, which indicates that these events are characteristic of the studied regions. It was noted that the analyzed regions are subject to extreme rains with a relatively high frequency, although in some cases these events have demonstrated to be somewhat rare. Therefore, in these areas, region-based measures should be adopted with a view to regulating the use and occupation of the soil and reducing risk of disasters. It is essential to seek adaptation measures of occupation of these areas, considering their hydrological regime.

Key words: Extreme events, rainfall, natural disasters, floods, landslides. 


\section{LISTA DE FIGURAS}

Figura 1 - Localização das Regiões estudadas no Brasil: Vale do Itajaí - SC, São Luís do Paraitinga

e Cunha - SP, Vale do Mundaú - AL, e Região Serrana do RJ (Fonte: Google Earth)

Figura 2 - Níveis d'água da seção fluviométrica Pirajuçara, localizada no rio Pirajuçara em São Paulo - SP (Fonte: SAISP)

Figura 3 - llustração esquemática dos procedimentos de cálculo do SPI (Fonte: Santos et al., 2013)

Figura 4 - Inundações ocorridas em novembro de 2008 nos municípios: Itajaí, Alto Baú em llhota, Timbó e Blumenau (da esquerda para a direita, de cima para baixo) ................................................ 50

Figura 5 - Brusque (08/09/2011) (Timbó (09/09/2011) Blumenau (10/09/2011) Rio Itajaí ................... 51

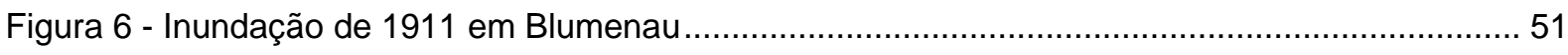

Figura 7 - Localização dos seis postos utilizados na da bacia do rio Itajaí-Açu................................... 53

Figura 8 - Totais mensais dos anos 2008 e 2011 e média mensal histórica ........................................ 56

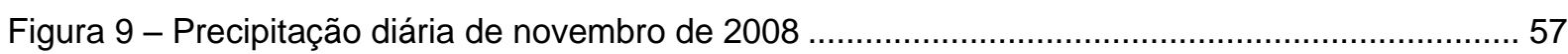

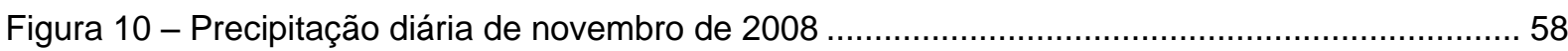

Figura 11 - Precipitação acumulada diária de novembro de 2008 e setembro de 2011 .................... 58

Figura 12 - Relação entre Tr e precipitações máximas para 1 dia de duração ................................... 61

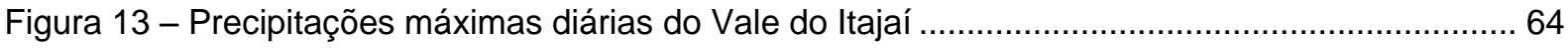

Figura 14 - Curvas das máximas acumuladas para as durações de 1 a 10 dias, 15, 20, 30 e 45 dias

Figura 15 - Classificação das chuvas máximas de duração de 1 dia - 2649004 - Timbó Novo ........... 70

Figura 16 - Classificação das chuvas máximas de duração de 1 dia - 2649005 - Indaial .................... 71

Figura 17 - Classificação das chuvas máximas de duração de 1 dia - 2649007 - Blumenau .............. 72

Figura 18 - Classificação das chuvas máximas de duração de 1 dia - 2649010 - Itoupava Central ... 73

Figura 19 - Classificação das chuvas máximas de duração de 1 dia - 2748000 - Brusque ................. 74

Figura 20 - Vista aérea do município de São Luís do Paraitinga no dia 2 de janeiro de 2010 ............ 76

Figura 21 - Vista aérea da cidade no dia 2/01/2010; prédio histórico danificado; escombros da Igreja das Mercês (Fonte: Sergio Neves/AE; Joel Silva/Folha Imagem; Mario Angelo/Folhapress).............. 77

Figura 22- Igreja Matriz e São Luís do Paraitinga após o desastre (Fotos: Verusca Sartorelli Medeiros)

Figura 23 - Localização dos seis postos utilizados na da bacia do Alto Paraíba do Sul ..................... 79

Figura 24 - Totais mensais dos anos 2009, 2010 e média mensal histórica .................................... 82

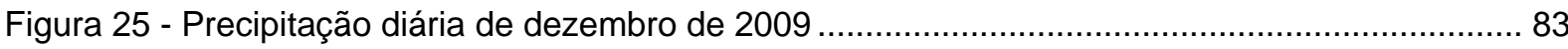

Figura 26 - Precipitação diária de janeiro de 2010 e acumulada de dezembro de 2009 e janeiro de

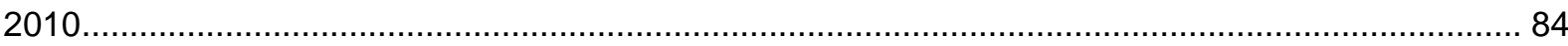

Figura 27 - Relação entre Tr e precipitações máximas para 1 dia de duração ………….................. 87

Figura 28 - Precipitações máximas diárias da região ................................................................. 90 
Figura 29 - Curvas das máximas acumuladas para as durações de 1 a 10 dias, 15, 20, 30 e 45 dias

Figura 30 - Classificação das chuvas máximas de duração de 1 dia - 2244048 - Campos de Cunha 97

Figura 31 - Classificação das chuvas máximas de duração de 1 dia - 2245055 - Estrada de Cunha 97

Figura 32 - Classificação das chuvas máximas de duração de 1 dia - 2344009 - Alto da Serra do Mar

Figura 33 - Classificação das chuvas máximas de duração de 1 dia - 2345065 - São Luís do

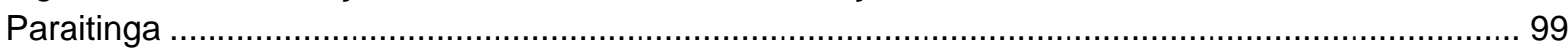

Figura 34 - Classificação das chuvas máximas de duração de 1 dia - 2345067 - Ponte Alta I........... 99

Figura 35 - Classificação das chuvas máximas de duração de 1 dia - 2245071 - Santa Branca...... 100

Figura 36 - Cenário de destruição em Quebrangulo (acima à esquerda) e União dos Palmares (abaixo à esquerda e à direita) (Fonte: Revista Isto é)

Figura 37 - Localização dos sete postos utilizados nas bacias dos rios Mundaú e Paraíba e precipitações médias anuais.

Figura 38 - Totais mensais dos anos 2008 e 2011 e média mensal histórica ..................................... 108

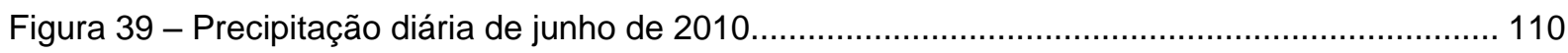

Figura 40 - Precipitação acumulada diária de junho de 2010 …................................................ 110

Figura 41 - Relação entre Tr e precipitações máximas para 1 dia de duração ................................ 113

Figura 42 - Precipitações máximas diárias do Vale do Mundaú e Paraíba ....................................... 116

Figura 43 - Curvas das máximas acumuladas para as durações de 1 a 10 dias, 15, 20, 30 e 45 dias

Figura 44 - Classificação das chuvas máximas de duração de 1 dia - 935012 - Murici .................... 123

Figura 45 - Classificação das chuvas máximas de duração de 1 dia - 935056 - Fazenda Boa Fortuna

Figura 46 - Classificação das chuvas máximas de duração de 1 dia - 935057 - Marechal Deodoro 124

Figura 47 - Classificação das chuvas máximas de duração de 1 dia - 2242024 - 936110 - Atalaia 125

Figura 48 - Classificação das chuvas máximas de duração de 1 dia - 936111 - Viçosa .................. 125

Figura 49 - Classificação das chuvas máximas de duração de 1 dia - 936112 - São José da Laje .. 126

Figura 50 - Classificação das chuvas máximas de duração de 1 dia - 936114 - Santana do Mundaú

Figura 51 - Classificação das chuvas máximas de duração de 1 dia - 936115 - Quebrangulo......... 127

Figura 52 - Município de Bom Jardim na Região Serrana do Rio de Janeiro................................... 130

Figura 53 - Comunidade de Campo Grande localizada no bairro Posse, município de Teresópolis

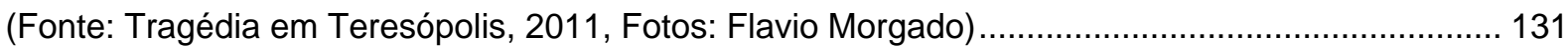

Figura 54 - Cicatrizes em Nova Friburgo e na Imagem do Google ................................................... 132

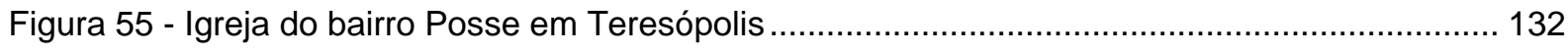

Figura 56 - Localização da Bacia do Paraíba do Sul e postos utilizados no estudo da Região Serrana

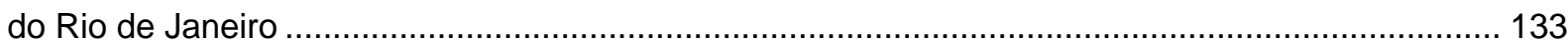

Figura 57 - Totais mensais dos anos 2010 e 2011 e média mensal histórica .................................. 136 
Figura 58 - Precipitação diária de janeiro de 2011

Figura 59 - Pluviograma da estação Vargem Alta das $7 \mathrm{~h}$ do dia 11 de janeiro de 2011 às $7 \mathrm{~h}$ do dia 12 de janeiro de 2011 (Fonte: CPRM)

Figura 60 - Relação entre Tr e precipitações máximas para 1 dia de duração ................................... 142

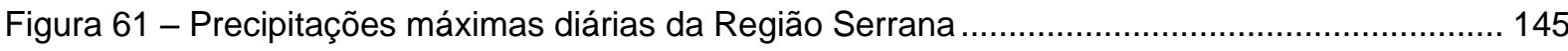

Figura 62 - Curvas das máximas acumuladas para as durações de 1 a 10 dias, 15, 20, 30 e 45 dias

Figura 63 - Classificação das chuvas máximas de duração de 1 dia - 2242019 - Vargem Alta........ 151

Figura 64 - Classificação das chuvas máximas de duração de 1 dia - 2242020 - Vargem Grande.. 152

Figura 65 - Classificação das chuvas máximas de duração de 1 dia - 2242022 - Fazenda Mendes 153

Figura 66 - Classificação das chuvas máximas de duração de 1 dia - 2242024 - Teodoro de Oliveira

Figura 67 - Classificação das chuvas máximas de duração de 1 dia - 2242027 - Fazenda Sobradinho 154

Figura 68 - Classificação das chuvas máximas de duração de 1 dia - 2243010 - Itamarati 155

Figura 69 - Classificação das chuvas máximas de duração de 1 dia - 2243011 - Rio da Cidade..... 155 


\section{LISTA DE TABELAS}

Tabela 1 - Os 10 mais importantes desastres causados por inundações no período de 2002 a 2011 classificados pelo número de mortos

Tabela 2 - Os dez principais Desastres Hidrológicos e Geofísicos no período de 1900 até 2012 , classificados segundo o número de vítimas

Tabela 3 - Estados do monitoramento do Sistema de Alerta do INEA 33

Tabela 4 - Valores críticos de $D_{N}, \alpha$

Tabela 5 - Classes de secas e chuvas e probabilidades associadas. 48

Tabela 6 - Classes de precipitações diárias máximas anuais (PDMA). 48

Tabela 7 - Relação das seis estações pluviométricas do Vale do Itajaí em SC 54

Tabela 8 - Chuvas de novembro de 2008, médias das máximas e médias mensais e anuais das estações do Vale do Itajaí

Tabela 9 - Resumo dos parâmetros estimados de cada distribuição

Tabela 10 - Períodos de retorno estimados para as máximas chuvas diárias 62

Tabela 11 - Resultados do Teste de KS para N > 40 e $\alpha=10 \%$.

Tabela 12 - Os cinco maiores eventos diários de precipitação $(\mathrm{em} \mathrm{mm})$ registrados em cada estação do Vale do Itajaí 65

Tabela 13 - SPI - 2649004 - Timbó Novo - Chuvas máximas anuais com duração de 1 dia ............. 70

Tabela 14 - SPI - 2649005 - Indaial - Chuvas máximas anuais com duração de 1 dia ....................... 71

Tabela 15 - SPI - 2649007 - Blumenau - chuvas máximas anuais com duração de 1 dia ................. 71

Tabela 16 - SPI - 2649008 - Arrozeira - chuvas máximas anuais com duração de 1 dia..................... 72

Tabela 17 - SPI - 2649010 - Itoupava Central - Chuvas máximas anuais com duração de 1 dia ........ 73

Tabela 18 - SPI - 2748000 - Brusque- Chuvas máximas anuais com duração de 1 dia ...................... 73

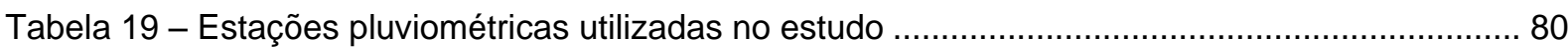

Tabela 20 - Chuvas de janeiro de 2010, médias das máximas e médias mensais e anuais das

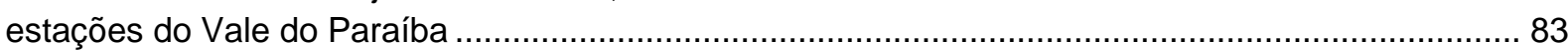

Tabela 21 - Resumo dos parâmetros estimados de cada distribuição ................................................ 85

Tabela 22 - Períodos de retorno estimados para as máximas chuvas diárias .................................... 88

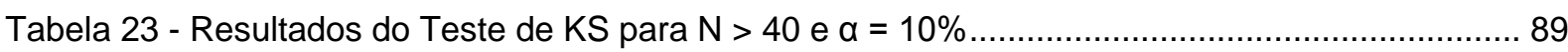

Tabela 24 - Os cinco maiores eventos diários de precipitação $(\mathrm{em} \mathrm{mm})$ registrados nas estações do Vale do Paraíba.

Tabela 25 - 2244048 - Campos de Cunha - Chuvas máximas anuais com duração de 1 dia ............ 96

Tabela 26 - SPI - 2245055 - Estrada de Cunha - Chuvas máximas anuais com duração de 1 dia .... 97

Tabela 27 - SPI - 2344009 - Alto da Serra do Mar - chuvas máximas anuais com duração de 1 dia 98

Tabela 28 - SPI - 2345065 - São Luís do Paraitinga - chuvas máximas anuais com duração de 1 dia 
Tabela 30 - SPI - 2245071 - Santa Branca - Chuvas máximas anuais com duração de 1 dia.......... 100

Tabela 31 - Relação das oito estações pluviométricas do Vale do Mundaú e Paraíba e, AL ........... 105

Tabela 32 - Chuvas de junho de 2010, médias das máximas e médias mensais e anuais das

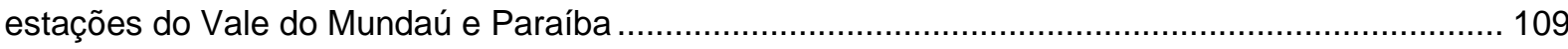

Tabela 33 - Resumo dos parâmetros estimados de cada distribuição ............................................. 111

Tabela 34 - Períodos de retorno estimados para as máximas chuvas diárias ................................. 114

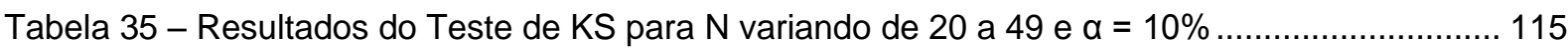

Tabela 36 - Os cinco maiores eventos diários de precipitação $(\mathrm{em} \mathrm{mm})$ registrados em cada estação do Vale do Mundaú e Paraíba.................................................................................................... 117

Tabela 37 - 935012 - Murici - Chuvas máximas anuais com duração de 1 dia .................................. 122

Tabela 38 - SPI - 935056 - Fazenda Boa Fortuna - Chuvas máximas anuais com duração de 1 dia

Tabela 39 - SPI - 935057 - Marechal Deodoro - chuvas máximas anuais com duração de 1 dia..... 124

Tabela 40 - SPI - 936110 - Atalaia - chuvas máximas anuais com duração de 1 dia ...................... 124

Tabela 41 - SPI - 936111 - Viçosa - Chuvas máximas anuais com duração de 1 dia ....................... 125

Tabela 42 - SPI - 936112 - São José da Laje - Chuvas máximas anuais com duração de 1 dia...... 126

Tabela 43 - SPI - 936114 - Santana do Mundaú - Chuvas máximas anuais com duração de 1 dia 126

Tabela 44 - SPI - 936115 - Quebrangulo - Chuvas máximas anuais com duração de 1 dia............ 127

Tabela 45 - Relação das sete estações pluviométricas da Região Serrana do RJ ............................ 134

Tabela 46 - Chuvas de janeiro de 2011, médias das máximas e médias mensais e anuais das

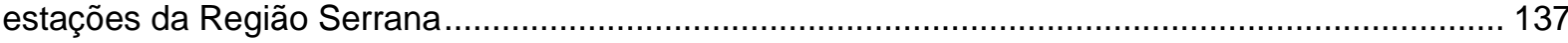

Tabela 47 - Resumo dos parâmetros estimados de cada distribuição ............................................ 140

Tabela 48 - Períodos de retorno estimados para as chuvas diárias................................................ 142

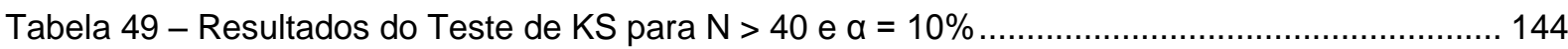

Tabela 50 - Os cinco maiores eventos diários de precipitação $(\mathrm{em} \mathrm{mm}$ ) registrados em cada estação

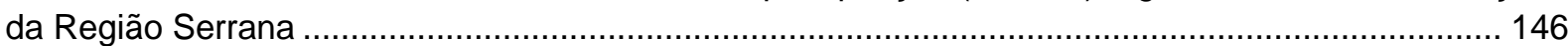

Tabela 51 - SPI 2242019 - Vargem Alta - Chuvas máximas anuais com duração de 1 dia ............. 151

Tabela 52 - SPI - 2242020 - Vargem Grande - Chuvas máximas anuais com duração de 1 dia ....... 152

Tabela 53 - SPI - 2242022 - Fazenda Mendes - chuvas máximas anuais com duração de 1 dia .... 152

Tabela 54 - SPI - 2242024 - Teodoro de Oliveira - chuvas máximas anuais com duração de 1 dia. 153

Tabela 55 - SPI - 2242027 - Fazenda Sobradinho - Chuvas máximas anuais com duração de 1 dia

Tabela 56 - SPI - 2243010 - Itamarati - Chuvas máximas anuais com duração de 1 dia................... 154

Tabela 57 - SPI - 2243011 - Rio da Cidade - Chuvas máximas anuais com duração de 1 dia......... 155 


\section{SUMÁRIO}

\section{LISTA DE FIGURAS}

\section{LISTA DE TABELAS}

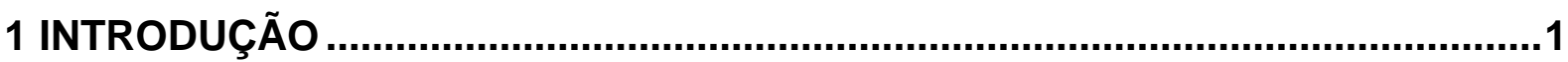

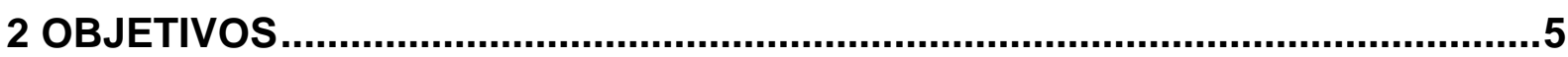

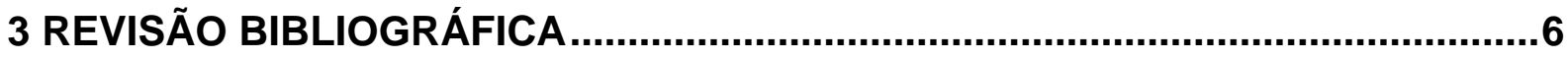

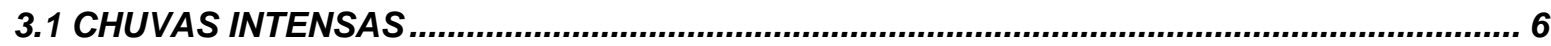

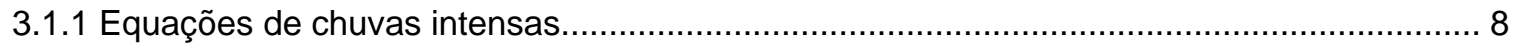

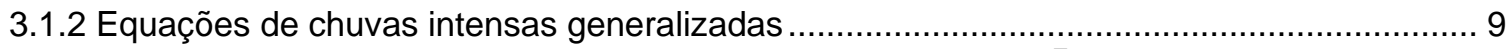

3.1.3 Relações entre as chuvas máximas de $24 \mathrm{~h}$ do pluviógrafo $\left(\mathrm{h}_{24}{ }^{\top}\right)$ e chuvas de um dia obtida

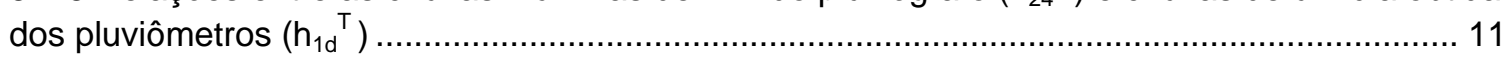

3.1.4 Análise da variabilidade da chuva na área de estudo ................................................... 13

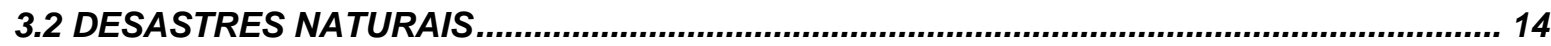

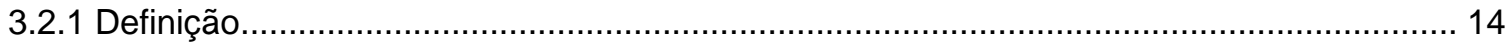

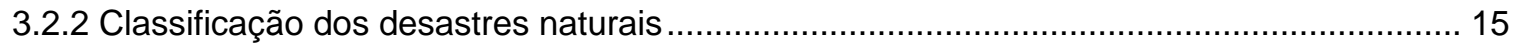

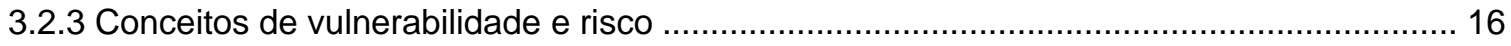

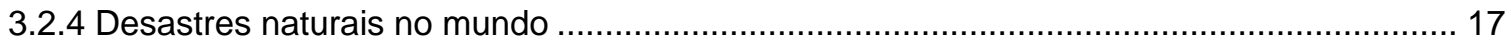

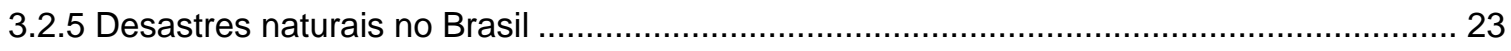

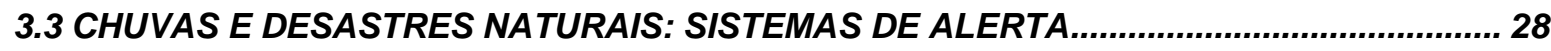

3.4 MEDIDAS GLOBAIS E LOCAIS PARA A REDUÇÃO DE DESASTRES............................ 33

4 METODOLOGIA DE ANÁLISE DAS CHUVAS EXTREMAS …..........................40

4.1 CARACTERIZAÇÃO DAS ÁREAS DE ESTUDO E SELEÇÃO DAS ESTAÇÕES .................. 40

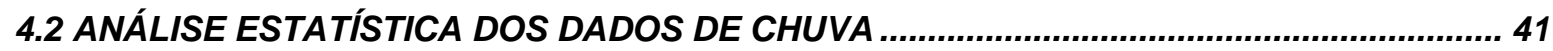

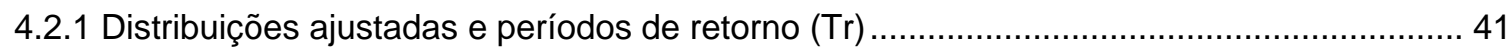

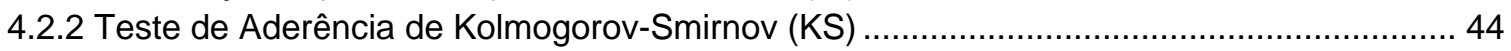

4.2.3 Chuvas máximas históricas em cada uma das regiões .................................................. 45

4.3 PRECIPITAÇÕES MÁXIMAS ACUMULADAS PARA DIFERENTES DURAÇÕES................ 46

4.4 CLASSIFICAÇÃO DAS CHUVAS UTILIZANDO O SPI .................................................. 46

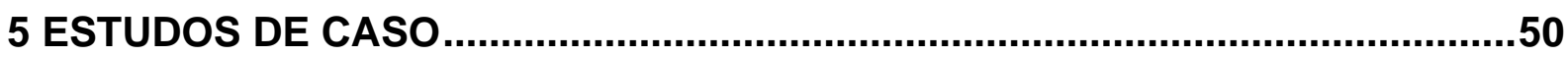

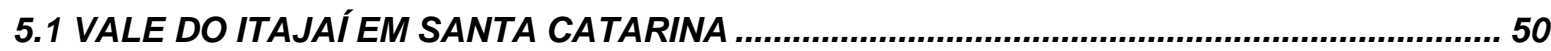

5.1.1 Descrição da área de estudo e estações pluviométricas utilizadas.................................... 52

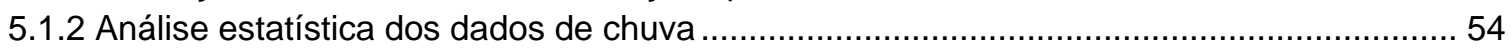

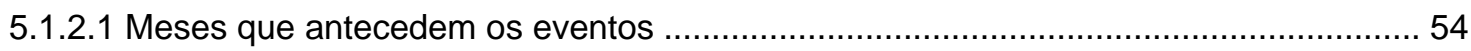

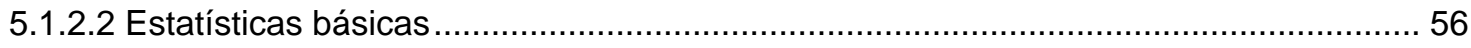

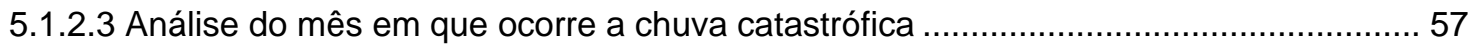

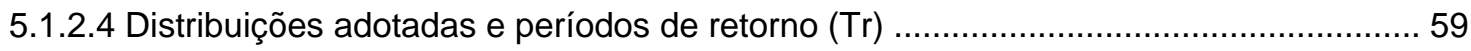

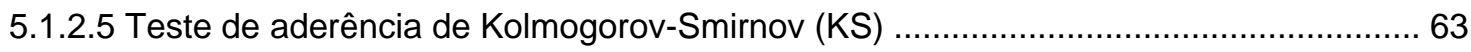

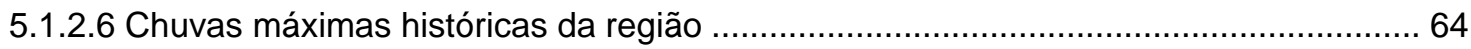

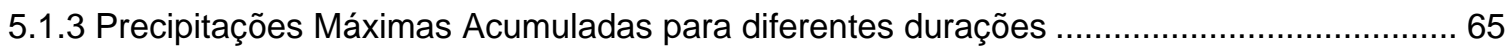

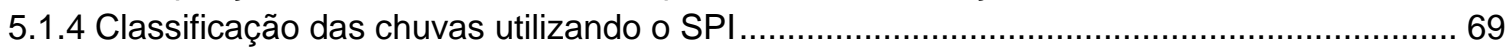


5.1.5 Conclusões

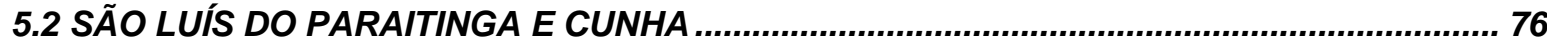

5.2.1 Descrição da área de estudo e estações pluviométricas utilizadas..................................... 78

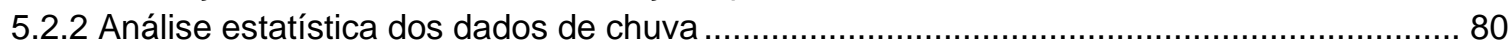

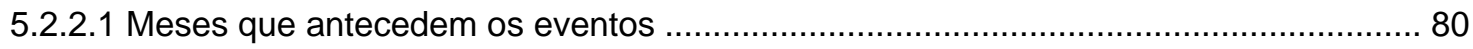

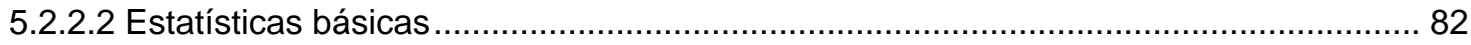

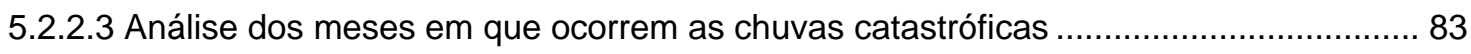

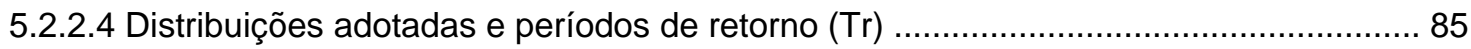

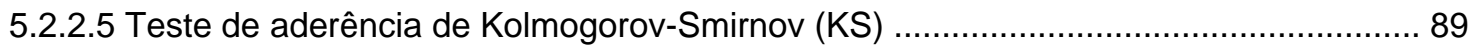

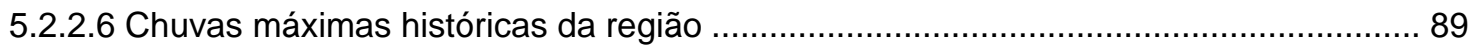

5.2.3 Precipitações Máximas Acumuladas para diferentes durações ....................................... 92

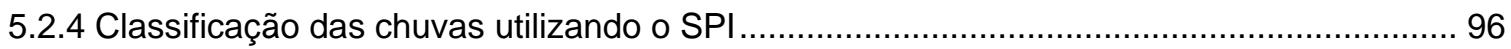

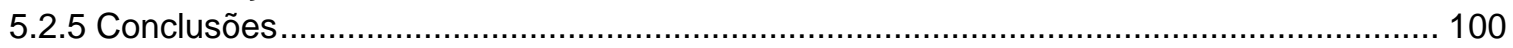

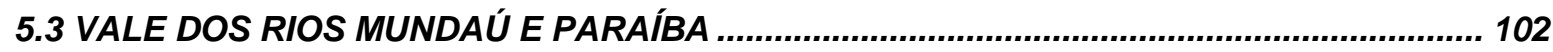

5.3.1 Descrição da área de estudo e estações pluviométricas utilizadas................................... 104

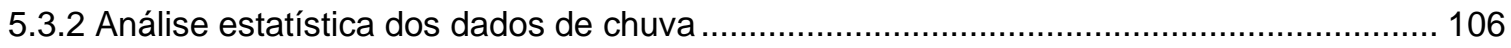

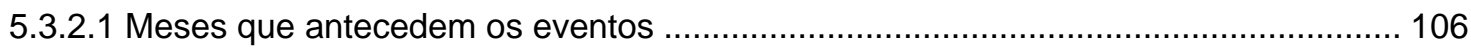

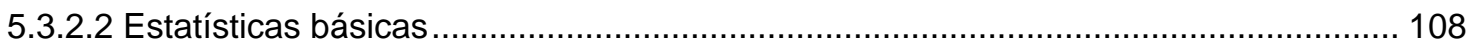

5.3.2.3 Análise do mês em que ocorre a chuva catastrófica ............................................... 109

5.3.2.4 Distribuições adotadas e períodos de retorno $(\mathrm{Tr})$................................................. 111

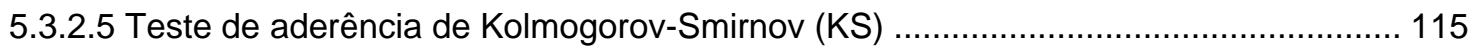

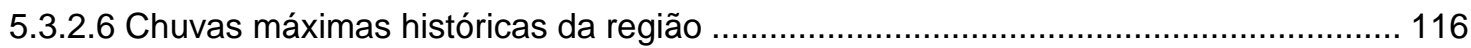

5.3.3 Precipitações Máximas Acumuladas para diferentes durações ....................................... 118

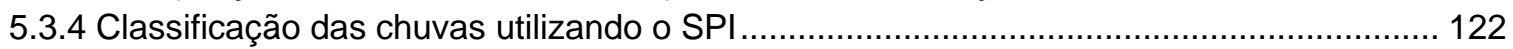

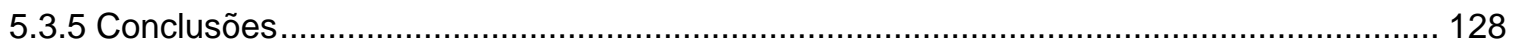

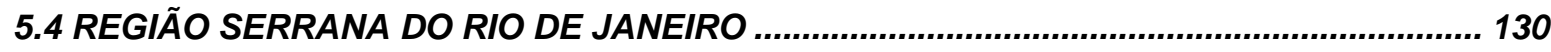

5.4.1 Descrição da área de estudo e estações pluviométricas utilizadas................................... 133

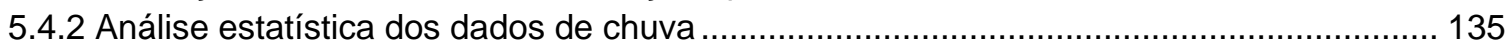

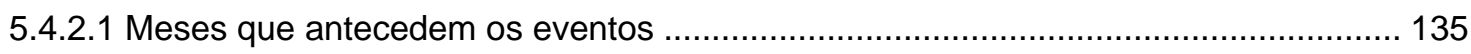

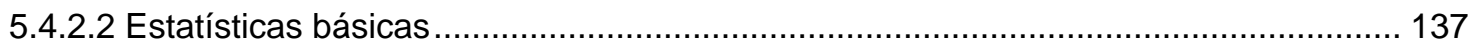

5.4.2.3 Análise do mês em que ocorre a chuva catastrófica ............................................. 137

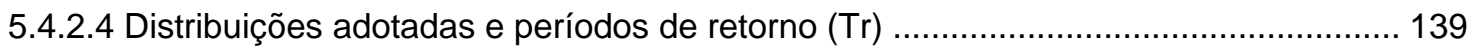

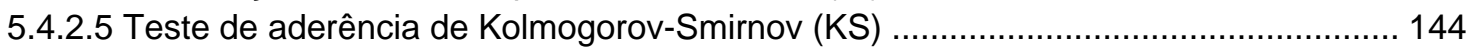

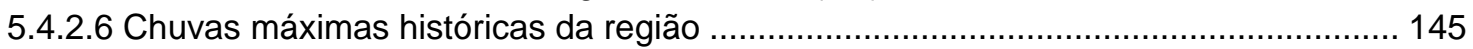

5.4.3 Precipitações Máximas Acumuladas para diferentes durações ....................................... 146

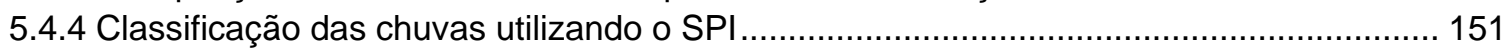

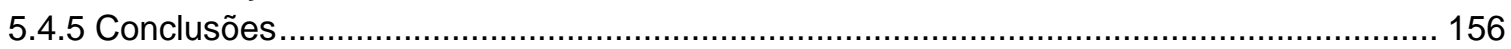

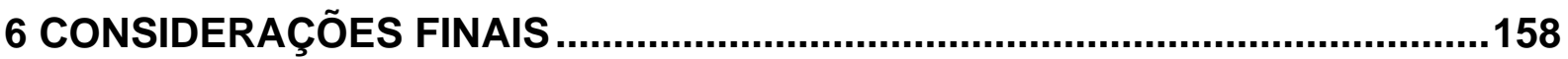

7 RECOMENDAÇÕES PARA ESTUDOS FUTUROS ...........................................162

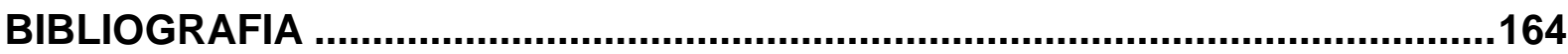




\section{INTRODUÇÃO}

Nos últimos anos, tem-se observado inúmeros eventos naturais extremos no Brasil e no mundo.

No dia 26 de dezembro de 2004, o Tsunami do Oceano Índico, causado pelo terremoto de origem em Sumatra, de magnitude 9.2, foi devastador. Segundo dados do banco mundial de desastres EM-DAT (Emergency Events Database - The International Disaster Database), do Centro de Pesquisa sobre Epidemiologia dos Desastres - CRED (Centre for Research Epideomology of Disasters), mais de 165 mil pessoas morreram na Indonésia.

O furacão Katrina, de 29 de agosto de 2005, causou um dos piores desastres naturais da história dos Estados Unidos, deixando mais de 1.600 mortos (LEWIS E. LINK, 2010). Os prejuízos estimados são de U\$125 bilhões e o número de pessoas afetadas foi 500.000 (EM-DAT, 2011).

Em 19 de novembro de 2008, a cheia do Vale do rio Itajaí atingiu várias cidades, causou a morte de 151 pessoas e deixou cerca de 1.500 .000 pessoas afetadas. Os prejuízos são estimados em U\$ 750 milhões (EM-DAT, 2011).

O ano de 2010 foi marcado por desastres naturais de todos os tipos no Brasil e no mundo.

No início do ano, no réveillon de 2009 para 2010, os escorregamentos ocorridos nas cidades de Angra dos Reis e Ilha Grande causaram a morte de 74 pessoas. Em janeiro de 2010, a enchente do rio Paraitinga destruiu grande parte do centro histórico na cidade de São Luís do Paraitinga. Na cidade de São Paulo, choveu cerca de 46 dias seguidos, no período de dezembro de 2009 a fevereiro de 2010, causando um verdadeiro colapso nas obras de drenagem urbana, com alagamentos em diversos pontos da cidade.

No Haiti, dia 12 de janeiro de 2010, um terremoto causou a morte de mais de 222.000 pessoas. A capital Porto Príncipe ficou sobre escombros. Este foi o segundo maior terremoto já registrado em número de mortos, ficando atrás apenas do terremoto de 27 de julho de1976 na China, com 242.000 mortos (EM-DAT, 2011). 
Em junho de 2010, municípios de Pernambuco e Alagoas ficaram inundados devido às fortes chuvas que atingiram a região do Vale do Mundaú e Paraíba. As enchentes se repetiram em 2011.

O desastre ocorrido na Região Serrana do Rio de Janeiro em janeiro de 2011 foi considerado uma das maiores catástrofes ocorridas no Brasil, deixando centenas de mortos e milhares de desabrigados. Em janeiro de 2012 novamente cidades do Rio de Janeiro entraram em estado de alerta.

Em um dos relatórios estatísticos do EM-DAT, que considera o número de óbitos devido a desastres provocados por inundações nos últimos 10 anos (2002 2011), o Brasil aparece em décimo lugar, com 806 mortes ocorridas no desastre da Região Serrana do Rio de Janeiro.

Tabela 1 - Os 10 mais importantes desastres causados por inundações no período de 2002 a 2011 classificados pelo número de mortos

\begin{tabular}{ccc}
\hline País, desastre & Data & Número de Vítimas \\
\hline Haiti, enchentes & $23 / 05 / 2004$ & 2.665 \\
Pakistan, enchente relâmpago & $28 / 07 / 2010$ & 1.985 \\
China, enchentes & $29 / 05 / 2010$ & 1.691 \\
Índia, enchentes & $24 / 07 / 2005$ & 1.200 \\
Bangladesh, enchentes & $21 / 07 / 2007$ & 1.110 \\
Índia, enchentes & $03 / 07 / 2007$ & 1.103 \\
Índia, enchente relâmpago & $11 / 06 / 2008$ & 1.063 \\
Índia, enchentes & $07 / 2009$ & 992 \\
Índia, enchentes & $20 / 06 / 2004$ & 900 \\
Brasil, enchentes & $\mathbf{1 1 / 0 1 / 2 0 1 1}$ & $\mathbf{8 0 6}$ \\
\hline
\end{tabular}

Fonte: "EM-DAT: The OFDA/CRED International Disaster Database www.em-dat.net - Université Catholique de Louvain - Brussels - Belgium"

Em 11 de março de 2011, um terremoto seguido de tsunamis atingiu o Japão e foi o mais devastador dos últimos 140 anos, causando grande destruição nas cidades da costa leste do país.

Em dezembro de 2011 e janeiro de 2012, a Região Sudeste sofreu novamente com as chuvas intensas. Segundo boletim do CPTEC (Centro de Previsão do Tempo e Estudos Climáticos) do dia 4 de janeiro de 2011, as cidades de Muriaé e Patrocínio de Muriaé, em Minas Gerais, foram inundadas devido ao transbordamento do rio Muriaé, causado pelas chuvas elevadas na região. Esta enchente foi a maior observada desde o ano de 1979. Em Belo Horizonte as chuvas 
também foram elevadas. O rio Xopotó, no leste do Estado de Minas Gerais, também transbordou no município de Visconde do Rio Branco deixando várias casas debaixo d'água. Até o dia 4 de janeiro de 2012, 53 cidades decretaram estado de alerta devido à continuidade e estragos causados pela chuva. No Espírito Santo as chuvas também causaram inundações em algumas cidades. Em Santo Antônio de Pádua, no Rio de Janeiro, segundo dados da defesa civil, 12.000 pessoas ficaram desalojadas devido ao transbordamento do rio Pomba. Algumas cidades da Região Serrana, como Nova Friburgo, entraram em estado de alerta.

A CPRM - Companhia de Pesquisa de Recursos Minerais, enviou equipes de geólogos e engenheiros às regiões das bacias dos rios Pomba e Muriaé e à Região Serrana, com o objetivo de: coletar dados para o mapeamento das áreas de risco; efetuar medições de vazão; reinstalar as réguas e pluviômetros que foram carregados pela enchente; determinar as marcas das cheia; avaliar as estações atingidas que servem de base em estudos para implantação de sistemas de alertas e de prevenção de desastres naturais nessas bacias.

Os desastres naturais estão cada vez mais presentes no cotidiano das pessoas, através da mídia, pelas inúmeras ocorrências registradas nos últimos anos, tanto no Brasil como em outras partes do mundo, mas, principalmente, pelo aumento da população e do número de pessoas que habitam áreas de risco.

"Ainda que em um primeiro momento o termo nos leve a associá-lo com terremotos, tsunamis, erupções vulcânicas, ciclones e furacões, os desastres naturais contemplam, também, processos e fenômenos mais localizados, tais como, deslizamentos, inundações, subsidências e erosão, que podem ocorrer naturalmente ou induzidos pelo homem" (TOMINAGA; SANTANA; AMARAL, 2009, p. 9).

No Brasil não costumam ocorrer desastres de grande magnitude como os terremotos, tsunamis etc. Os desastres naturais mais comuns em nosso território decorrem de escorregamentos e de inundações, fenômenos diretamente relacionados com variáveis hidrológicas como a precipitação. Estes são agravados pela ação do homem, principalmente interferindo no uso e ocupação do solo de uma região. 
Dessa forma, o estudo de variáveis hidrológicas, como a precipitação, é de grande importância para o entendimento desses desastres, podendo auxiliar no seu gerenciamento, prevenção e mitigação.

O estudo das chuvas intensas também é importante no dimensionamento de obras hidráulicas, como reservatórios de contenção e detenção, que auxiliam no controle de enchentes e inundações, no dimensionamento de galerias e outras partes componentes da macrodrenagem e da microdrenagem. Seu monitoramento é importante na previsão de eventos extremos, na implementação e operação de sistemas de alerta, que são ferramentas de gestão de áreas de risco. Essas previsões são dados de entrada de modelos de transformação chuva-vazão, modelos hidrológicos-hidrodinâmicos, utilizados para determinar a várzea de inundação, amplamente utilizados em sistemas de alerta.

Tendo em vista a importância do tema, o trabalho pretende contribuir, através de análises e estatísticas básicas, para o entendimento das chuvas catastróficas que atingiram algumas regiões brasileiras nos últimos anos. 


\section{OBJETIVOS}

Esta dissertação objetiva estudar alguns desastres naturais ocorridos no Brasil nos últimos anos, decorrentes de eventos críticos de precipitação. Ela pretende contribuir para o entendimento da magnitude desses eventos, sua ocorrência e estimativa do seu período de retorno, com base nas séries históricas obtidas das leituras dos pluviômetros localizados nas regiões atingidas. Isso é feito verificando tanto as chuvas máximas diárias, como as séries de chuvas máximas acumuladas para diferentes durações. Desse modo, é possível classificar as chuvas quantitativa e qualitativamente em intervalos segundo seus períodos de retorno, utilizando o SPI. Com isso, pretende-se contribuir para a compreensão desses fenômenos críticos e, principalmente, dar subsídios aos diversos profissionais que atuam no tema redução de risco de desastres naturais através de sistemas de alerta. 


\section{REVISÃO BIBLIOGRÁFICA}

\subsection{CHUVAS INTENSAS}

Entende-se precipitação como toda água proveniente do meio atmosférico que atinge a superfície terrestre como a chuva, granizo, geada, neve. O que as diferencia é o estado em que se encontram. Sua ocorrência é um processo aleatório e sua previsão pode ser feita estatisticamente com base em eventos passados. Os estudos estatísticos permitem caracterizar as chuvas de uma região, verificar com que frequência elas ocorrem, bem como determinar sua magnitude e estimativa da probabilidade de ocorrência (TUCCI, 1993).

As principais características da chuva são: o volume precipitado, a duração, e a distribuição espacial e temporal.

A chuva possui variabilidade espacial e temporal e não se distribui uniformemente sobre a bacia hidrográfica. A determinação dos intervalos de duração de chuva, bem como sua intensidade e frequência, são fundamentais para projetos de estruturas hidráulicas tanto em áreas urbanas quanto para áreas rurais. Em áreas urbanas, sua estimativa e caracterização são importantes para o cálculo dos hidrogramas utilizados no dimensionamento de obras hidráulicas, de controle de cheias, como os reservatórios de detenção e os sistemas de micro e macrodrenagem. Outro fator importante é determinação dos tempos de retorno, utilizados no dimensionamento dos sistemas hidráulicos e que variam de acordo com o tipo de obra a ser executada ou redimensionada. Já em áreas rurais, a estatística das chuvas é fundamental para os projetos de irrigação e a escolha do tipo de cultura que melhor se adapta à região.

Segundo Tucci (1993), a precipitação máxima é entendida como a ocorrência extrema, com duração, distribuição temporal e espacial crítica para uma determinada área ou bacia hidrográfica. A disponibilidade de longas séries de precipitação é muito mais comum do que as séries de vazões e seu estudo é um dos caminhos para se conhecer a vazão de enchente de uma bacia. As precipitações máximas são retratadas pontualmente através das curvas intensidade, duração e 
frequência (IDF) e através da precipitação máxima provável (PMP). As IDFs relacionam a duração e intensidade a uma à probabilidade de serem igualadas ou superadas e a PMP é definida pela maior coluna pluviométrica fisicamente possível de ocorrer em uma dada área, para uma dada duração em uma época do ano. A PMP também considera a distribuição espacial.

A PMP implica admitir uma distribuição espacial. É um evento extremo proposto para dimensionamento de obras hidráulicas. Supõe-se que a PMP tem frequência próxima à chuva deca milenar.

No cálculo ou previsão de enchentes em uma bacia hidrográfica é necessário o estudo de modelos de transformação chuva-vazão, que necessitam da estimativa da chuva na bacia. O cálculo das chuvas médias na bacia, bem como a determinação das equações de chuvas intensas, tormenta de projeto e sua variabilidade temporal e espacial são formas de estimativa da chuva. As equações IDF são as mais utilizadas para a estimativa da chuva de projeto no dimensionamento de obras hidráulicas.

Os intervalos de duração das curvas IDF geralmente variam de 5 minutos a 1440 minutos (24 horas), podendo ser encontrados estudos com intervalos superiores a 24 horas.

A hipótese clássica dos projetos de drenagem é admitir intensidade de chuva constante e igualmente distribuída na bacia. A duração geralmente é igualada ao tempo de concentração da bacia. Entretanto, sabe-se que a chuva não se distribui uniformemente sobre a bacia, além disso, os eventos anteriores também impactam a bacia hidrográfica. Portanto, este critério precisa ser revisto, principalmente para bacias de grande porte.

Em dezembro de 2009, janeiro e fevereiro de 2010 a cidade de São Paulo sofreu com as chuvas contínuas que causaram transtornos à população. Em janeiro de 2010, de acordo com dados da estação do IAG - Instituto de Astronomia, Geofísica e Ciências Atmosféricas da USP, choveu praticamente o mês inteiro, apenas em 4 dias não foi observado chuva. Este evento evidencia a necessidade de se estudar chuvas com durações maiores que um dia e, se necessário, traçar as equações IDF para valores maiores que um dia de duração. 
Estudos de cenarização das chuvas são essenciais para o dimensionamento de obras de drenagem urbana em grandes bacias urbanas ou rurais.

Outra motivação do estudo das precipitações diz respeito aos fatores que podem impactar as chuvas em determinadas áreas, como modificações no uso e ocupação do solo de uma região, que podem dar origem, por exemplo, às ilhas de calor nas regiões urbanizadas, características do aumento da temperatura média de uma determinada área devido à elevada capacidade de absorção de calor em superfícies asfálticas ou de concreto.

\subsubsection{Equações de chuvas intensas}

Dentre os pioneiros no estudo de chuvas intensas no Brasil, não se pode deixar de citar Pfastetter (1957), que determinou as curvas IDF para 98 localidades do Brasil, determinadas a partir de dados das estações do INMET (Instituto Nacional de Meteorologia).

Occhipinti e Santos (1965) utilizando dados da estação do IAG (Instituto de Astronomia, Geofísica e Ciências Atmosféricas), obtiveram a equação de chuvas intensas para a cidade de São Paulo. Wilken (1971) também obteve uma relação das chuvas intensas para o município de São Paulo a partir de séries parciais com base em 25 anos de observações da estação do IAG. Setzer (1973) realizou estudos em 12 postos distribuídos pelo Estado de São Paulo.

Mero e Magni (1982) obtiveram as equações IDF para 11 localidades no Estado de São Paulo e, através do posto do IAG (período de 1931 a 1979), para a cidade de São Paulo. Eles ajustaram a distribuição de Gumbel para cada duração de chuva.

Magni e Martinez (1999) traçaram as equações que relacionam a intensidade, duração e período de retorno para 30 localidades do Estado de São Paulo. A metodologia adotada por eles segue a equação de Ven-Te-Chow, admitindo-se que as precipitações intensas atendem à distribuição de Gumbel. 
O CTH/DAEE (1999), Centro Tecnológico de Hidráulica e Recursos Hídricos do Departamento de Águas e Energia Elétrica do Estado de São Paulo, no Manual de Drenagem Urbana do Município de São Paulo, atualizou a equação de chuvas intensas para o município de São Paulo. Os dados de chuva são do posto do IAG, no período de 1931 a 1994, com duração de até 3 dias:

$h_{d}^{\top}=(d-6)^{0,242} \cdot\{12,6-4,49 \cdot \ln [\ln (T /(T-1)]\}$, para $10 \min \leq d \leq 4320 \min$

onde $h_{d}^{\top}$ é a altura pluviométrica (em $\mathrm{mm}$ ) da chuva de duração $d$ (em minutos) e período de retorno $\mathrm{T}$ (em anos)

Os autores verificaram que a equação fornece valores superiores às equações encontradas anteriormente por Occhipinti e Santos (1965), Wilken (1971) e Mero e Magni (1982) para todas as durações.

Genovez e Zuffo (2000) fizeram uma análise comparativa dos estudos existentes de chuvas intensas no Estado de São Paulo, relacionando o tamanho das séries e o período de abrangência e comparando diferentes métodos com o objetivo de fornecer subsídios para a melhor escolha das equações a serem utilizadas. Dentre as equações estão as IDF locais, as equações de chuvas intensas generalizadas e as equações de chuvas intensas para diferentes durações. Como conclusão as equações IDF apresentam melhores resultados. Os métodos que utilizam as equações generalizadas podem fornecer estimativas razoáveis em locais onde os pluviógrafos são escassos.

\subsubsection{Equações de chuvas intensas generalizadas}

Quando a rede de pluviógrafos é escassa ou inexistente, pode-se calcular as equações com base nas leituras dos pluviômetros e na regionalização de parâmetros de escala para regiões carentes de dados.

Bell (1969) estudou as chuvas intensas considerando intervalos menores que 2 horas (onde predominam as chuvas convectivas) e obteve valores próximos para Estados Unidos, Austrália e África do Sul. Apesar de algumas variações que podem ocorrer devido ao relevo, propôs uma equação generalizada que foi justificada pelo 
fato de que as chuvas convectivas, de elevada intensidade e pequena duração, assumem processos físicos similares, independente da localidade. A equação proposta por ele foi:

$h_{d}{ }^{\top}=(0,21 \ln T+0,52)\left(0,54 d^{0,25}-0,50\right) h_{1}{ }^{10}$

para $2 \leq \mathrm{T} \leq 100$ anos; $5 \leq \mathrm{d} \leq 120$ minutos (2 horas)

onde $h_{d}{ }^{\top}$ é a altura de chuva (em $\mathrm{mm}$ ) de duração $d$ (minutos) para o período de retorno $\mathrm{T}$ (em anos)

Uehara et al. (1980) aplicou a equação de Bell para os dados dos 26 postos obtidos do estudo de Pfastetter obtendo valores um pouco diferente que foram justificados por diferenças de relevo ou clima entre as regiões.

Chen (1983) propôs uma generalização da equação de Bell, estendendo a duração da chuva de duas para 24 horas, necessitando não apenas de $h_{1}{ }^{10}$ (chuva de duração de 1 hora e período de retorno de 10 anos), mas também de $\mathrm{h}_{24}{ }^{10}$ (chuva de duração de 24 horas e período de retorno de 10 anos) e $h_{1}{ }^{100}$ (chuva de duração de 1 hora e período de retorno de 100 anos).

Hernandez (1991) adaptou a equação de Chen substituindo 2 dos três parâmetros determinados através de dados pluviográficos pelos determinados por dados do pluviômetro, para tentar resolver o problema de se calcular as chuvas para períodos de retorno de 100 anos.

Pegoraro (1996) analisou as equações de chuvas intensas generalizadas proposta por Bell e Chen e suas adaptações propostas por Uehara (Bell adaptado) e Hernandez (Chen adaptado) e recalculou os parâmetros propostos por Chen (que denominou Chen Novo) e da adaptação sugerida por Hernandez (o qual denominou Chen adaptado novo). Foram estudadas 23 estações pluviográficas localizadas no Estado de São Paulo com um período de dados entre 17 e 19 anos. Comparando-se os métodos, o Chen Novo apresentou menores desvios, seguido pelo Chen adaptado Novo.

Falaguasta (2001) realizou o estudo das equações de chuvas intensas generalizadas para os Estado de São Paulo e Paraná através das mesmas equações de Chen, Chen Adaptado por Hernandez, Chen Novo e Chen adaptado 
por Hernandez Novo. Foram analisados também os métodos de Bell e Bell adaptado por Uehara para o Brasil e para São Paulo. Foram empregados dados de 49 estações e durações de 10 a 1440 minutos. Constatou-se que o método de Chen Novo apresenta os menores desvios absolutos.

Davis e Naghettini (2001) atualizaram as equações de chuvas intensas no Estado do Rio de Janeiro. Dos 44 postos pluviográficos selecionados, 34 foram utilizados no estudo. A metodologia utilizada foi a análise regional de frequência baseada nos momentos-L, cuja motivação seria a obtenção de estimativas mais robustas de parâmetros e quantis associados às distribuições de probabilidades de eventos extremos, a Poisson-Logística e a Poisson-GEV. Foram determinadas as equações IDF regionais de quatro regiões com períodos de retorno de 2, 5, 10, 50 , 75 e 100 anos e durações de 5, 10, 15, 30, 45 minutos e 1, 2, 3, 4, 8, 14 e 24 horas e utilizando dados de séries parciais. As equações obtidas nos postos de Campos, Nova Friburgo, Xerém, Bangu e Resende (com as durações de 5, 15, 30 minutos, 4, 14 e 24 horas e períodos de retorno de 2, 10, 50 e 100 anos) foram comparadas às obtidas por Otto Pfastetter em 1957, que utilizou estações do INMET com dados de aproximadamente 22 anos (acredita-se que cubram o período de 1933 a 1955), às equações obtidas pelo DER (Departamento de Estradas e Rodagem) do Rio de Janeiro, e às equações da Universidade Federal de Viçosa (UFV), que utilizaram dados de 1974 a 1989, ajustando a distribuição de Gumbel. No estudo também foi traçado o mapa de isoietas dos totais anuais para o Estado do RJ.

\subsubsection{Relações entre as chuvas máximas de $24 \mathrm{~h}$ do pluviógrafo $\left(h_{24}{ }^{\top}\right)$ e chuvas de um dia obtida dos pluviômetros $\left(\mathrm{h}_{1 \mathrm{~d}}{ }^{\top}\right)$}

Diversos autores concluíram que a relação entre as alturas de precipitação máximas de $24 \mathrm{~h}$ obtidas dos pluviógrafos $\left(\mathrm{h}_{24}{ }^{\top}\right)$ e a leitura de um dia do pluviômetro $\left(\mathrm{h}_{1 \mathrm{~d}}{ }^{\top}\right)$ independe do período de retorno.

Weiss (1964) obteve a proporção teórica de 1,14 através de análise probabilística utilizando a relação entre as precipitações médias móveis e as médias obtidas de intervalos fixos. 
Occhipinti e Santos (1966) obtiveram o valor de 1,14 para esta relação para a cidade de São Paulo através de dados anuais para o período de 1928 a 1965.

Torrico (1974), utilizando as estações de Pfastetter (1957), verificou que a relação entre as alturas de precipitação máximas de $24 \mathrm{~h}$ obtidas dos pluviógrafos $\left(h_{24}{ }^{\top}\right)$ e a leitura de um dia do pluviômetro $\left(h_{1 d}{ }^{\top}\right)$ era constante igual a 1,095 .

Genovez et al. (1994) obtiveram o valor de 1,11 utilizando 23 postos localizados no Estado de São Paulo.

Back (2009) analisaram os pluviogramas do período de 1981 a 2004 da estação meteorológica em Urussanga, SC. A partir das séries de chuvas máximas anuais foram estimadas, por meio da distribuição de Gumbel-Chow, as chuvas máximas com durações variando de 5 min a 24 h, e também para a duração de 1 dia considerando-se os períodos de retorno de 2, 5, 10, 20, 25, 50 e 100 anos. A aderência dos dados ao modelo de Gumbel foi comprovada através do teste de Kolmogorov-Smirnov, com nível de significância de 5\%. A razão entre a precipitação máxima de 24 h e a precipitação máxima de 1 dia variou de 1,17 para o período de retorno de 2 anos até 1,11 para o período de retorno de 100 anos, com média de 1,13 .

Sampaio (2011) determinou os coeficientes das equações de IDF da precipitação máxima, em diferentes bacias hidrográficas do Rio Grande Sul, a partir da desagregação de chuvas de 24 horas de duração. Os valores foram comparados aos obtidos no trabalho de Beltrame et al. (1991) sobre chuvas intensas no RS. A metodologia utilizou o modelo de plotagem de Cunnane e a distribuição de probabilidade de Gumbel. As funções e período de retorno foram coerentes comparados ao modelo de Gumbel e as funções de desagregação não apresentaram diferença estatística significativa. Os coeficientes variaram nas diferentes bacias hidrográficas, e foram representados através de mapas temáticos. A espacialização dos coeficientes das equações de chuvas intensas através da metodologia de desagregação proposta se mostrou factível e pode ser aplicada em outras regiões, onde exista falta de dados observados. 


\subsubsection{Análise da variabilidade da chuva na área de estudo}

Medeiros (2002) fez o estudo da distribuição espacial de chuvas intensas. Foram analisadas 24 estações localizadas na sub-bacia do rio Paraitinga para os períodos de retorno de 2, 10, 25 e 100 anos e durações de 1 a 10 dias. O método foi comparado aos modelos do United States Weather Bureau, que estabelecem uma razão entre a máxima chuva média na área e no ponto, e os de Rodrigues Iturbe e Mejia (1975). Foi observado que quanto maior a duração da chuva, menor sua variabilidade espacial. Isso se deve ao fato de chuvas de maiores duração terem origem frontal e menor intensidade, ocupando áreas maiores. $O$ contrário ocorreu com as chuvas convectivas, de menor duração e atingindo menores áreas, com maior variabilidade espacial. $O$ modelo de Rodrigues Iturbe, que considera 0 decaimento da chuva na área, a forma da bacia e os dados disponíveis na região, seria o mais adequado para o estudo de cheias.

A CPRM (2011) no projeto Atlas Pluviométrico do Brasil, confeccionou diversos mapas de isoietas para todo o Brasil, determinados utilizando métodos geoestatísticos de interpolação como IDW (Inverse Distance Weighted), Spline, Kriging, disponíveis nas ferramentas do programa ArcGIS 9.3. Detalhes de cada um dos métodos de interpolação podem ser obtidos no site de ajuda da ESRI (http://webhelp.esri.com/arcgiSDEsktop/9.3/index.cfm?TopicName=Spline). Acesso em 17 de janeiro de 2013. Foram utilizadas séries de 30 anos de dados (1977-2006) de chuva de pluviômetros distribuídos em todo o país. Dentre os vários produtos obtidos estão os mapas das isoietas da precipitação média anual, precipitação média mensal, média trimestral de JFM, AMJ, JAS, OND, número de dias chuvosos, mês mais chuvoso, mês mais seco, trimestre mais chuvoso, trimestre mais seco, precipitações médias das máximas. As informações estão disponíveis no site da CPRM (http://www.cprm.gov.br/). Os dados são bastante úteis para caracterizar o regime de chuvas de cada região. Nas próximas etapas do Projeto, pretende-se atualizar as equações IDF para diferentes localidades do Brasil através dos métodos dos Momentos-L e estatísticas-L propostos por Hosking e Wallis. Os municípios prioritários para determinação das IDFs serão os que fazem parte do Projeto Cartas Municipais de Suscetibilidade a Movimentos de Massa e Inundações, também da CPRM. 


\subsection{DESASTRES NATURAIS}

\subsubsection{Definição}

Castro (2007, p. 12) define desastre como o "resultado de eventos adversos, naturais ou provocados pelo homem, sobre um ecossistema vulnerável, causando danos humanos, materiais e ambientais e consequentes prejuízos econômicos e sociais."

De acordo com Amaral e Gutjahr (2011), para que uma ocorrência seja considerada um desastre é necessário que o fenômeno ou o perigo atinja a população, causando uma grave perturbação do funcionamento de uma comunidade, que vai além de sua capacidade de recuperação. Se o fenômeno ocorre em uma área onde não existe população, ele é classificado como evento natural.

Os desastres por sua vez, podem ser classificados, quanto à origem, em naturais, antropogênicos ou mistos. A diferença entre eles está basicamente na ação (ou omissão) do homem como agravante do desastre.

Os desastres antropogênicos são aqueles em que o homem tem participação direta como nos acidentes de trânsito, contaminação hídrica por efluentes industriais, resíduos sólidos, incêndios urbanos ou florestais, guerras, terrorismo, rompimento de barragens etc.

Os desastres naturais são os causados por eventos ou fenômenos da natureza, de origem externa, que independem da ação humana, sobre uma área povoada, podendo ou não ser agravado pelas atividades antrópicas (CASTRO, 2003). Os desastres naturais podem ser causados pela dinâmica interna ou externa da terra. Exemplos são os terremotos, tsunamis, tornados, atividades vulcânicas, avalanches, inundações, escorregamento de encostas etc.

Os desastres mistos são os causados por eventos naturais e agravados pela ação (ou omissão) do homem, como o efeito estufa, as chuvas ácidas, a salinização do solo (intrusão marinha). Outros casos típicos em que a ação antrópica agrava os desastres é a impermeabilização do solo em áreas urbanas aumentando as 
inundações, a falta de planejamento do uso e ocupação do solo, que leva à ocupação de áreas de risco (com alta declividade), deixando a população exposta aos escorregamentos.

\subsubsection{Classificação dos desastres naturais}

O CRED (Centre for Research on Epideomology of Disasters), com apoio da Organização Mundial da Saúde - OMS e do governo Belga organiza, desde 1988, o banco de dados mundial de desastres denominado EM-DAT (Emergency Events Database - The International Disaster Database).

O EM-DAT é um banco de dados com estatísticas de desastres ocorridos em todas as partes do mundo. Para que um desastre seja inserido em seu banco, é necessário que tenha ocorrido pelo menos um dos seguintes critérios: 10 ou mais óbitos; 100 ou mais pessoas afetadas; pedido de auxílio internacional; declaração de estado de emergência.

Seu banco de dados possui registros de desastres de 1900 até hoje e é compilado a partir de várias fontes, incluindo agências das Nações Unidas, organizações não governamentais, companhias de seguros, institutos de pesquisa e agências de notícias (EM-DAT, 2011).

Segundo o EM-DAT, os desastres naturais podem ser classificados em:

- Biológicos: desastres causados pela exposição a organismos vivos causadores de doenças ou tóxicos. Exs.: epidemias, infestação de insetos.

- Climatológicos: processos atmosféricos de médio a longo prazo, sazonais, como temperaturas extremas, secas, ondas de calor, incêndios florestais.

- Geofísicos: eventos com origem no centro da terra. Exs.: terremotos, erupções vulcânicas, movimentos de massa (seca), avalanches (causadas por terremotos).

- Hidrológicos: causados pelas variações do ciclo natural da água, como inundações, movimentos de massa (úmida), rolamento de blocos, avalanches (causadas pelo delego da neve). 
- Meteorológicos: processos atmosféricos de curto a médio prazos (de minutos a dias). Exs.: tempestades (storms) tropicais, ciclones extratropicais, tempestades convectivas.

A United Nations International Strategy Disaster Reduction (UNISDR), um secretariado da ONU - Organização das Nações Unidas, criado em 1999 com o objetivo de implementar a Estratégia Internacional para a Redução de Desastres, classifica os desastres naturais em três grupos:

- Desastres Geofísicos: terremotos, tsunamis e erupções vulcânicas;

- Desastres Hidrometeorológicos: inundações, secas, escorregamentos, avalanches, tornados, furações etc.;

- Desastres Biológicos: epidemias, infestação de insetos.

\subsubsection{Conceitos de vulnerabilidade e risco}

Vulnerabilidade é o nível ou a medida na qual um indivíduo, comunidade, estrutura, serviço ou área geográfica pode ser destruído ou perturbado pelo impacto de um desastre.

A vulnerabilidade é determinada pelas condições físicas, sociais, econômicas, políticas, técnicas, institucionais, ambientas que podem atuar de maneira a aumentar a suscetibilidade de uma comunidade ao impacto de eventos perigosos (TOMINAGA; SANTANA; AMARAL, 2009).

O potencial de um evento adverso causar um desastre está diretamente relacionado à vulnerabilidade, ou seja, depende do quão exposta está uma comunidade a tais riscos. $\mathrm{O}$ conceito de risco está associado a uma probabilidade de ocorrência.

A intensificação do processo de urbanização nas cidades brasileiras, aliada ao crescimento populacional das últimas décadas resulta na pressão por espaço e moradia e na ocupação desordenada do solo urbano. A população passa a ocupar encostas de morros, terrenos com alta declividade, suscetíveis a escorregamentos e 
áreas de várzea, suscetíveis a inundações. Isso faz com que estas áreas se tornem vulneráveis. Nessas áreas passa a ser comum, principalmente no período chuvoso, a ocorrência de desastres naturais.

Nem todos os grupos sociais, comunidades ou regiões sofrem as consequências dos desastres da mesma maneira. Fatores de vulnerabilidade como a pobreza, a falta de organização social e política, a falta de acesso à informação, aumentam os riscos e o impacto de um desastre.

A vulnerabilidade é maior em países menos desenvolvidos, pois aspectos econômicos e sociais fazem com que a capacidade de recuperação seja menor nestes locais.

O risco pode ser definido pelas perdas que podem ocorrer (de vidas, ferimentos em pessoas, propriedades, rupturas das atividades econômicas ou danos ambientais), resultantes da interação de perigos naturais que podem ter sido induzidos ou não pelo homem, da vulnerabilidade e do dano potencial (AMARAL e GUTJAHR, 2011).

As consequências dos desastres são as perdas e os danos sociais, econômicos e ambientais nas regiões atingidas.

\subsubsection{Desastres naturais no mundo}

A ocorrência de desastres naturais no planeta data de muito antes da existência humana. Algumas teorias de cientistas que estudaram as rochas do período Mesozoico indicam que há cerca de 65 milhões de anos (no fim do período Cetáceo), um asteroide tenha atingido o planeta, deixando um rastro de destruição que teria causado a extinção de muitas formas de vida na terra, dentre elas os dinossauros.

De acordo com o banco de dados de desastres naturais EM-DAT, de 1900 até 2012, o país em que foi maior o número de vítimas devido aos desastres hidrológicos e geofísicos ocorridos em todo o mundo é a China (Tabela 2). 
Tabela 2 - Os dez principais Desastres Hidrológicos e Geofísicos no período de 1900 até 2012, classificados segundo o número de vítimas

\begin{tabular}{ccc}
\hline País, Desastres Hidrológicos & Data & Número de Mortos \\
\hline China, inundações & Jul/1931 & 3.700 .000 \\
China, inundações & Jul/1959 & 2.000 .000 \\
China, inundações & Jul/1939 & 500.000 \\
China, inundações & 1935 & 142.000 \\
China, inundações & 1911 & 100.000 \\
China, inundações & Jul/1949 & 57.000 \\
Guatemala, inundações & Out/1949 & 40.000 \\
China, inundações & Ago/1954 & 30.000 \\
Venezuela, inundações & $15 / 12 / 1999$ & 30.000 \\
Bangladesh, inundações & Jul/1974 & 28.700 \\
\hline País, Desastres Geofísicos & Data & Número de Mortos \\
\hline China, terremoto & $27 / 07 / 1976$ & 242.000 \\
Haiti, terremoto & $12 / 01 / 2010$ & 222.570 \\
China, terremoto & $22 / 05 / 1927$ & 200.000 \\
China, terremoto & $16 / 12 / 1920$ & 180.000 \\
Indonésia, terremoto & $26 / 12 / 2004$ & 165.708 \\
Japão, terremoto & $01 / 09 / 1923$ & 143.000 \\
União Soviética, terremoto & $05 / 10 / 1948$ & 110.000 \\
China, terremoto & $12 / 05 / 2008$ & 87.476 \\
Itália, terremoto & $28 / 12 / 1908$ & 75.000 \\
Paquistão, terremoto & $08 / 10 / 2005$ & 73.338 \\
\hline
\end{tabular}

Fonte: "EM-DAT: The OFDA/CRED International Disaster Database www.em-dat.net - Université Catholique de Louvain - Brussels - Belgium"

Hubpt e Inbar (2002) estudaram os desastres naturais na América Latina. Dentre os desastres ocorridos na América do Sul, destaca-se o terremoto do Chile em 21 e 22 de maio de 1960, o maior já registrado em escala em todo o mundo, 9.5 na escala Richter, desde que se iniciaram as leituras, 5.700 pessoas morreram. Outros terremotos já haviam sido registrados neste país, em 16 de agosto de 1906, deixando 150 vítimas e em 29 de janeiro de 1939, onde 28.000 pessoas morreram.

O maior terremoto da América do Sul em números de mortos ocorreu em 31 de maio de 1970, no Peru, deixando 70.000 vítimas. Segundo Oliver-Smith (2002), o terremoto do Peru começou logo depois do meio-dia, com seu epicentro localizado a aproximadamente $110 \mathrm{~km}$ a oeste da cidade de Chimbote, no oceano Pacífico. O evento teve duração de 45 segundos e as edificações começaram a desmoronar 15 segundos depois do início do terremoto. Uma área de aproximadamente $83.000 \mathrm{~km}^{2}$ foi atingida, afetando a infraestrutura, as comunicações e transportes, tanto na área 
costeira quando no interior. Cidades inteiras ficaram soterradas. A província de Yungay foi completamente destruída por uma avalanche que se seguiu ao terremoto. A área afetada e as necessidades dos sobreviventes eram tão grandes e que foi impossível pensar na reconstrução sem o envolvimento da população. As autoridades tentavam relacionar a reconstrução a um marco geral de desenvolvimento no país e uma oportunidade e obrigação de melhorar a vida da maior parte da população que habitava as áreas de risco. Nessa época começam as mudanças no enfoque sobre os trabalhos de emergência e reconstrução de áreas atingidas por desastres e a se vincular vulnerabilidade aos danos e destruição.

O furacão Katrina, ocorrido em 2005, causou um dos piores desastres naturais da história dos Estados Unidos, deixando mais de 1600 mortos (LEWIS E. LINK, 2010). As ondas registradas no Golfo do México se igualaram às maiores já medidas pelas boias da National Oceanican Atmospheric Administration (NOAA) na região.

O furacão atingiu a costa sudeste dos Estados Unidos, os Estados da Flórida, Mississipi, Alabama e Luisiana, chegando à região metropolitana de Nova Orleans em 29 de agosto de 2005. Parte da cidade de Nova Orleans fica abaixo do nível do mar e é protegida por diques. Como consequência da tempestade, alguns diques do Lago Pontchartrain romperam, deixando a cidade quase totalmente alagada. Houve danos nos sistemas de esgoto sanitário e de abastecimento de água. Muitas pessoas tiveram que desocupar suas casas e só puderam retornar no verão de 2006.

O que aconteceu em Nova Orleans sintetiza o risco de se viver abaixo do nível do mar em regiões costeiras. Todo o sudeste da Luisiana e Nova Orleans são altamente vulneráveis a inundações se atingidos por furacões de grande magnitude.

A evacuação da área nestes casos é a uma maneira eficaz de se reduzir substancialmente as vítimas. No caso das perdas materiais, a construção de estruturas de contenção mais eficientes e gerenciamento adequado do uso e ocupação do solo podem auxiliar para minimizar os danos.

Outro desastre de grande magnitude foi o terremoto de 11 de março de 2011, seguido de tsunamis que destruíram varias cidades da costa oeste do Japão. 
A ADRC - Asian Disaster Reduction Center, em parceria com a IRP International Recovery Platform publicou, em 2011, as observações preliminares do terremoto de 11 de março de 2011 no Japão. Segundo o ADRC e a IRP, o terremoto de magnitude 9.0 ocorreu às $14 \mathrm{~h} 46 \mathrm{~min}$ e seu epicentro estava a $150 \mathrm{~km}$ da costa. A série de tremores deu origem às ondas de tsunamis que atingiram zonas costeiras de Hokkaido, Aomori, Iwate Miyagi, Fukui, Ibaraki e Chiba. Foram sete ondas de tsunamis no intervalo de 6 horas atingindo as áreas costeiras em direções diferentes, passando uma sobre a outra, o que explica o poder destrutivo do tsunami.

Pesquisas realizadas pela Tokyo University of Marine Science and Technology indicam que as ondas atingiram a altura de aproximadamente 15 metros nas zonas costeiras e chegaram a 38,9 metros em Miyako. Agência de informações geoespaciais do Japão, usando tecnologias de sensoriamento remoto e GIS estima as áreas inundadas em aproximadamente $561 \mathrm{~km}^{2}$.

Até o dia 28 de abril de 2011, o governo havia confirmado a morte de 14.508 pessoas e 11.452 desaparecidos e 400.000 desalojados. Os números ultrapassaram o terremoto de Kobe ocorrido em 1995, tornando-se o pior desastre no Japão desde a Segunda Guerra Mundial.

Dentre as medidas adotadas pelo Japão antes, durante e depois do desastre, podemos destacar:

As medidas estruturais:

Construção de diques de 10 metros de altura e 2,5 km de comprimento, chamado de A Grande Muralha, na cidade de Miyako e o maior quebra-mar do mundo localizado na cidade de Kamaishi, com 8 metros de altura acima do mar que ali tem $63 \mathrm{~m}$ de profundidade. A parede de quebra-mar da cidade Kamaishi na foz do Kamaishi Bay entrou em colapso e o tsunami atingiu de 6,9 m a $9 \mathrm{~m}$ de altura em vários pontos. No entanto, baseado em simulações do Instituto de Pesquisa de Portos e Aeroportos, o tsunami teria chegado até $13,7 \mathrm{~m}$ de altura e teria sido mais devastador se os diques não estivessem ali.

As medidas não estruturais: 
Alerta de Tsunami: A Agência Meteorológica do Japão começou a emitir alertas de tsunamis três minutos após o primeiro choque principal. Através de meios de comunicação e outros canais, foram divulgadas mensagens de aviso, incluindo informações sobre o tempo de chegada e a altura esperada dos tsunamis. Os governos locais também enviaram 0 alerta através de sirenes e mensagens enviadas pelo sistema sem fio da comunidade. Essas medidas ajudaram as pessoas a escapar do tsunami, evacuando a área e indo para locais mais elevados.

Na região de Tohoku Sanriku, a palavra Tsunami Tendenko significa, de acordo com a sabedoria popular, além de Tsunami, corra para o lugar mais alto, cuidando apenas de sua própria segurança. Isso também fez com que os habitantes procurassem os locais mais elevados.

$\mathrm{Na}$ cidade de Kamaishi, uma das áreas mais duramente atingidas, atividades de sensibilização e educação tinham sido realizadas antes do desastre, o que ajudou muitas pessoas a tomar as medidas apropriadas e salvar vidas.

Por outro lado, no interior, muitas pessoas não esperavam que as ondas fossem tão altas a ponto de chegar até o local onde elas estavam. Como resultado, muitas áreas que anteriormente eram consideradas seguras foram atingidas pelo tsunami.

Dentre os esforços para a recuperação, pode-se citar:

Infraestrutura: Segundo o Ministério de Terras, Infraestrutura e Transportes (MLIT), cerca de $90 \%$ das redes de transporte terrestres, marítimas e aéreas danificadas pelo terremoto e tsunamis haviam sido restauradas até o final de março. Todos os 12 aeroportos na região estavam em operação, inclusive para uso público.

Centros de evacuação: dos 323 centros de evacuação que responderam à pesquisa, 72,8\% tinham acesso à água, eletricidade e gás; em 151 centros, os desalojados não tinham roupas para trocar ou não era possível lavá-las. Em 91 centros não havia partição entre espaços de famílias. Havia visita frequente de médicos, medicamentos suficientes, banheiro, WC e eliminação de resíduos. Em suma, 36 centros de evacuação estavam em condições extremamente precárias. 
Alojamentos temporários: Das 72.290 unidades habitacionais requisitados, aproximadamente 30.400 unidades seriam concluídas até o final de maio, de acordo com o MLIT. Como alternativa para acomodar as pessoas desabrigadas, das $\mathbf{5 2 . 9 1 3}$ unidades que se destinavam originalmente como apartamentos ou moradias para funcionários do governo, 7.805 já foram concedidas para as família desabrigadas.

Em 11 de Abril, um mês após o terremoto e os tsunamis, foi criado um Conselho de projetos de reconstrução, com a participação de especialistas de diversos campos, para formular e entregar um plano de reconstrução em junho.

O primeiro-ministro, em 15 de Abril, colocou sua mensagem em diversos jornais no exterior (Washington Post e Herald Tribune) afirmando: "O governo vai dedicar-se a mostrar ao mundo sua capacidade de estabelecer os planos de reconstrução mais sofisticados para Japão Oriental, baseada em três princípios: criar uma sociedade altamente resistente a catástrofes naturais, estabelecer um sistema social que permita às pessoas viver em harmonia com o ambiente global e construir uma sociedade que se preocupa com as pessoas em situação mais vulnerável."

O Parlamento aprovou orçamento suplementar, totalizando JPY 4 trilhões em 2 de Maio, que seria utilizado para medidas tais como remoção de detritos, construção de habitação temporária e reparação de infraestrutura, bem como apoio financeiro para as empresas afetadas pelo desastres.

O Comité Central de gestão de desastres, presidido pelo primeiro-ministro e cujos membros incluem todos os Ministros, chefes de organismos públicos, e especialistas, havia iniciado a análise de medidas necessárias para futuros mega desastres, com o intuito de melhorar os planos de gestão de desastres e as políticas do governo.

Como consequência do terremoto seguido de tsunamis, destaca-se também o acidente nuclear ocorrido em Fukushima, devido a um colapso no sistema de refrigeração dos reatores do complexo. O acidente de Fukushima, com nível de gravidade 7, o mais elevado na escala Inês, foi equiparado ao de Chernobyl, o maior acidente nuclear da história, ocorrido na União Soviética em 25 de abril de 1986, onde a nuvem radioativa se espalhou por toda a Europa Central, atingindo 12 países e uma distância de $3.100 \mathrm{~km}$. No dia 15 de março de 2011, 4 dias após o acidente, a 
Comissão Europeia havia qualificado Fukushima como um "apocalipse", por considerar que as autoridades locais haviam perdido o controle da situação na central nuclear. O governo do Japão havia informado que ampliaria a área de evacuação em torno da Usina, que até o momento era em torno de 20 a $30 \mathrm{~km}$, em função da detecção de níveis de radioatividade acima do permitido em novas localidades. Novos planos de evacuação seriam aplicados a localidades como Litate, a $40 \mathrm{~km}$ da central, e ao povoado de Minami Soma, onde os níveis já ultrapassavam os permitidos (VEJA, 2011).

O evento do Terremoto no Japão mostrou a todo o mundo como uma sociedade organizada, obediente, rica e preparada está vulnerável a um evento natural combinado de terremoto e tsunami. Este exemplo infeliz mostra que para certos eventos é possível reduzir prejuízos humanos e materiais, mas não evitá-los (TUCCI, 2011).

\subsubsection{Desastres naturais no Brasil}

Não ocorrem tsunamis, erupções vulcânicas, tornados e furacões no Brasil. Os terremotos também não são comuns e quando acontecem são de baixa magnitude.

No Brasil, os principais fenômenos relacionados a desastres naturais são derivados da dinâmica externa da Terra, tais como, inundações, escorregamentos de solos e/ou rochas e tempestades. Estes fenômenos ocorrem normalmente associados a eventos pluviométricos intensos e prolongados (TOMINAGA; SANTANA; AMARAL, 2009). Ocorrem principalmente em períodos chuvosos, que correspondem ao verão na região Sudeste e ao inverno na região Nordeste, as quais possuem sazonalidade bem definida. Na região Sul, esses eventos podem ocorrer em qualquer época do ano, pois a caracterização das chuvas dessa região não possui sazonalidade bem definida.

Escorregamentos são movimentos rápidos, de porções de terrenos (solos e rochas), que se deslocam por ação da gravidade, para baixo e para fora da encosta.

O termo escorregamento tem diversos sinônimos de uso, e é mais generalizado na 
linguagem popular como deslizamento, queda de barreira, desbarrancamento e desmoronamento (AMARAL e GUTJAHR, 2011).

São agravados pela presença de água, que reduz a resistência dos materiais (solo). A saturação do solo em períodos chuvosos é fator predominante para a ocorrência de escorregamentos. Normalmente ocorrem em regiões de alta declividade, como encostas de morros e regiões serranas, que no Brasil são características das regiões Sul e Sudeste, mas podem ser observados também na região Nordeste.

Os principais condicionantes dos escorregamentos estão relacionados à geologia, geomorfologia, condições hidrológicas e climatológicas, vegetação e influência antrópica no uso e ocupação do solo (TOMINAGA; SANTANA; AMARAL, 2009).

Os escorregamentos são definidos com relação ao tipo e a forma do material transportado e velocidade em que ocorrem.

A precipitação é sem dúvida, um dos principais fatores para deflagrar os escorregamentos. As principais causas são os fatores físicos, mas a ação antrópica pode influenciar tanto para minimizar seus efeitos quando aumentar os danos.

As enchentes $e$ as consequentes inundações são eventos naturais caracterizadas pelo aumento do nível d'água nos rios em decorrência das chuvas elevadas. Nas enchentes, a água atinge o leito maior do rio e nas inundações ocorre o extravasamento e a água atinge a área de várzea, denominada planície de inundação.

A impermeabilização do solo e retificação dos rios nas cidades urbanizadas aumenta a velocidade do escoamento e o pico dos hidrogramas, agravando os problemas das inundações. Em áreas rurais, o desmatamento e a retirada da mata ciliar contribuem para o assoreamento dos rios e consequentemente para as enchentes e inundações.

Os alagamentos são caracterizados pelo acúmulo momentâneo de água em determinados locais deflagrado por falhas nas estruturas de drenagem em decorrência das chuvas em áreas urbanas. A deficiência no sistema de coleta e 
disposição de resíduos sólidos em áreas urbanas pode contribuir para o entupimento de bueiros, obstrução de galerias e posteriores alagamentos após períodos de chuvas elevadas. Obstruções nos leitos dos rios, como a construção de pontes ou outras obras podem agravar as inundações.

Abaixo estão relacionados alguns desastres ocorridos no Brasil., segundo o jornal G1.

Em 02 de janeiro de 1966, no Rio de Janeiro, os escorregamentos ocorridos após a forte chuva deixaram mortos e desabrigados.

Em 18 de março de 1967, em Caraguatatuba, no litoral de São Paulo, os escorregamentos e as inundações provocaram a morte de 436 pessoas, destruindo casas e estradas da região. A cidade ficou isolada e só conseguiu comunicação no dia seguinte.

Em 1979, choveu muitos dias em janeiro e fevereiro e Minas Gerais teve a pior enchente de sua história. Cerca de 246 pessoas morreram e 37 cidades ficaram ilhadas, deixando milhares de desabrigados.

Em fevereiro de 1988 um temporal alagou o Rio de Janeiro e provocou escorregamentos. Na cidade de Petrópolis, desabamentos causaram a mortes e centenas de pessoas ficaram desabrigadas.

Em Minas Gerais, em janeiro de 1997, as chuvas que atingiram a região deixaram 82 mortos, afetando 175 municípios. As piores enchentes foram as do Rio Jacutinga, próximo à divisa com o RJ, e do Rio Mandú, no sul do Estado. A cidade de Jequitibá, localizada a $100 \mathrm{~km}$ de Belo Horizonte, foi totalmente inundada pelo Rio das Velhas. Em Ouro Preto, a lama cobriu ruas de alguns bairros.

As chuvas de dezembro de 2001 na cidade de Petrópolis provocaram escorregamentos na estrada que liga o município ao Rio. Petrópolis decretou estado de calamidade pública.

Em dezembro de 2002 e janeiro de 2003, as chuvas provocaram escorregamentos e mortes em Teresópolis, Petrópolis e Angra. 
Em 2004 ocorreu o rompimento da barragem de Camará, construída no rio Riachão, na bacia do Mamanguape, entre Alagoa Nova e Areia, na Paraíba. Dentre as localidades atingidas estão Alagoa Nova, Areia, Mulungu e Alagoa Grande.

Em 2007, no Estado do Rio de Janeiro, as chuvas causaram inundações e sete municípios da Região Serrana decretaram situação de emergência. Mais de 12 mil pessoas tiveram que deixar suas casas. Nova Friburgo foi uma das cidades mais atingidas.

As enchentes ocorridas no Vale do Itajaí em 22 de novembro de 2008 deixaram cerca de 135 mortos e 30 mil desalojados e desabrigados.

Em abril de 2009 as enchentes provocadas pelas chuvas que atingiram 0 Norte e Nordeste, principalmente Maranhão e Piauí, deixaram mortos e milhares desabrigados.

A cidade de São Luís do Paraitinga, no interior de São Paulo, foi arrasada pela cheia de janeiro de 2010, que destruiu boa parte do patrimônio histórico local. Não foram registrados mortos. A cidade de Cunha também foi atingida. A chuva também provocou mortes na Grande São Paulo.

O Estado do RJ registrou prejuízos com as chuvas de 2009/2010. Na virada do ano, escorregamentos deixaram 53 mortos em Angra dos Reis e em llha Grande. Na cidade de Niterói, o escorregamento no Morro do Bumba deixou 166 mortos.

Em junho de 2010, ocorreram inundações em Pernambuco e Alagoas. O nível do rio Mundaú ficou 14 metros acima do normal na cidade de União dos Palmares, $\mathrm{AL}$.

Em janeiro de 2011 as chuvas que atingiram a Região Serrana do Estado do Rio de Janeiro foram responsáveis por uma das maiores tragédias ocorridas no Brasil, deixando centenas de mortos (MEDEIROS; BARROS, 2011).

Em dezembro de 2011 e janeiro de 2012 novamente as chuvas castigaram o Sudeste do Brasil, atingindo principalmente cidades do Rio de Janeiro, Minas Gerais e Espírito Santo. 
Dentre os vários desastres ocorridos no Brasil, esta dissertação trata especificamente de quatro regiões atingidas: O Vale do Itajaí, em Santa Catarina; São Luís do Paraitinga e Cunha, em São Paulo; o Vale do Mundaú, em Alagoas; e a Região Serrana do Rio de Janeiro. As regiões serão descritas e analisadas em cada um dos estudos de caso. A Figura 1 apresenta uma imagem do Google com a localização das regiões estudadas no Brasil.

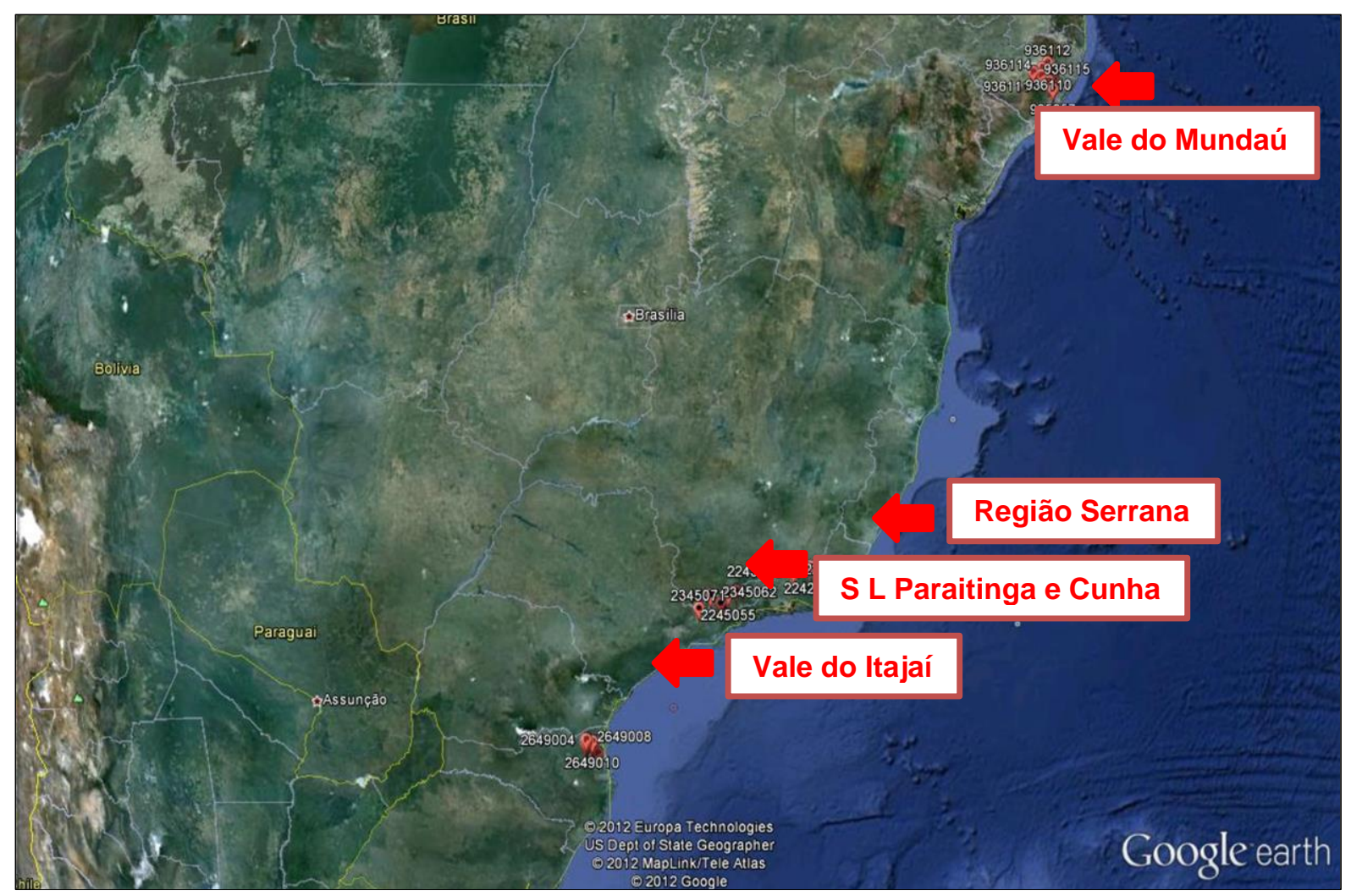

Figura 1 - Localização das Regiões estudadas no Brasil: Vale do Itajaí - SC, São Luís do Paraitinga e Cunha - SP, Vale do Mundaú - AL, e Região Serrana do RJ (Fonte: Google Earth) 


\subsection{CHUVAS E DESASTRES NATURAIS: SISTEMAS DE ALERTA}

"A ocorrência de eventos extremos de precipitação, causadores de inundações, escorregamentos, é tema de vários estudos e discussões sobre sua incidência e possível aumento das ocorrências nos últimos anos. O estudo da magnitude desses eventos críticos, se eles são fenômenos naturais ou sofrem influência antrópica, se possuem relação com possíveis mudanças climáticas é constantemente discutido na comunidade científica" (MEDEIROS; BARROS, 2011).

As chuvas são, sem dúvida, um dos principais condicionantes para a ocorrência dos desastres naturais mais característicos do Brasil: as inundações e os escorregamentos. Estes desastres ocorrem principalmente nas estações chuvosas, nas regiões Sul e Sudeste do Brasil, mas também ocorrem em alguns Estados do NE, como Pernambuco e Alagoas.

Dessa forma, pesquisadores sempre tentaram correlacionar as chuvas aos desastres naturais, como inundações e escorregamentos de morros.

No caso das inundações, é comum utilizar modelos que transformam a chuva em vazão, principalmente em áreas onde não existem postos fluviométricos. Para a determinação da ocorrência da chuva, as equações mais utilizadas são as curvas IDF.

Para a determinação das áreas de inundações é comum o uso de modelos hidrológicos e hidráulicos, como o HEC-HMS, HEC-RAS do Hydrologic Enginnering Center (HEC), uma organização do Instituto de Recursos Hídricos americano que atua como centro de especialização nas áreas técnicas de hidrologia de superfície e águas subterrâneas, hidráulica e sedimentos fluviais, análises estatísticas e de

riscos hidrológicos, análise de sistema de reservatórios, planejamento e gerenciamento dos recursos hídricos em tempo real. Os produtos e softwares desenvolvidos pelo centro estão disponíveis ao público e podem ser baixados gratuitamente do web site do Corpo de Engenheiros do Exército dos Estados Unidos (US Army Corps of Engineers). Dentre eles se encontra o HEC-HMS, um modelo hidrológico projetado para simular os processos de precipitação-escoamento em bacias hidrográficas. Os hidrogramas produzidos pelo programa são usados diretamente ou em conjunto com outro softwares para estudos de drenagem urbana, 
previsão de vazões, impactos de futura urbanização, determinar áreas de inundação, projetos de reservatórios, vertedouros, redução de danos de enchentes e operação de sistemas.

Cirilo et al. (2011) utilizaram os modelos HEC-HMS para simular as vazões de contribuição na parte alta da bacia do rio Una, em Pernambuco, a partir de precipitações previstas. Os dados de vazões estimadas pelo HEC-HMS são utilizados como variáveis de entrada no modelo HEC-RAS, para determinar as manchas de inundação através da plataforma HEC-GEO-RAS. Os dados fazem parte do Sistema de Suporte à Decisão desenvolvido pelos autores para previsão e acompanhamento das enchentes aplicado à bacia do rio Una.

Em sistemas de alerta a inundações e escorregamentos, são utilizados determinados valores, relacionados a variáveis hidrológicas como chuva, níveis dos rios, para passar de um estado de normalidade para os demais estados, como atenção, alerta, emergência, que vão depender do risco associado ao evento. Em cada sistema e localidade são determinados os limiares para a mudança de estado.

No caso de rios onde existem medições de cotas limnimétricas, esses limiares estão relacionados ao tipo de seção transversal e aos níveis de cheia e extravasamento. A mudança de estado é feita através de monitoramento e conforme estas cotas limnimétricas atingem os níveis pré-estabelecidos. No sistema de Alerta a Inundações do Estado de São Paulo (SAISP), foram estabelecidos 4 estados, além do estado de normalidade: atenção, alerta, emergência e extravasamento. Exemplo é apresentado na Figura 2 abaixo.

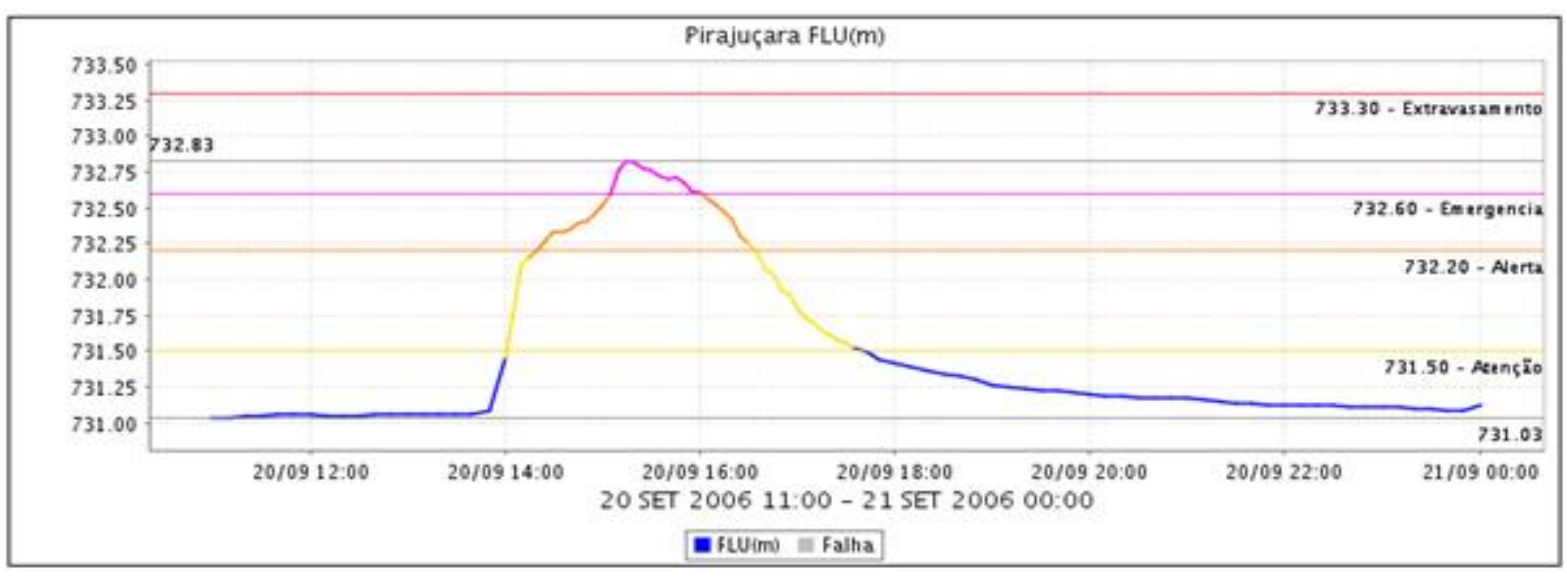

Figura 2 - Níveis d'água da seção fluviométrica Pirajuçara, localizada no rio Pirajuçara em São Paulo - SP (Fonte: SAISP) 
Em lugares onde não existem medições de níveis, são utilizados limiares relacionados ao volume de chuvas acumulados em um período para determinar a mudança de estado.

Esses limiares também são estabelecidos tentando correlacionar o volume de chuvas acumulado em um determinado período às ocorrências de escorregamentos em regiões serranas ou de alta declividade.

O Plano Preventivo da Defesa Civil (PPDC) do Estado de São Paulo, que tem como objetivo a prevenção de desastres em áreas de riscos associados a escorregamentos, considera quatro níveis de operação, observação, atenção, alerta e alerta máximo, relacionados a três parâmetros, chuvas acumuladas de 72 horas, previsão meteorológica e as vistorias de campo.

Desde a década de 60 já se tentava correlacionar as chuvas intensas aos escorregamentos. Pichler (1957) apresenta um relato sobre os numerosos escorregamentos ocorridos nos morros de Santos, em março de 1956, e procura estabelecer a relação entre esses os eventos e os diversos aspectos geológicos da área atingida, e estabelecer as medidas de prevenção.

Tatizana et al. (1987) estudaram a relação entre chuvas e escorregamentos em Cubatão, na Serra do Mar, no período de 30 anos e tentaram estabelecer uma correlação entre a chuva acumulada anterior aos escorregamentos e as chuvas horárias. Ainda não se entendia porque eventos de chuvas pouco intensos como os ocorridas em 1978, 1981 e 1984, onde os volumes acumulados em dois dias não ultrapassaram $120 \mathrm{~mm}$, causaram escorregamentos, e as chuvas de 1959, 1872 e 1985, que ultrapassaram 250 mm em dois dias, não causaram escorregamentos. Foi feita então uma retro análise dos eventos que causaram escorregamentos com o objetivo de definir o número de dias anteriores que influenciava os escorregamentos e a relação entre a chuva acumulada e as chuvas horárias. Foram selecionados 35 eventos com intensidade de: $100 \mathrm{~mm}$ em 1 dia; $150 \mathrm{~mm}$ em dois dias; $200 \mathrm{~mm}$ em 3 dias; os dados acumulados de 7 dias anteriores ao evento e 1 dia posterior. Os autores concluíram que a suscetibilidade aos escorregamentos é função do grau de saturação do solo, representado pelas chuvas acumuladas, e pela ação das chuvas de curta duração, que atuam como detonantes dos processos de instabilização. 
Para a área de estudo, as chuvas acumuladas de 4 dias foram as mais efetivas nos escorregamentos.

Almeida, Nakazawa e Tatizana (1993) estudaram a correlação entre chuvas e escorregamentos no município de Petrópolis, com registros de 1.131 ocorrências de escorregamentos cadastradas no período de 1938 a 1989 e utilizando os postos de Petrópolis e Itamarati. Os escorregamentos foram classificados em 5 tipos, sendo 0 tipo A (ocorrência de 1 escorregamento), B (2 a 5), C (6 a 15), D (16 a 30) e E (acima de 30). A distribuição de escorregamentos foi feita por década, pois as transformações ocasionadas pela interferência antrópica com relação ao uso e ocupação do solo nas encostas pode interferir significativamente na sua estabilidade. Notou-se que os escorregamentos aumentaram com o tempo, principalmente os de maior intensidade. Sendo assim, a correlação foi feita somente com dados das últimas décadas (70 e 80), pois refletiam as condições mais atuais de uso e ocupação do solo da região. Confrontando as chuvas acumuladas de 1 até 5 dias e os escorregamentos, os autores e concluíram que as chuvas acumuladas de 4 dias foram as mais críticas no processo de deflagração de escorregamentos. Foram definidos 3 limiares para a mudança de estado, sendo os valores críticos determinados para as chuvas acumuladas de 4 dias. Estado 1, ativado quando as chuvas atingem $40 \mathrm{~mm}$ em Petrópolis e $30 \mathrm{~mm}$ em Itamarati, Estado 2, ativado quando as chuvas atingem $90 \mathrm{~mm}$ em Petrópolis e $60 \mathrm{~mm}$ em Itamarati e Estado 3, ativado quando as chuvas atingem $150 \mathrm{~mm}$ em Petrópolis e $130 \mathrm{~mm}$ em Itamarati.

O PPDC (Plano Preventivo da Defesa Civil) considera as chuvas acumuladas de $120 \mathrm{~mm}$ em $72 \mathrm{~h}$ como limite para a mudança de nível operacional no litoral norte de São Paulo, a partir do qual aumenta a probabilidade de ocorrência de escorregamentos.

Coutinho (2002) estudou as chuvas e escorregamentos no Morro do Artur, em Blumenau - SC. Em seu estudo foram relacionados os principais escorregamentos ocorridos no Brasil desde 1928, obtidos de diversas fontes (Anexo I). Foi feito o levantamento das datas em que ocorreram escorregamentos no Morro do Arthur, as chuvas diárias e as chuvas acumuladas de 5 dias anteriores aos eventos.

Tavares et al. (2004) estudaram as chuvas no litoral norte de São Paulo e a ocorrência de escorregamentos no período de 1991 a 2000, onde foram registrados 
141 escorregamentos deixando 13 vítimas. Foram calculados os períodos de retorno para chuvas de 70, 80, 100 e $120 \mathrm{~mm}$ em 24 horas e para as chuvas acumuladas de 80, 100, 120 e $150 \mathrm{~mm}$ em 72 horas. A maioria dos escorregamentos ocorreu em eventos de chuvas acima de $120 \mathrm{~mm}$ num período de 72 h (69\%), mas também foram consideráveis as ocorrências abaixo de 80 mm (21\%) e entre 80 e 120 (10\%). Segundo os autores, uma possível explicação seria a influência antrópica agravando os escorregamentos, com cortes e aterros mal construídos, lançamento inadequado de águas servidas e sistemas precários de drenagem, ocorrência de chuvas anteriores ao período de 72 horas, evento intenso em 24 horas que não acumula 80 $\mathrm{mm}$ em 72 horas.

Michel et al. (2011) utilizou o modelo SHALSTAB para determinar as áreas de perigo da bacia do rio Cunha em SC, onde ocorreram quatro escorregamentos severos, e utilizou seus resultados juntamente com dados de precipitação para estimar a chuva que deflagrou os escorregamentos ocorridos em novembro de 2008. Foram encontrados 4 períodos chuvosos potencias para deflagrar os escorregamentos: 1.042 mm em 69 dias; 533 mm em 28 dias; 216 mm em 8 dias; 167 mm em 3 dias; que foram comparados com a série histórica. Apenas um período, $1.042 \mathrm{~mm}$ em 69 dias, não havia sido registrado na série histórica, o que levou os autores a acreditar que estes escorregamentos tenham sido desencadeados por um longo período chuvoso.

A classificação das chuvas é imprescindível na operação dos Sistemas de Alerta. Definir os intervalos de classes como, por exemplo, chuva fraca, chuva moderada, chuva severa e chuva extrema e, a estas classes relacionar os valores de precipitação (limites inferior e superior) é extremamente importante.

A operação do Sistema de Alerta de Cheias do INEA - Instituto Estadual do Ambiente do Estado do Rio de Janeiro - teve início no início de 2008, com as primeiras estações telemétricas, que enviam dados via SMS a cada 15 minutos. $O$ INEA monitora o comportamento do nível d'água dos rios e os acumulados pluviométricos no estado que, associado a informações meteorológicas, possibilita a emissão de alertas de chuvas fortes e probabilidade de ocorrência de cheias nas regiões monitoradas para os agentes da Defesa Civil. Para determinar a mudança 
de estágio (estado), é necessário que ocorra uma das seguintes situações, como ilustra a Tabela 3 abaixo:

Tabela 3 - Estados do monitoramento do Sistema de Alerta do INEA

\begin{tabular}{|c|l|}
\hline Estágio & \multicolumn{1}{c|}{ Situação } \\
\hline VIGILÂNCIA & $\begin{array}{l}\text { - Sem chuvas ou chuvas fracas e esparsas } \\
\text { - Nível d'água normal }\end{array}$ \\
\hline ATENÇÃO & $\begin{array}{l}\text { - Previsão de ocorrência de chuvas } \\
\text { moderadas e fortes }\end{array}$ \\
\hline ALERTA & $\begin{array}{l}\text { - Registro de chuvas intensas } \\
\text { - Subida do nível do rio acima do normal }\end{array}$ \\
\hline ALERTA MÁXIMO & $\begin{array}{l}\text { - Continuação da chuva } \\
\text { - Nível atingindo 80\% da capacidade de } \\
\text { transbordamento }\end{array}$ \\
\hline
\end{tabular}

Fonte: INEA - http://inea.infoper.net/

No caso de escorregamentos, os alertas são emitidos de acordo com o monitoramento de acumulados de chuva para as seguintes durações: chuvas maiores que $30 \mathrm{~mm}$ em 1 hora; $P$ > $100 \mathrm{~mm}$ em 24 horas; $P$ > $115 \mathrm{~mm}$ em 96 horas; $\mathrm{P}>270 \mathrm{~mm}$ em 30 dias.

Outros autores, como Santos et al. (2013); Weschenfelder, Pickbrenner e Pinto (2011); Dantas (2012), classificaram as chuvas de acordo com a sua probabilidade de superação, obtida através do ajuste de uma distribuição de frequência. Para a classificação das chuvas, utilizaram o SPI (Standardized Precipitation Index) ou Índice de Precipitação Padronizada, desenvolvido em 1993 por Tom McKee, Nolan Doesken e John Kleist, do Centro de Clima do Colorado.

\subsection{MEDIDAS GLOBAIS E LOCAIS PARA A REDUÇÃO DE DESASTRES}

Em 1999 foi criada a UNISDR, o secretariado das Nações Unidas, responsável pela coordenação e implementação da Estratégia Internacional para a Redução de Desastres (ISDR - International Strategy Disaster Reduction). 
Segundo a UNISDR, com o número crescente de pessoas afetadas por desastres naturais, existe também um crescente reconhecimento por parte dos governos e organizações de que é necessário reduzir os riscos e construir comunidades e sistemas resilientes.

A redução de risco de desastres (DRR - Disaster Risk Reduction) visa reduzir os danos causados por desastres naturais como terremotos, furacões, inundações, secas através de uma ética de prevenção. É feita através de esforços sistemáticos para analisar e reduzir seus efeitos, através de redução da exposição aos riscos, diminuindo a vulnerabilidade de pessoas e habitações, gerenciamento territorial e ambiental e preparação para os eventos adversos (UNISDR, 2011).

A UNISDR coordena, orienta e monitora os esforços internacionais na DRR e emite relatórios regulares sobre o progresso da Implementação do Plano de Ação de Hyogo (HFA - Hyogo Framework Action). O HFA é um plano de ação de 10 anos, criado em 2005 e adotado por 168 países membros. Seu objetivo é diminuir substancialmente as perdas causadas por desastres até 2015 através da construção de resiliência nas comunidades e nações, reduzindo o número de vítimas e as perdas materiais, sociais em ambientais causadas por eventos adversos. O HFA apresenta 5 prioridades de ação:

1. Garantir que a DRR é de prioridade nacional e local com base institucional para a sua implementação.

Através da implementação de políticas e quadros institucionais para a DRR que sejam capazes de desenvolver e acompanhar o progresso através de indicadores e que promovam um consenso e envolvimento de todos os setores da sociedade.

2. Identificar, avaliar e monitorar os riscos dos desastres e melhorar os sistemas de alerta.

Conhecimento dos perigos e das vulnerabilidades físicas, econômicas e sociais aos desastres da maioria da sociedade e planos de ação com base nesse conhecimento. 
3. Usar o conhecimento, inovação e educação para construir uma cultura de segurança e resiliência em todos os níveis.

Os desastres podem ser substancialmente reduzidos se a sociedade está bem informada sobre os riscos e vulnerabilidades a que estão sujeitas, se está organizada e motivada por uma cultura de prevenção, resiliência e disseminação do conhecimento adquirido a outros membros da comunidade em que vivem.

4. Reduzir os fatores de risco.

Através de melhor planejamento e gerenciamento do uso e ocupação do solo, realocação de indivíduos das áreas de risco.

5. Reforçar a preparação e resposta ao desastre em todos os níveis.

Os impactos e as perdas podem ser substancialmente reduzidos se as autoridades locais, a comunidade e os indivíduos que habitam as áreas sujeitas a eventos adversos estiverem efetivamente preparadas, equipadas e treinadas, prontas para agir quando o evento ocorra.

A UNISDR também promove, a cada dois anos, a Plataforma Global de DRR, um fórum de discussões, troca de conhecimento e informações e parcerias entre os representantes dos governos, ONGs, cientistas, organizações das Nações Unidas com o objetivo de melhorar a DRR.

O Serviço Geológico dos Estados Unidos (USGS - U. S. Geological Survey), em 1 de outubro de 2010, colocou em seus temas e áreas de atuação os riscos naturais (Natural Hazards), onde estão contemplados alguns programas para redução de risco de desastres, tais como:

O programa de perigos de terremoto (EHP - The Earthquake Hazards Program) é parte do programa nacional de redução de riscos dos terremotos (NEHRP - National Earthquake Hazards Reduction Program) liderado pelo Instituto Nacional de Padrões e Tecnologia (NIST). Os terremotos representam risco significativo a 75 milhões de americanos em 39 Estados-Membros. O EHP fornece informações e produtos para a redução das perdas causadas por terremotos, incluindo avaliação de risco e monitoramento em tempo real. 
O programa dos perigos dos vulcões (VHP - Volcano Hazards Program) tem como objetivos avançar na compreensão científica dos processos vulcânicos e diminuir os impactos nocivos das atividades vulcânicas. O programa monitora vulcões ativos, avalia seus perigos e responde às erupções, emitindo avisos dos potenciais riscos de erupções vulcânicas às autoridades responsáveis pelo gerenciamento de emergência e à população a ser afetada.

A rede global sismográfica (GSN - Global Seismographic Network) fornece o monitoramento de mais de 150 estações sísmicas distribuídas globalmente. A GSN foi formada através de uma parceria entre os USGS, o National Science Foundation (NSF) e as instituições de pesquisa de sismologia incorporadas (IRIS - Incorporated Research Institutions for Seismology).

O programa de perigos de escorregamentos de terra (LHP - Landslide Hazards Program) tem como missão fornecer informações que levem à redução das perdas causadas por escorregamentos de terra e aumentar a segurança da população através da melhor compreensão dos riscos e estratégias de mitigação de risco. O LHP realiza avaliações de risco de escorregamentos de terra, previsões, assistência para responder às emergências e se envolve em atividades de divulgação.

O USGS possui um site com informações sobre as inundações (Floods) dos Estados Unidos, o WaterWatch (http:waterwatch.usgs.gov, acesso em 17 de abril de 2013), que apresenta mapas, gráficos e tabelas descrevendo as condições dos níveis e vazões dos rios no passado e em tempo real, com informações atualizadas de hora a hora. A WaterWatch fornece mapas com a localização e dados de mais de 3.000 postos fluviométricos (com séries de 30 anos ou mais). São usadas cores para representar condições de vazão atuais em comparação com a série histórica. Os mapas apresentam uma interface que permite aos usuários recuperar gráficos de nível e vazão e realçar locais onde eventos hidrológicos extremos, tais como inundações e secas, estão ocorrendo.

No Brasil, as ações emergenciais de enfrentamento dos riscos decorrentes dos desastres naturais são coordenadas e executadas pelo Sistema de Defesa Civil, estruturado em nível federal, estadual e municipal, com diretrizes e planos de ação para atendimentos emergenciais em todo o país. Entretanto, as ações de prevenção 
não tem o mesmo tratamento, ficando em segundo plano. Ainda é reduzido o número de municípios que contemplam a gestão de riscos em seu plano de desenvolvimento urbano (TOMINAGA; SANTANA; AMARAL, 2009).

Dentre as medidas que podem ser adotadas no gerenciamento de risco e redução de risco de desastres estão:

- Prevenção de desastres - através de planejamento do uso e ocupação do solo, zoneamento das áreas de risco, educação ambiental (não depositar lixo em locais onde possam atingir o sistema de drenagem, não construir em áreas de proteção permanente etc.), elaboração de planos de contingência. Aspectos legais como as ações municipais de revisão e adequação dos códigos de edificações, planos diretores municipais também devem ser previstos;

- Preparação para os desastres e situações de emergência - através da implementação de sistemas de alerta, treinamento da população para enfrentar os eventos adversos quando vierem a ocorrer. Planos de ação da defesa civil e treinamento;

- Resposta aos desastres - remoção das pessoas das áreas de risco com rapidez e eficácia, resgate, assistência médica aos feridos etc.;

- Reconstrução das áreas atingidas - reparar danos na infraestrutura das áreas atingidas, sistemas de abastecimento de água, estradas etc.

Brollo et al. (2011) apresentam um panorama da situação dos Desastres Naturais no Estado de São Paulo e como eles vem sendo enfrentados pelo poder público através de instrumentos de gerenciamento e gestão de riscos. Como não há um registro sistemático de acidentes no Estado, o número de acidentes foi obtido através da interpretação dos dados do cadastro de vistorias e atendimentos da Coordenadoria Estadual da Defesa Civil (CEDEC). Nesse cadastro estão as vistorias e atendimentos emergenciais dos acidentes relacionados a inundações, escorregamentos, erosão, chuvas fortes, raios etc. prestados nos meses de verão (dezembro a março) na Operação Verão. Os resultados mostram que o maior número de acidentes e os maiores danos (levando-se em consideração o número de pessoas afetadas) são os relacionados a inundações seguidos de escorregamentos. As regiões mais atingidas são as bacias do Alto Tietê, Paraíba do Sul, Ribeira de 
Iguape e do PCJ - Piracicaba, Capivari e Jundiaí. Segundo os autores, as políticas públicas voltadas à redução de desastres já vem sendo implementadas no Estado de São Paulo há mais de 25 anos e dentre os instrumentos de gestão de riscos incluem-se:

- $\quad$ Planos Preventivos de Defesa Civil (PPDC) e os Planos de Contingência;

Teve início no verão de 1988/89 nas encostas da Serra do Mar. Entra em operação anualmente na estação de verão através do monitoramento dos índices de chuva diária, previsão meteorológica, atendimento emergencial, remoção temporária e preventiva das pessoas das áreas de risco quando há perigo de escorregamentos devido aos eventos críticos de precipitação, com o objetivo de salvar o maior número possível de pessoas em caso de escorregamentos.

- Mapeamento das áreas de risco a inundações e escorregamentos;

Iniciou-se no verão de 2004, em uma ação conjunta entre a CEDEC, Ministério da Integração Nacional e Ministério das Cidades e tem como objetivo conhecer as áreas de risco e assim programar as medidas estruturais, como obras de contenção, e as não estruturais, de convivência, como monitoramento, planos de prevenção, sistemas de alarme, educação ambiental.

- $\quad$ Planos Municipais de Redução de Risco (PMRR).

Depois do mapeamento deve ser feita a hierarquização das áreas prioritárias e necessidades financeiras para a implementação das medidas estruturais e não estruturais para a redução do risco.

Dos municípios do Estado de São Paulo, 114 possuem PPDC e 65 foram mapeados até 2010, segundo dados do IG. Verificou-se a necessidade de tornar mais eficientes os instrumentos de gestão através de algumas medidas como: Organizar uma política pública com maior articulação entre os órgãos estaduais; fazer um diagnóstico das situações de risco; ordenamento territorial e planejamento ambiental; monitoramento de risco em áreas sujeitas a inundações e escorregamentos; intervenção e mitigação dos riscos; informação, capacitação e treinamento das equipes municipais, dos agentes da defesa civil e demais envolvidos e conscientização da população; comprometimento do poder público municipal, fortalecimento do quadro dos agentes da defesa Civil e da secretaria de obras, planejamento e meio ambiente. 
No ano de 2011, foi lançado o Plano Nacional de Gestão de Riscos e Resposta a Desastres Naturais. Dentre suas ações prioritárias estão: a prevenção; mapeamento de áreas de ricos; monitoramento e alerta; resposta aos desastres naturais no país.

Para auxiliar as ações do Plano foi criado, no final de 2011, pelo Ministério de Ciência e Tecnologia e Inovação (MCTI), o CEMADEN - Centro Nacional de Monitoramento e Alerta de Desastres Naturais. A missão do CEMADEN é monitorar o território brasileiro e emitir alertas de desastres naturais com o objetivo de subsidiar as ações de preparação e resposta aos desastres do SINDEC - Sistema Nacional de Defesa Civil.

Dentre os objetivos de sua criação, pode-se mencionar: planejamento das ações de preparação e resposta aos desastres; diminuição das perdas e danos através da redução de riscos com ações de evacuação em tempo hábil; maior eficiência na alocação de recursos do SINDEC aos locais mais críticos (DI GREGÓRIO et al., 2012).

Para estruturar o sistema de alerta, dados de cartas de risco são cruzados com informações hidrológicas e dados de previsão de tempo, como os do CPTEC (Centro de previsão de Tempo e Estudos Climáticos) e INMET (Instituto Nacional de Meteorologia).

Os alertas são emitidos quando existe probabilidade de que as chuvas atinjam os limiares pré-estabelecidos para a mudança de estado (chuvas elevadas em um dia ou volume elevado acumulado em alguns dias). Exemplo são as situações em que frentes frias ou chuvas convectivas estão concentradas em regiões com alto risco de ocorrência de escorregamentos ou inundações.

Depois que o alerta é emitido, o Centro Nacional de Gerenciamento de Riscos de Desastres (CENAD) do Ministério da Integração Nacional (MI), ligado à Defesa Civil Nacional, entrar em contato com os serviços de defesa civis estaduais e municipais e os Ministérios da Saúde e da Defesa. O CENAD faz a comunicação e articulação entre os órgãos federais, estaduais e municipais na resposta aos desastres. 


\section{METODOLOGIA DE ANÁLISE DAS CHUVAS EXTREMAS}

A dissertação apresenta quatro estudos de caso, seguindo a metodologia de análise descrita neste capítulo.

Foram selecionadas quatro regiões que sofreram desastres naturais no Brasil nos últimos anos: Vale do Itajaí - SC, São Luís do Paraitinga e Cunha - SP, Vale do Mundaú - PE e AL e Região Serrana do Rio de Janeiro.

\subsection{CARACTERIZAÇÃO DAS ÁREAS DE ESTUDO E SELEÇÃO DAS ESTAÇÕES}

Inicialmente, nos estudos de caso, foi feita uma breve descrição das características físicas e climatológicas das regiões e dos desastres ocorridos em cada uma delas.

Os postos pluviométricos foram selecionados através do SNIRH - Sistema Nacional de Informações sobre Recursos Hídricos, da ANA, Agência Nacional de Águas. A seleção foi feita por bacia hidrográfica localizada nas regiões atingidas pelos desastres e a partir dessa seleção obteve-se a relação de todas as estações pluviométricas contidas nessas bacias. A escolha das estações foi feita de acordo com o tamanho da série histórica, qualidade dos dados (de preferência estações com poucas falhas) e disponibilidade de dados no período em que ocorreram os escorregamentos e inundações.

Os dados das séries de chuvas diárias foram obtidos de várias fontes, dependendo das entidades que operavam as estações nas regiões estudadas. Dentre as fontes estão: Hidroweb, do site da ANA, o CTH/DAEE - Centro Tecnológico de Hidráulica e Recursos Hídricos do Departamento de Águas e Energia Elétrica, a CPRM - Companhia de Pesquisa de Recursos Minerais com dados da Operação da Rede Hidrometeorológica Nacional e outras estações contidas no banco de dados utilizado no projeto Atlas Pluviométrico do Brasil (CPRM, 2011). 
A relação das estações utilizadas, o código de cada estação, as coordenadas, as altitudes, bem como a área de estudo podem ser visualizadas nas tabelas e nas figuras contidas no início de cada estudo de caso, nos capítulos 5.1.1, 5.2.1, 5.3.1 e 5.4.1.

\subsection{ANÁLISE ESTATÍSTICA DOS DADOS DE CHUVA}

Com o objetivo de caracterizar o regime de chuvas das regiões, bem como entender sua magnitude e ocorrência, foram feitas algumas análises estatísticas dos dados das séries de chuvas coletadas nos pluviômetros localizados em cada área de estudo.

Foram analisados os totais mensais dos meses que antecedem cada evento crítico de precipitação, com o objetivo de verificar a situação em que se encontravam as bacias hidrográficas no momento em que os desastres aconteceram.

Foram calculadas algumas estatísticas básicas como a média mensal, a média anual, a média das máximas diárias do mês em que os eventos ocorreram, o dia da máxima no mês em que ocorreram os desastres, com o objetivo de caracterizar o comportamento das chuvas de cada região. No cálculo das chuvas máximas diárias, foi considerado o ano hidrológico.

Em seguida foram analisados os dados diários dos meses em que ocorreram as chuvas catastróficas em cada região. Os dados de chuva foram comparados às estatísticas básicas calculadas anteriormente para verificar a magnitude dos eventos diários observados.

\subsubsection{Distribuições ajustadas e períodos de retorno (Tr)}

Foi feito o ajuste das distribuições de probabilidade às séries de chuvas máximas diárias de cada estação, calculadas por ano hidrológico, de outubro a setembro. Duas distribuições foram testadas: a Log-Normal e a Gumbel. A 
motivação da escolha dessas duas distribuições se deve, além da facilidade de estimativa de seus parâmetros e ao fato de serem largamente utilizadas em estudos de máximas em hidrologia.

Segundo Davis e Naghettini (2000, p.84), as distribuições de Gumbel, Frechét e Weibull, oriundas da teoria clássica de eventos extremos (Gumbel, 1958), seriam as únicas para as quais existem justificativas teóricas de seu emprego na modelação de máximos (ou mínimos) de dados empíricos. Estas distribuições seguem a premissa de que os dados são aleatórios e considerados independentes e igualmente distribuídas (IID).

Sabe-se que dificilmente as variáveis hidrológicas e hidrometeorológicas seguem esta premissa. Isso justificaria o emprego de distribuições não extremais, como é o caso da Log-Normal. Chow (1954) justifica seu emprego dizendo que os fatores causais de variáveis hidrológicas agirem de forma multiplicativa, ao invés de aditiva e a soma dos logaritmos desses fatores tende a ser normalmente distribuída em consequência do teorema do limite central.

As chuvas máximas diárias foram ordenadas de forma decrescente e calculados: a posição de plotagem $\left(\mathrm{q}_{\mathrm{i}}\right)$, o período de retorno $(\operatorname{Tr})$, a média $(\mu)$, 0 desvio-padrão $(\sigma)$ e a assimetria $(\gamma)$ da distribuição empírica. Em seguida foi feito o ajuste das duas distribuições para cada estação.

Inicialmente a posição de plotagem $q_{i}$ foi calculada através da fórmula de Weibull (1), que é uma das mais utilizadas.

$$
\mathrm{q}_{\mathrm{i}}=\mathrm{i} /(\mathrm{N}+1)
$$

onde i é a ordem de classificação e N o tamanho da série.

O período de retorno ( $\mathrm{Tr}$ ) é estimado através do inverso da probabilidade de ocorrência, que corresponde à posição de plotagem da série empírica.

$$
\operatorname{Tr}=1 /\left(q_{i}\right)
$$

Observou-se que para séries mais curtas, como no caso da estação de Vargem Alta, localizada na Região Serrana do RJ, que possuía 42 anos de dados de máximas diárias, o cálculo do período de retorno para a chuva máxima de janeiro de 
2011 seria de apenas 43 anos e a chuva, que neste ano era um outlier, ficaria ainda mais fora da curva nesta estação. Como alternativa, foi utilizada outra fórmula para o cálculo da posição de plotagem para tentar melhorar as estimativas dos períodos de retorno.

Existem diferentes fórmulas para o cálculo da posição de plotagem, que variam conforme a especificação da distribuição de probabilidades $F_{x}(x)$. A maioria destas fórmulas pode ser expressa por:

$$
q_{i}=(i-\mathbf{a}) /(N+1-2 \mathbf{a})
$$

Onde a varia conforme a distribuição $F_{x}(x)$.

Como alternativa para o cálculo das posições de plotagem, foi utilizada a fórmula de Cunnane. O motivo para a utilização desta fórmula são os quantis aproximadamente não aviesados para todas as distribuições (Naghettini e Pinto, 2007).

$\mathrm{Na}$ fórmula de Cunnane, a corresponde ao valor $0,40 \mathrm{e}$, substituindo na expressão 3, a posição de plotagem é dada por:

$$
q_{i}=(i-0,40) /(N+0,2)
$$

Calculadas as posições de plotagem, foram feitos os cálculos dos períodos de retorno e, em seguida, ajustadas as distribuições Log-Normal e Gumbel para todas as estações.

\section{Distribuição Log-Normal}

Nesta distribuição a suposição é que os logaritmos das chuvas seguem uma distribuição normal. Para isso, o cálculo estatístico é aplicado sobre os logaritmos das chuvas, em vez de manusear diretamente com os valores de chuva, obtendo a seguinte equação:

$$
\log x=\overline{\log x}+K \cdot \sigma
$$

Onde x é o logaritmo da precipitação máxima para uma dada probabilidade; $\bar{x}$ é a média dos logaritmos das precipitações máximas anuais; e $\sigma$ é o desvio padrão 
dos logaritmos das vazões máximas anuais. O valor de $\mathrm{K}$ é obtido de tabelas de distribuição normal.

Distribuição de Gumbel

A distribuição de Gumbel pode ser expressa pela seguinte equação:

$$
P=1-e^{-e^{-b}}
$$

Onde: $P$ é a probabilidade; $\boldsymbol{e}$ é a base dos logaritmos naturais; $b$ é dado por:

$$
b=\frac{1}{0,7797 . \sigma} \cdot(x-\bar{x}+0,45 . \sigma)
$$

Onde $\boldsymbol{x}$ é a chuva máxima; $\bar{x}$ é a média das chuvas máximas anuais; e $\sigma$ é o desvio padrão das chuvas máximas anuais.

\subsubsection{Teste de Aderência de Kolmogorov-Smirnov (KS)}

Para testar a aderência das distribuições escolhidas, foi feito o teste de Kolmogorov-Smirnov (KS) para o nível de significância de $\alpha=10 \%$.

O teste de aderência de Kolmogorov-Smirnov é um teste não paramétrico, cuja estatística do teste tem como base a diferença máxima entre as funções de probabilidade acumuladas empírica e teórica (Naghettini e Pinto, 2007).

A amostra é classificada em ordem crescente de modo que $1 \leq m \leq N$, onde $m$ é a ordem de classificação e $\mathrm{N}$ é o tamanho da série. Para cada elemento da amostra, a distribuição empírica $F_{N}(x)$ é calculada pela proporção de valores que não excedem $x_{(m)}$.

$$
F_{N}\left(x_{m}\right)=m / N
$$

A estatística do teste KS é dada por:

$$
D_{N}=\sup _{-\infty \leq x \leq \infty}|F N(x)-F x(x)|
$$

Para amostras de tamanho superior a 40, os valores críticos da estatística de teste $D_{N}, \alpha$, utilizados nas Tabelas dos testes $K S$ contidas em cada estudo de caso, 
são calculados através das fórmulas da Tabela 3. Para amostras com $N<40$, ver Naghettini e Pinto, 2007.

Tabela 4 - Valores críticos de $D_{N}, \boldsymbol{\alpha}$

\begin{tabular}{c|c|c|c}
\hline $\mathbf{N}$ & $\mathbf{D}_{\mathbf{N}, \mathbf{0}, \mathbf{1 0}}$ & $\mathbf{D}_{\mathbf{N}, \mathbf{0}, \mathbf{0 5}}$ & $\mathbf{D}_{\mathbf{N}, \mathbf{0}, \mathbf{0 1}}$ \\
\hline$>40$ & $1,22 / \sqrt{\mathrm{N}}$ & $1,36 / \sqrt{\mathrm{N}}$ & $1,63 / \sqrt{\mathbf{N}}$ \\
\hline
\end{tabular}

Fonte: Naghettini e Pinto, 2007

Os resultados do teste de KS são apresentados em tabelas, contidas em cada um dos estudos de caso, que indicam se as duas distribuições escolhidas foram ou não aderentes, em cada uma das estações, para $10 \%$ de nível de significância adotado. Foi adotado $10 \%$ por ser o nível mais restritivo do intervalo entre $1 \%$ e $10 \%$.

\subsubsection{Chuvas máximas históricas em cada uma das regiões}

Os dados das chuvas máximas diárias das estações pertencentes a cada região foram plotadas em conjunto em um único gráfico regional, com o objetivo de verificar a magnitude dos eventos de chuvas máximas diárias e caracterizar as máximas de cada uma das regiões.

Os cinco maiores eventos de chuvas máximas diárias de cada estação e o ano hidrológico em que ocorreram foram ilustrados em Tabelas denominadas os cinco maiores eventos diários de precipitação (em $\mathrm{mm}$ ) registrados em cada estação. 


\subsection{PRECIPITAÇÕES MÁXIMAS ACUMULADAS PARA DIFERENTES DURAÇÕES}

A partir das séries históricas, foram calculadas as chuvas máximas acumuladas para diferentes durações, de 1 a 10 dias, 15, 20, 30 e 45 dias. As chuvas diárias foram acumuladas para cada uma das diferentes durações (a máxima acumulada móvel), obtendo dessa maneira a série das máximas acumuladas por ano hidrológico de cada uma das estações analisadas. O objetivo dessa análise foi tentar entender o processo de chuvas contínuas não explicados com as séries das chuvas máximas de um dia de duração. Em algumas regiões, o acúmulo de muitos dias de chuva foi determinante para a ocorrência dos desastres.

\subsection{CLASSIFICAÇÃO DAS CHUVAS UTILIZANDO O SPI}

A classificação das chuvas foi realizada utilizando o SPI, Índice de Precipitação Padronizada, a partir da identificação dos limites de altura diária de precipitação de cada classe, de acordo com o período de retorno correspondente.

De acordo com Santos et al. (2013), seu cálculo é baseado nas probabilidades de superação de um determinado volume precipitado acumulado. Os valores de precipitações são somados em escalas diversas, por exemplo, 3, 6, 12 ou 24 meses, dependendo do interesse ou necessidade do analista. Para determinado mês, por exemplo, outubro, o SPI relativo a 7 meses (SPI-7) é obtido a partir do somatório das precipitações ao longo dos sete meses que antecedem o mês de referência.

A série de dados, resultantes do somatório das precipitações ao longo dos meses é em seguida ajustada a uma distribuição de probabilidades. Na formulação original, McKee (1993) utilizou a distribuição Gama. Outros autores fizeram uso de outras funções para o cálculo do SPI. A partir do ajuste da distribuição de probabilidades, a cada elemento da série ajustada é atribuída uma probabilidade de não superação. Cada uma dessas probabilidades de não superação é, por fim, 
associada ao quantil correspondente da distribuição normal padrão (média 0,0 e desvio-padrão 1,0). O valor do quantil da distribuição normal padrão associado à probabilidade calculada no período de interesse é o valor do SPI para o mês em questão. A Figura 3 ilustra o procedimento de calculo do SPI (Santos et al., 2013).

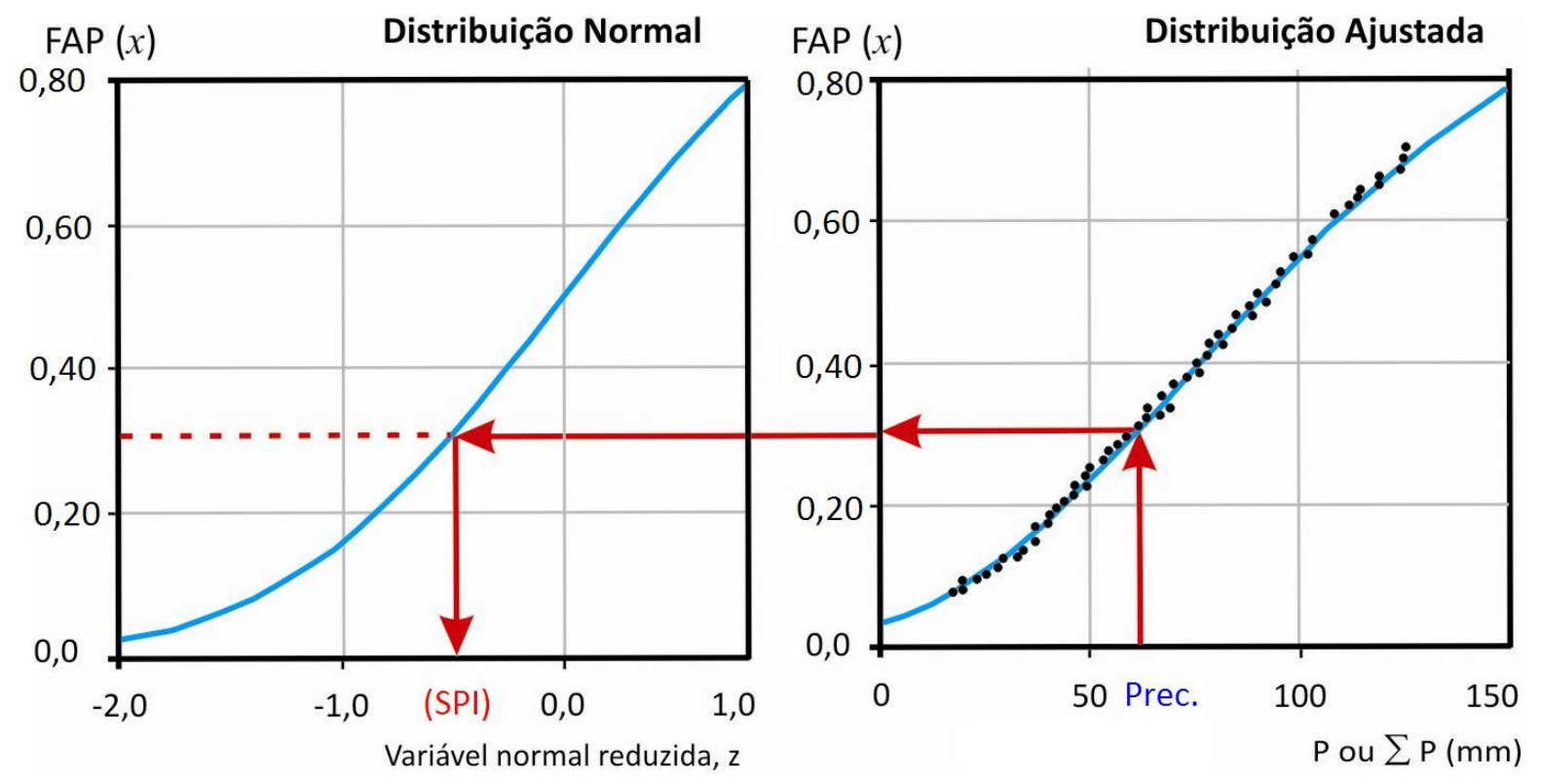

Figura 3 - Ilustração esquemática dos procedimentos de cálculo do SPI

(Fonte: Santos et al., 2013)

Uma das vantagens do uso do SPI, segundo McKee (1993), é o fato de o SPI ser função apenas da probabilidade. Sendo assim, independente da função de distribuição de probabilidade que se utilize, o SPI pode ser adequadamente calculado. Outras vantagens são o fato de o SPI ser capaz de caracterizar tanto períodos secos quanto chuvosos, bem como o fato de ele se adequar a qualquer variável hidrológica. Contudo, o uso desse índice também apresenta limitações. Mishra e Singh (2010) argumentam que a principal delas é a necessidade de longos registros históricos para seu cálculo consistente, o que nem sempre é possível (WESCHENFELDER; PICKBRENNER; PINTO, 2011).

Diversas classes de SPI podem ser definidas, dependendo da necessidade do usuário. A Tabela 5 ilustra a classificação segundo a formulação original, que considera tanto as secas como também situações chuvosas. Nela estão ilustradas as classes de precipitação, o SPI correspondente, as probabilidades de não superação dos limites inferior e superior de cada uma das classes de SPI 
considerada, p (inf.) e p (sup.), bem como as probabilidades de ocorrência em cada uma delas ( $p$ classe).

Tabela 5 - Classes de secas e chuvas e probabilidades associadas

\begin{tabular}{|c|c|c|c|c|c|}
\hline Classe & \multicolumn{2}{|c|}{ SPI } & p (inf.) & p (sup.) & p classe \\
\hline Seca Extrema (SE) & & $\leq-2$ & 0 & 0,0228 & $2,3 \%$ \\
\hline Seca Severa (SS) & -2 & $-1,5$ & 0,0228 & 0,0668 & $4,4 \%$ \\
\hline Seca Moderada (SM) & $-1,5$ & -1 & 0,0668 & 0,1587 & $9,2 \%$ \\
\hline Seca Leve (SL) & -1 & 0 & 0,1587 & 0,5000 & $34,1 \%$ \\
\hline Chuvoso Leve (CL) & 0 & 1 & 0,5000 & 0,8413 & $34,1 \%$ \\
\hline Chuvoso Moderado (CM) & 1 & 1,5 & 0,8413 & 0,9332 & $9,2 \%$ \\
\hline Chuvoso Severo (CS) & 1,5 & 2 & 0,9332 & 0,9772 & $4,4 \%$ \\
\hline Chuvoso Extremo (CE) & $>2$ & & 0,9772 & 1 & $2,3 \%$ \\
\hline
\end{tabular}

(Fonte: Weschenfelder et al., 2011)

Weschenfelder; Pickbrenner e Pinto (2011) adaptaram a Tabela 5, utilizada no SPI, para se estabelecer as classes para precipitações diárias máximas anuais como apresentado na Tabela 6. Dessa forma, foram definidas as classes: Chuva Fraca (CF); Chuva Leve (CL); Chuva Moderada (CM); Chuva Severa (CS); Chuva Extrema $(C E)$. As probabilidades inferior e superior foram relacionadas aos períodos de retorno das precipitações $(\mathrm{T})$.

Tabela 6 - Classes de precipitações diárias máximas anuais (PDMA)

\begin{tabular}{|c|c|c|c|c|c|}
\hline Classe de PMDA & \multicolumn{2}{|c|}{ SPI } & p (inf.) & p (sup.) & T (anos) \\
\hline Chuva Fraca (CF) & & 0 & & 0,500 & $\leq 2$ \\
\hline Chuva Leve (CL) & 0 & 1 & 0,500 & 0,841 & $2<\mathrm{T} \leq 6,3$ \\
\hline Chuva Moderada (CM) & 1 & 1,5 & 0,841 & 0,933 & $6,3<\mathrm{T} \leq 15$ \\
\hline Chuva Severa (CS) & 1,5 & 2 & 0,933 & 0,977 & $15<\mathrm{T} \leq 44$ \\
\hline Chuva Extrema (CE) & 2 & & 0,977 & & $>44$ \\
\hline
\end{tabular}

(Fonte: Weschenfelder et al., 2011)

No presente trabalho foi utilizada a tabela adaptada (Tabela 6). O cálculo dos limiares de precipitação foi feito, para cada uma das estações pluviométricas selecionadas nas regiões estudadas, adotando-se o ajuste da distribuição de probabilidades de Gumbel. Esta distribuição foi escolhida por ser usualmente utilizada em estudos de máximas. Segundo Naghettini e Pinto (2007), a distribuição de Gumbel (máximos) é a distribuição de valores extremos mais usada na análise de 
frequência de variáveis hidrológicas, com inúmeras aplicações na determinação de relações intensidade-duração-frequência de precipitações intensas e estudos de vazões de enchentes.

$\mathrm{Na}$ escolha das séries de chuvas máximas a serem classificadas, foram adotados os intervalos de duração de 1 dia, 2, 3, 4 e 5 dias. Os limiares para o intervalo de duração de 1 dia foram ilustrados em Tabelas e Figuras em cada um dos estudos de caso. Os resultados das durações de 2 a 5 dias constam do Anexo II ao Anexo V. 


\section{ESTUDOS DE CASO}

\subsection{VALE DO ITAJAÍ EM SANTA CATARINA}

Em novembro de 2008, as chuvas elevadas que atingiram a Região do Vale do Itajaí, em Santa Catarina, causaram um dos maiores desastres naturais do estado. Dentre as localidades atingidas, 63 decretaram situação de emergência e 14 cidades decretaram estado de calamidade pública. A situação de emergência e o estado de calamidade pública são o reconhecimento, pelo poder público, de situação anormal causada por desastre, a primeira, provocando danos suportáveis à comunidade, e a segunda provocando sérios danos à população afetada e à vida de seus integrantes, comprometendo substancialmente sua capacidade de resposta. Houve inundações e escorregamentos de encostas que deixaram 158 vítimas e mais de 80.000 desabrigados ou desalojados. Cerca de 1,5 milhão de pessoas foram atingidas. As chuvas elevadas diárias, o volume de chuva acumulado durante vários dias, desde o mês de setembro ou outubro de 2008, e as condições de relevo contribuíram para a catástrofe observada na região.

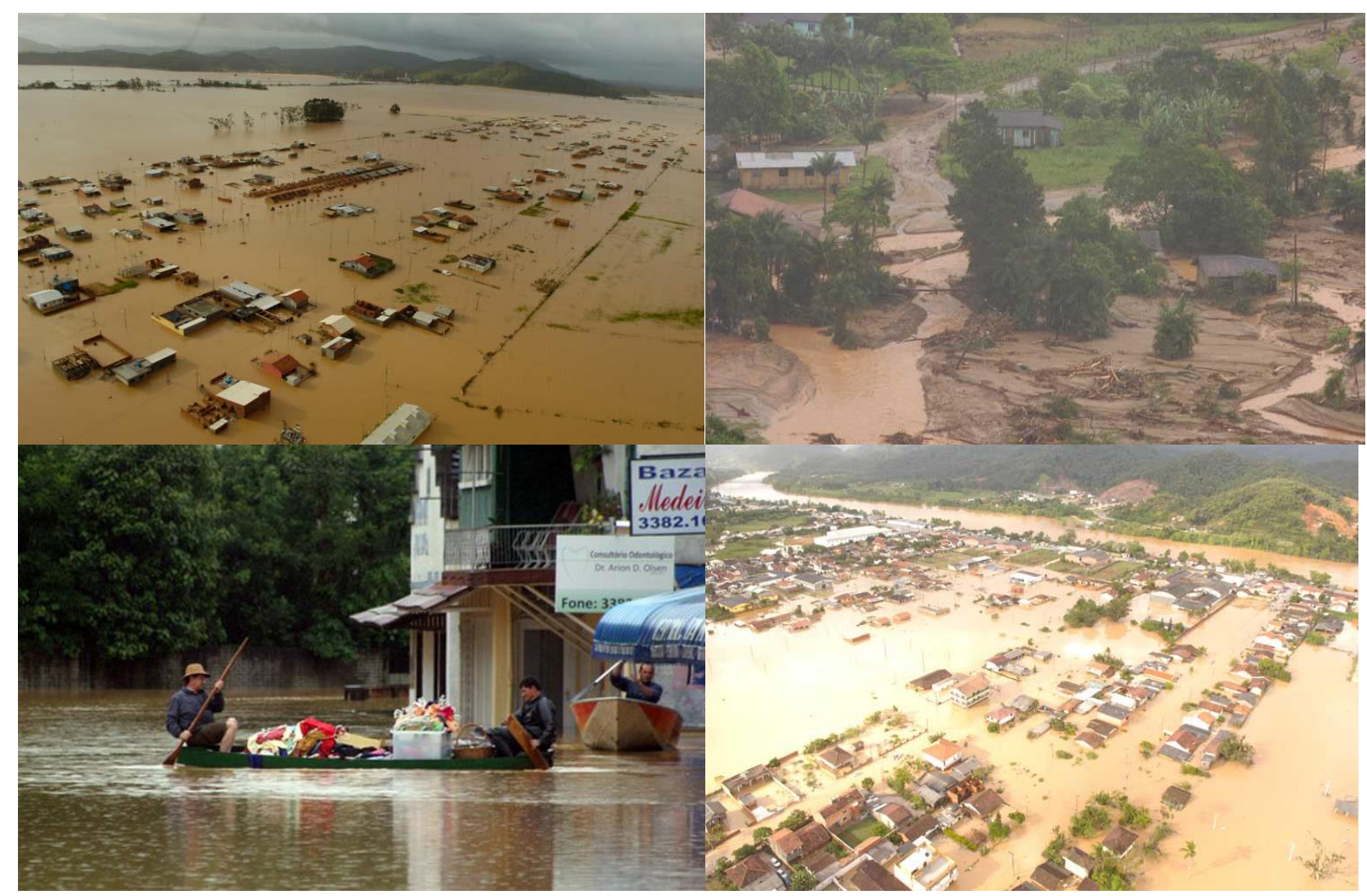

Figura 4 - Inundações ocorridas em novembro de 2008 nos municípios: Itajaí, Alto Baú em Ilhota, Timbó e Blumenau (da esquerda para a direita, de cima para baixo)

(FONTE: Emergência em Santa Catarina. Créditos: Patrick Rodrigues, Marcos Porto, André Schroeder e Patrick Rodrigues) 
Nos dias 8 e 9 de setembro de 2011, novamente a região sofre com os desastres naturais. Os volumes de chuva diários não foram tão elevados quanto os de 2008, mas suficientes para desencadear inundações e escorregamentos no Vale do Itajaí.

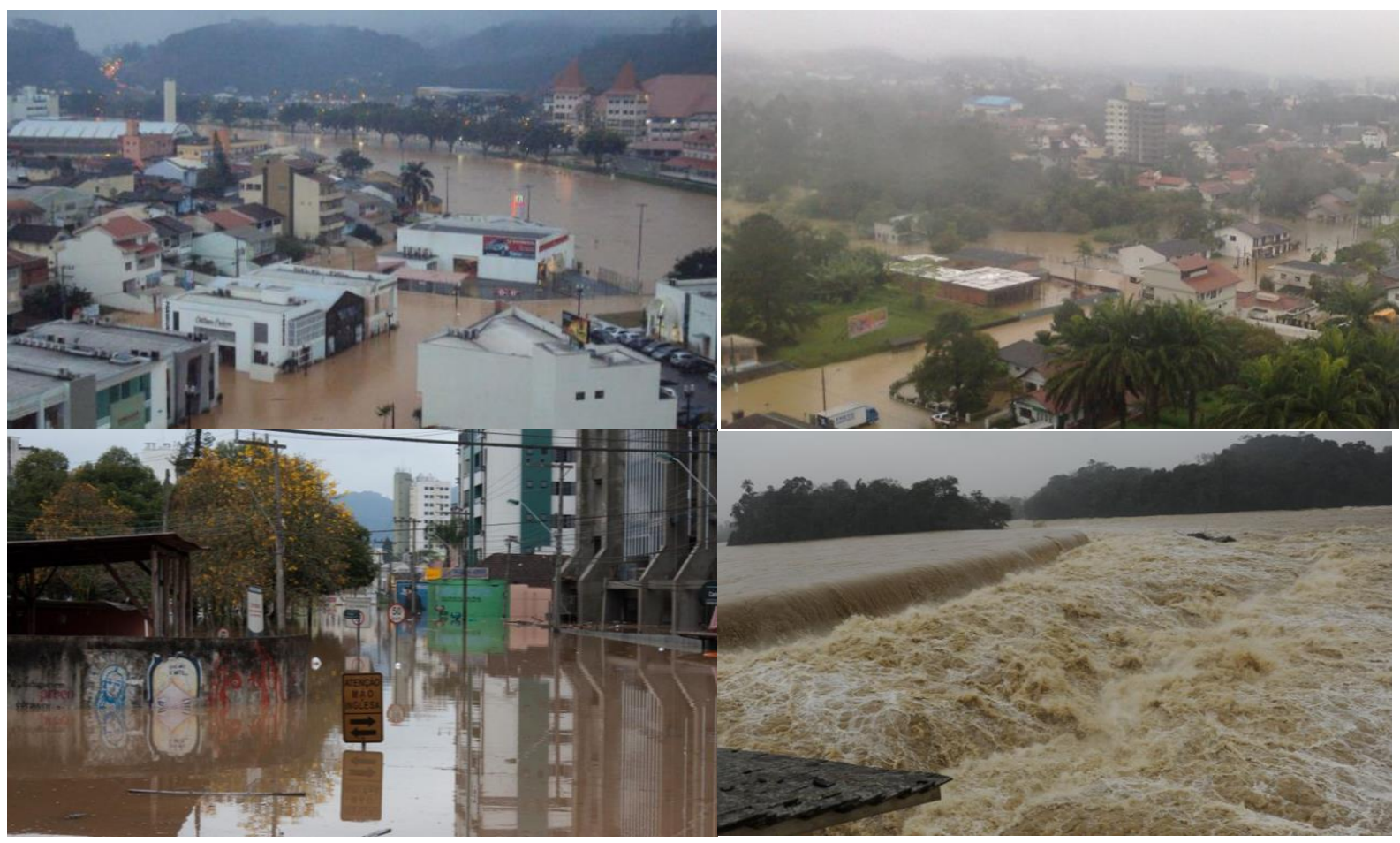

Figura 5 - Brusque (08/09/2011) (Timbó (09/09/2011) Blumenau (10/09/2011) Rio Itajaí (FONTE: Chuvas no Sul. Créditos: Rafael Dobatin, Nelson Ruprecht, Leo Laps e Jadyr Nascimento)

A região sofre constantemente com os desastres, como os ocorridos em julho de 1983 e agosto de 1984, onde se iniciaram as ações na bacia para gerenciamento dos desastres. Outras grandes inundações ocorreram nos anos de 1911, 1927 e 1957.

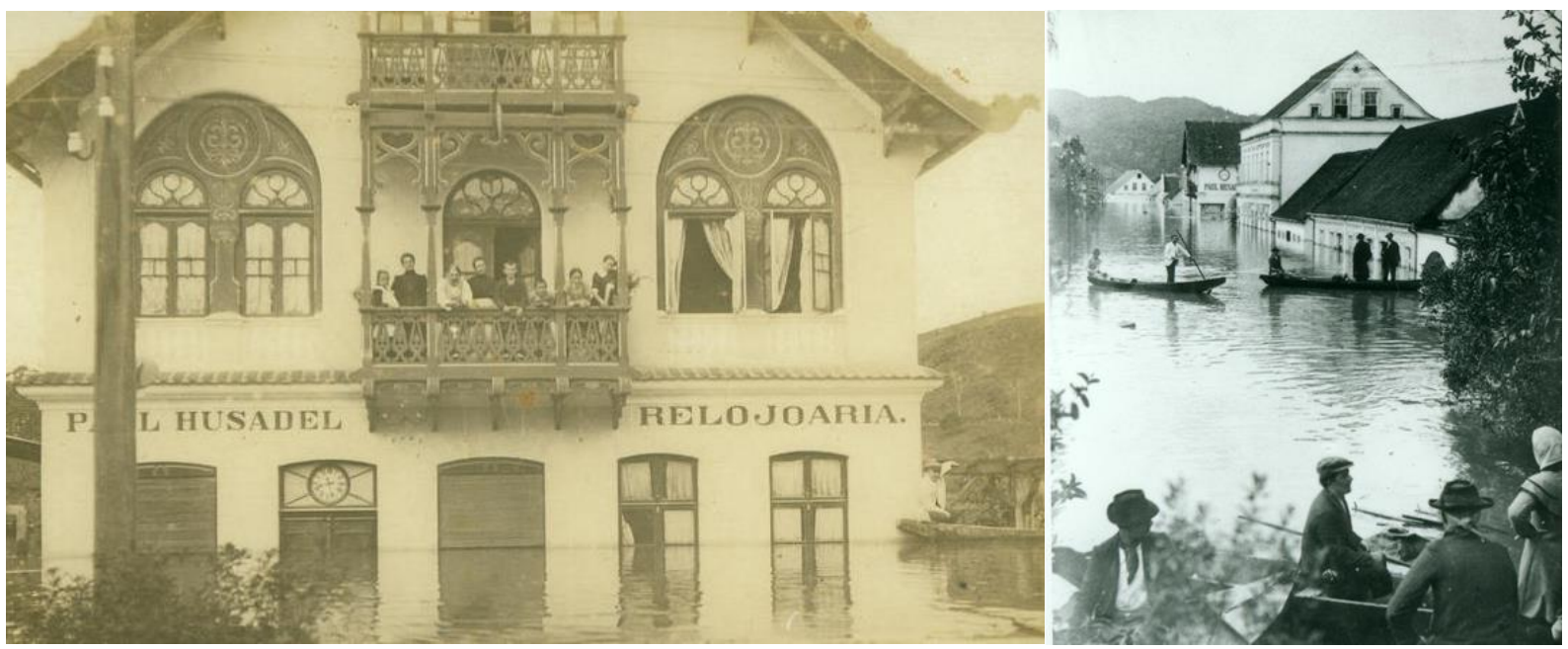

Figura 6 - Inundação de 1911 em Blumenau

(FONTE: Reprodução de DIÁRIO CATARINENSE, arquivo José Ferreira da Silva) 
Dentre os desastres observados na região, destacam-se os movimentos de massa, as inundações bruscas e as inundações graduais. Estes sempre relacionados a causas naturais: chuvas intensas, relevo da região, e as sociais: comunidades habitando áreas de risco.

Como agravante dos desastres, podemos destacar a ação (ou omissão) do homem. Segundo pesquisa da EPAGRI, no morro do Baú, grande parte dos escorregamentos foi intensificada por atividades humanas inadequadas, como cortes de encostas, aterros, desmatamentos (MEDEIROS; BARROS, 2012).

\subsubsection{Descrição da área de estudo e estações pluviométricas utilizadas}

A Região do Vale do Itajaí está localizada na bacia do Rio Itajaí (83), no Estado de Santa Catarina. A bacia se divide em baixo, médio e alto vale Itajaí. É cercada pelas serras de Moema e Jaraguá, ao Norte, a Oeste pelas Serras Geral e do Espigão e, ao Sul, as Serras da Boa Vista, dos Faxinais e Tijucas. Possui relevo, com altitudes que variam de 12 metros até 80 metros nas estações utilizadas no estudo, podendo atingir mais de 1.500 metros no Planalto da Serra Geral. As condições geológicas, geomorfológicas e climatológicas indicam que a região é suscetível à ocorrência de desastres, principalmente os hidrometeorológicos, como as inundações e escorregamentos, associados a eventos extremos de precipitação.

As moradias, quando não estão localizadas em áreas de vale sujeitas a inundações, estão situadas em regiões mais altas, com maior risco de deslizamento. A vulnerabilidade da região é elevada, com alto risco de ocorrência de inundações nas áreas mais planas e várzeas dos rios, e escorregamentos de encostas, nas regiões mais íngremes, em épocas chuvosas.

O clima da região é classificado, segundo Köppen, como Clima Subtropical com verão quente (Cfa) que tem como características chuvas bem distribuídas ao longo do ano e temperaturas acima de $22^{\circ}$ no verão. 


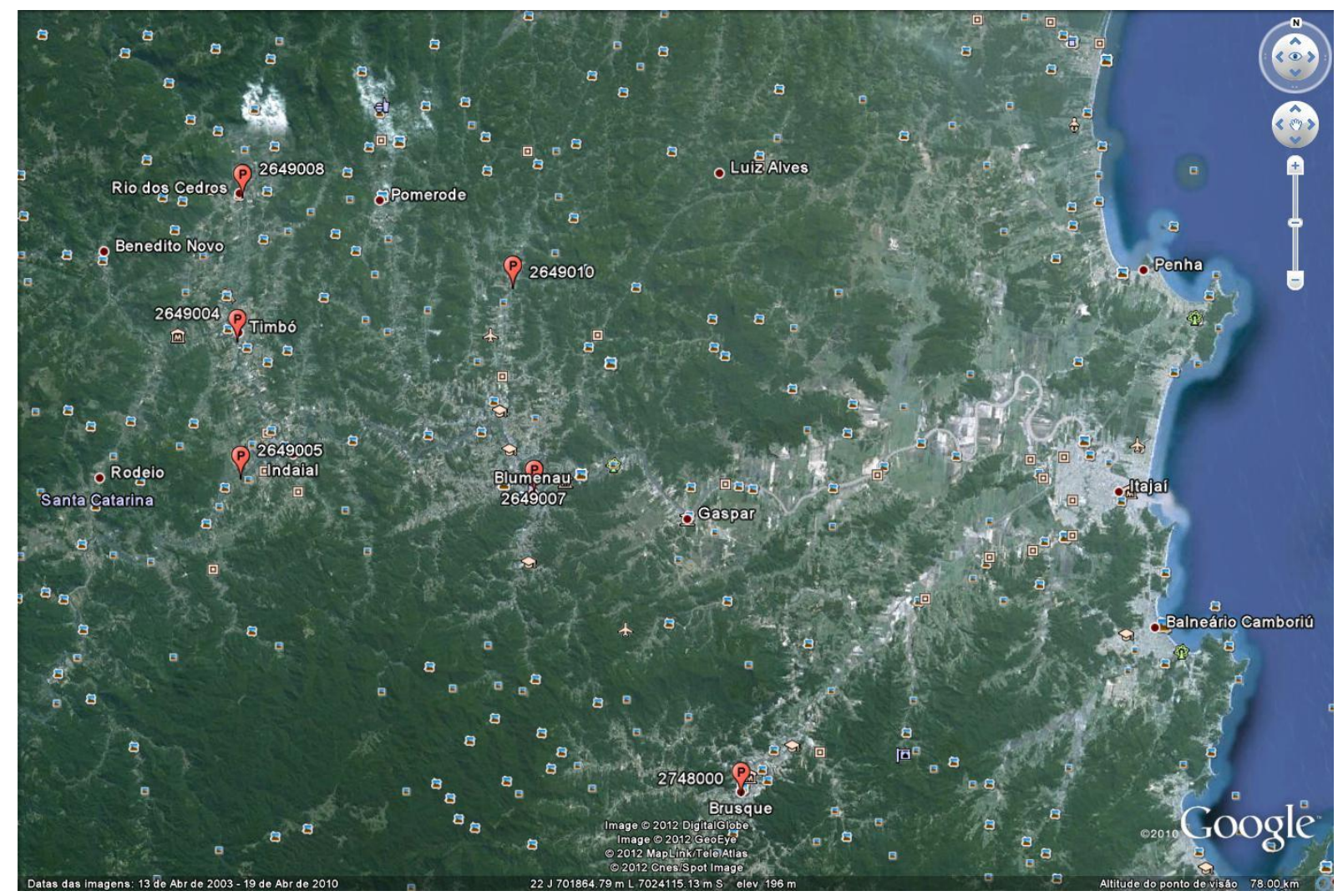

Figura 7 - Localização dos seis postos utilizados na da bacia do rio Itajaí-Açu (Fonte - SNIRH, Google)

As estações do Vale do Itajaí, utilizadas nesse estudo, estão localizadas no médio e baixo Itajaí, região que mais sofreu com as catástrofes de 2008. Suas altitudes variam de 12 a 80 metros. As precipitações médias anuais ficam em torno de $1.625 \mathrm{~mm}$ nos postos utilizados, variando de $1.477 \mathrm{~mm}$ em Indaial e chegando a $1.678 \mathrm{~mm}$ em uma das estações localizadas em Blumenau. O mês mais chuvoso é janeiro, seguido de fevereiro e dezembro. A região não possui sazonalidade bem definida. Não existe um período seco bem caracterizado, como ocorre em algumas bacias da região Sudeste do Brasil. As chuvas podem ocorrer em qualquer época do ano na região Sul.

Foram selecionadas seis estações pluviométricas operadas pela EPAGRI Empresa de Pesquisa Agropecuária e Extensão Rural de Santa Catarina. A seleção e a escolha foi feita de acordo com dados disponíveis, pois em algumas estações os dados de novembro de 2008 eram inexistentes.

$\mathrm{Na}$ Tabela 7 estão relacionadas as seis estações pluviométricas selecionadas na Região do Vale do Itajaí. 
Tabela 7 - Relação das seis estações pluviométricas do Vale do Itajaí em SC

\begin{tabular}{|c|c|c|c|c|c|c|c|}
\hline Código & Estação & Bacia & Latitude & Longitude & $\begin{array}{c}\text { Alt. } \\
(\mathbf{m})\end{array}$ & Estado & Município \\
\hline 2649004 & Timbó Novo & 83 & $-26^{\circ} 49^{\prime} 47^{\prime \prime}$ & $-49^{\circ} 16^{\prime} 19^{\prime \prime}$ & 70 & SC & Timbó \\
\hline 2649005 & Indaial & 83 & $-26^{\circ} 54^{\prime} 49^{\prime \prime}$ & $-49^{\circ} 16^{\prime} 03^{\prime \prime}$ & 60 & SC & Indaial \\
\hline 2649007 & Blumenau & 83 & $-26^{\circ} 55^{\prime} 05^{\prime \prime}$ & $-49^{\circ} 03^{\prime} 55^{\prime \prime}$ & 12 & SC & Blumenau \\
\hline 2649008 & Arrozeira & 83 & $-26^{\circ} 44^{\prime} 27^{\prime \prime}$ & $-49^{\circ} 16^{\prime} 14^{\prime \prime}$ & 80 & SC & $\begin{array}{c}\text { Rio dos } \\
\text { Cedros }\end{array}$ \\
\hline 2649010 & $\begin{array}{c}\text { Itoupava } \\
\text { Central }\end{array}$ & 83 & $-26^{\circ} 47^{\prime} 35^{\prime \prime}$ & $-49^{\circ} 05^{\prime} 00^{\prime \prime}$ & 65 & SC & Blumenau \\
\hline 2748000 & Brusque & 83 & $-27^{\circ} 06^{\prime} 02^{\prime \prime}$ & $-48^{\circ} 55^{\prime} 04^{\prime \prime}$ & 40 & SC & Brusque \\
\hline
\end{tabular}

\subsubsection{Análise estatística dos dados de chuva}

Foi feita a análise dos eventos críticos de precipitação, em particular os que causaram inundações e escorregamentos no Vale do Itajaí nos anos de 2008 e 2011.

\subsubsection{Meses que antecedem os eventos}

Foram analisados os totais mensais dos meses que antecedem os eventos críticos ocorridos em novembro de 2008 e setembro de 2011. As médias mensais das séries históricas de cada uma das estações foram calculadas e plotadas nos gráficos da Figura 8, que contém também os totais mensais nos anos de 2008 e 2011.

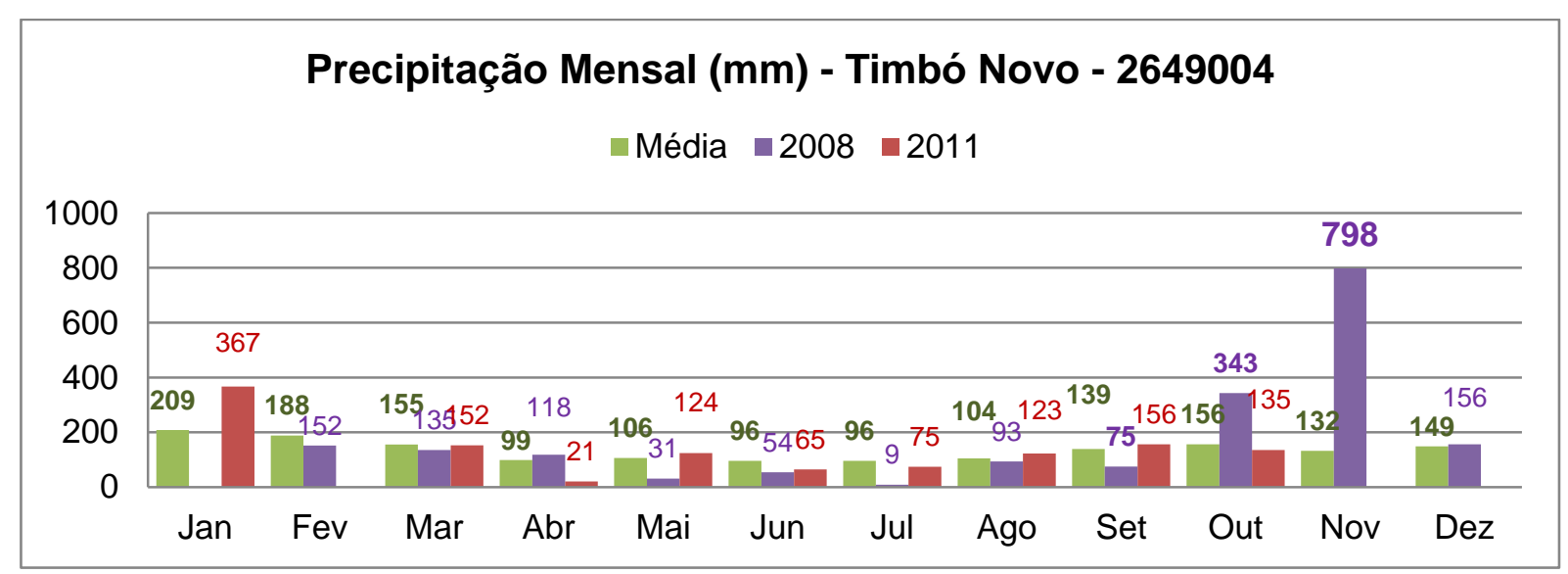

Figura 8 - Totais mensais dos anos 2008 e 2011 e média mensal histórica (continua) 


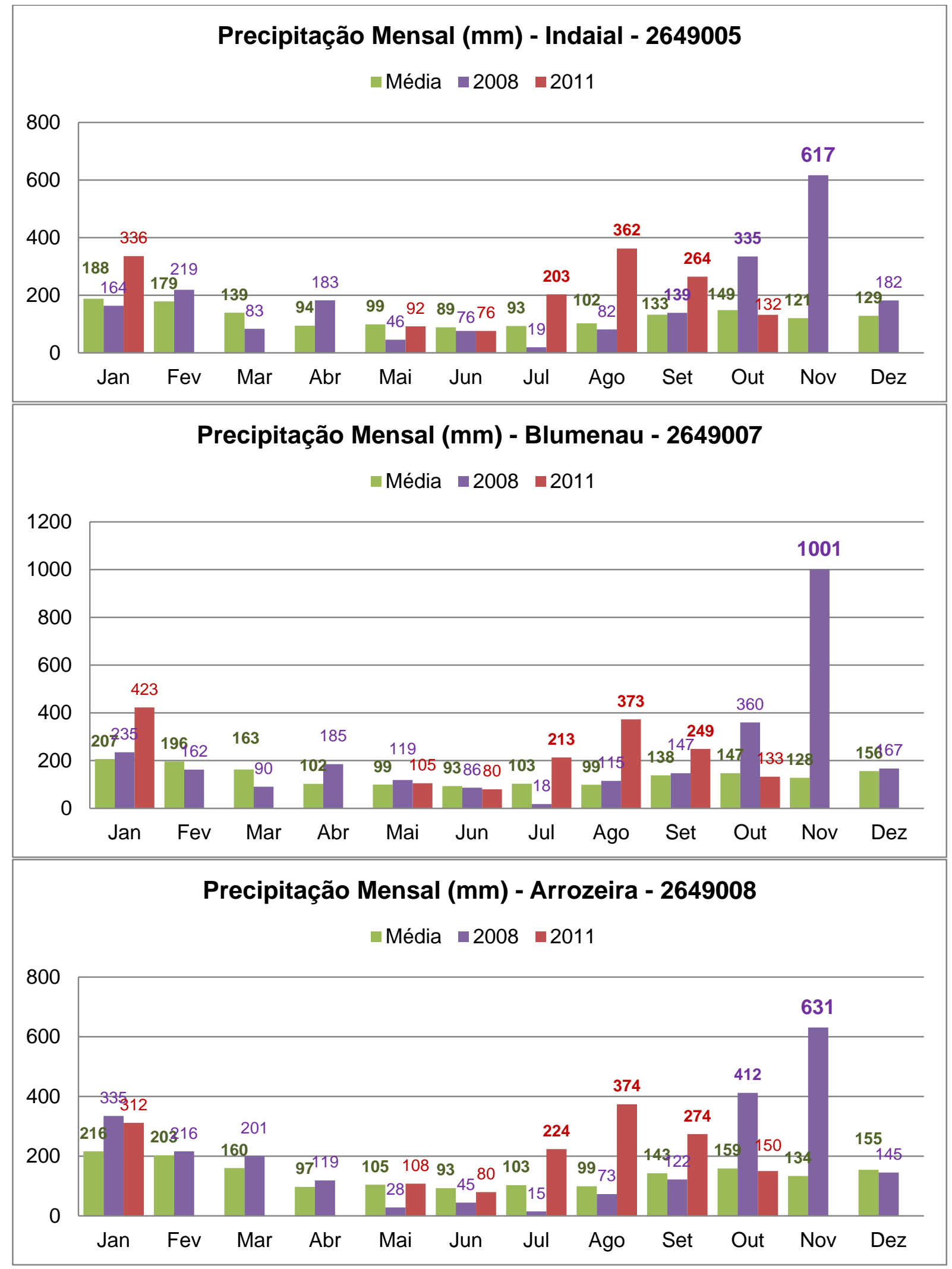

Figura 8 - Totais mensais dos anos 2008 e 2011 e média mensal histórica (continua) 


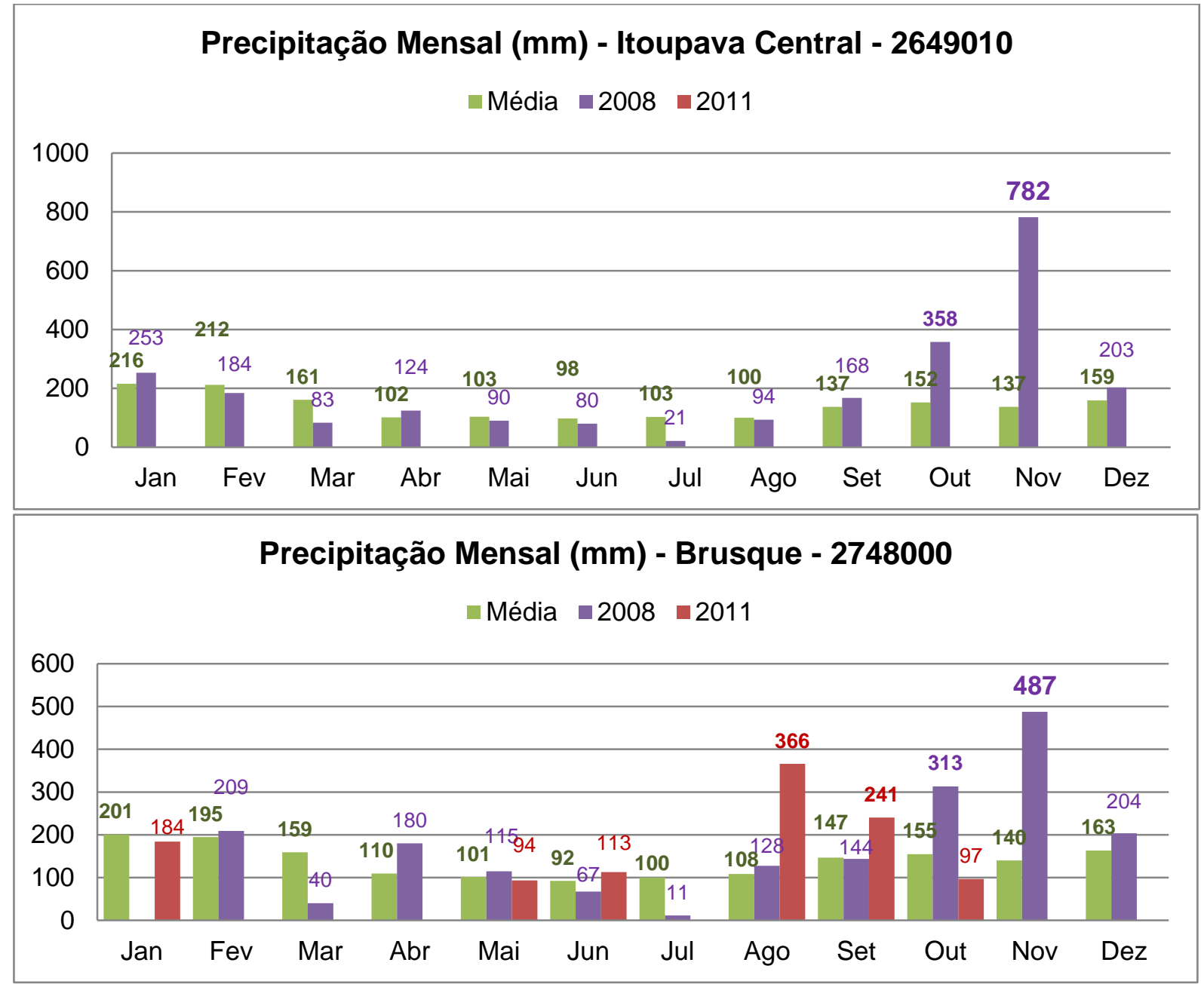

Figura 8 - Totais mensais dos anos 2008 e 2011 e média mensal histórica

Percebe-se que o mês de outubro de 2008, que antecede os eventos extremos de novembro desse ano, foi bastante chuvoso. Choveu mais que o dobro da média mensal em todas as estações analisadas.

Novamente em 2011, os meses de julho e agosto, que antecedem os eventos críticos de setembro, foram extremamente chuvosos, com destaque para os totais precipitados no mês de agosto.

\subsubsection{Estatísticas básicas}

Para entender a magnitude dos eventos, foram calculadas algumas estatísticas básicas, como a precipitação máxima diária no mês em que o evento ocorreu, neste caso o mês de novembro de 2008, ( $P_{\max }$ nov/08) e o dia da máxima, a 
precipitação média das máximas diárias anuais $\left(P_{\text {med }}\right.$ max $)$, o total mensal de novembro de 2008 ( $P_{\text {mensal }}$ nov/08), a precipitação média mensal de novembro $\left(P_{\text {med }}\right.$ mensal) e a precipitação média anual ( $P_{\text {med }}$ anual), que são mostradas na Tabela 8.

Tabela 8 - Chuvas de novembro de 2008, médias das máximas e médias mensais e anuais das estações do Vale do Itajaí

\begin{tabular}{|l|c|c|c|c|c|c|c|c|c|c|c|c|}
\hline Código & Estação & Dados & $\begin{array}{c}P_{\text {max }} \\
\text { nov/08 }\end{array}$ & $\begin{array}{c}\text { Dia } \\
\text { da } \\
\text { max }\end{array}$ & $\begin{array}{c}P \\
\text { mensal } \\
\text { nov/08 }\end{array}$ & $\begin{array}{c}P_{\text {max }} \\
\text { set/11 }\end{array}$ & $\begin{array}{c}\text { Dia } \\
\text { da } \\
\text { max }\end{array}$ & $\begin{array}{c}P \\
\text { mensal } \\
\text { set/11 }\end{array}$ & $\begin{array}{c}P_{\text {me }} \\
\text { d das } \\
\text { max }\end{array}$ & $\begin{array}{c}P_{\text {med }} \\
\text { mensal } \\
\text { nov }\end{array}$ & $\begin{array}{c}P_{\text {med }} \\
\text { mensal } \\
\text { set }\end{array}$ & $\begin{array}{c}P_{\text {med }} \\
\text { anual }\end{array}$ \\
\hline $\mathbf{2 6 4 9 0 0 4}$ & $\begin{array}{c}\text { Timbó } \\
\text { Novo }\end{array}$ & $\begin{array}{c}\text { jan/29 a } \\
\text { out/11 }\end{array}$ & $\mathbf{1 8 4 , 9}$ & 23 & 789 & 37,9 & 10 & 156 & 85,1 & 132 & 139 & 1.625 \\
\hline $\mathbf{2 6 4 9 0 0 5}$ & Indaial & $\begin{array}{c}\text { jan/41 a } \\
\text { out/11 }\end{array}$ & 110,3 & 23 & 617 & 93,1 & 9 & 264 & 78,2 & 121 & 133 & 1.477 \\
\hline $\mathbf{2 6 4 9 0 0 7}$ & Blumenau & $\begin{array}{c}\text { mar/44 } \\
\text { a out/11 }\end{array}$ & $\mathbf{2 5 0 , 9}$ & $\mathbf{2 4}$ & $\mathbf{1 0 0 1}$ & 101,4 & 9 & 249 & 89,3 & 128 & 138 & 1.622 \\
\hline $\mathbf{2 6 4 9 0 0 8}$ & Arrozeira & $\begin{array}{c}\text { jan/41 a } \\
\text { out/11 }\end{array}$ & 125,2 & 23 & 631 & $\mathbf{1 3 2 , 3}$ & $\mathbf{8}$ & 274 & 89,2 & 134 & 143 & 1676 \\
\hline $\mathbf{2 6 4 9 0 1 0}$ & $\begin{array}{c}\text { Itoupava } \\
\text { Central }\end{array}$ & $\begin{array}{c}\text { jan/41 a } \\
\text { set/09 }\end{array}$ & $\mathbf{1 9 3 , 6}$ & $\mathbf{2 4}$ & 782 & - & - & - & 89,9 & 137 & 137 & 1678 \\
\hline $\mathbf{2 7 4 8 0 0 0}$ & Brusque & $\begin{array}{c}\text { jan/41 a } \\
\text { out/11 }\end{array}$ & 109,5 & $\mathbf{2 4}$ & 487 & $\mathbf{8 6 , 2}$ & 9 & 241 & 80,4 & 140 & 147 & 1.674 \\
\hline
\end{tabular}

As chuvas máximas diárias de novembro de 2008 foram maiores que média das máximas em todas as estações e, em três delas, choveu mais em um dia do que em média chove no mês de novembro.

\subsubsection{Análise do mês em que ocorre a chuva catastrófica}

Em seguida foram analisados os eventos críticos de novembro de 2008 e de setembro de 2011. As chuvas diárias de todas as estações foram plotadas no gráfico das Figuras 9 e 10.

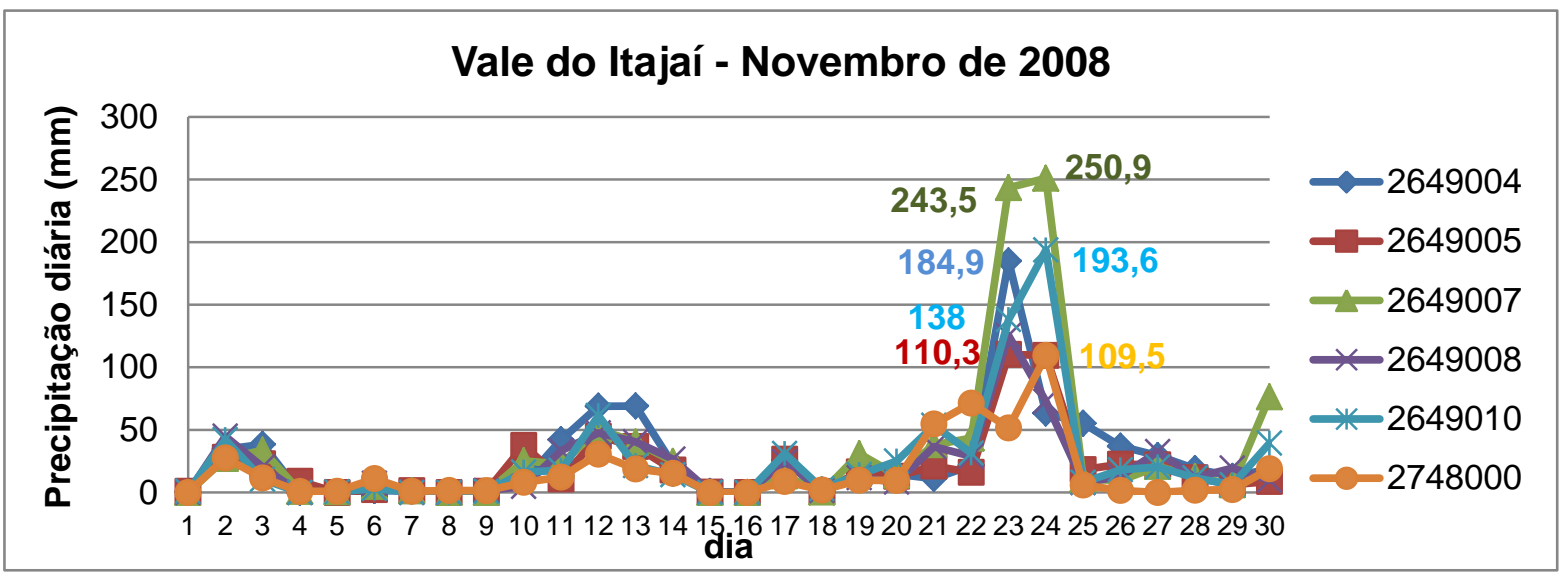

Figura 9 - Precipitação diária de novembro de 2008 


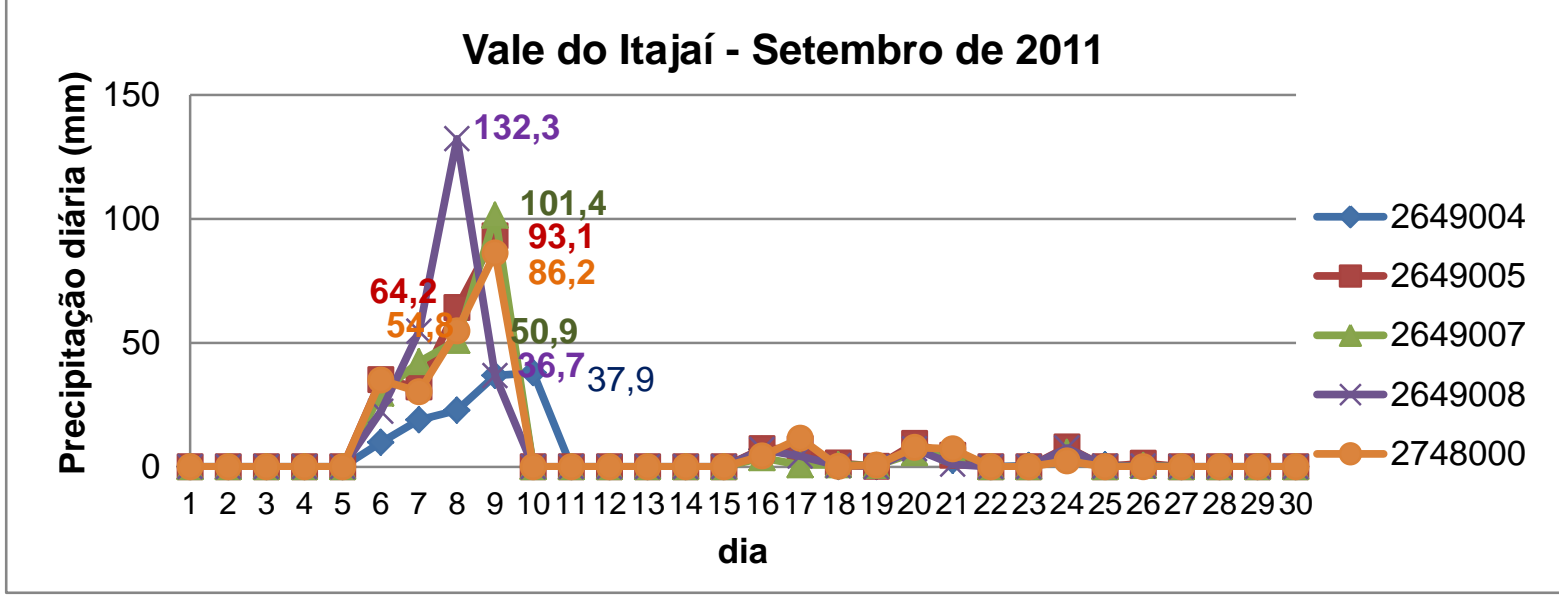

Figura 10 - Precipitação diária de novembro de 2008

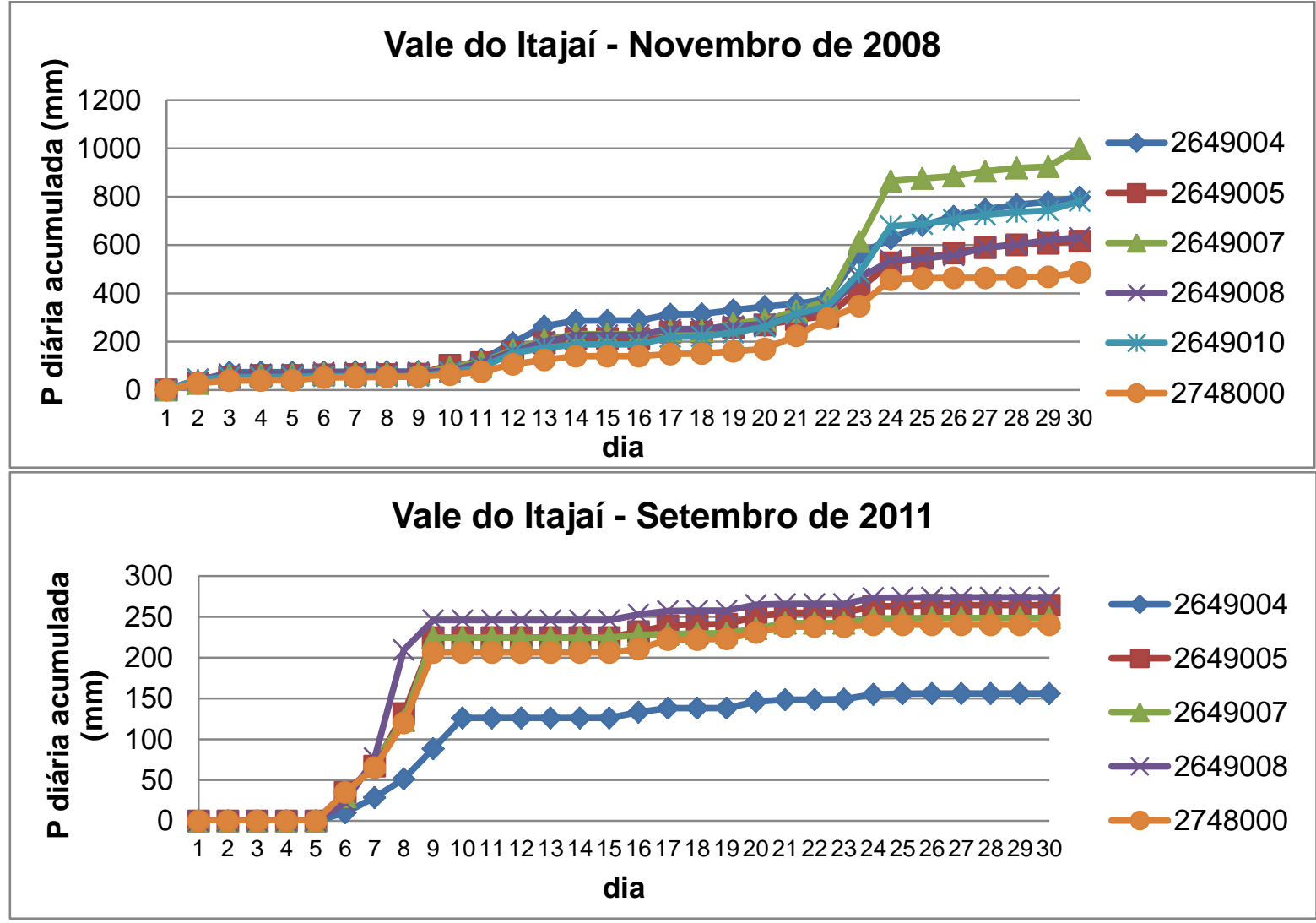

Figura 11 - Precipitação acumulada diária de novembro de 2008 e setembro de 2011

Destaca-se o volume precipitado nos dias 23 e 24 nas estações Blumenau, onde choveu 243,5 mm e 250,9 mm, e Itoupava Central, com 138 mm e 193,6 mm, ambas localizadas no município de Blumenau. Os volumes acumulados nessas estações em apenas dois dias foram elevadíssimos, de 494,4 mm e 331,6 mm.

As chuvas foram mais intensas no dia 23 nas estações Timbó Novo, onde choveu 184,9 mm, Arrozeira, localizada no município de Rio dos Cedros, com 125,2 
mm e Indaial, 110,3 mm. Em Brusque a chuva mais elevada ocorreu no dia 24, $109,5 \mathrm{~mm}$.

Em setembro de 2011 as chuvas mais elevadas ocorreram nos dias 8 e 9, com destaque para a estação Arrozeira, onde foi observado $132,3 \mathrm{~mm}$ no dia 8 . No dia 9 choveu 101,4 mm, 93,1 mm e 86,2 mm nas estações Blumenau, Indaial e Brusque. Nas demais estações as chuvas não foram elevadas.

\subsubsection{Distribuições adotadas e períodos de retorno (Tr)}

Foram calculadas as posições de plotagem das séries de chuvas máximas diárias, através da fórmula de Cunnane, os períodos de retorno e então foram ajustadas as distribuições Log-Normal e Gumbel para todas as estações. O resumo dos parâmetros estimados de cada distribuição encontra-se na Tabela 9.

Tabela 9 - Resumo dos parâmetros estimados de cada distribuição

\begin{tabular}{|c|c|c|c|c|}
\hline \multirow{2}{*}{ Estação } & \multirow{2}{*}{$\begin{array}{l}\text { Parâmetros } \\
\text { Estimados }\end{array}$} & \multicolumn{3}{|c|}{ Distribuição } \\
\hline & & Empírica & Log-Normal & Gumbel \\
\hline \multirow{3}{*}{2649004} & Média $\mu$ & 85,2 & 85,0 & 85,0 \\
\hline & Desvio-padrão $\sigma$ & 25,2 & 23,7 & 24,6 \\
\hline & Assimetria Y & 1,3 & 0,7 & 1,0 \\
\hline \multirow{3}{*}{2649005} & $\mu$ & 75,7 & 75,6 & 75,5 \\
\hline & $\sigma$ & 20,9 & 20,5 & 20,4 \\
\hline & Y & 0,7 & 0,7 & 0,9 \\
\hline \multirow{3}{*}{2649007} & $\mu$ & 88,5 & 88,1 & 88,3 \\
\hline & $\sigma$ & 31,9 & 31,5 & 31,1 \\
\hline & $\mathrm{Y}$ & 2,3 & 0,8 & 0,9 \\
\hline \multirow{3}{*}{2649008} & $\mu$ & 89,2 & 89,2 & 89,0 \\
\hline & $\sigma$ & 23,1 & 24,4 & 22,5 \\
\hline & Y & 0,1 & 0,7 & 0,9 \\
\hline \multirow{3}{*}{2649010} & $\mu$ & 89,9 & 89,7 & 89,7 \\
\hline & $\sigma$ & 29,3 & 27,7 & 28,5 \\
\hline & $\mathrm{Y}$ & 1,2 & 0,8 & 0,9 \\
\hline \multirow{3}{*}{2748000} & $\mu$ & 80,4 & 80,2 & 80,2 \\
\hline & $\sigma$ & 27,3 & 25,9 & 26,6 \\
\hline & y & 1,4 & 0,8 & 0,9 \\
\hline
\end{tabular}

Os gráficos contendo as distribuições empíricas e as ajustadas para cada estação podem ser visualizados na Figura 12. 


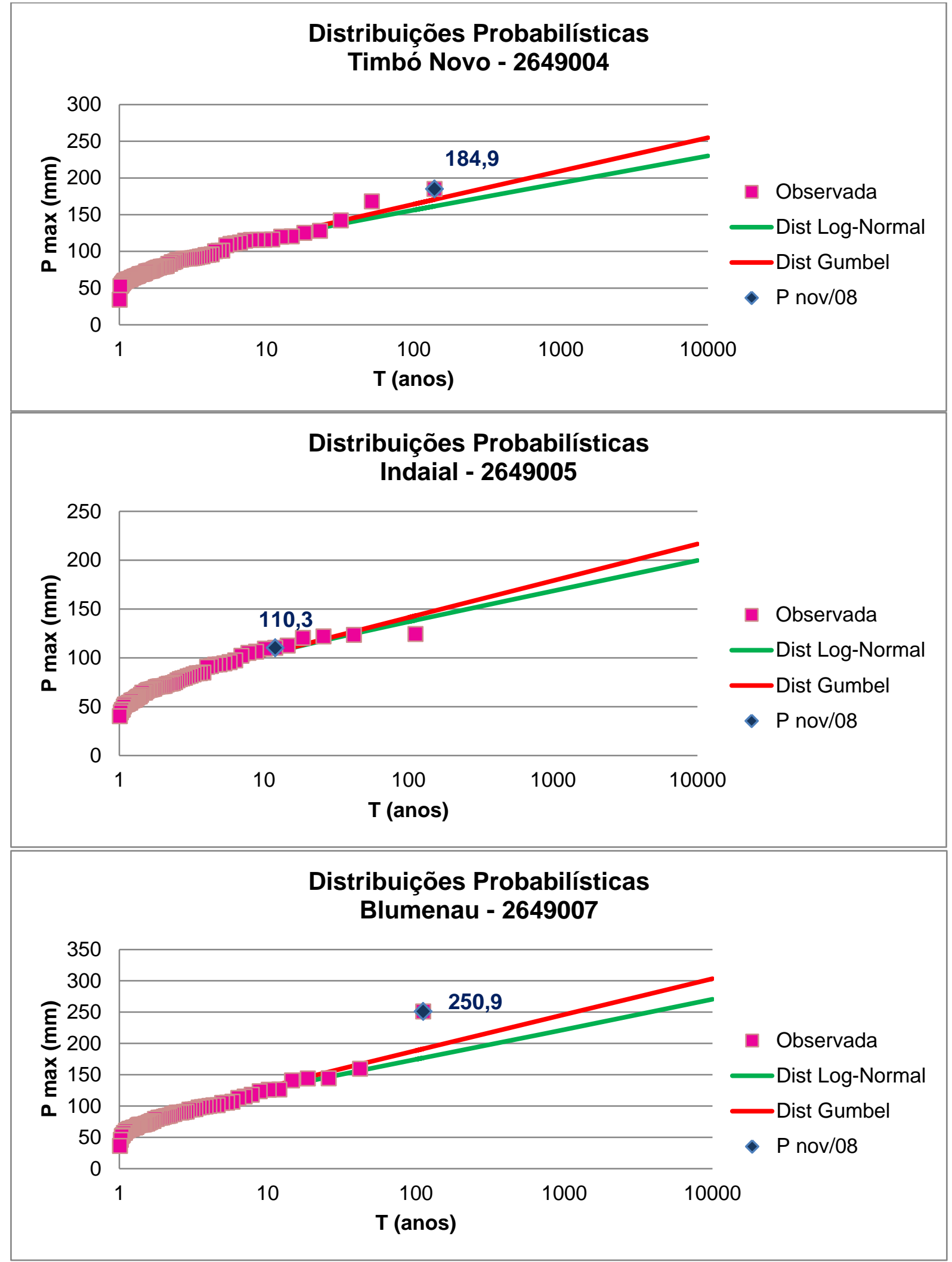

Figura 12 - Relação entre Tr e precipitações máximas para 1 dia de duração (continua) 


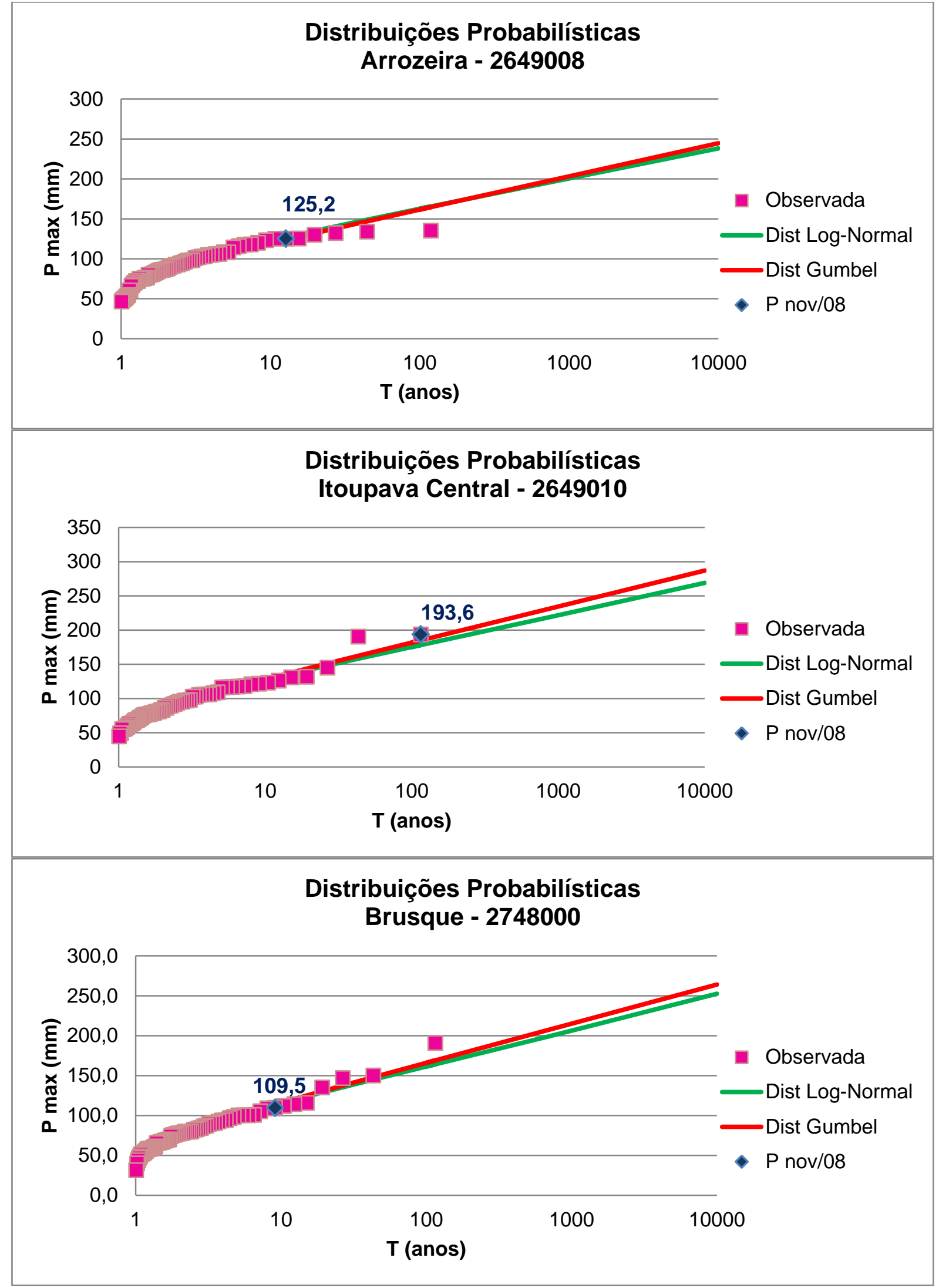

Figura 12 - Relação entre Tr e precipitações máximas para 1 dia de duração 
Através dos gráficos das distribuições, nota-se que a precipitação de novembro de 2008 foi a máxima já registrada em três das seis estações, duas delas localizadas em Blumenau e uma no município de Timbó.

Foram estimados os períodos de retorno das chuvas ocorridas em novembro de 2008 para as distribuições de probabilidade Log-Normal e Gumbel. Os resultados se encontram na Tabela 10.

Tabela 10 - Períodos de retorno estimados para as máximas chuvas diárias

\begin{tabular}{|c|c|c|c|c|}
\hline Estação & $\begin{array}{c}\mathbf{P} \text { max } \\
\text { novembro de } \\
\mathbf{2 0 0 8}(\mathbf{m m})\end{array}$ & $\begin{array}{c}\text { Tr } \\
\text { Empírica } \\
\text { (anos) } \\
\text { Cunnane }\end{array}$ & $\begin{array}{c}\text { Tr } \\
\text { Log-Normal } \\
\text { (anos) }\end{array}$ & $\begin{array}{c}\mathbf{T r} \\
\text { Gumbel } \\
\text { (anos) }\end{array}$ \\
\hline 2649004 & $\mathbf{1 8 4 , 9}$ & $\mathbf{1 3 9}$ & 595 & 285 \\
\hline 2649005 & 110,3 & 12 & 16 & 15 \\
\hline 2649007 & $\mathbf{2 5 0 , 9}$ & $\mathbf{1 1 2}$ & 3900 & 1200 \\
\hline 2649008 & 125,2 & 13 & 12 & 14 \\
\hline 2649010 & $\mathbf{1 9 3 , 6}$ & $\mathbf{1 1 5}$ & 247 & 167 \\
\hline 2748000 & 109,5 & 9 & 8 & 8 \\
\hline
\end{tabular}

Na estação Timbó Novo a chuva de 2008 está acima da curva das distribuições adotadas. O $\operatorname{Tr}$ do evento de novembro, calculado através da distribuição de Gumbel, fica em torno de duas vezes o da distribuição empírica e 0 Tr da LogNormal é ainda maior, mais de quatro vezes.

$\mathrm{Na}$ estação Blumenau, nota-se que o Tr calculado através da fórmula de Cunanne é de 112 anos e o Tr estimado através distribuições de Gumbel é de 1.200 anos e da Distribuição Log-Normal é de mais de 3.900 anos. A chuva de 2008 pode ser considerada um outlier, que faz com que as estimativas do $\mathrm{Tr}$ através das distribuições ajustadas sejam mais elevadas. Analisando graficamente, a LogNormal nesta estação está acima da curva da Gumbel para valores elevados de Tr. Nestes casos, deve-se tomar cuidado ao estimar períodos de retorno através das distribuições, pois eles podem resultar em valores superestimados.

Na estação Itoupava Central, os Trs estimados não foram tão discrepantes entre si. 
Nas demais estações, onde as chuvas foram menos elevadas, os períodos de retorno estimados variaram entre 8 e 16 anos. Nesses casos, os Trs estimados através da distribuição empírica foram bem próximos aos estimados através das distribuições Log-Normal e Gumbel.

\subsubsection{Teste de aderência de Kolmogorov-Smirnov (KS)}

Os resultados do teste de KS, adotado para o nível de significância de $\alpha=$ $10 \%$, que são apresentados na Tabela 11, indicam que as duas distribuições foram aderentes em todas as estações.

Tabela 11 - Resultados do Teste de KS para N > 40 e $\alpha=10 \%$

\begin{tabular}{|c|c|c|c|}
\hline \multicolumn{2}{|l|}{ Distribuição } & Log-Normal & Gumbel \\
\hline \multicolumn{4}{|c|}{2649004} \\
\hline \multicolumn{2}{|c|}{ Estatística do teste D max } & 0,0599 & 0,0486 \\
\hline $\mathrm{N}$ & 83 & \multicolumn{2}{|c|}{ Decisão } \\
\hline \begin{tabular}{|l|l|} 
Região Crítica para $\alpha$ & $10 \%$ \\
\end{tabular} & 0,1339 & Aceito $\mathrm{HO}$ & Aceito $\mathrm{HO}$ \\
\hline \multicolumn{4}{|c|}{2649005} \\
\hline \multicolumn{2}{|c|}{ Estatística do teste D max } & 0,0577 & 0,0523 \\
\hline $\mathrm{N}$ & 67 & \multicolumn{2}{|c|}{ Decisão } \\
\hline \begin{tabular}{l|l|} 
Região Crítica para $\alpha$ & $10 \%$ \\
\end{tabular} & 0,1490 & Aceito $\mathrm{HO}$ & Aceito $\mathrm{HO}$ \\
\hline \multicolumn{4}{|c|}{2649007} \\
\hline \multicolumn{2}{|c|}{ Estatística do teste D max } & 0,0659 & 0,0751 \\
\hline $\mathrm{N}$ & 67 & \multicolumn{2}{|c|}{ Decisão } \\
\hline \begin{tabular}{l|l|} 
Região Crítica para $\alpha$ & $10 \%$ \\
\end{tabular} & 0,1490 & Aceito $\mathrm{HO}$ & Aceito $\mathrm{HO}$ \\
\hline \multicolumn{4}{|c|}{2649008} \\
\hline \multicolumn{2}{|c|}{ Estatística do teste D max } & 0,0645 & 0,0908 \\
\hline $\mathrm{N}$ & 71 & \multicolumn{2}{|c|}{ Decisão } \\
\hline \begin{tabular}{l|l|} 
Região Crítica para a & $10 \%$ \\
\end{tabular} & 0,1448 & Aceito $\mathrm{HO}$ & Aceito $\mathrm{HO}$ \\
\hline \multicolumn{4}{|c|}{2649010} \\
\hline \multicolumn{2}{|c|}{ Estatística do teste D max } & 0,0484 & 0,0424 \\
\hline $\mathrm{N}$ & 69 & \multicolumn{2}{|c|}{ Decisão } \\
\hline \begin{tabular}{l|l|} 
Região Crítica para a & $10 \%$ \\
\end{tabular} & 0,1469 & Aceito $\mathrm{HO}$ & Aceito $\mathrm{HO}$ \\
\hline \multicolumn{4}{|c|}{2748000} \\
\hline \multicolumn{2}{|c|}{ Estatística do teste D max } & 0,0498 & 0,0495 \\
\hline $\mathrm{N}$ & 69 & \multicolumn{2}{|c|}{ Decisão } \\
\hline \begin{tabular}{|l|l|} 
Região Crítica para a & $10 \%$ \\
\end{tabular} & 0,1469 & Aceito $\mathrm{HO}$ & Aceito $\mathrm{HO}$ \\
\hline
\end{tabular}




\subsubsection{Chuvas máximas históricas da região}

Os dados de chuva máximas diárias de todas as estações foram plotados em conjunto para verificar a magnitude das máximas na região do Itajaí, como pode ser visto na Figura 13

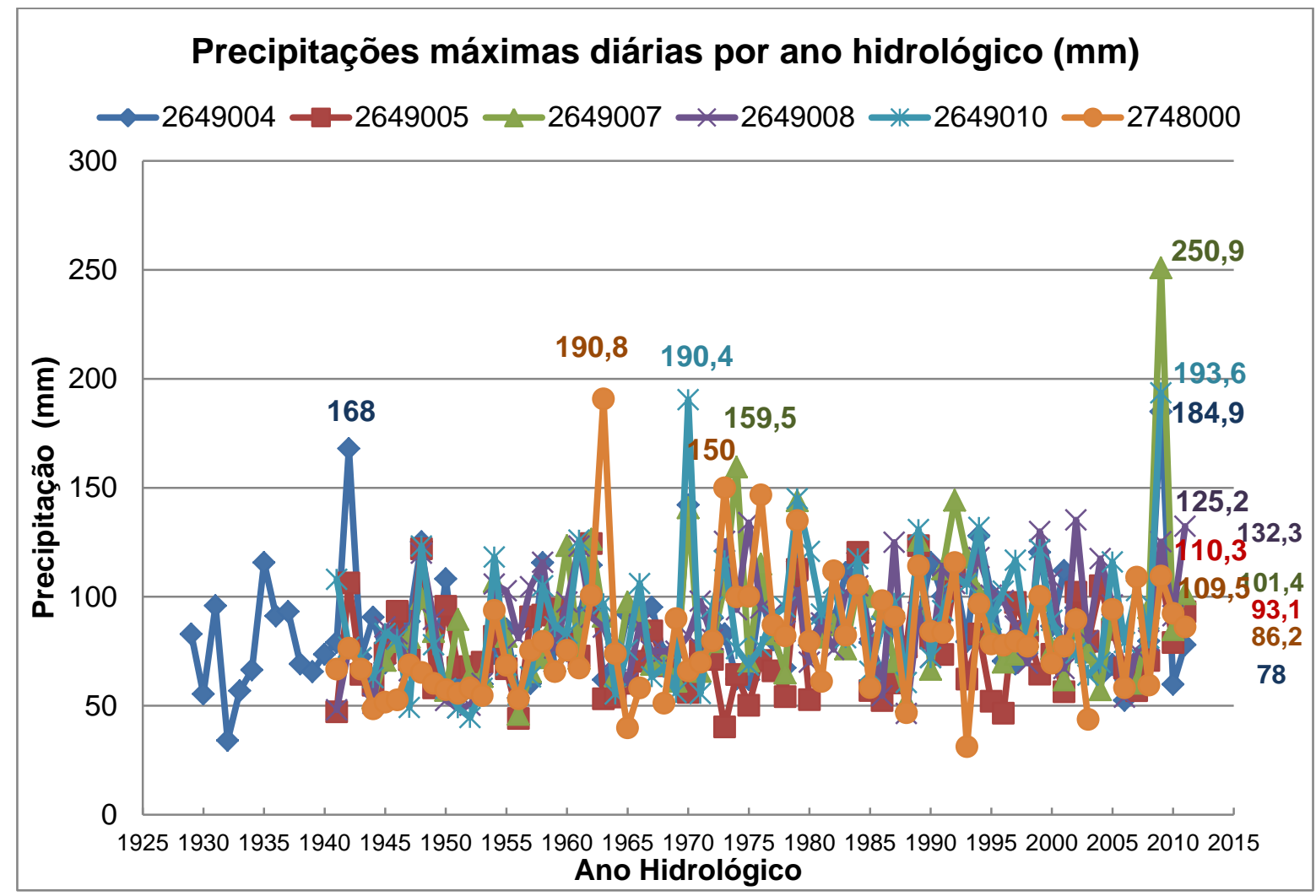

Figura 13 - Precipitações máximas diárias do Vale do Itajaí

A chuva coletada na estação Blumenau, de $250,9 \mathrm{~mm}$, no ano hidrológico de 2008/2009 foi o máximo valor observado na região desde que se iniciaram as leituras nas estações analisadas.

As chuvas diárias observadas nas estações Timbó Novo, 184,9mm, e Itoupava Central, 193,6 mm, são as máximas históricas dessas estações. Valores maiores não haviam sido observados anteriormente nesses postos.

Nas demais estações as chuvas de 2008 não correspondem às máximas históricas. Outros eventos mais elevados foram registrados anteriormente.

No ano de 2011 as chuvas máximas diárias variaram de 78 mm em Timbó Novo a 132,3 mm em Itoupava Central. 
Apesar do volume precipitado em novembro de 2008 ser elevado, nota-se na Figura 13 que esses eventos são característicos da região. Muitos valores elevados já foram registrados nos postos utilizados. Entre eles os registrados nos anos de 1963 em Brusque e em 1970 em Itoupava Central, localizada em Blumenau.

Foi feito um resumo dos cinco maiores eventos de chuvas diárias observados em cada posto e o ano hidrológico em que ocorreram. Os resultados estão na Tabela 12.

Tabela 12 - Os cinco maiores eventos diários de precipitação $(\mathrm{em} \mathrm{mm})$ registrados em cada estação do Vale do Itajaí

\begin{tabular}{|c|c|c|c|c|c|}
\hline Ano & P max diária & Ano & P max diária & Ano & P max diária \\
\hline \multicolumn{2}{|c|}{$\mathbf{2 6 4 9 0 0 4}$} & \multicolumn{2}{|c|}{$\mathbf{2 6 4 9 0 0 5}$} & \multicolumn{2}{|c|}{$\mathbf{2 6 4 9 0 0 7}$} \\
\hline 2009 & 184,9 & 1962 & 124,4 & 2009 & 250,9 \\
\hline 1942 & 168 & 1989 & 123,5 & 1974 & 159,5 \\
\hline 1970 & 142,2 & 1948 & 122 & 1992 & 144,3 \\
\hline 1994 & 128 & 1984 & 120,4 & 1979 & 144 \\
\hline 1948 & 125,2 & 1979 & 112,6 & 1970 & 140,8 \\
\hline \multicolumn{7}{|c|}{$\mathbf{2 6 4 9 0 0 8}$} & $\mathbf{2 6 4 9 0 1 0}$ & & $\mathbf{2 7 4 8 0 0 0}$ \\
\hline 2002 & 135,2 & 2009 & 193,6 & 1963 & 190,8 \\
\hline 1975 & 134 & 1970 & 190,4 & 1973 & 150 \\
\hline 2011 & 132,3 & 1979 & 145 & 1976 & 146,8 \\
\hline 1999 & 129,9 & 1994 & 131,8 & 1979 & 135 \\
\hline 1973 & 125,4 & 1989 & 130,8 & 1992 & 115,7 \\
\hline
\end{tabular}

Verifica-se que a chuva máxima diária do ano hidrológico de 2008/2009 foi o máxima observada em três das seis estações. Nos anos de 1961/1962, 1962/1963 e 2001/2002 foram registradas as máximas nas demais estações. A chuva máxima diária do ano de 2010/2011 foi o terceiro valor observado na estação Arrozeira.

\subsubsection{Precipitações Máximas Acumuladas para diferentes durações}

Foram acumuladas as máximas chuvas para as durações de 1 a 10 dias, 15, 20, 30 e 45 dias. O cálculo foi feito como a acumulada móvel e o intervalo considerado foi o ano hidrológico. Em seguida, as séries das máximas para as diferentes durações foram plotadas nos gráficos da Figura 14. 


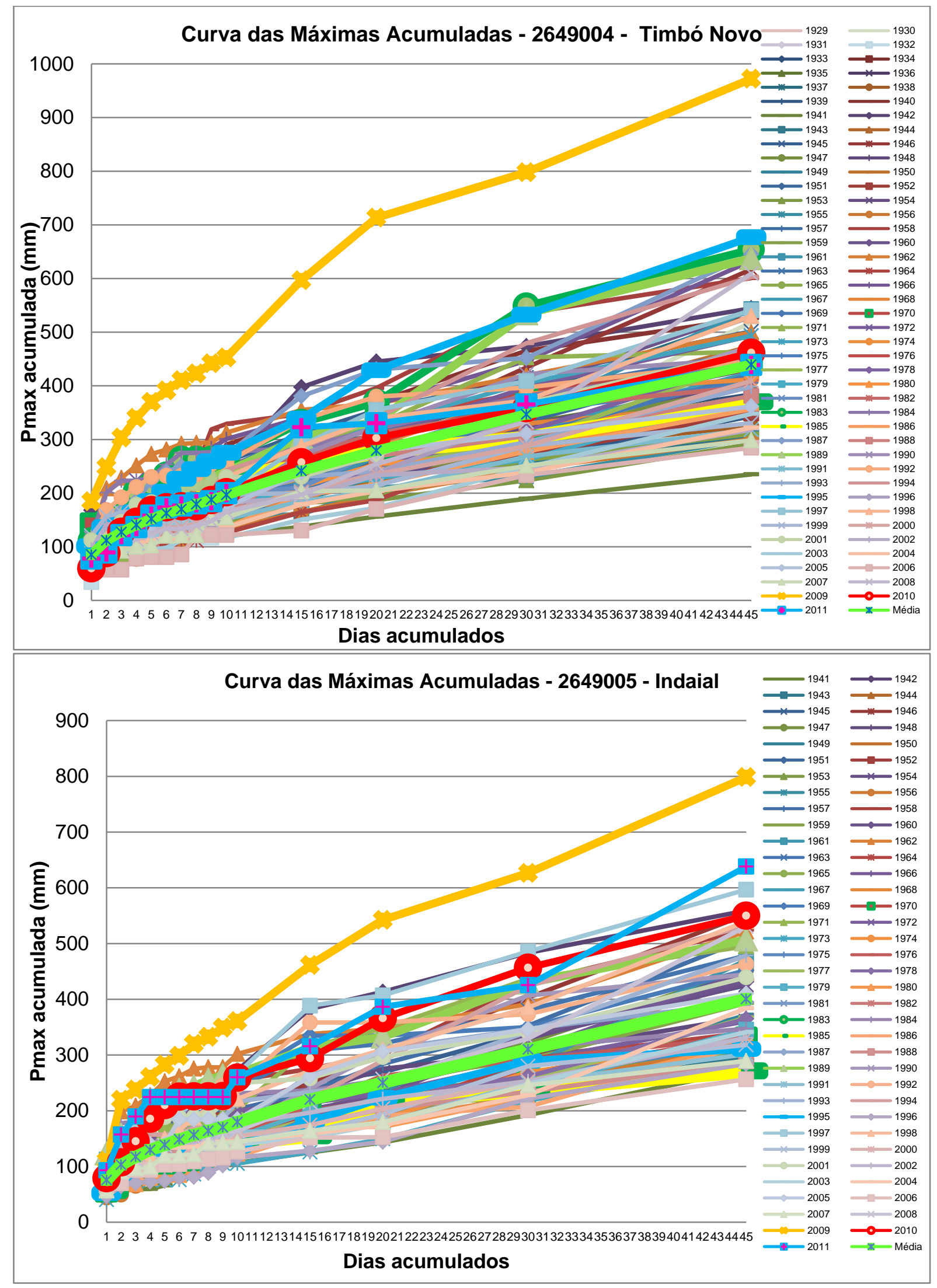

Figura 14 - Curvas das máximas acumuladas para as durações de 1 a 10 dias, 15, 20, 30 e 45 dias (continua) 


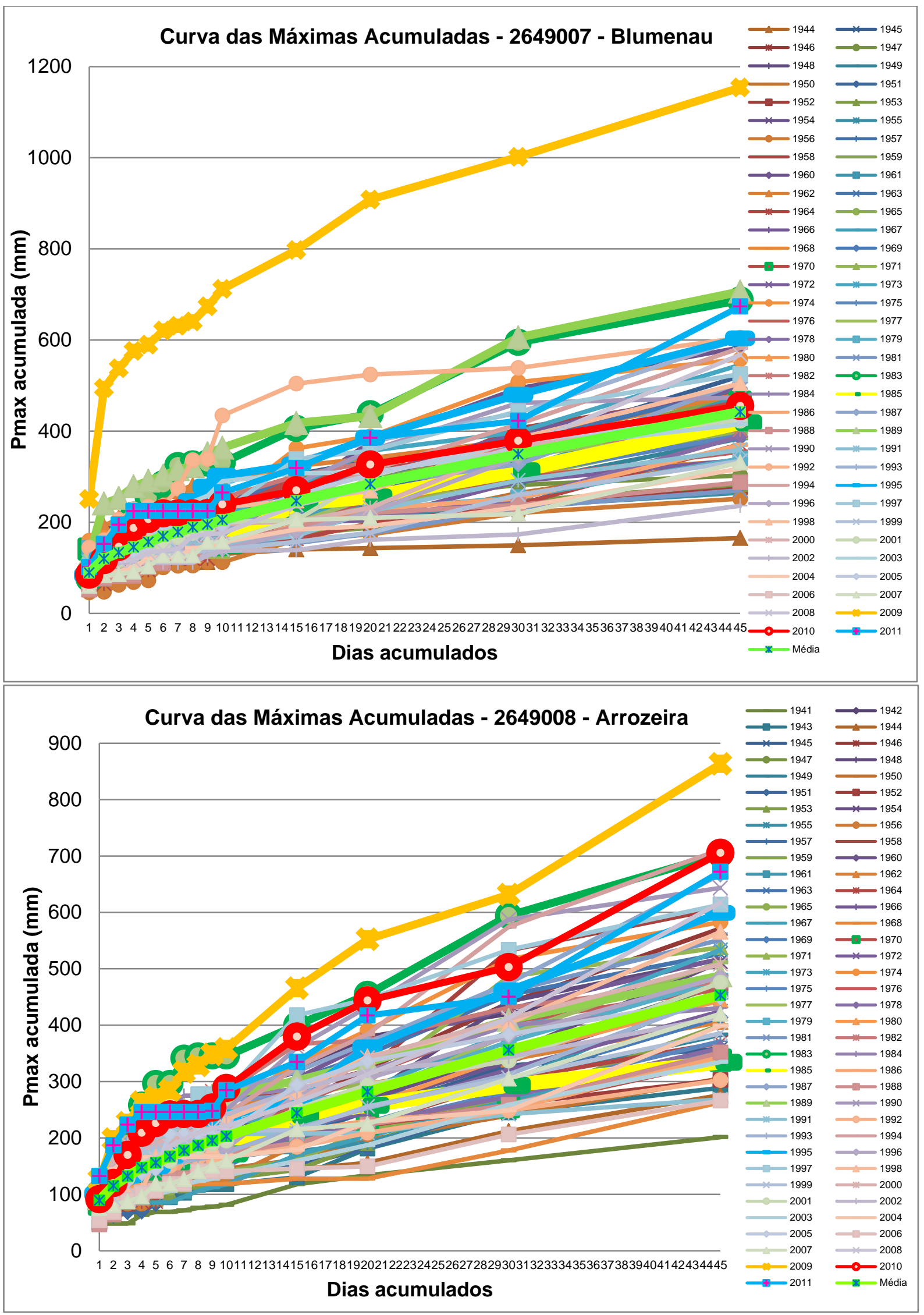

Figura 14 - Curvas das máximas acumuladas para as durações de 1 a 10 dias, 15, 20, 30 e 45 dias (continua) 


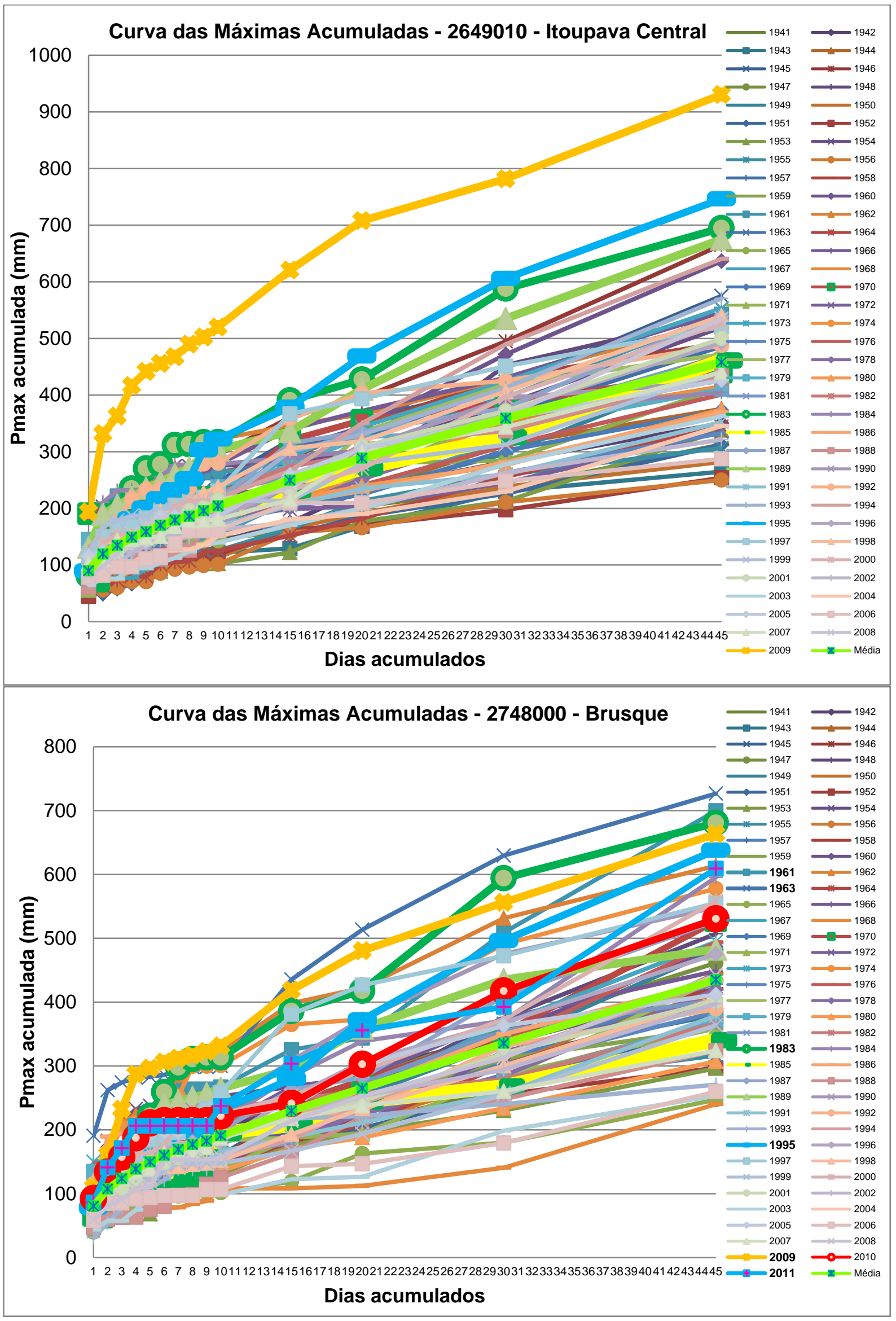

Figura 14 - Curvas das máximas acumuladas para as durações de 1 a 10 dias, 15, 20, 30 e 45 dias 
Através dos gráficos das curvas acumuladas, nota-se que o ano hidrológico de 2008/2009 foi de chuvas elevadas em todas as estações, com volumes acumulados bastante expressivos, os maiores já registrados em cinco dos seis postos pluviométricos utilizados desde que se iniciaram as leituras.

Destaca-se o volume acumulado no município de Blumenau, nas estações Itoupava Central e Blumenau. Nessa última, as chuvas acumuladas em 45 dias ultrapassaram $1.150 \mathrm{~mm}$, valor muito elevado, visto que em média a chuva anual desse posto é de $1.622 \mathrm{~mm}$. Em Itoupava Central o volume acumulado atingiu 930,6 $\mathrm{mm}$.

Em Timbó Novo choveu 972,2 mm no intervalo de 45 dias. Em Arrozeira, Indaial e Brusque os valores registrados no mesmo intervalo foram 863,2 mm, 789,7 $\mathrm{mm}$ e $663,4 \mathrm{~mm}$.

Somente na estação de Brusque os volumes de 1961 e 1963 foram mais elevados que o de 2008.

As chuvas acumuladas nos anos de 1983, 1989 e 1995 também podem ser destacadas. Os volumes acumulados foram bastante elevados na maioria das estações.

No ano de 2011, os valores acumulados em 45 dias atingiram 673,5 mm em Blumenau, 672,1 mm em Arrozeira, 638,1 mm em Indaial, 609,1 mm em Brusque e 438,8 mm em Timbó Novo. Em Itoupava Central os dados de 2011 não estavam disponíveis.

\subsubsection{Classificação das chuvas utilizando o SPI}

As chuvas registradas no Vale do Itajaí foram classificadas através do Standardized Precipitation Index (SPI), ou Índice de Precipitação Padronizada, desenvolvido por McKee em 1993.

Cinco classes de chuva foram adotadas: chuva fraca (CF); chuva leve (CL); chuva moderada (CM); chuva severa (CS); chuva extrema (CE), como descrito na metodologia. 
O cálculo dos limiares de precipitação foi feito individualmente, para cada uma das estações pluviométricas selecionadas, adotando-se o ajuste da distribuição de probabilidades de Gumbel.

Adotou-se os intervalos de duração de 1 dia, 2, 3, 4 e 5 dias.

Abaixo estão ilustrados, através de Tabelas e Figuras, os limiares para a duração de 1 dia. As chuvas diárias ocorridas em 2008 estão destacadas com rótulos de fundo azul.

Os limiares definidos para as demais durações estão no Anexo II.

Tabela 13 - SPI - 2649004 - Timbó Novo - Chuvas máximas anuais com duração de 1 dia

\begin{tabular}{|c|c|c|c|c|c|c|}
\hline Classe de PMDA & \multicolumn{2}{|c|}{ SPI } & p (inf.) & p (sup.) & T (anos) & P 1 dia (mm) \\
\hline Chuva Fraca (CF) & & 0 & & 0,500 & $\leq 2$ & $\leq 81$ \\
\hline Chuva Leve (CL) & 0 & 1 & 0,500 & 0,841 & $2<\mathrm{T} \leq 6,3$ & $81<\mathrm{T} \leq 108,3$ \\
\hline Chuva Moderada (CM) & 1 & 1,5 & 0,841 & 0,933 & $6,3<\mathrm{T} \leq 15$ & $108,3<\mathrm{T} \leq 126,4$ \\
\hline Chuva Severa (CS) & 1,5 & 2 & 0,933 & 0,977 & $15<\mathrm{T} \leq 44$ & $126,4<\mathrm{T} \leq 148$ \\
\hline Chuva Extrema (CE) & 2 & & 0,977 & & $>44$ & $>148$ \\
\hline
\end{tabular}

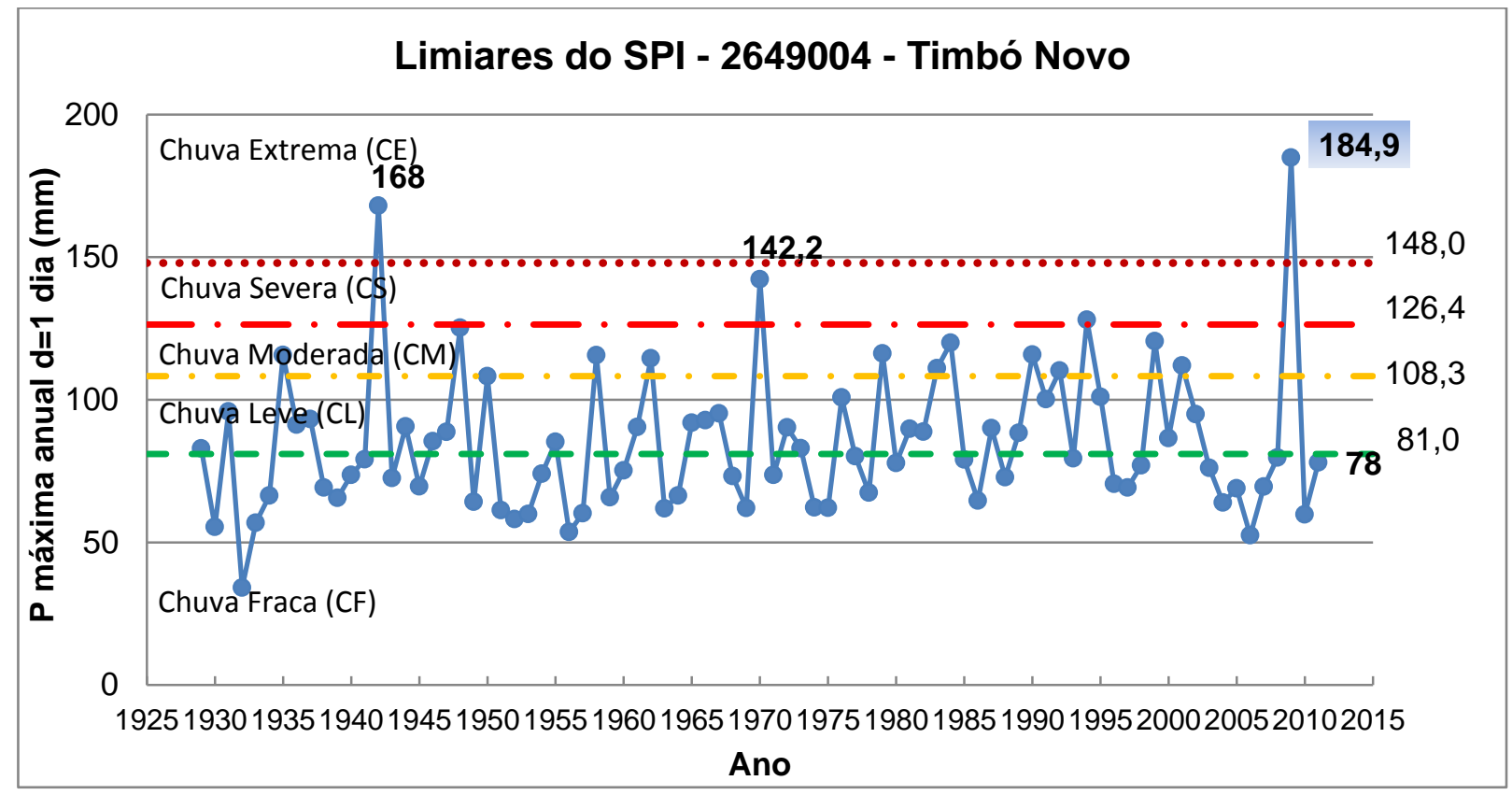

Figura 15 - Classificação das chuvas máximas de duração de 1 dia - 2649004 - Timbó Novo

Segundo a classificação adotada, a chuva de 2009 nessa estação pode ser considerada uma chuva extrema. 
Tabela 14 - SPI - 2649005 - Indaial - Chuvas máximas anuais com duração de 1 dia

\begin{tabular}{|c|c|c|c|c|c|c|}
\hline Classe de PMDA & \multicolumn{2}{|c|}{ SPI } & p (inf.) & p (sup.) & T (anos) & P 1 dia (mm) \\
\hline Chuva Fraca (CF) & & 0 & & 0,500 & $\leq 2$ & $\leq 72,2$ \\
\hline Chuva Leve (CL) & 0 & 1 & 0,500 & 0,841 & $2<\mathrm{T} \leq 6,3$ & $72,2<\mathrm{T} \leq 94,9$ \\
\hline Chuva Moderada (CM) & 1 & 1,5 & 0,841 & 0,933 & $6,3<\mathrm{T} \leq 15$ & $94,9<\mathrm{T} \leq 109,9$ \\
\hline Chuva Severa (CS) & 1,5 & 2 & 0,933 & 0,977 & $15<\mathrm{T} \leq 44$ & $109,9<\mathrm{T} \leq 127,9$ \\
\hline Chuva Extrema (CE) & 2 & & 0,977 & & $>44$ & $>127,9$ \\
\hline
\end{tabular}

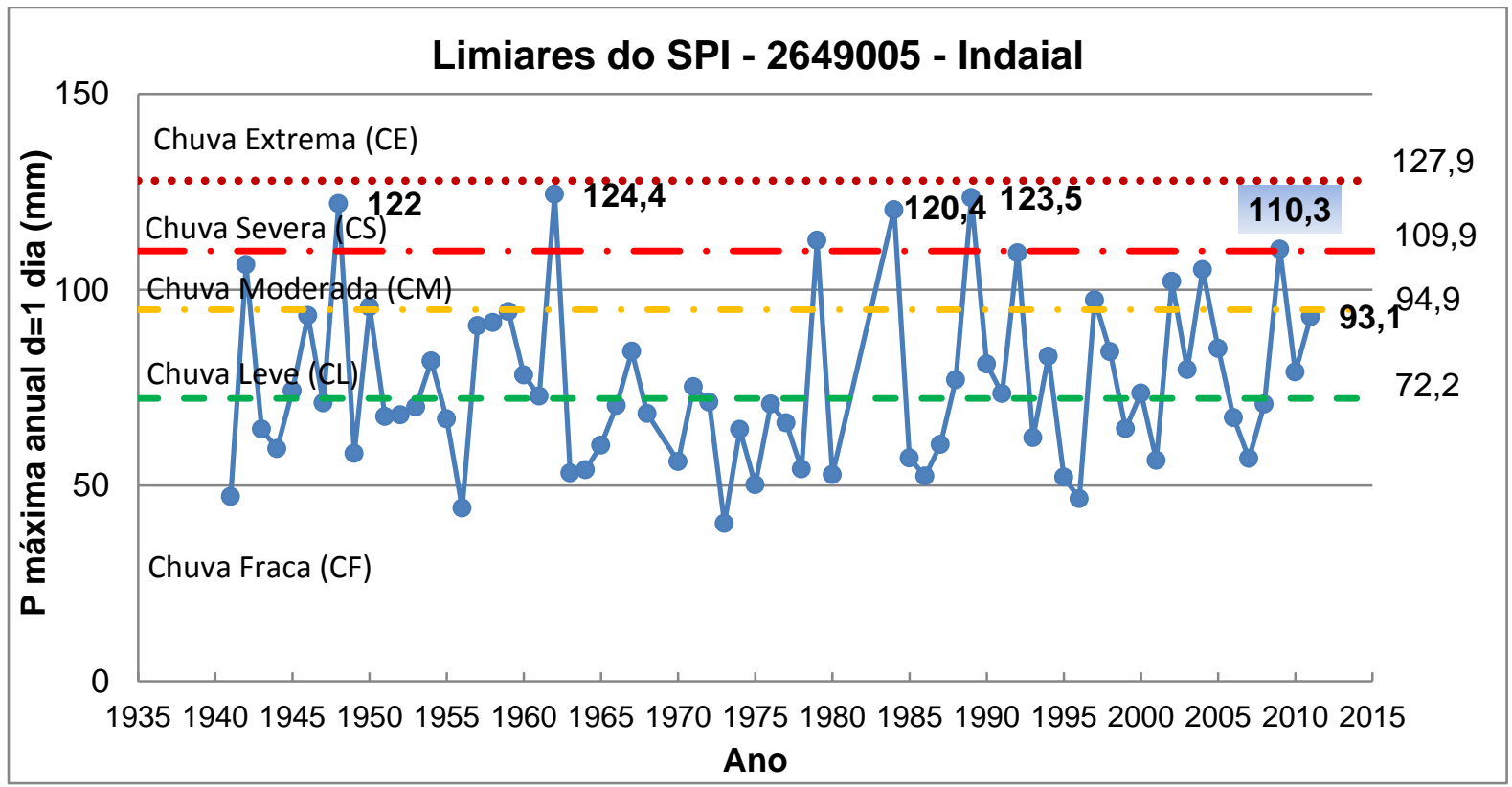

Figura 16 - Classificação das chuvas máximas de duração de 1 dia - 2649005 - Indaial Em Indaial, a chuva ocorrida em 2008 é classificada como chuva severa.

Tabela 15 - SPI - 2649007 - Blumenau - chuvas máximas anuais com duração de 1 dia

\begin{tabular}{|c|c|c|c|c|c|c|}
\hline Classe de PMDA & \multicolumn{2}{|c|}{ SPI } & $\mathbf{p}$ (inf.) & $\mathbf{p}$ (sup.) & T (anos) & P 1 dia (mm) \\
\hline Chuva Fraca (CF) & & 0 & & 0,500 & $\leq 2$ & $\leq 83,2$ \\
\hline Chuva Leve (CL) & 0 & 1 & 0,500 & 0,841 & $2<\mathrm{T} \leq 6,3$ & $83,2<\mathrm{T} \leq 117,8$ \\
\hline Chuva Moderada (CM) & 1 & 1,5 & 0,841 & 0,933 & $6,3<\mathrm{T} \leq 15$ & $117,8<\mathrm{T} \leq 140,7$ \\
\hline Chuva Severa (CS) & 1,5 & 2 & 0,933 & 0,977 & $15<\mathrm{T} \leq 44$ & $140,7<\mathrm{T} \leq 168,0$ \\
\hline Chuva Extrema (CE) & 2 & & 0,977 & & $>44$ & $>168,0$ \\
\hline
\end{tabular}




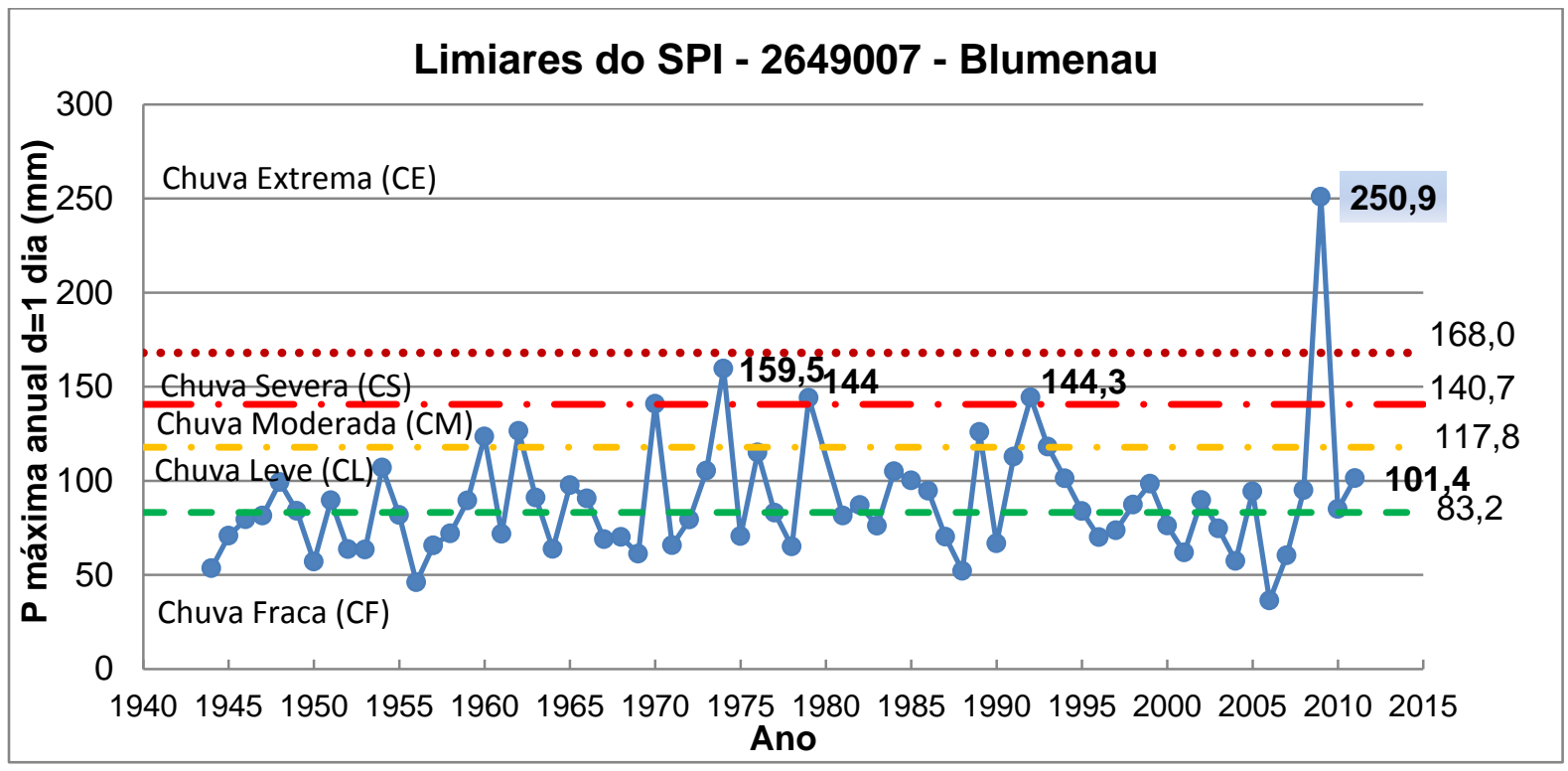

Figura 17 - Classificação das chuvas máximas de duração de 1 dia - 2649007 - Blumenau

Em Blumenau, a chuva elevadíssima observada no ano de 2008 classifica-se chuva extrema. Em Arrozeira, a classificação é de chuva severa tanto para a chuva observada em 2008 quanto a observada em 2010/2011.

Tabela 16 - SPI - 2649008 - Arrozeira - chuvas máximas anuais com duração de 1 dia

\begin{tabular}{|c|c|c|c|c|c|c|}
\hline Classe de PMDA & \multicolumn{2}{|c|}{ SPI } & p (inf.) & $\mathbf{p}$ (sup.) & T (anos) & P 1 dia (mm) \\
\hline Chuva Fraca (CF) & & 0 & & 0,500 & $\leq 2$ & $\leq 85,4$ \\
\hline Chuva Leve (CL) & 0 & 1 & 0,500 & 0,841 & $2<\mathrm{T} \leq 6,3$ & $85,4<\mathrm{T} \leq 110,4$ \\
\hline Chuva Moderada (CM) & 1 & 1,5 & 0,841 & 0,933 & $6,3<\mathrm{T} \leq 15$ & $110,4<\mathrm{T} \leq 126,9$ \\
\hline Chuva Severa (CS) & 1,5 & 2 & 0,933 & 0,977 & $15<\mathrm{T} \leq 44$ & $126,9<\mathrm{T} \leq 146,7$ \\
\hline Chuva Extrema (CE) & 2 & & 0,977 & & $>44$ & $>146,7$ \\
\hline
\end{tabular}

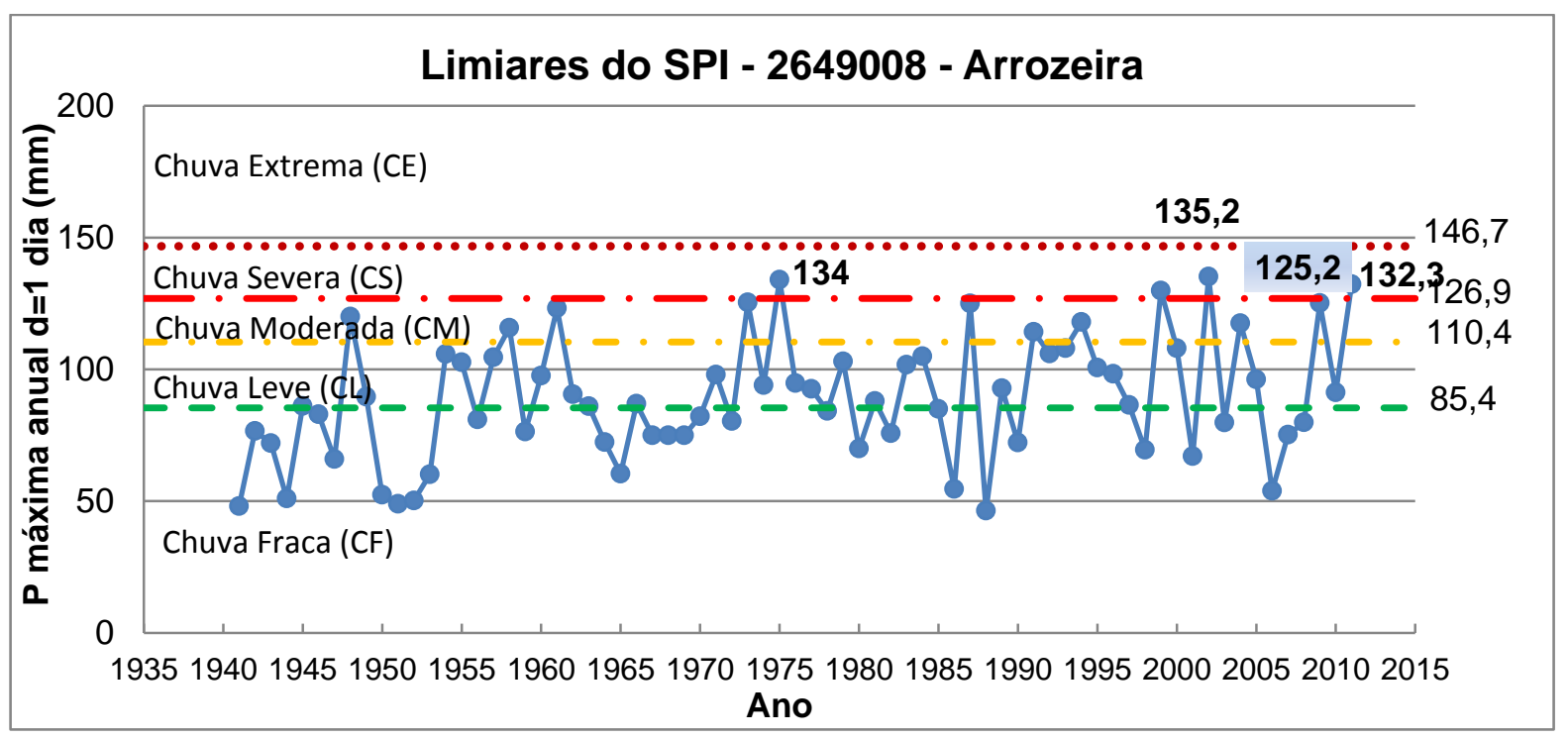


Em Arrozeira, a chuva diária é classificada como moderada. Porém, para as durações de 2 a 5 dias, a chuva é classificada como severa nesta estação, como ilustrado no Anexo II.

Tabela 17 - SPI - 2649010 - Itoupava Central - Chuvas máximas anuais com duração de 1 dia

\begin{tabular}{|c|c|c|c|c|c|c|}
\hline Classe de PMDA & \multicolumn{2}{|c|}{ SPI } & p (inf.) & p (sup.) & T (anos) & P 1 dia (mm) \\
\hline Chuva Fraca (CF) & & 0 & & 0,500 & $\leq 2$ & $\leq 85,1$ \\
\hline Chuva Leve (CL) & 0 & 1 & 0,500 & 0,841 & $2<\mathrm{T} \leq 6,3$ & $85,1<\mathrm{T} \leq 116,8$ \\
\hline Chuva Moderada (CM) & 1 & 1,5 & 0,841 & 0,933 & $6,3<\mathrm{T} \leq 15$ & $116,8<\mathrm{T} \leq 137,8$ \\
\hline Chuva Severa (CS) & 1,5 & 2 & 0,933 & 0,977 & $15<\mathrm{T} \leq 44$ & $137,8<\mathrm{T} \leq 162,9$ \\
\hline Chuva Extrema (CE) & 2 & & 0,977 & & $>44$ & $>162,9$ \\
\hline
\end{tabular}

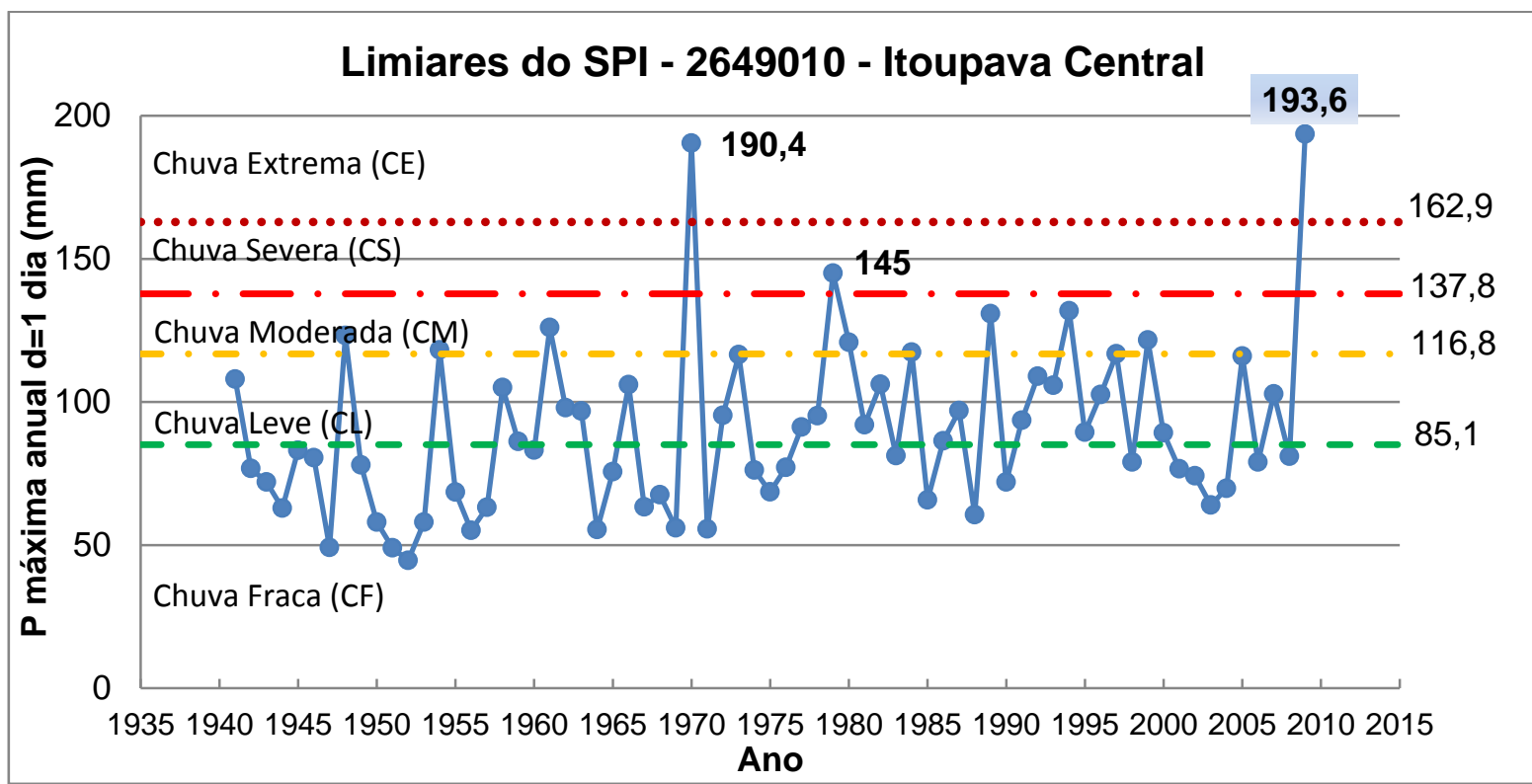

Figura 18 - Classificação das chuvas máximas de duração de 1 dia - 2649010 - Itoupava Central

A chuva de 2008 observada em Itoupava Central é classificada como chuva extrema.

Tabela 18 - SPI - 2748000 - Brusque- Chuvas máximas anuais com duração de 1 dia

\begin{tabular}{|c|c|c|c|c|c|c|}
\hline Classe de PMDA & \multicolumn{2}{|c|}{ SPI } & p (inf.) & p (sup.) & T (anos) & P 1 dia (mm) \\
\hline Chuva Fraca (CF) & & 0 & & 0,500 & $\leq 2$ & $\leq 75,9$ \\
\hline Chuva Leve (CL) & 0 & 1 & 0,500 & 0,841 & $2<\mathrm{T} \leq 6,3$ & $75,9<\mathrm{T} \leq 105,5$ \\
\hline Chuva Moderada (CM) & 1 & 1,5 & 0,841 & 0,933 & $6,3<\mathrm{T} \leq 15$ & $105,5<\mathrm{T} \leq 125,0$ \\
\hline Chuva Severa (CS) & 1,5 & 2 & 0,933 & 0,977 & $15<\mathrm{T} \leq 44$ & $125,0<\mathrm{T} \leq 148,4$ \\
\hline Chuva Extrema (CE) & 2 & & 0,977 & & $>44$ & $>148,4$ \\
\hline
\end{tabular}




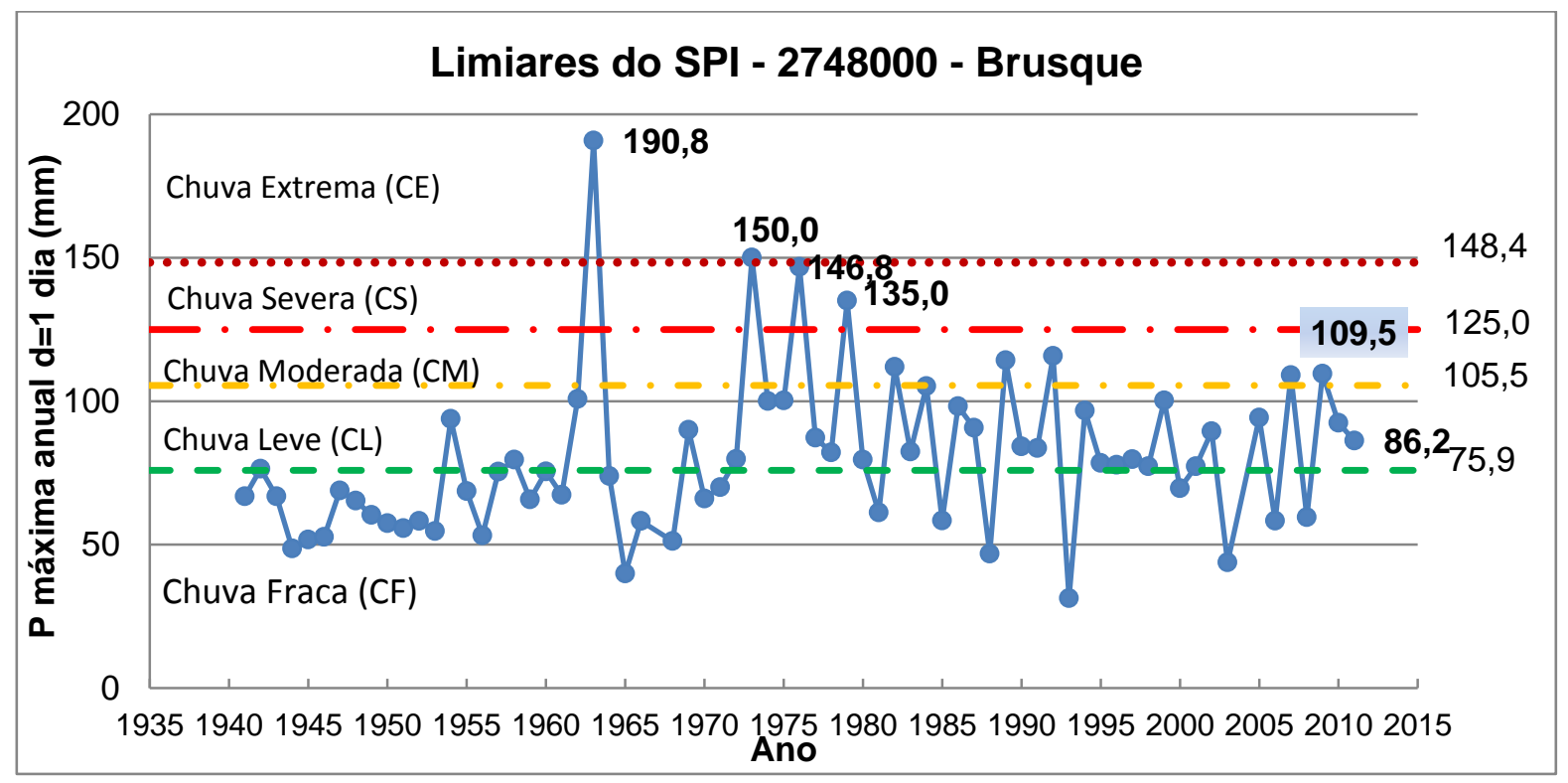

Figura 19 - Classificação das chuvas máximas de duração de 1 dia - 2748000 - Brusque

Apenas em Brusque, a chuva de novembro de 2008 foi classificada como chuva moderada. Entretanto, para durações as durações de 3 a 5 dias, este evento é considerado extremo, como ilustra o Anexo II.

\subsubsection{Conclusões}

As chuvas registradas no Vale do Itajaí em novembro de 2008 foram extremamente elevadas. As máximas diárias foram as maiores observadas desde que se iniciaram as leituras na maioria das estações utilizadas, atingindo valores acima de $250 \mathrm{~mm}$. Além do elevado volume diário, destaca-se o volume precipitado nos dias 23 e 24 nas estações Blumenau, onde choveu 243,5 mm e $\mathbf{2 5 0 , 9} \mathbf{~ m m ~ e ~}$ Itoupava Central, $138 \mathrm{~mm}$ e 193,6 mm, ambas localizadas no mesmo município.

O gráfico dos volumes acumulados para diferentes durações confirma os valores extremamente elevados. Os volumes acumulados no ano de 2008 foram os maiores já observados na maioria das estações e estão muito acima dos observados anteriormente nesses postos pluviométricos. Na estação Blumenau choveu 1.153 mm em 45 dias. Em Timbó Novo choveu 972,2 mm. Em Itoupava Central o volume acumulado atingiu 930,6 mm. Em Arrozeira, Indaial e Brusque os valores registrados no mesmo intervalo foram $863,2 \mathrm{~mm}, 789,7 \mathrm{~mm}$ e $663,4 \mathrm{~mm}$. 
A classificação das chuvas pelo SPI confirma as chuvas elevadas. Na maioria das estações as chuvas máximas diárias ocorridas em novembro de 2008 são classificadas como chuvas extremas ou severas. Já em Brusque, a chuva máxima com duração de 1 dias foi considerada chuva moderada. Para durações maiores que 2 dias, em todas as estações as chuvas de 2008 são classificadas como chuvas severas ou extremas (Anexo II).

Tudo indica que as inundações e escorregamentos ocorridos em 2008 tenham sido causados pelo elevado volume diário precipitado nos dias 23 e 24 de novembro, aliado ao volume de chuva acumulado nos dias e meses antecedentes.

O relevo da região também contribuiu para a ocorrência de inundações. A baixa declividade próxima à região costeira dificulta o escoamento da água dos rios para o mar, fazendo com que a água permaneça retida na bacia durante períodos mais longos do que em bacias com maior declividade.

No ano de 2011, novamente a região sofre com as inundações. Apesar de o volume precipitado não ser tão significativo quanto o observado em 2008, foi suficiente para deflagrar os escorregamentos e as inundações na região do Vale do Itajaí. Os valores acumulados em 45 dias atingiram 673,5 mm em Blumenau, 672,1 $\mathrm{mm}$ em Arrozeira, 638,1 mm em Indaial, 609,1 mm em Brusque e 438,8 mm em Timbó Novo. A máxima diária foi observada no dia 8 de setembro na estação Arrozeira, 132,3 mm. Nessa estação a chuva é classificada como severa. No dia 9 choveu 101,4 mm, 93,1 mm e 86,2 mm nas estações Blumenau, Indaial e Brusque e foram classificadas como chuvas leves. Para durações maiores que dois dias as chuvas de 2011 foram consideradas chuvas moderadas ou severas, como mostra o Anexo II, indicando que as inundações podem ter sido causadas pelos volumes acumulados em períodos maiores que dois dias.

Nota-se na Figura 13 que os eventos extremos são característicos da região. Outros valores elevados já foram registrados nos postos utilizados, entre eles os observados nos anos de 1963 em Brusque e em 1970 em Itoupava Central, localizada em Blumenau. 


\subsection{SÃO LUÍS DO PARAITINGA E CUNHA}

No réveillon de 2009, as chuvas elevadas que atingiram a Região Sudeste do Brasil causaram desastres em localidades como Angra dos Reis, Ilha Grande, São Luís do Paraitinga e Cunha, situadas nos estados do Rio de Janeiro e São Paulo.

A cidade de São Paulo sofreu com os alagamentos diários nos meses de dezembro, janeiro e fevereiro.

Houve inundações e escorregamentos de encostas que deixaram vítimas no Morro da Carioca, em Angra dos Reis, RJ, e na praia do Bananal, em Ilha Grande, RJ.

No município de São Luís do Paraitinga, SP, o rio Paraitinga subiu cerca de 11 metros acima de seu nível normal, dando origem à maior inundação já registrada no município. O centro histórico ficou completamente inundado e houve escorregamentos em áreas rurais e urbanas. De acordo com o Jornal da Reconstrução, dos 426 imóveis tombados pelo Patrimônio, 18 foram arruinados e 65 sofreram avarias. A catedral da Matriz desabou.

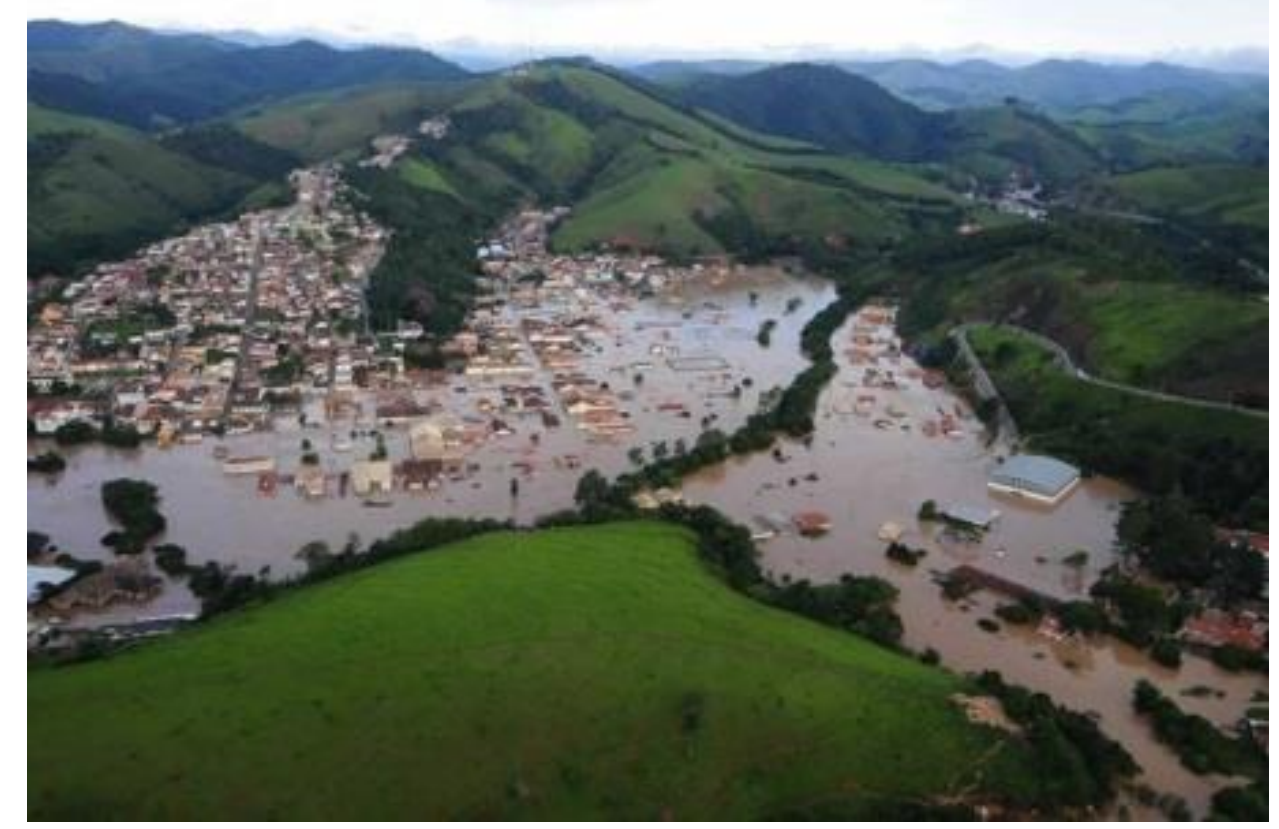

Figura 20 - Vista aérea do município de São Luís do Paraitinga no dia 2 de janeiro de 2010 (Fonte: VEJA SP; foto: Lucas Lacaz Ruiz) 


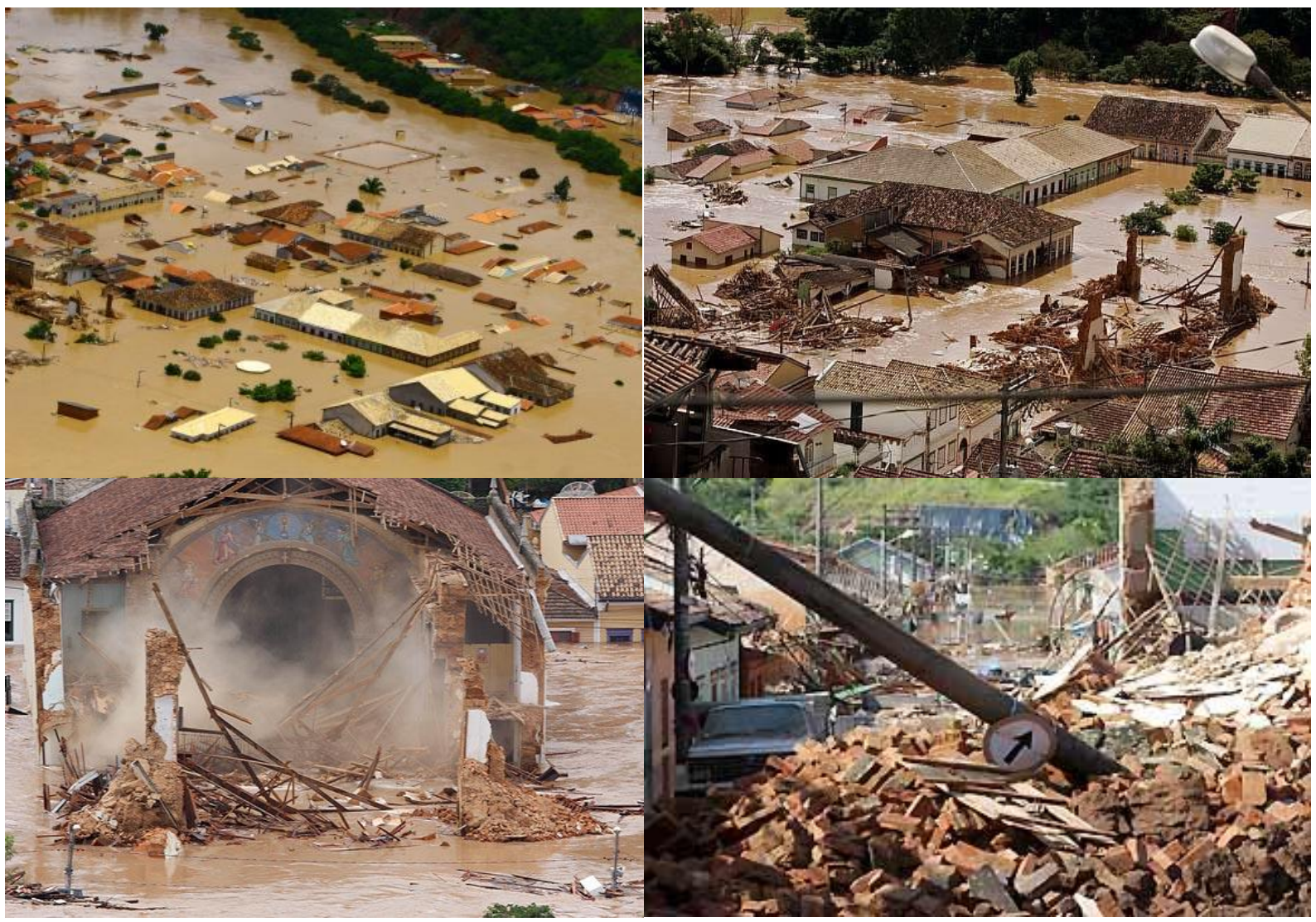

Figura 21 - Vista aérea da cidade no dia 2/01/2010; prédio histórico danificado; escombros da Igreja das Mercês (Fonte: Sergio Neves/AE; Joel Silva/Folha Imagem; Mario Angelo/Folhapress)

Segundo dados do SINDEC - Sistema Nacional de Defesa Civil, em relatório de avaliação de danos - AVADAN, do dia 01 de janeiro de 2010, 11.000 pessoas foram afetadas, 4.030 ficaram desalojadas e 93 desabrigadas em consequência das inundações. No município de Cunha, SP, houve escorregamentos de encostas, quedas de barreiras que interromperam o fornecimento de água e energia em alguns bairros e isolaram a população rural, deixando 12.000 pessoas afetadas, 492 desalojadas, 38 desabrigadas e 6 vítimas.

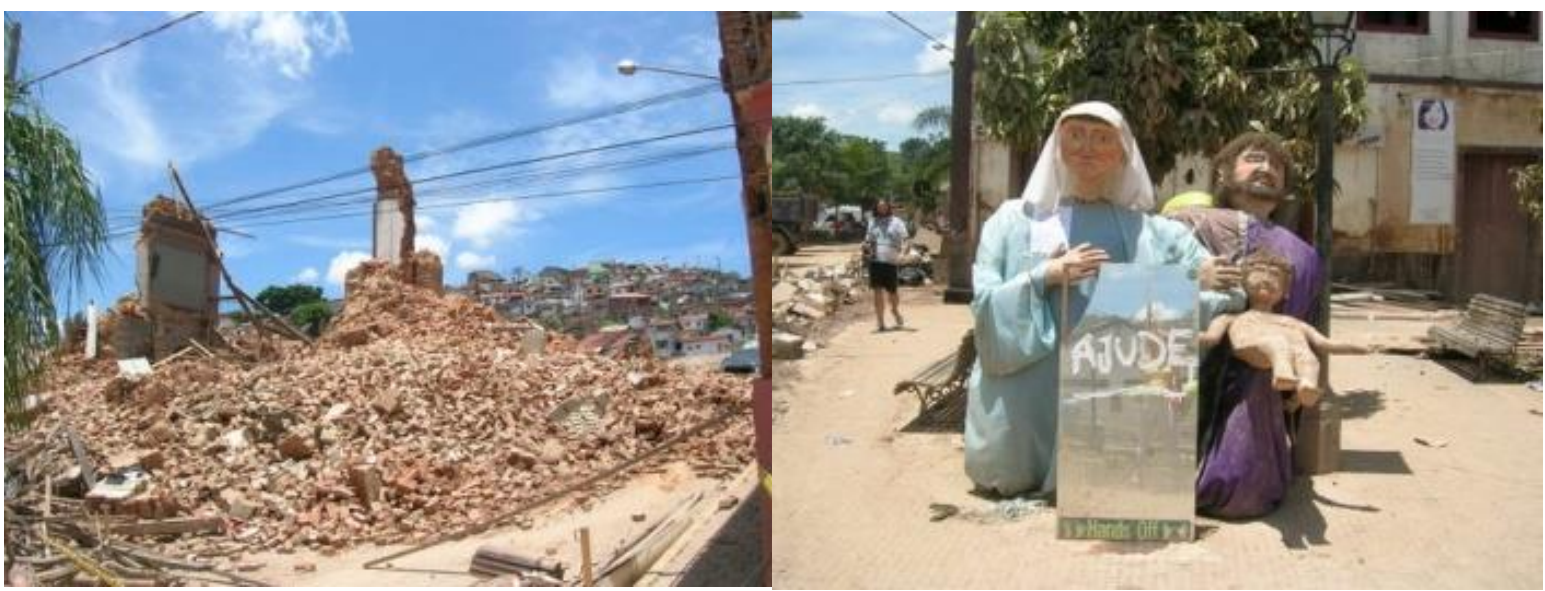

Figura 22- Igreja Matriz e São Luís do Paraitinga após o desastre (Fotos: Verusca Sartorelli Medeiros) 


\subsubsection{Descrição da área de estudo e estações pluviométricas utilizadas}

Os municípios São Luís do Paraitinga e Cunha estão localizados na bacia do Paraíba do Sul (58), em seu trecho paulista, no Alto Paraíba, no estado de São Paulo.

A bacia do Paraíba estende-se entre as Serras do Mar e da Mantiqueira, no sentido leste oeste. Possui relevo acidentado, variando desde alguns metros de altitude nas planícies litorâneas próximas à foz até altitudes superiores a 1.500 metros na Serra do Mar e 2.700 metros na Serra da Mantiqueira. Os pontos mais elevados são o Pico das Agulhas Negras, situado no Parque Nacional de Itatiaia, na Serra da Mantiqueira, com 2.792 metros, e o Pico Pedra da Mina, com 2798 metros, segundo medição de 2004 do IBGE - Instituto Brasileiro de Geografia e Estatística.

O rio Paraíba do Sul é formado pela confluência dos rios Paraibuna e Paraitinga, com suas nascentes localizadas nos municípios de Cunha e Areias. Em toda sua extensão, percorre os estados de São Paulo, Minas Gerais e Rio de Janeiro. Sua foz está localizada na praia de Atafona, no município de São João da Barra, no Rio de Janeiro. Seus principais afluentes são os rios Jaguari, Paraibuna, Pomba e Muriaé, na margem esquerda, e Una, Bananal, Piraí, Piabanha e Dois Rios, na margem direita.

Sua cobertura vegetal é composta de mata Atlântica nas Serras e, nas demais áreas da bacia, pastagens e solos compactados, com elevado aporte de sedimentos.

A população, ao longo dos anos, foi ocupando as várzeas dos rios, sujeitas a inundações, e encostas de morros, sujeitas a escorregamentos. A vulnerabilidade da região é elevada, sendo os desastres mais comuns aqueles associados a chuvas intensas ou longos períodos de precipitação.

O município de São Luís do Paraitinga é um dois únicos do estado de São Paulo que tem preservado em seu patrimônio cultural construções arquitetônicas em grande número, que datam do século XIX.

As edificações de São Luís são um raro registro histórico da primeira área de expansão da cafeicultura brasileira no século 19, no Vale do Paraíba. O período não 
é, geralmente, foco de políticas públicas de preservação de patrimônio, como ocorrem em cidades com construções do período colonial vinculadas à mineração mineira ou à economia açucareira nordestina (FOLHA, 2012).

A cidade tem sua economia voltada para o turismo. Destacam-se as festas populares como a Festa do Divino e o Carnaval, esta última atraindo milhares de turistas para o município. É comum a prática de esportes como a canoagem, o rafting e o rapel nos rios da região.

Dentre as grandes inundações ocorridas em São Luís do Paraitinga, destacam-se as cheias de 1863, 1969, 1985, 1996 e 2010 (informação pessoal).

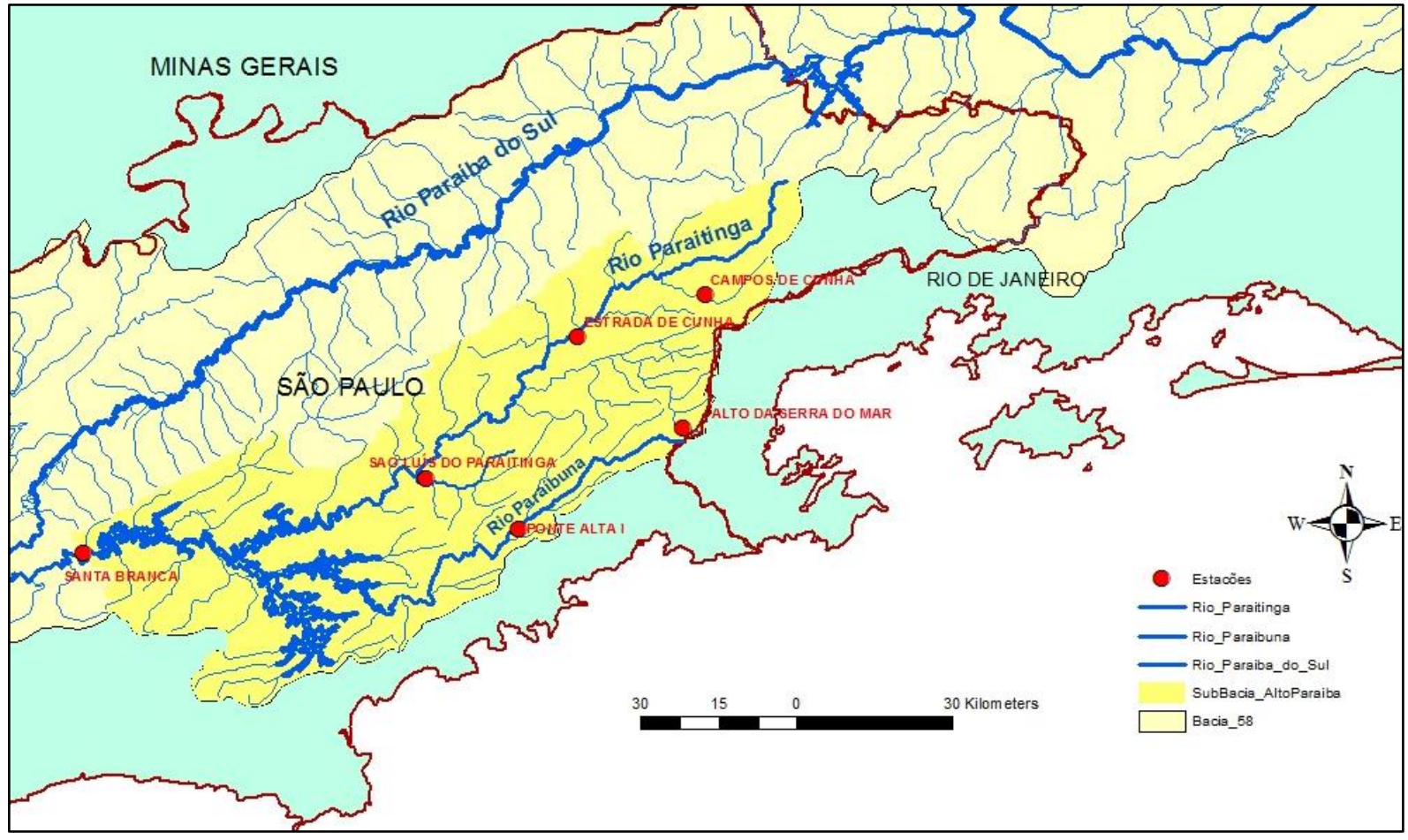

Figura 23 - Localização dos seis postos utilizados na da bacia do Alto Paraíba do Sul

O clima da região é classificado, segundo Köppen, como Subtropical de Altitude (Cwb), que tem como características verões chuvosos e invernos mais frios e secos. As temperaturas são mais amenas que nas regiões de menor altitude.

As estações utilizadas nesse estudo estão localizadas na bacia do Alto Paraíba, no estado de São Paulo, região que sofreu com os desastres naturais de janeiro de 2010. Foram selecionadas seis estações da Rede Hidrometeorológica Nacional da ANA, operadas pela CPRM - Serviço Geológico do Brasil. Os postos 
estão localizados nos municípios de São Luís do Paraitinga, onde ocorreu a inundação histórica, Cunha, situada na cabeceira da bacia, onde ocorreram escorregamentos e inundações, e em Santa Branca, que fica à jusante de São Luís do Paraitinga. Suas altitudes variam de 573 metros a 1.050 metros. As precipitações médias anuais são fortemente influenciadas pela orografia, variando de $1.243 \mathrm{~mm}$ em São Luís do Paraitinga, chegando a 2.080 mm em uma das estações localizadas em Cunha, na cabeceira da bacia. O mês mais chuvoso é janeiro, seguido de fevereiro e dezembro.

A seleção foi feita de forma que se pudesse avaliar a distribuição espacial da chuva na bacia e entender a inundação ocorrida. Os postos estão relacionados na Tabela 19.

Tabela 19 - Estações pluviométricas utilizadas no estudo

\begin{tabular}{|c|c|c|c|c|c|c|c|}
\hline Código & Estação & Bacia & Latitude & Longitude & $\begin{array}{c}\text { Alt. } \\
(\mathbf{m})\end{array}$ & $\begin{array}{c}\text { Esta } \\
\text { do }\end{array}$ & Município \\
\hline 2244048 & $\begin{array}{c}\text { Campos de } \\
\text { Cunha }\end{array}$ & 58 & $-22^{\circ} 55^{\prime} 16^{\prime \prime}$ & $-44^{\circ} 49^{\prime} 20^{\prime \prime}$ & 750 & $\mathrm{SP}$ & Cunha \\
\hline 2245055 & $\begin{array}{c}\text { Estrada de } \\
\text { Cunha }\end{array}$ & 58 & $-2^{\circ} 59^{\prime} 45^{\prime \prime}$ & $-45^{\circ} 02^{\prime} 30^{\prime \prime}$ & 790 & $\mathrm{SP}$ & Cunha \\
\hline 2344009 & $\begin{array}{c}\text { Alto da Serra } \\
\text { do Mar }\end{array}$ & 58 & $-2^{\circ} 03^{\prime} 13^{\prime \prime}$ & $-44^{\circ} 51^{\prime} 32^{\prime \prime}$ & 1050 & $\mathrm{SP}$ & Cunha \\
\hline 2345065 & $\begin{array}{c}\text { São Luís do } \\
\text { Paraitinga }\end{array}$ & 58 & $-23^{\circ} 13^{\prime} 19^{\prime \prime}$ & $-45^{\circ} 19^{\prime} 24^{\prime \prime}$ & 760 & $\mathrm{SP}$ & $\begin{array}{c}\text { São Luís do } \\
\text { Paraitinga }\end{array}$ \\
\hline 2345067 & $\begin{array}{c}\text { Ponte Alta I } \\
2345071\end{array}$ & 58 & $-2^{\circ} 13^{\prime} 44^{\prime \prime}$ & $-45^{\circ} 08^{\prime} 38^{\prime \prime}$ & 888 & $\mathrm{SP}$ & $\begin{array}{c}\text { São Luís do } \\
\text { Paraitinga }\end{array}$ \\
\hline Branca & 58 & $-23^{\circ} 22^{\prime} 08^{\prime \prime}$ & $-45^{\circ} 54^{\prime} 00^{\prime \prime}$ & 573 & $\mathrm{SP}$ & Santa Branca \\
\hline
\end{tabular}

\subsubsection{Análise estatística dos dados de chuva}

\subsubsection{Meses que antecedem os eventos}

Foram analisados os totais mensais do ano de 2009, que antecedem o evento crítico de janeiro de 2010, e os totais mensais do ano de 2010. As médias mensais das séries históricas foram calculadas e podem ser comparadas com os totais mensais de 2009 e 2010 através dos gráficos da Figura 24. 


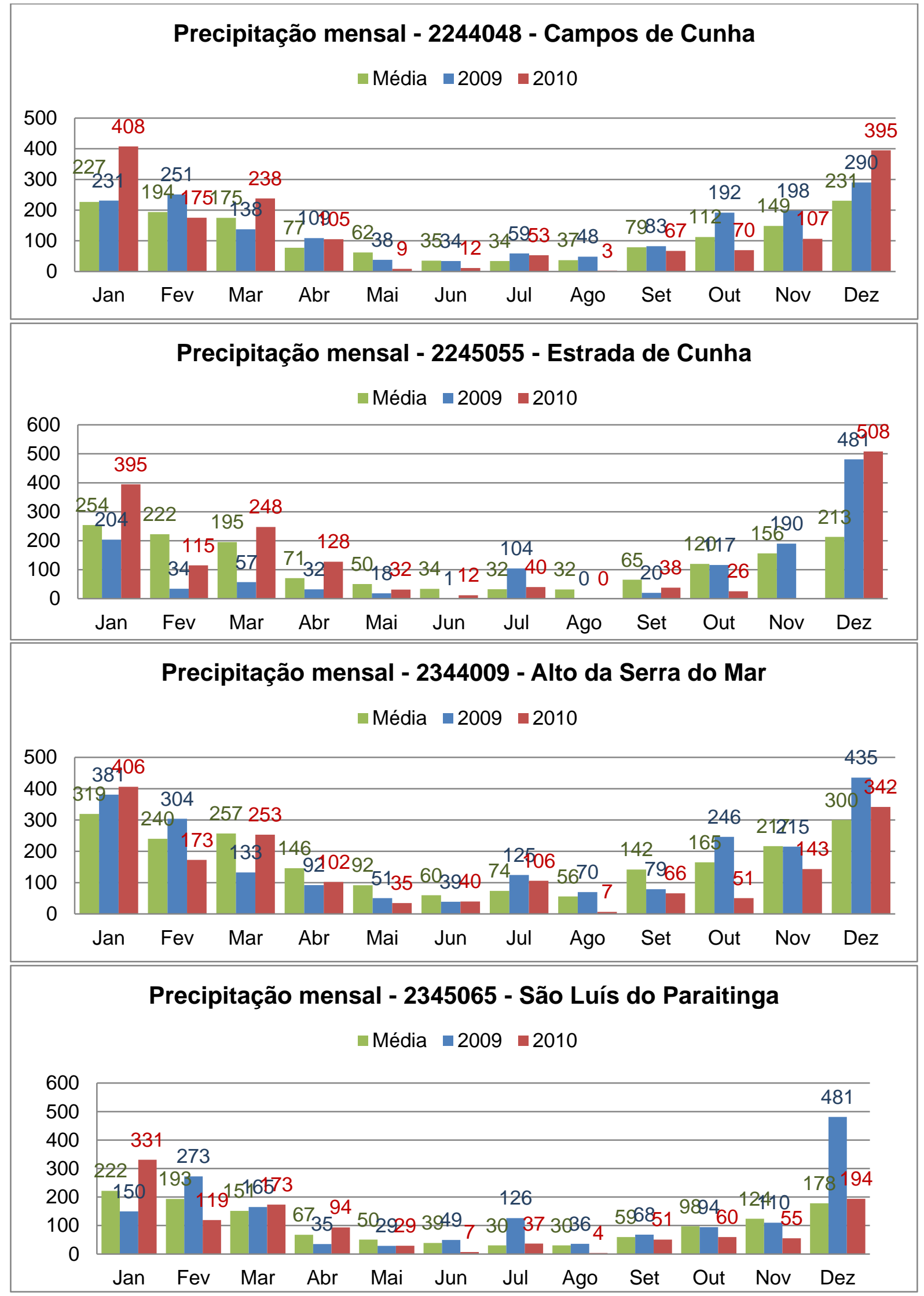

Figura 24 - Totais mensais dos anos 2009, 2010 e média mensal histórica (continua) 


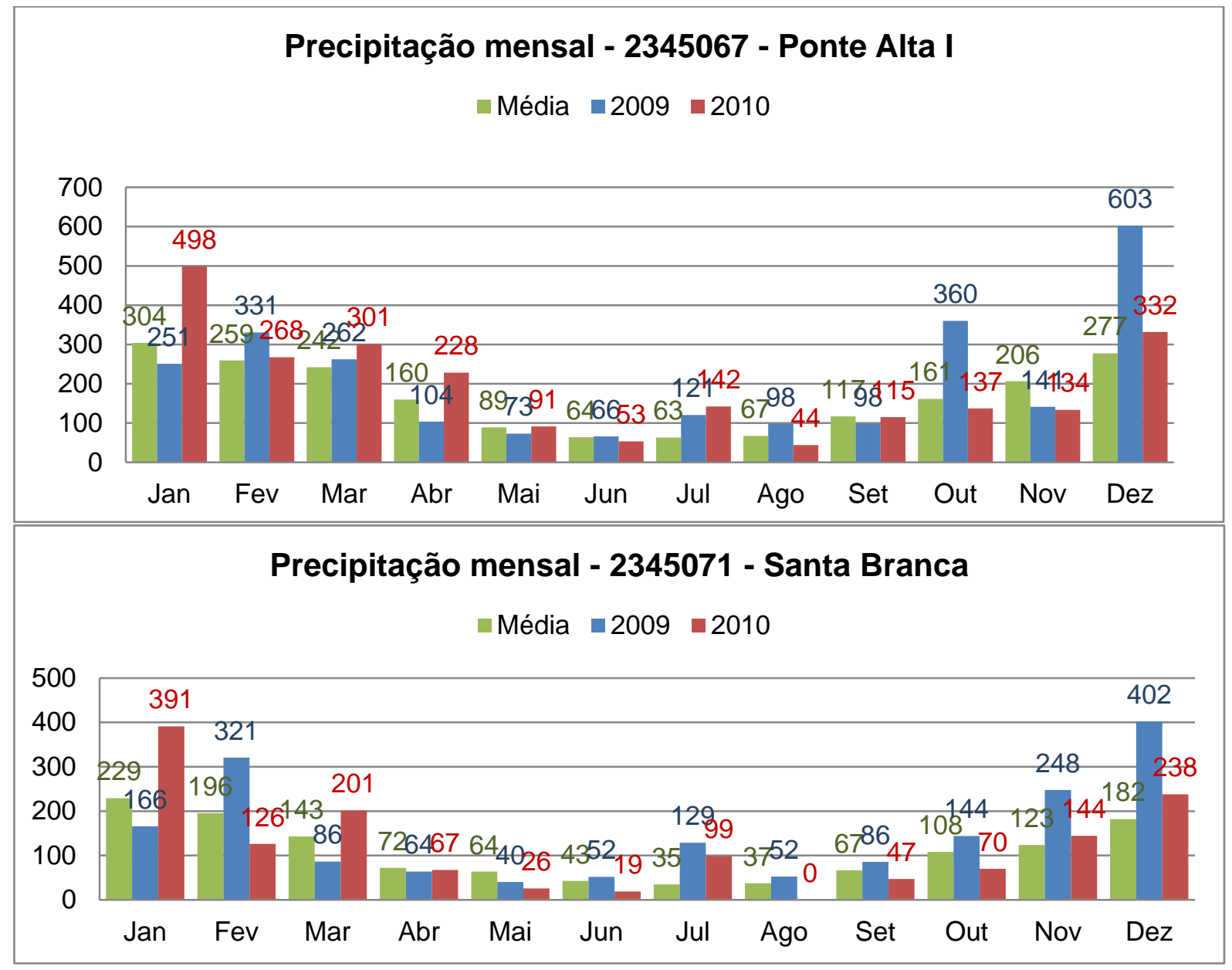

Figura 24 - Totais mensais dos anos 2009, 2010 e média mensal histórica

Percebe-se que o mês de dezembro de 2009, que antecede os eventos extremos de janeiro de 2010, foi bastante chuvoso. Choveu mais que o dobro da média mensal na maioria das estações analisadas. Em Ponte Alta I choveu mais de $600 \mathrm{~mm}$.

\subsubsection{Estatísticas básicas}

Para entender a magnitude dos eventos, foram calculadas algumas estatísticas básicas: a precipitação máxima diária no mês em que o evento ocorreu, janeiro de 2010, ( $P_{\max }$ jan/10), o dia da máxima, a precipitação média das máximas diárias anuais $\left(P_{\text {med }} \max \right)$, o total mensal de janeiro de 2010 ( $P_{\text {mensajan/10), a }}$ precipitação média mensal de janeiro ( $P_{\text {med }}$ mensal) e a precipitação média anual ( $P_{\text {med }}$ anual). Os dados estão na Tabela 20. 
Tabela 20 - Chuvas de janeiro de 2010, médias das máximas e médias mensais e anuais das estações do Vale do Paraíba

\begin{tabular}{|c|c|c|c|c|c|c|c|c|}
\hline Código & Estação & Dados & $\begin{array}{c}\mathrm{P}_{\text {max }} \\
\text { jan/10 } \\
(\mathrm{mm})\end{array}$ & $\begin{array}{c}\text { Dia } \\
\text { da } \\
\mathbf{m a x}\end{array}$ & $\begin{array}{c}\mathrm{P}_{\text {med }} \\
\text { das } \\
\mathbf{m a x} \\
(\mathrm{mm})\end{array}$ & $\begin{array}{c}\mathrm{P} \\
\text { mensal } \\
\text { jan/10 } \\
(\mathrm{mm})\end{array}$ & $\begin{array}{c}\mathrm{P}_{\text {med }} \\
\text { mensal } \\
\text { jan } \\
(\mathrm{mm})\end{array}$ & $\begin{array}{c}\mathrm{P}_{\text {med }} \\
\text { anual } \\
(\mathrm{mm})\end{array}$ \\
\hline 2244048 & $\begin{array}{c}\text { Campos de } \\
\text { Cunha }\end{array}$ & ago/67 a mai/11 & $\mathbf{1 6 5}$ & 1 & 70,3 & 408 & 227 & 1.408 \\
\hline 2245055 & $\begin{array}{c}\text { Estrada de } \\
\text { Cunha }\end{array}$ & nov/35 a mai/11 & $\mathbf{1 7 4 , 2}$ & 1 & 77,8 & 395 & 254 & 1.448 \\
\hline 2344009 & $\begin{array}{c}\text { Alto da Serra } \\
\text { do Mar }\end{array}$ & set/67 a fev/12 & $\mathbf{2 0 5 , 7}$ & 1 & 102,1 & 406 & 319 & 2.080 \\
\hline 2345065 & $\begin{array}{c}\text { São Luís do } \\
\text { Paraitinga }\end{array}$ & nov/35 a fev/11 & 67,4 & 1 & 66,9 & 331 & 222 & 1.243 \\
\hline 2345067 & Ponte Alta I & out/36 a mai/11 & $\mathbf{1 5 5 , 3}$ & 1 & 127 & 498 & 304 & 2.009 \\
\hline 2345071 & $\begin{array}{c}\text { Santa } \\
\text { Branca }\end{array}$ & jun/52 a mai/11 & $\mathbf{1 0 0 , 8}$ & 2 & 71,5 & 391 & 229 & 1.292 \\
\hline
\end{tabular}

As chuvas máximas diárias de janeiro de 2010 foram maiores que a média das máximas na maioria das estações. Na estação São Luís do Paraitinga a máxima de janeiro não foi tão elevada, ficando em torno da média.

\subsubsection{Análise dos meses em que ocorrem as chuvas catastróficas}

Em seguida foram analisados os eventos críticos de dezembro de 2009 e janeiro de 2010. As chuvas diárias de todas as estações foram plotadas nos gráficos das Figuras 25 e 26.

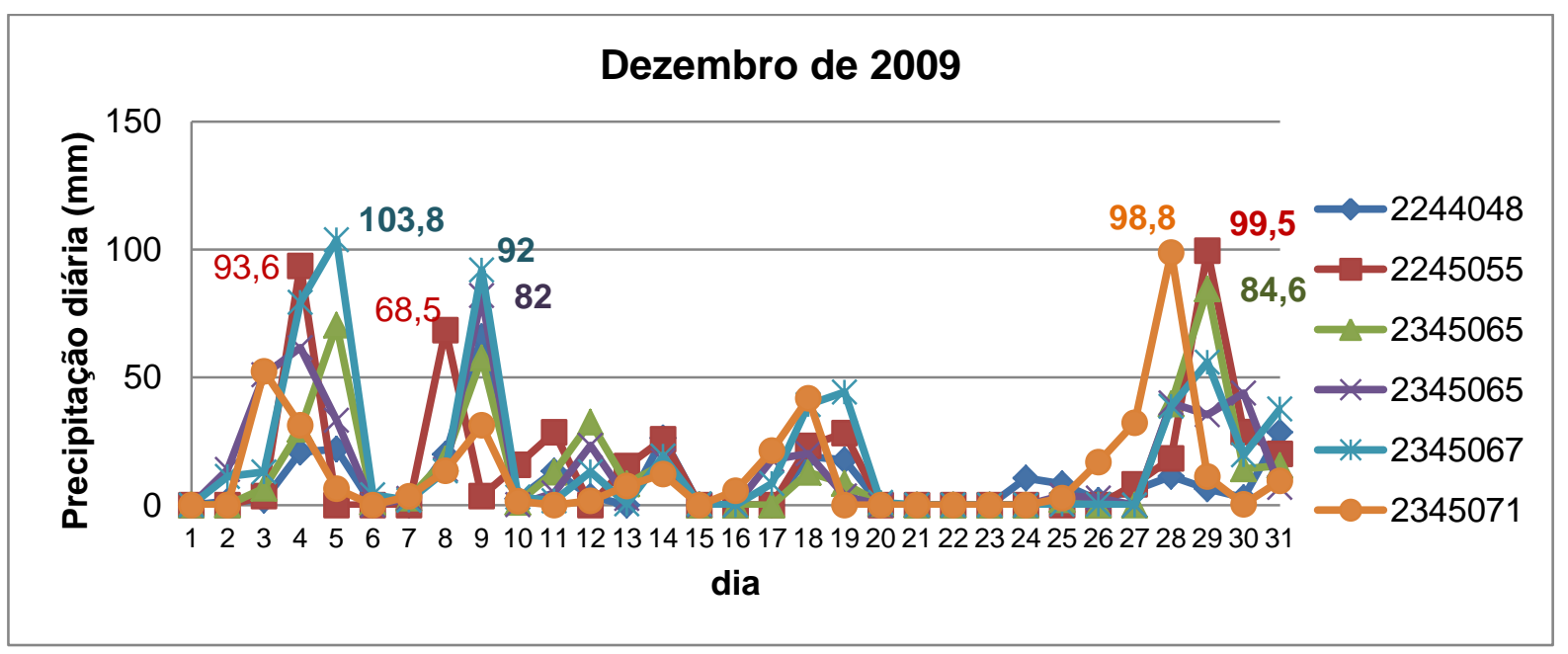

Figura 25 - Precipitação diária de dezembro de 2009 


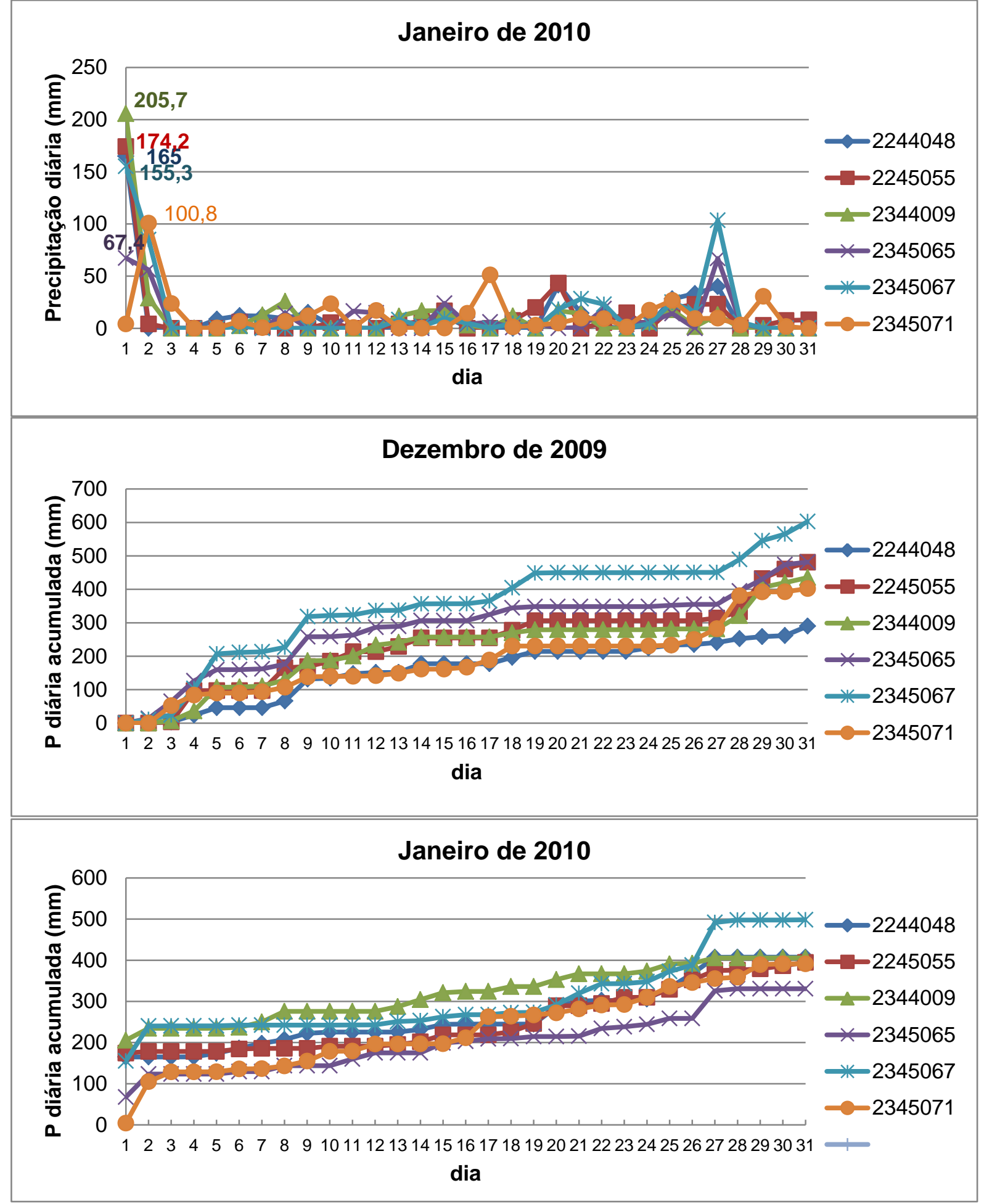

Figura 26 - Precipitação diária de janeiro de 2010 e acumulada de dezembro de 2009 e janeiro de 2010

Destacam-se as chuvas precipitadas nos dias 4 e 5, 9 e 28 e 29 de dezembro, em torno de $100 \mathrm{~mm}$. O volume precipitado no mês de dezembro foi extremamente elevado, atingindo de 400 a $600 \mathrm{~mm}$ na maioria das estações. 
No dia 1 de janeiro, quando ocorreram as inundações, as chuvas foram mais intensas nas estações Alto da Serra do Mar, onde choveu 205,7 mm, Estrada de Cunha e Campos de Cunha, 174,2 mm e 165 mm. Em Ponte Alta I, localizada em São Luís do Paraitinga, choveu 155,3 mm. Na estação de São Luís do Paraitinga as chuvas não foram tão elevadas, atingindo $66,9 \mathrm{~mm}$.

\subsubsection{Distribuições adotadas e períodos de retorno (Tr)}

Foram calculadas as posições de plotagem das séries de chuvas máximas diárias, através da fórmula de Cunnane, os períodos de retorno e depois ajustadas as distribuições Log-Normal e Gumbel para todas as estações. O resumo dos parâmetros estimados de cada distribuição encontra-se na Tabela 21.

Tabela 21 - Resumo dos parâmetros estimados de cada distribuição

\begin{tabular}{|c|c|c|c|c|}
\hline \multirow{2}{*}{ Estação } & \multirow{2}{*}{$\begin{array}{l}\text { Parâmetros } \\
\text { Estimados }\end{array}$} & \multicolumn{3}{|c|}{ Distribuição } \\
\hline & & Empírica & Log-Normal & Gumbel \\
\hline \multirow{3}{*}{2244048} & Média $\mu$ & 71,1 & 70,6 & 70,8 \\
\hline & Desvio-padrão $\sigma$ & 26,4 & 21,0 & 25,5 \\
\hline & Assimetria y & 2,4 & 0,7 & 0,9 \\
\hline \multirow{3}{*}{2245055} & $\mu$ & 77,8 & 77,6 & 77,7 \\
\hline & $\sigma$ & 25,0 & 22,9 & 24,4 \\
\hline & $\mathrm{Y}$ & 1,4 & 0,8 & 0,9 \\
\hline \multirow{3}{*}{2344009} & $\mu$ & 102,1 & 101,9 & 101,7 \\
\hline & $\sigma$ & 36,8 & 36,3 & 35,5 \\
\hline & Y & 0,8 & 0,9 & 0,9 \\
\hline \multirow{3}{*}{2345065} & $\mu$ & 66,9 & 66,8 & 66,8 \\
\hline & $\sigma$ & 16,9 & 15,4 & 16,5 \\
\hline & $\mathrm{Y}$ & 1,5 & 0,6 & 0,9 \\
\hline \multirow{3}{*}{2345067} & $\mu$ & 123,9 & 124,1 & 123,7 \\
\hline & $\sigma$ & 42,0 & 44,3 & 41,0 \\
\hline & Y & 0,4 & 0,9 & 0,9 \\
\hline \multirow{3}{*}{2345071} & $\mu$ & 73,7 & 73,7 & 73,6 \\
\hline & $\sigma$ & 18,3 & 18,5 & 17,8 \\
\hline & $y$ & 0,4 & 0,6 & 0,9 \\
\hline
\end{tabular}

Os gráficos contendo as distribuições empíricas e as ajustadas para cada estação podem ser visualizados na Figura 27. 


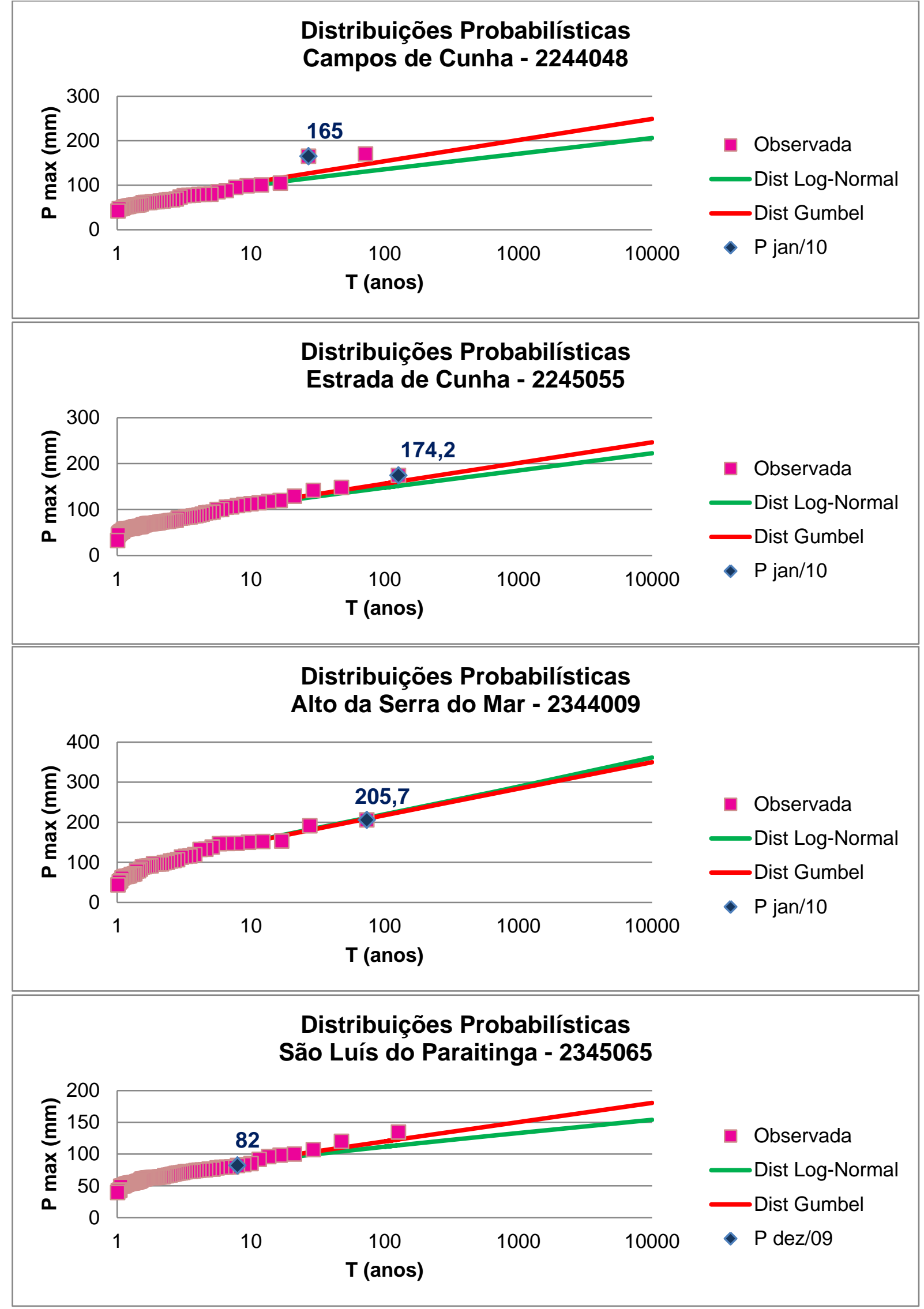

Figura 27 - Relação entre Tr e precipitações máximas para 1 dia de duração (continua) 


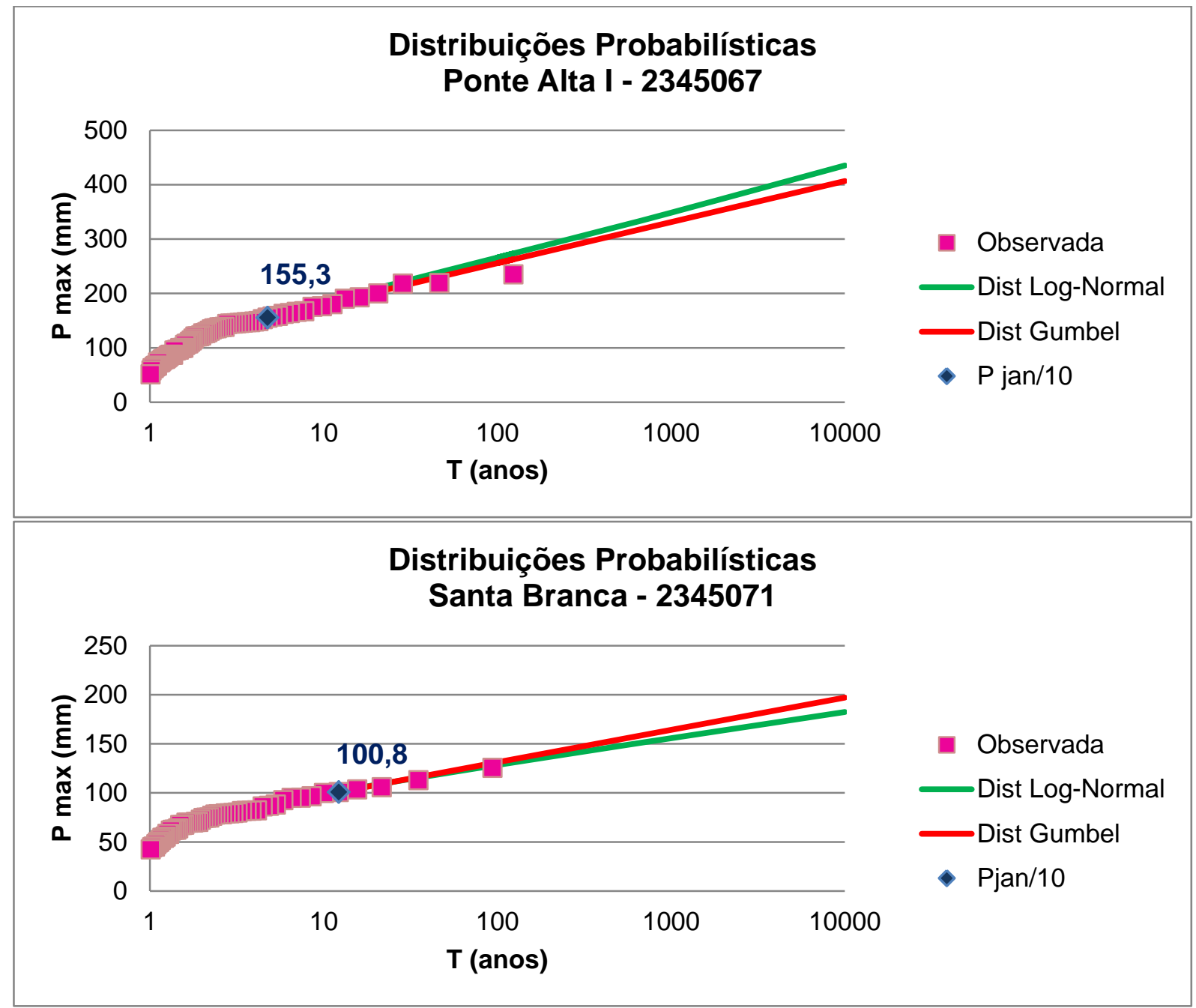

Figura 27 - Relação entre Tr e precipitações máximas para 1 dia de duração

Através dos gráficos das distribuições, nota-se que a precipitação de janeiro de 2010 foi a máxima já registrada em duas das seis estações, Estrada de Cunha e Alto da Serra do Mar.

Em São Luís do Paraitinga, a máxima chuva observada em janeiro foi $65,2 \mathrm{~mm}$, mas não corresponde à máxima do ano hidrológico 2009/2010. A máxima do ano hidrológico foi observada no dia 9 de dezembro de 2008, $82 \mathrm{~mm}$.

Foram estimados os períodos de retorno das chuvas ocorridas em janeiro de 2010 para as distribuições de probabilidade Log-Normal e Gumbel. Os resultados dos valores estimados podem ser vistos na Tabela 22. 
Tabela 22 - Períodos de retorno estimados para as máximas chuvas diárias

\begin{tabular}{|c|c|c|c|c|}
\hline Estação & $\begin{array}{c}\text { P max } \\
\text { janeiro de } \\
\mathbf{2 0 1 0 ( m m )}\end{array}$ & $\begin{array}{c}\text { Tr } \\
\text { Empírica } \\
\text { (anos) } \\
\text { Cunnane }\end{array}$ & $\begin{array}{c}\text { Tr } \\
\text { Log-Normal } \\
\text { (anos) }\end{array}$ & $\begin{array}{c}\text { Tr } \\
\text { Gumbel } \\
\text { (anos) }\end{array}$ \\
\hline 2244048 & 165 & $\mathbf{2 7}$ & 700 & 170 \\
\hline 2245055 & 174,2 & $\mathbf{1 2 7}$ & 517 & 250 \\
\hline 2344009 & 205,7 & $\mathbf{7 4}$ & 62 & 67 \\
\hline 2345065 & 65,2 & $\mathbf{2}$ & 2 & 2 \\
\hline 2345067 & 155,3 & $\mathbf{5}$ & 5 & 5 \\
\hline 2345071 & 100,8 & $\mathbf{1 2}$ & 12 & 12 \\
\hline
\end{tabular}

A maior chuva foi observada na estação Alto da Serra do Mar, localizada na cabeceira da bacia. Apesar de o valor ser bastante elevado e equivalente ao maior valor já observado nessa estação, por não se tratar de um outlier, os Trs calculados através da distribuição empírica e os estimados através das distribuições Gumbel e Log-Normal são bem semelhantes. As distribuições estão bem ajustadas aos valores observados.

O mesmo não ocorre em Campos de Cunha e Estrada de Cunha, onde Trs calculados através das distribuições são mais elevados. Novamente deve-se ter cuidado na estimativa destes Trs. Dependendo da distribuição adotada, podem resultar em valores superestimados.

Nas estações São Luís do Paraitinga, Ponte Alta e Santa Branca as chuvas observadas em 2010 não correspondem às máximas históricas. Seus períodos de retorno foram idênticos, independente da distribuição adotada e variaram de 2 a 12 anos.

A distribuição de Gumbel foi a adotada para todas as estações. Esta escolha foi feita com base na estimativa dos períodos de retorno. 


\subsubsection{Teste de aderência de Kolmogorov-Smirnov (KS)}

Os resultados do teste de KS, adotado para o nível de significância de $\alpha=$ $10 \%$, que são apresentados na Tabela 23, indicam que as duas distribuições foram aderentes em todas as estações.

Tabela 23 - Resultados do Teste de KS para N > 40 e $\alpha=10 \%$

\begin{tabular}{|c|c|c|c|}
\hline \multicolumn{2}{|l|}{ Distribuição } & Log-Normal & Gumbel \\
\hline \multicolumn{4}{|c|}{2244048} \\
\hline \multicolumn{2}{|c|}{ Estatística do teste D max } & 0,1328 & 0,1219 \\
\hline $\mathrm{N}$ & 43 & \multicolumn{2}{|c|}{ Decisão } \\
\hline \begin{tabular}{|l|l|} 
Região Crítica para a & $10 \%$ \\
\end{tabular} & 0,1860 & Aceito $\mathrm{HO}$ & Aceito $\mathrm{HO}$ \\
\hline \multicolumn{4}{|c|}{2245055} \\
\hline \multicolumn{2}{|c|}{ Estatística do teste D max } & 0,1059 & 0,0948 \\
\hline $\mathrm{N}$ & 76 & \multicolumn{2}{|c|}{ Decisão } \\
\hline \begin{tabular}{|l|l|} 
Região Crítica para $\alpha$ & $10 \%$ \\
\end{tabular} & 0,1399 & Aceito $\mathrm{HO}$ & Aceito $\mathrm{HO}$ \\
\hline \multicolumn{4}{|c|}{2344009} \\
\hline \multicolumn{2}{|c|}{ Estatística do teste D max } & 0,0683 & 0,0769 \\
\hline $\mathrm{N}$ & 44 & \multicolumn{2}{|c|}{ Decisão } \\
\hline \begin{tabular}{|l|l|} 
Região Crítica para & $10 \%$ \\
\end{tabular} & 0,1839 & Aceito $\mathrm{HO}$ & Aceito $\mathrm{HO}$ \\
\hline \multicolumn{4}{|c|}{2345065} \\
\hline \multicolumn{2}{|c|}{ Estatística do teste D max } & 0,0771 & 0,0617 \\
\hline $\mathrm{N}$ & 76 & \multicolumn{2}{|c|}{ Decisão } \\
\hline \begin{tabular}{|l|l|} 
Região Crítica para $\alpha$ & $10 \%$ \\
\end{tabular} & 0,1399 & Aceito $\mathrm{HO}$ & Aceito $\mathrm{HO}$ \\
\hline \multicolumn{4}{|c|}{2345067} \\
\hline \multicolumn{2}{|c|}{ Estatística do teste D max } & 0,0835 & 0,09410 \\
\hline $\mathrm{N}$ & 74 & \multicolumn{2}{|c|}{ Decisão } \\
\hline \begin{tabular}{|l|l|} 
Região Crítica para $\alpha$ & $10 \%$ \\
\end{tabular} & 0,1418 & Aceito $\mathrm{HO}$ & Aceito $\mathrm{HO}$ \\
\hline \multicolumn{4}{|c|}{2345071} \\
\hline \multicolumn{2}{|c|}{ Estatística do teste D max } & 0,0630 & 0,0769 \\
\hline $\mathrm{N}$ & 56 & \multicolumn{2}{|c|}{ Decisão } \\
\hline \begin{tabular}{|l|l|} 
Região Crítica para $\alpha$ & $10 \%$ \\
\end{tabular} & 0,1630 & Aceito $\mathrm{HO}$ & Aceito $\mathrm{HO}$ \\
\hline
\end{tabular}

\subsubsection{Chuvas máximas históricas da região}

Para entender a magnitude dos eventos máximos diários registrados na região, as chuvas máximas calculadas por ano hidrológico foram plotadas em conjunto em um gráfico regional. Os dados de chuva máximas diárias de todas as estações podem ser visualizados na Figura 28. 


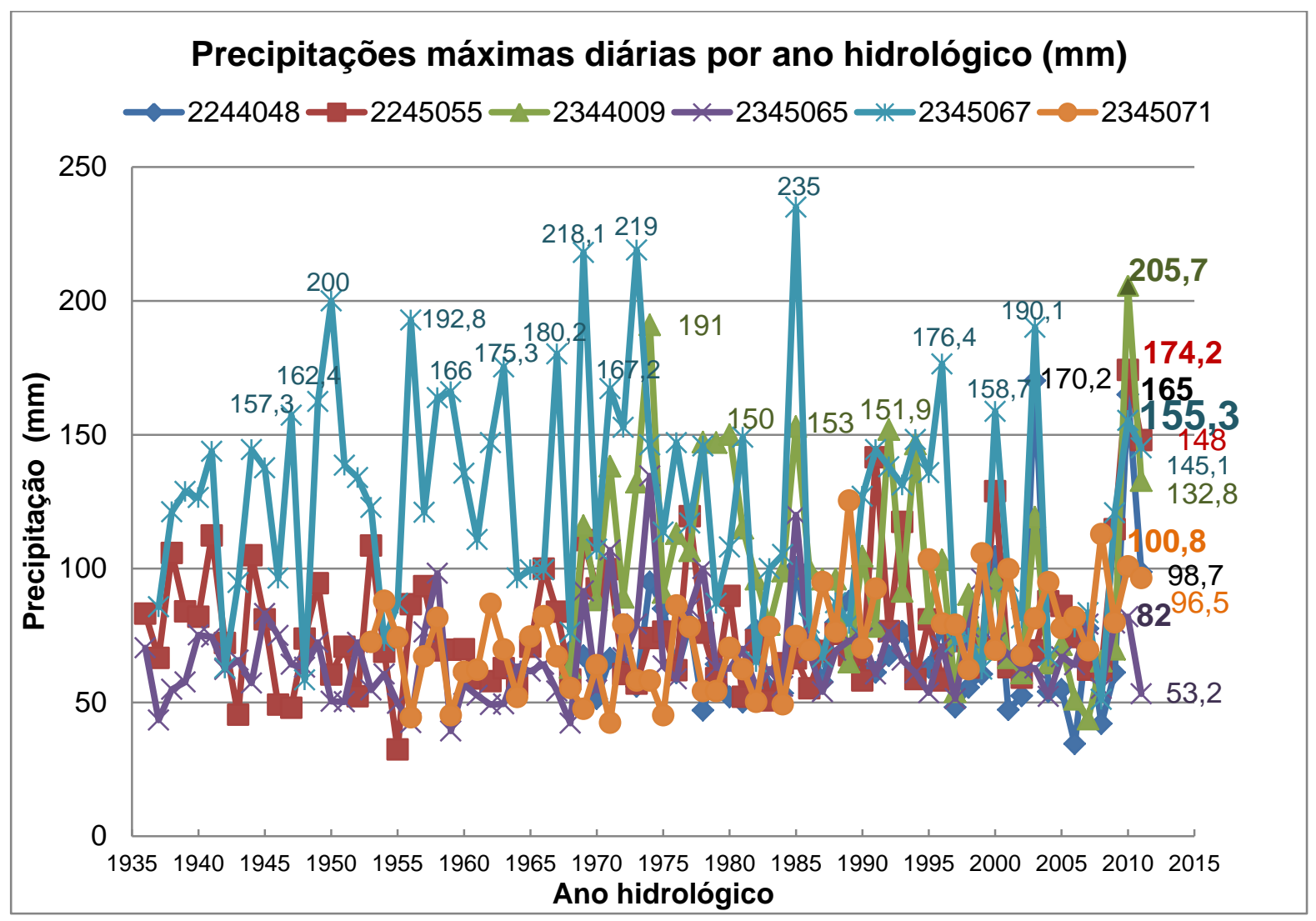

Figura 28 - Precipitações máximas diárias da região

Em janeiro de 2010 a chuva máxima foi observada na estação Alto da Serra do Mar, que corresponde também à máxima histórica dessa estação.

A estação mais chuvosa é Ponte Alta I, localizada na cabeceira da bacia. Muitos valores elevados já foram observados desde 1937, ano em que se iniciaram as leituras nesse posto.

Por outro lado, a estação menos chuvosa é São Luís do Paraitinga, que teve sua máxima histórica no ano de 1974, correspondente a 134,6 mm.

No ano de 2011 as chuvas máximas diárias ficaram abaixo de 150 mm, em todas as estações.

Apesar do alto volume precipitado em janeiro de 2010, nota-se na Figura 28 que estes eventos são característicos da região. Muitos valores elevados já foram registrados nos postos utilizados, principalmente nas estações Alto da Serra do Mar (2344009) e Ponte Alta I (2345067), localizadas na cabeceira da bacia, na Serra do Mar. A máxima histórica da região foi registrada no ano de 1985 em Ponte Alta I, no município de São Luís do Paraitinga, onde choveu $235 \mathrm{~mm}$. 
Foi feito o resumo das cinco maiores chuvas diárias registradas em cada posto e o ano hidrológico em que ocorreram. Dados na Tabela 24.

Tabela 24 - Os cinco maiores eventos diários de precipitação $(\mathrm{em} \mathrm{mm}$ ) registrados nas estações do Vale do Paraíba

\begin{tabular}{|c|c|c|c|c|c|}
\hline Ano & P max diária & Ano & P max diária & Ano & P max diária \\
\hline & $\mathbf{2 2 4 4 0 4 8}$ & \multicolumn{2}{c|}{$\mathbf{2 2 4 5 0 5 5}$} & \multicolumn{2}{c|}{$\mathbf{2 3 4 4 0 0 9}$} \\
\hline 2003 & 170,2 & 2010 & 174,2 & 2010 & 205,7 \\
\hline 2010 & 165 & 2011 & 148 & 1974 & 191 \\
\hline 2000 & 104,5 & 1991 & 141,6 & 1985 & 153 \\
\hline 1985 & 100,4 & 2000 & 128,9 & 1992 & 151,9 \\
\hline 2011 & 98,7 & 1977 & 119,6 & 1980 & 150 \\
\hline & $\mathbf{2 3 4 5 0 6 5}$ & & $\mathbf{2 3 4 5 0 6 7}$ & & $\mathbf{2 3 4 5 0 7 1}$ \\
\hline 1974 & 134,6 & 1985 & 235 & 1989 & 125,4 \\
\hline 1985 & 120 & 1973 & 219 & 2008 & 112,9 \\
\hline 1971 & 106,9 & 1969 & 218,1 & 1999 & 105,7 \\
\hline 1978 & 100 & 1950 & 200 & 1995 & 103,4 \\
\hline 1958 & 98,2 & 1956 & 192,8 & 2010 & 100,8 \\
\hline
\end{tabular}

Verifica-se que o ano hidrológico de 2009/2010 foi o mais chuvoso em duas das seis estações.

Os anos de 1973/1974, 1984/1985, 1988/1989 e 2002/2003 foram os mais chuvosos nas demais estações.

Os anos de 1974, 1985, 2000 e 2011 foram chuvosos em pelo menos duas estações.

Segundo informações do irmão da observadora de São Luís do Paraitinga, Sr. Claudio Coelho, destacam-se as enchentes ocorridas nos anos de 1863, 1969, 1985, 1996 e 2010, sendo a de 2010 a maior delas. De acordo com a Tabela 24, chuvas elevadas foram observadas nas estações: Ponte Alta I, no ano de 1969, e Santa Branca, em 1995. No ano de 1985, foram observados valores elevados em quatro das seis estações: Ponte Alta I, Alto da Serra do Mar, São Luís do Paraitinga e Campos de Cunha. Nas estações: Alto da Serra do Mar, Estrada de Cunha, Campos de Cunha e Santa Branca as chuvas foram elevadas no ano de 2010. Portanto, os dados confirmam as cheias informadas pelo morador de São Luís. 


\subsubsection{Precipitações Máximas Acumuladas para diferentes durações}

Foram acumuladas as máximas chuvas para as durações de 1 a 10 dias, 15, 20, 30 e 45 dias. O cálculo foi feito através da chuva acumulada móvel para as diferentes durações e o intervalo considerado foi o ano hidrológico. Em seguida, as séries das máximas para as diferentes durações foram plotadas nos gráficos da Figura 29.

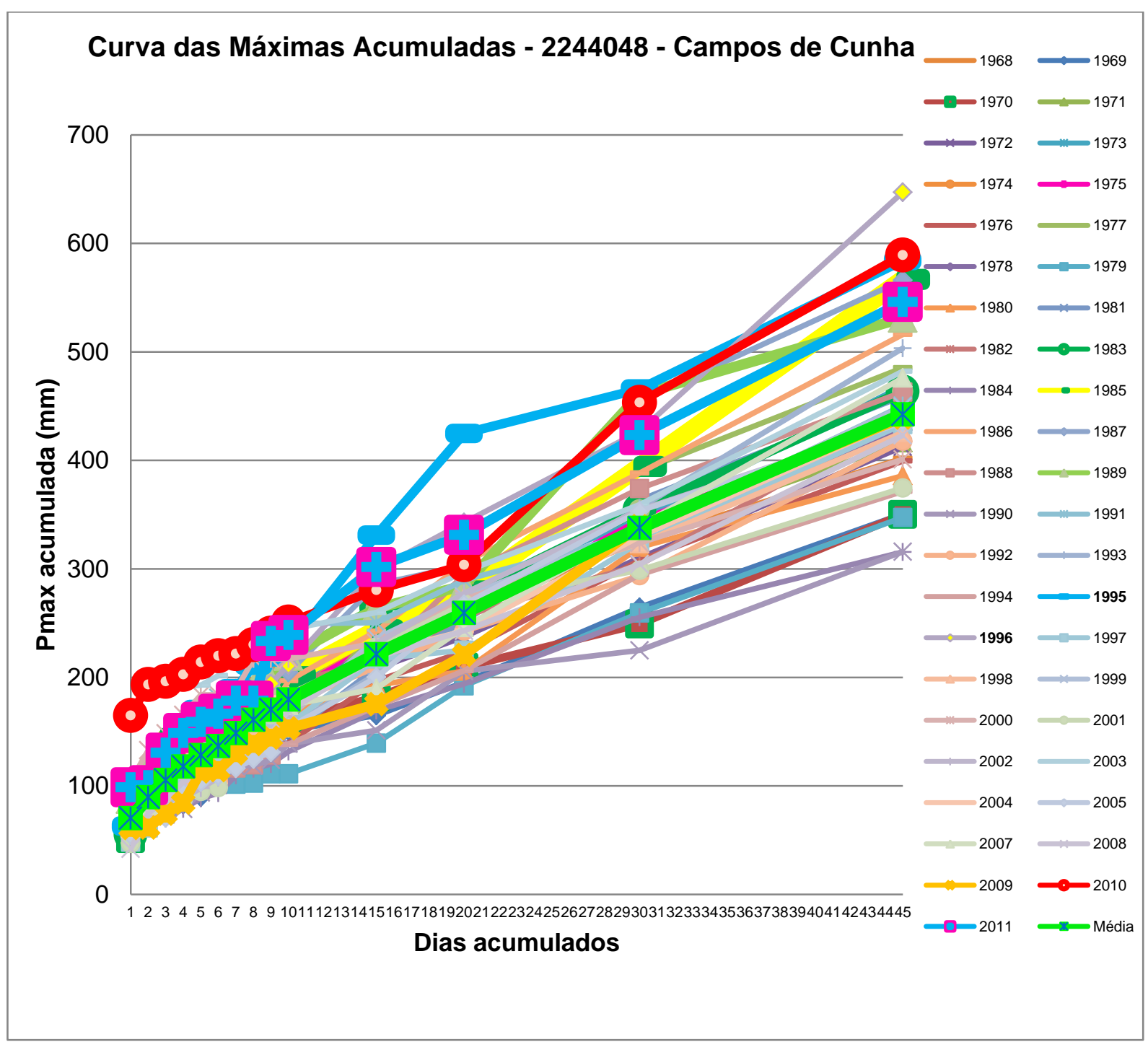

Figura 29- Curvas das máximas acumuladas para as durações de 1 a 10 dias, 15, 20, 30 e 45 dias (continua) 


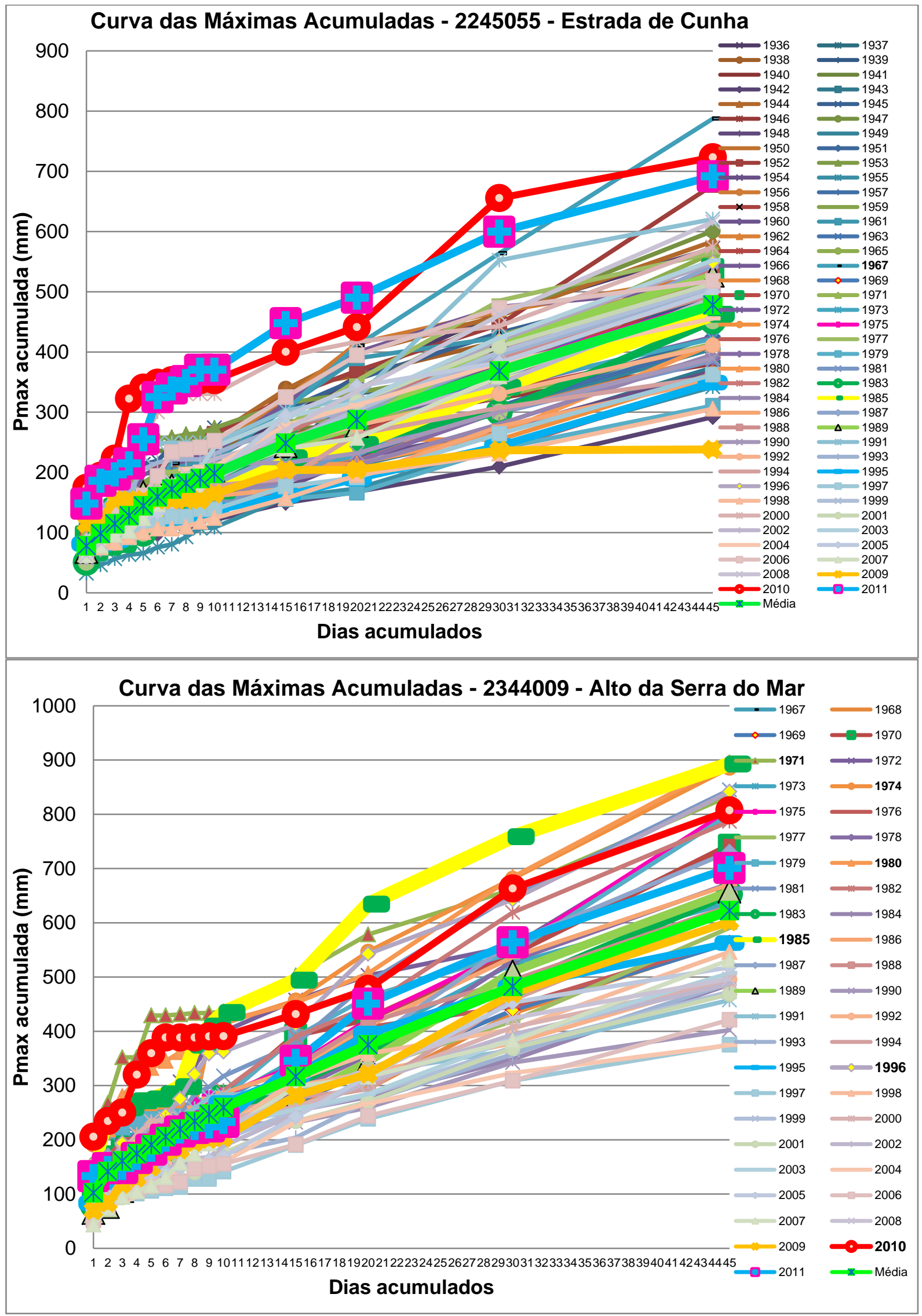

Figura 29- Curvas das máximas acumuladas para as durações de 1 a 10 dias, 15, 20, 30 e 45 dias (continua) 


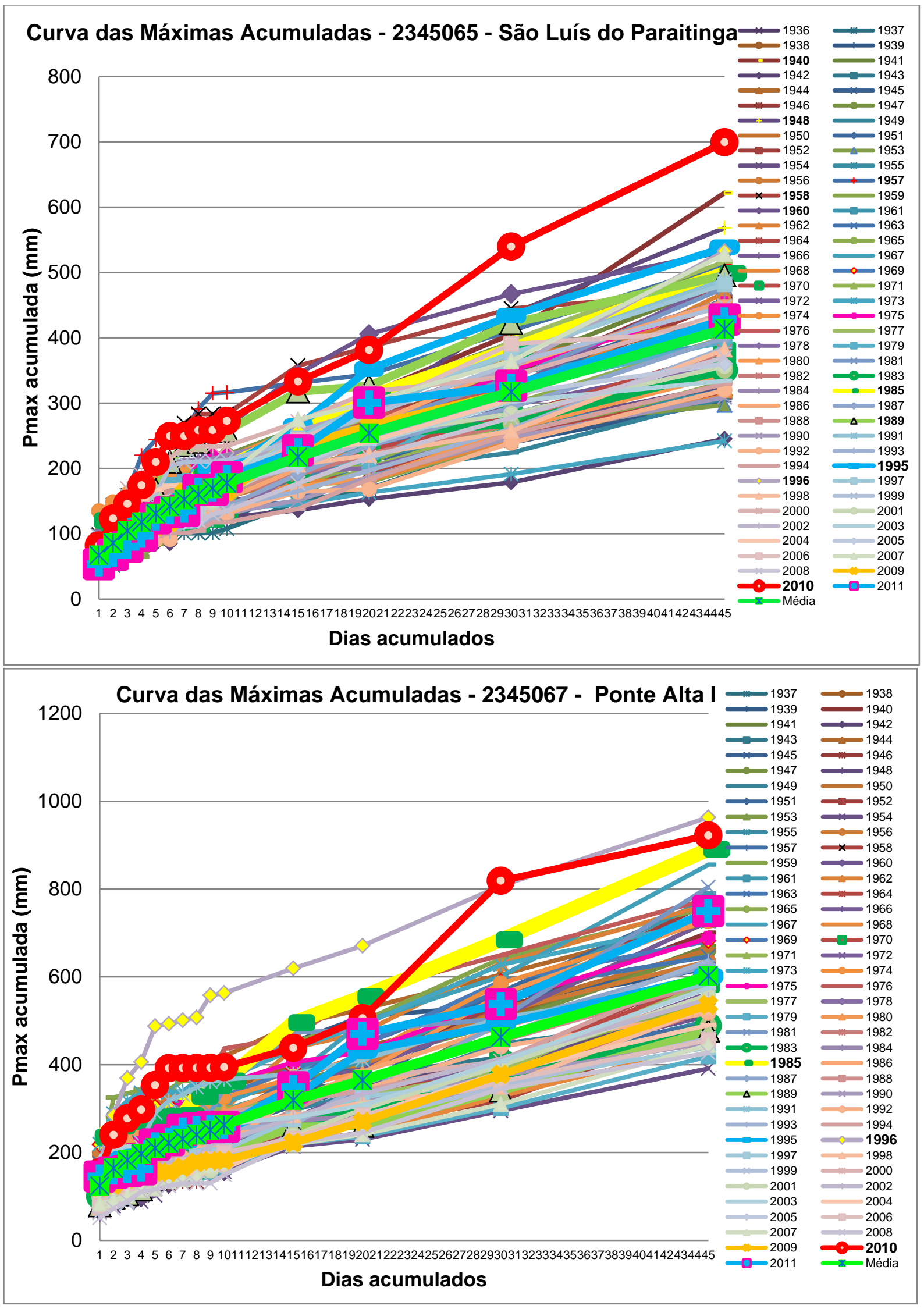

Figura 29 - Curvas das máximas acumuladas para as durações de 1 a 10 dias, 15, 20, 30 e 45 dias (continua) 


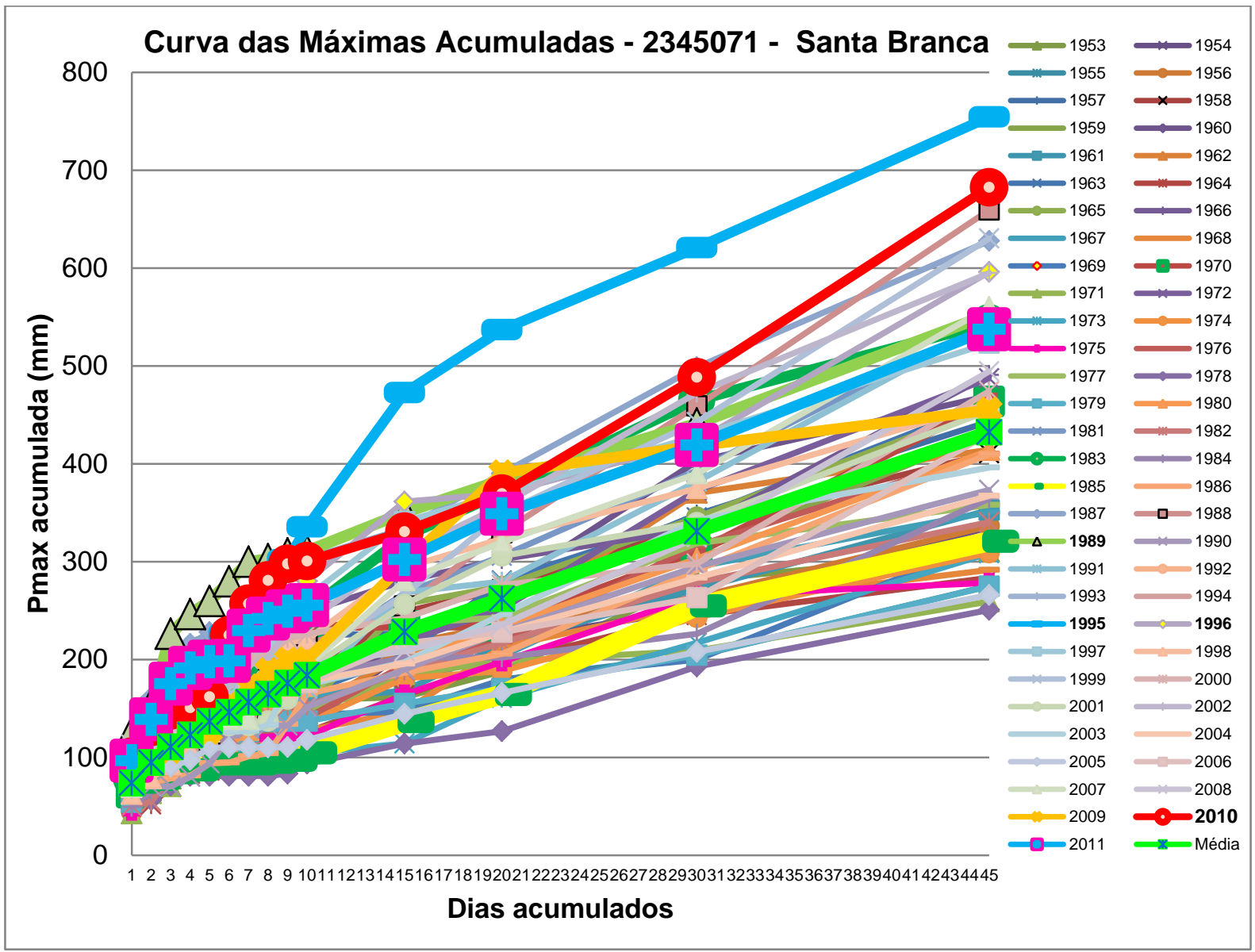

Figura 29 - Curvas das máximas acumuladas para as durações de 1 a 10 dias, 15, 20, 30 e 45 dias

Através dos gráficos das curvas acumuladas, nota-se que o ano de 2010 é o que exibe chuvas diárias elevadas em todas as estações, com volumes acumulados também bastante expressivos para durações maiores que um dia.

As chuvas diárias de 2010 foram elevadas, principalmente nas estações Alto da Serra do Mar, Campos de Cunha, Estrada de Cunha e Ponte Alta I, localizadas nas cabeceiras da bacia.

Quando analisamos as chuvas diárias ocorridas nas estações São Luís do Paraitinga e em Santa Branca no ano de 2010, os valores não são tão elevados. Porém, as chuvas acumuladas para durações maiores que 5 dias são bastante expressivas. Em São Luís as chuvas acumuladas no intervalo de 30 e 45 dias são os maiores valores da série histórica. Na década de 40 e 50 também foram observados volumes acumulados elevados em São Luís do Paraitinga.

Em Ponte Alta I, os volumes acumulados nos anos de 1985, 1996 e 2010 foram bastante elevados, coincidindo com a informação dos anos das grandes 
cheias ocorridas em SLP. Em fevereiro de 1996, em apenas cinco dias, dos dias 11 a 15 , choveu $487,6 \mathrm{~mm}(81,4 \mathrm{~mm}, 36,8 \mathrm{~mm}, 174,6 \mathrm{~mm}, 108,6 \mathrm{~mm}$ e $84,4 \mathrm{~mm}$, respectivamente).

Em Santa Branca, localizada a jusante de São Luís do Paraitinga, destacamse os volumes acumulados nos anos de 1995 e 2010.

No ano de 2011, as chuvas acumuladas também foram bastante elevadas em Campos de Cunha e Estrada de Cunha. Esse evento coincide com as chuvas ocorridas nas estações localizadas na região Serrana do Rio de Janeiro, em janeiro de 2011, que provocaram escorregamentos e um dos maiores desastres naturais nesta região.

\subsubsection{Classificação das chuvas utilizando o SPI}

O cálculo dos limiares de precipitação foi feito para cada uma das estações pluviométricas, adotando-se a distribuição de probabilidades de Gumbel ajustada para as chuvas máximas anuais para diferentes durações.

Como nas demais regiões, adotou-se os intervalos de duração de 1 dia, 2, 3, 4 e 5 dias.

As Tabelas e Figuras que seguem ilustram os limiares para a duração de 1 dia. Os resultados obtidos para as durações de 2 a 5 dias podem ser visualizados no Anexo III.

Tabela 25 - 2244048 - Campos de Cunha - Chuvas máximas anuais com duração de 1 dia

\begin{tabular}{|c|c|c|c|c|c|c|}
\hline Classe de PMDA & \multicolumn{2}{|c|}{ SPI } & $\mathbf{p}$ (inf.) & $\mathbf{p}$ (sup.) & T (anos) & P 1 dia (mm) \\
\hline Chuva Fraca (CF) & & 0 & & 0,500 & $\leq 2$ & $\leq 66,8$ \\
\hline Chuva Leve (CL) & 0 & 1 & 0,500 & 0,841 & $2<\mathrm{T} \leq 6,3$ & $66,8<\mathrm{T} \leq 95,4$ \\
\hline Chuva Moderada (CM) & 1 & 1,5 & 0,841 & 0,933 & $6,3<\mathrm{T} \leq 15$ & $95,4<\mathrm{T} \leq 114,3$ \\
\hline Chuva Severa (CS) & 1,5 & 2 & 0,933 & 0,977 & $15<\mathrm{T} \leq 44$ & $114,3<\mathrm{T} \leq 136,9$ \\
\hline Chuva Extrema (CE) & 2 & & 0,977 & & $>44$ & $>136,9$ \\
\hline
\end{tabular}




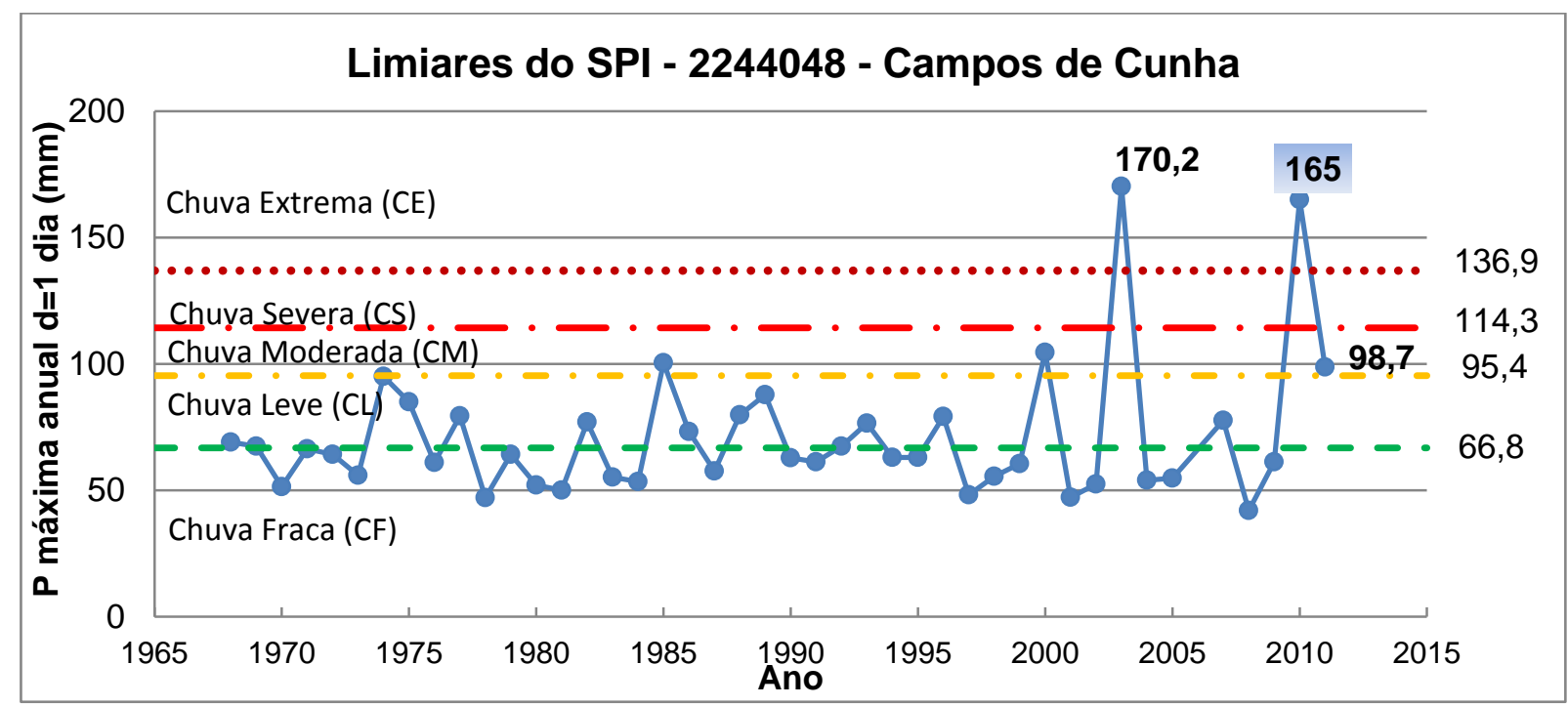

Figura 30 - Classificação das chuvas máximas de duração de 1 dia - 2244048 - Campos de Cunha

Em Campos de Cunha a chuva de janeiro de 2010 pode ser classificada como chuva extrema.

Tabela 26 - SPI - 2245055 - Estrada de Cunha - Chuvas máximas anuais com duração de 1 dia

\begin{tabular}{|c|c|c|c|c|c|c|}
\hline Classe de PMDA & \multicolumn{2}{|c|}{ SPI } & $\mathbf{p}$ (inf.) & $\mathbf{p}$ (sup.) & $\mathbf{T}$ (anos) & P 1 dia (mm) \\
\hline Chuva Fraca (CF) & & 0 & & 0,500 & $\leq 2$ & $\leq 73,7$ \\
\hline Chuva Leve (CL) & 0 & 1 & 0,500 & 0,841 & $2<\mathrm{T} \leq 6,3$ & $73,7<\mathrm{T} \leq 100,8$ \\
\hline Chuva Moderada (CM) & 1 & 1,5 & 0,841 & 0,933 & $6,3<\mathrm{T} \leq 15$ & $100,8<\mathrm{T} \leq 118,7$ \\
\hline Chuva Severa (CS) & 1,5 & 2 & 0,933 & 0,977 & $15<\mathrm{T} \leq 44$ & $118,7<\mathrm{T} \leq 140,2$ \\
\hline Chuva Extrema (CE) & 2 & & 0,977 & & $>44$ & $>140,2$ \\
\hline
\end{tabular}

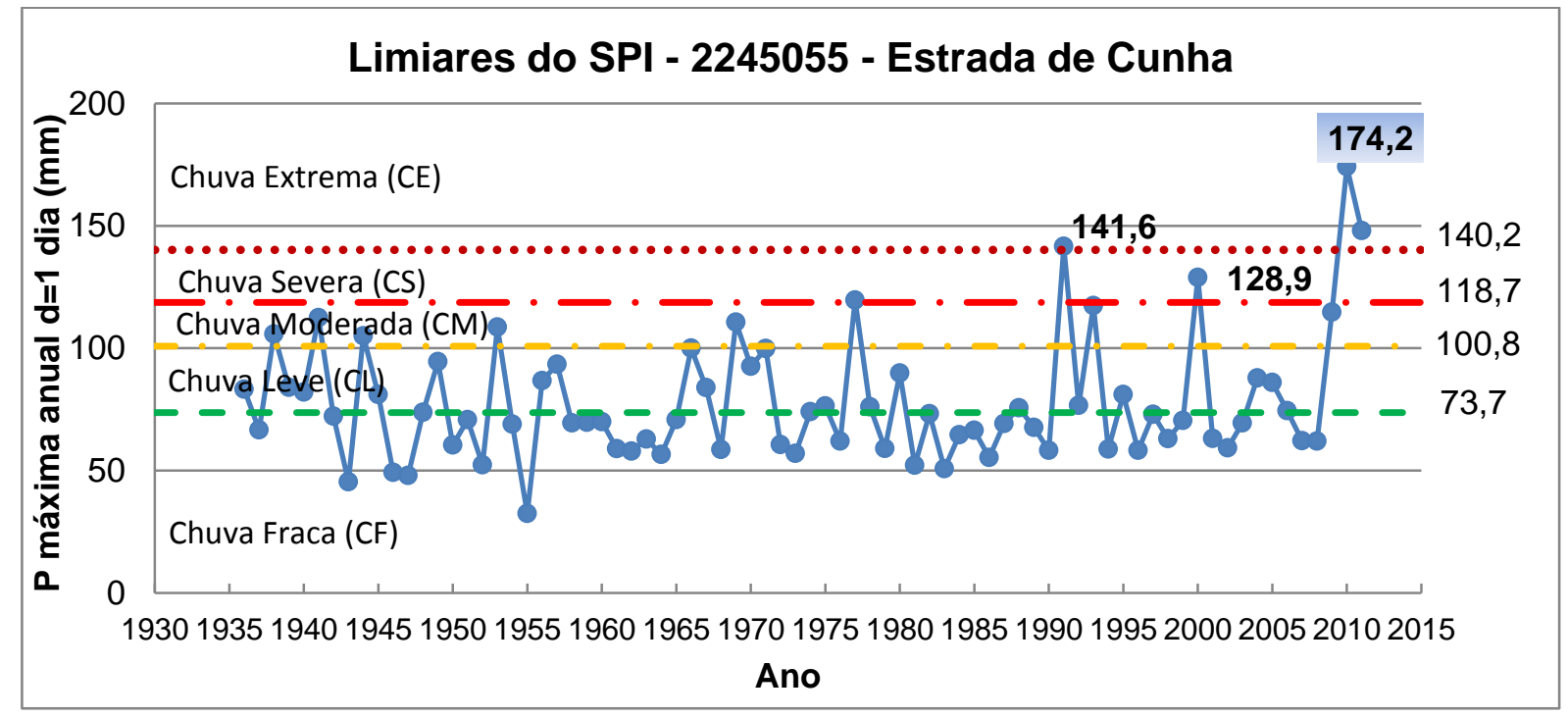

Figura 31 - Classificação das chuvas máximas de duração de 1 dia - 2245055 - Estrada de Cunha 
Em Estrada de Cunha e Alto da Serra do Mar a os valores observados em janeiro de 2010 também podem ser classificados como chuvas extremas.

Tabela 27 - SPI - 2344009 - Alto da Serra do Mar - chuvas máximas anuais com duração de 1 dia

\begin{tabular}{|c|c|c|c|c|c|c|}
\hline Classe de PMDA & \multicolumn{2}{|c|}{ SPI } & p (inf.) & p (sup.) & T (anos) & P 1 dia (mm) \\
\hline Chuva Fraca (CF) & & 0 & & 0,500 & $\leq 2$ & $\leq 96,1$ \\
\hline Chuva Leve (CL) & 0 & 1 & 0,500 & 0,841 & $2<\mathrm{T} \leq 6,3$ & $96,1<\mathrm{T} \leq 135,9$ \\
\hline Chuva Moderada (CM) & 1 & 1,5 & 0,841 & 0,933 & $6,3<\mathrm{T} \leq 15$ & $135,9<\mathrm{T} \leq 162,3$ \\
\hline Chuva Severa (CS) & 1,5 & 2 & 0,933 & 0,977 & $15<\mathrm{T} \leq 44$ & $162,3<\mathrm{T} \leq 193,8$ \\
\hline Chuva Extrema (CE) & 2 & & 0,977 & & $>44$ & $>193,3$ \\
\hline
\end{tabular}

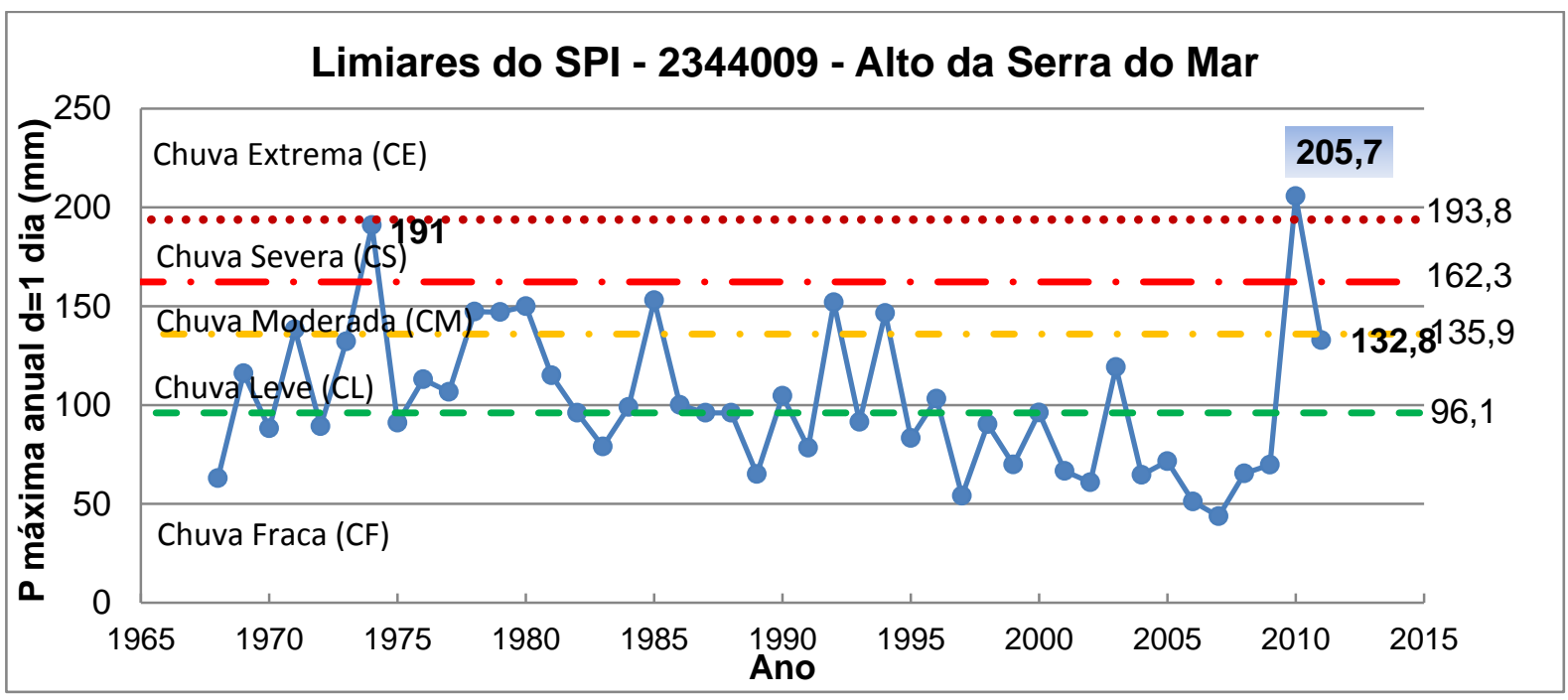

Figura 32 - Classificação das chuvas máximas de duração de 1 dia - 2344009 - Alto da Serra do Mar

Tabela 28 - SPI - 2345065 - São Luís do Paraitinga - chuvas máximas anuais com duração de 1 dia

\begin{tabular}{|c|c|c|c|c|c|c|}
\hline Classe de PMDA & \multicolumn{2}{|c|}{ SPI } & p (inf.) & p (sup.) & T (anos) & P 1 dia (mm) \\
\hline Chuva Fraca (CF) & & 0 & & 0,500 & $\leq 2$ & $\leq 64,2$ \\
\hline Chuva Leve (CL) & 0 & 1 & 0,500 & 0,841 & $2<\mathrm{T} \leq 6,3$ & $64,2<\mathrm{T} \leq 82,5$ \\
\hline Chuva Moderada (CM) & 1 & 1,5 & 0,841 & 0,933 & $6,3<\mathrm{T} \leq 15$ & $82,5<\mathrm{T} \leq 94,5$ \\
\hline Chuva Severa (CS) & 1,5 & 2 & 0,933 & 0,977 & $15<\mathrm{T} \leq 44$ & $94,5<\mathrm{T} \leq 109,0$ \\
\hline Chuva Extrema (CE) & 2 & & 0,977 & & $>44$ & $>109,0$ \\
\hline
\end{tabular}

Já nas estações localizadas no município de São Luís do Paraitinga, a chuva observada em novembro de 2009 e em janeiro de 2010 são classificadas como chuvas leves, assim como a observada em 2010 em Ponte Alta I. 


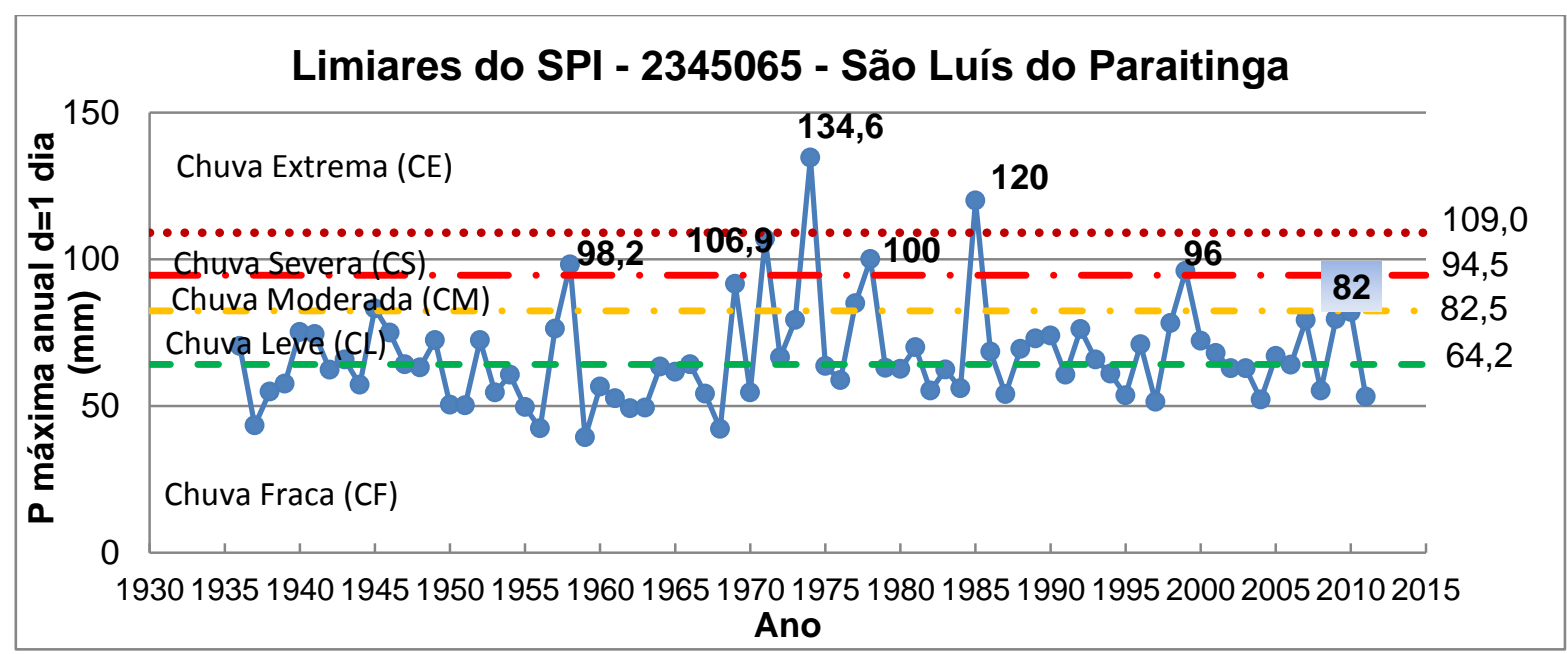

Figura 33 - Classificação das chuvas máximas de duração de 1 dia - 2345065 - São Luís do Paraitinga

Tabela 29 - SPI - 2345067 - Ponte Alta I - Chuvas máximas anuais com duração de 1 dia

\begin{tabular}{|c|c|c|c|c|c|c|}
\hline Classe de PMDA & \multicolumn{2}{|c|}{ SPI } & p (inf.) & p (sup.) & T (anos) & P 1 dia (mm) \\
\hline Chuva Fraca (CF) & & 0 & & 0,500 & $\leq 2$ & $\leq 117,0$ \\
\hline Chuva Leve (CL) & 0 & 1 & 0,500 & 0,841 & $2<\mathrm{T} \leq 6,3$ & $117,0<\mathrm{T} \leq 162,5$ \\
\hline Chuva Moderada (CM) & 1 & 1,5 & 0,841 & 0,933 & $6,3<\mathrm{T} \leq 15$ & $162,5<\mathrm{T} \leq 192,6$ \\
\hline Chuva Severa (CS) & 1,5 & 2 & 0,933 & 0,977 & $15<\mathrm{T} \leq 44$ & $192,6<\mathrm{T} \leq 228,6$ \\
\hline Chuva Extrema (CE) & 2 & & 0,977 & & $>44$ & $>228,6$ \\
\hline
\end{tabular}

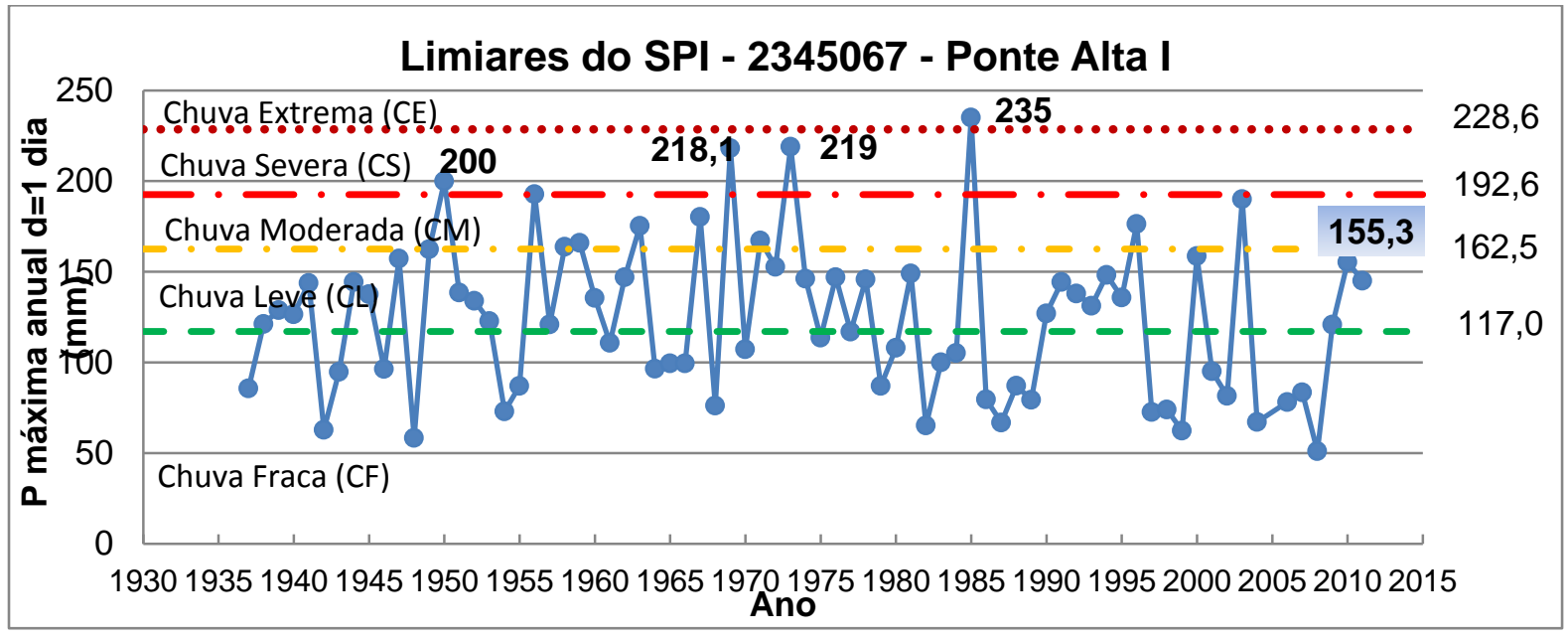

Figura 34 - Classificação das chuvas máximas de duração de 1 dia - 2345067 - Ponte Alta I

Em Santa Branca, a chuva de janeiro de 2010 foi classificada como moderada. 
Tabela 30 - SPI - 2245071 - Santa Branca - Chuvas máximas anuais com duração de 1 dia

\begin{tabular}{|c|c|c|c|c|c|c|}
\hline Classe de PMDA & \multicolumn{2}{|c|}{ SPI } & $\mathbf{p}$ (inf.) & $\mathbf{p}$ (sup.) & T (anos) & P 1 dia (mm) \\
\hline Chuva Fraca (CF) & & 0 & & 0,500 & $\leq 2$ & $\leq 70,7$ \\
\hline Chuva Leve (CL) & 0 & 1 & 0,500 & 0,841 & $2<\mathrm{T} \leq 6,3$ & $70,7<\mathrm{T} \leq 90,6$ \\
\hline Chuva Moderada (CM) & 1 & 1,5 & 0,841 & 0,933 & $6,3<\mathrm{T} \leq 15$ & $90,6<\mathrm{T} \leq 103,7$ \\
\hline Chuva Severa (CS) & 1,5 & 2 & 0,933 & 0,977 & $15<\mathrm{T} \leq 44$ & $103,7<\mathrm{T} \leq 119,4$ \\
\hline Chuva Extrema (CE) & 2 & & 0,977 & & $>44$ & $>119,4$ \\
\hline
\end{tabular}

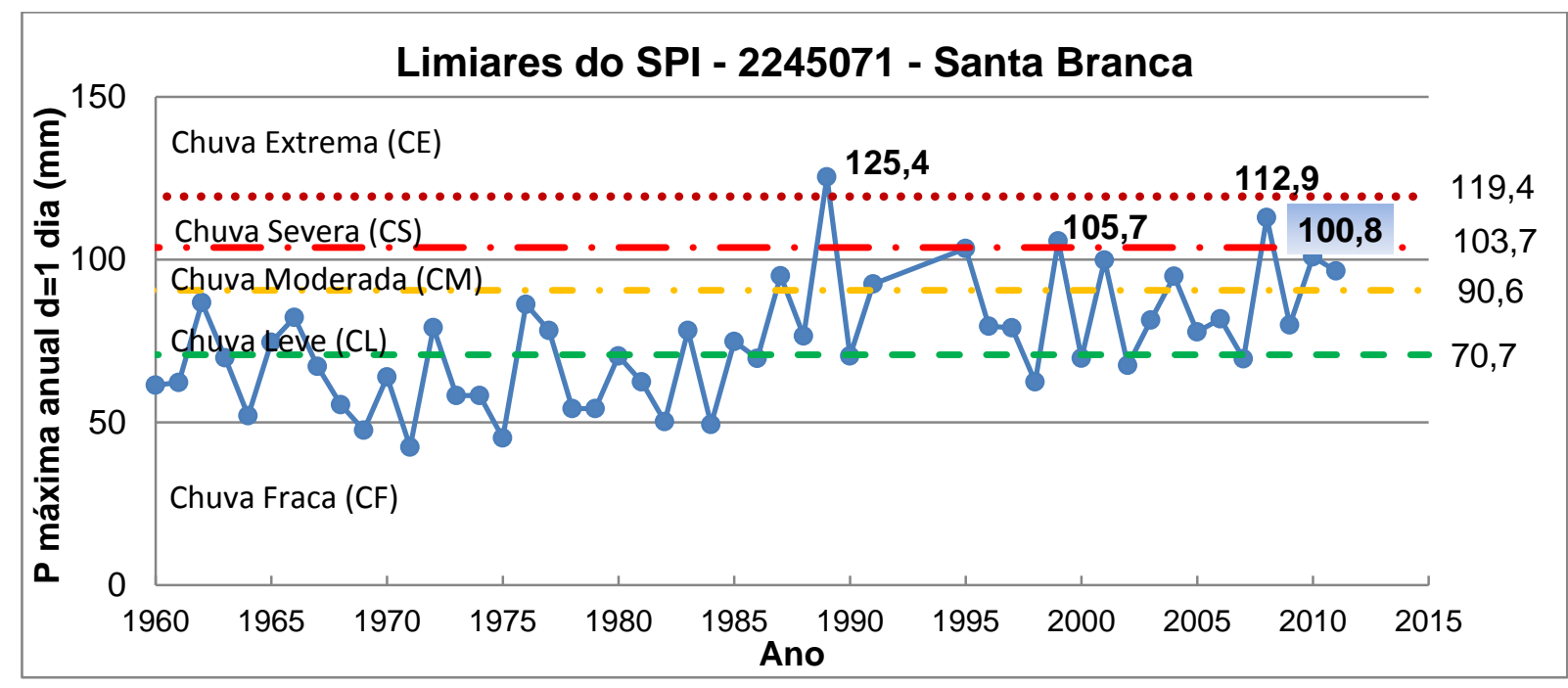

Figura 35 - Classificação das chuvas máximas de duração de 1 dia - 2245071 - Santa Branca

\subsubsection{Conclusões}

Em janeiro de 2010, na estação localizada em São Luís do Paraitinga, as chuvas não foram tão elevadas, chegando a $67,4 \mathrm{~mm}$ no dia 1, quando ocorreu a inundação. No ano hidrológico de 2009/2010, a máxima chuva observada nessa estação foi $82 \mathrm{~mm}$ no dia 9 de dezembro de 2009. A chuva nessa estação foi classificada como chuva leve.

As chuvas observadas em janeiro de 2010 em Ponte Alta I, São Luís do Paraitinga e Santa Branca possuem frequência elevada, com períodos de retorno entre 2 e 12 anos. O mesmo não ocorre nas estações Campos de Cunha, Estrada de Cunha e Alto da Serra do Mar, localizadas na cabeceira da bacia. Nessas estações as chuvas são de baixa frequência, com elevados períodos de retorno, 
variando de 67 a 250 anos, estimados através de distribuição de Gumbel. A Tabela 22 ilustra os períodos de retorno estimados.

Nota-se na Figura 28 que muitos valores elevados já foram registrados nos postos utilizados, principalmente nas estações Alto da Serra do Mar (2344009) e Ponte Alta I (2345067), localizadas na cabeceira da bacia, na Serra do Mar. A máxima histórica da região foi registrada no ano de 1985 em Alto da Serra do Mar, no município de Cunha, onde choveu $235 \mathrm{~mm}$.

Quando as chuvas acumuladas são analisadas, observa-se um alto volume precipitado, que pode ter contribuído para a saturação do solo e posteriores inundações ocorridas no dia 1 de janeiro de 2010.

Nas estações localizadas na cabeceira da bacia, as chuvas diárias de janeiro de 2010 foram classificadas como chuvas extremas. O mesmo não ocorreu nas estações localizadas em São Luís do Paraitinga e Santa Branca, onde as chuvas diárias foram classificadas como leves ou moderadas. Para durações superiores a 2 dias, as chuvas de São Luís do Paraitinga são classificadas como severas e na duração de 5 dias elas são consideradas chuvas extremas, como ilustrado no Anexo III. Percebe-se que a região está sujeita a eventos severos com verta recorrência, como em Ponte Alta I.

O alto volume precipitado na cabeceira da bacia, onde se observou $205,7 \mathrm{~mm}$ na estação Alto da Serra do Mar, combinado à precipitação acumulada nos dias que antecedem o evento, originou as inundações nos municípios de Cunha e São Luís do Paraitinga. Nas demais estações localizadas na cabeceira as chuvas também foram elevadas. Em Estrada de Cunha choveu 174,2 mm e em Campos de Cunha $165 \mathrm{~mm}$ no dia 1 de janeiro. Nestas duas estações as chuvas foram classificadas como chuvas extremas em todas as durações consideradas (de 1 a 5 dias), como monstra o Anexo III.

Este caso caracteriza a criticidade da distribuição espacial das chuvas.

As chuvas diárias elevadas observadas na cabeceira da bacia, assim como os meses chuvosos no ano de 2009, o alto volume acumulado e as condições de relevo contribuíram para a catástrofe observada na região. Os danos observados decorrem da ocupação da planície de inundação. 


\subsection{VALE DOS RIOS MUNDAÚ E PARAÍBA}

$\mathrm{Na}$ região Nordeste, os desastres naturais mais comuns são os de caráter hidrometeorológico, como as estiagens e as inundações, estas relacionadas a eventos extremos de precipitação. Dentre a combinação dos diversos fatores que causam esses desastres podem ser destacados a ausência ou o excesso de chuva como agente desencadeador das secas ou inundações em locais e comunidades vulneráveis.

Os desastres relacionados ao excesso de precipitação têm sido bastante frequentes, principalmente nos Estados de Pernambuco e Alagoas. Nos Estados de Pernambuco e Alagoas, nos anos de 2010, 2011 e 2012, ocorreram inundações que atingiram principalmente populações instaladas nas margens de rios. As inundações tiveram relação direta com as precipitações elevadas diárias e/ou chuvas acumuladas em maiores períodos de tempo. Esses eventos acontecem principalmente nos meses de maio, junho e julho, que correspondem à estação chuvosa da região.

Em junho de 2010, as chuvas que atingiram a região causaram inundações em diversos municípios localizados nas bacias dos rios Mundaú e Paraíba. Este evento é considerado o mais intenso observado nessas bacias. Segundo dados da SEDEC - Secretaria Nacional da Defesa Civil, 95 municípios foram atingidos. Em Alagoas, quatro municípios decretaram situação de emergência, 15 em estado de calamidade pública. No Estado de Pernambuco, 27 decretaram situação de emergência, 12 em estado de calamidade pública. As inundações deixaram 57 vítimas fatais e mais de 157.000 pessoas desabrigadas ou desalojadas.

Dentre as cidades alagoanas atingidas estão Branquinha, Murici, Rio Largo Santana do Mundaú, São José da Laje e União dos Palmares, na bacia hidrográfica do Mundaú, Atalaia, Capela, Paulo Jacinto, Quebrangulo e Viçosa e na bacia do Paraíba.

O cenário de destruição pode ser visualizado na Figura 36 , que mostra algumas cidades atingidas pelas inundações. 


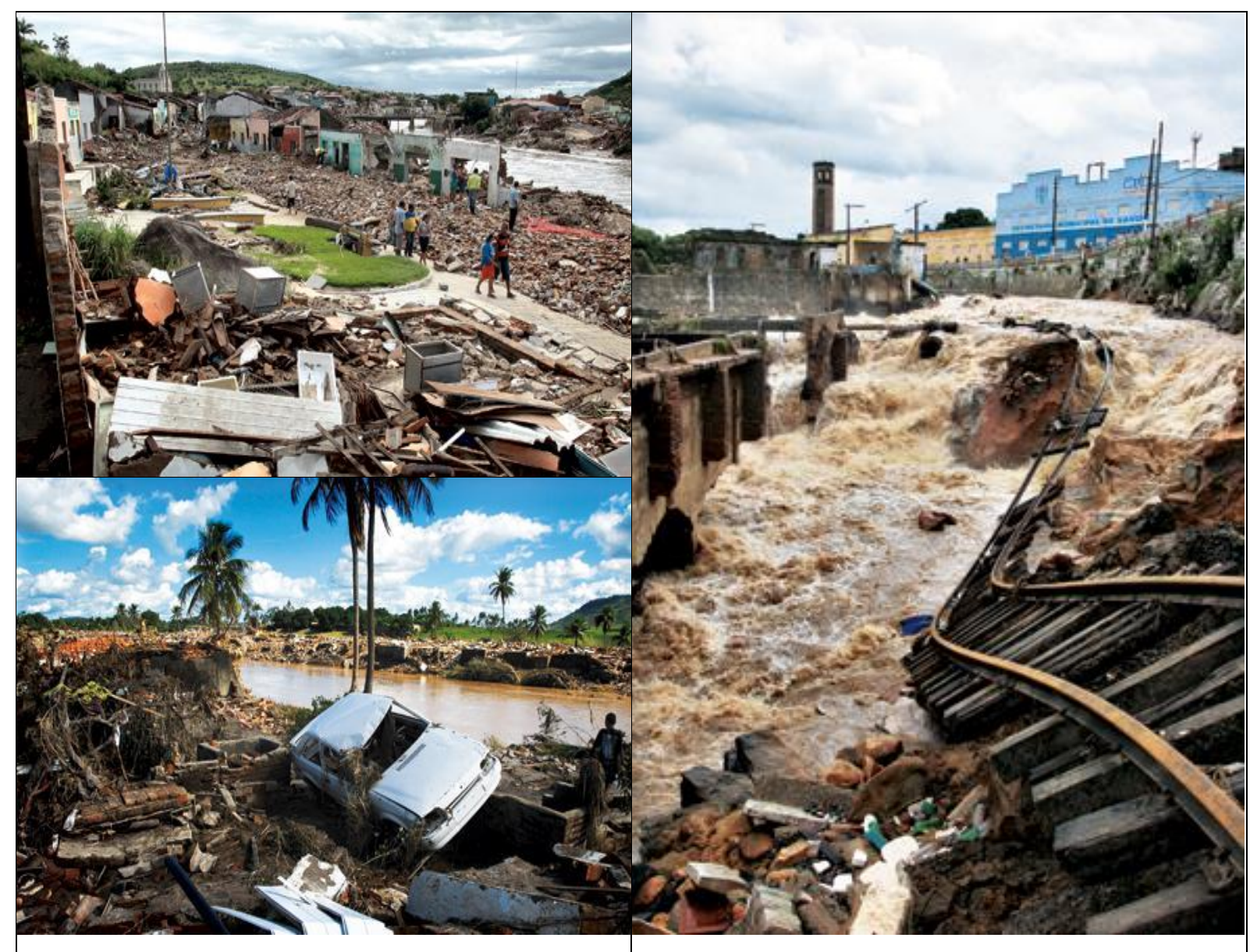

Figura 36 - Cenário de destruição em Quebrangulo (acima à esquerda) e União dos Palmares (abaixo à esquerda e à direita) (Fonte: Revista Isto é)

Segundo Fragoso Jr., Pedrosa e Souza (2010), ocorreram sete grandes inundações nas bacias do Mundaú e Paraíba: 1914, 1941, 1969, 1988, 1989, 2000 e 2010, com destaque para as catástrofes de 1969 tendo em vista o número de mortos, mais de 1.100 .

Em maio de 2011, novamente Pernambuco e Alagoas sofrem com as inundações. Na zona da mata pernambucana e na região metropolitana ocorreu o transbordamento de rios como o Una, Capibaribe, Pirangí e Mundaú, atingindo 45 municípios. Mesmo com volumes precipitados elevados, segundo o alerta da SEMARH no dia 02 de maio de 2012 os níveis dos rios Mundaú e Paraíba não apresentavam elevações significativas e continuariam estáveis nas estações monitoradas no estado de Alagoas. As chuvas mais intensas atingiram o litoral Norte de Alagoas, os municípios de Jacuípe, Jundiá, Campestre e Novo Lino e o estado de Pernambuco. 


\subsubsection{Descrição da área de estudo e estações pluviométricas utilizadas}

A bacia hidrográfica do Mundaú possui área de aproximadamente $4.290 \mathrm{~km}^{2} \mathrm{e}$ tem como rio principal o rio Mundaú, com sua nascente no município de Garanhuns $(P E)$ e sua foz na Lagoa Mundaú (AL). Seu afluente mais importante é o rio Canhoto. Abrange 30 municípios, 15 em Pernambuco e 15 em Alagoas.

A bacia hidrográfica do Paraíba possui como rio principal o Paraíba. Tem sua nascente no município de Saloá, localizado em Pernambuco, na parte superior da bacia, atravessa o estado de Alagoas e deságua na Lagoa Manguaba. Possui área de aproximadamente $3.138 \mathrm{~km}^{2}$ e drena 8 municípios pernambucanos e 17 alagoanos. Ver Figura 37 abaixo.

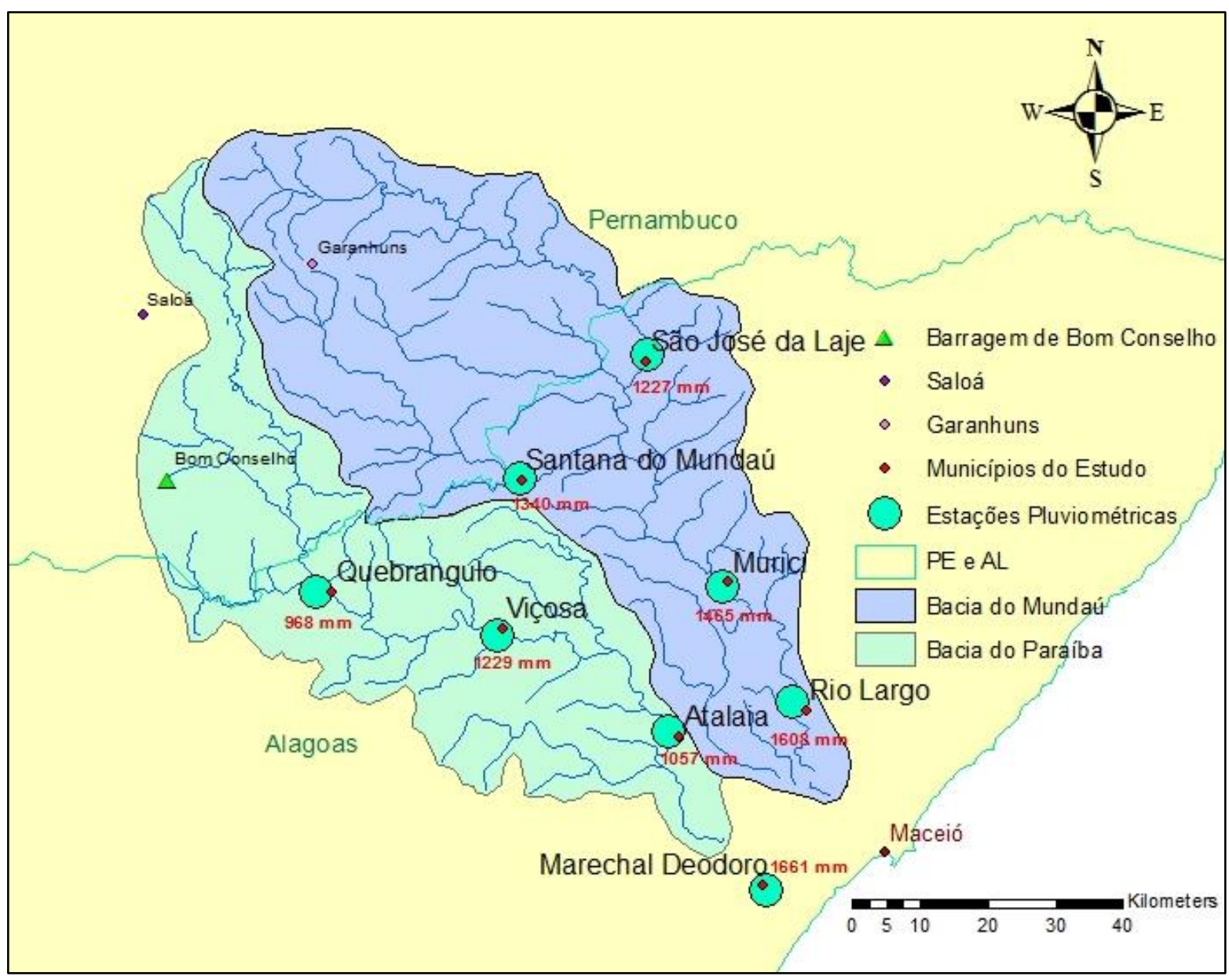

Figura 37 - Localização dos sete postos utilizados nas bacias dos rios Mundaú e Paraíba e precipitações médias anuais

O clima da região é classificado, segundo Köppen, como Clima Tropical com estação seca de verão (As) que tem como características chuvas no inverno. A temperatura média no mês mais frio é superior a $18^{\circ}$. 
As precipitações médias anuais, calculadas através das séries históricas de oito postos localizados na região, variam de $968 \mathrm{~mm}$ em Quebrangulo a $1.661 \mathrm{~mm}$ em Marechal Deodoro. Os meses mais chuvosos são junho, em seguida julho e maio.

As estações do Vale do Mundaú e Paraíba, utilizadas nesse estudo, estão localizadas no estado de Alagoas, em municípios que sofreram com as inundações de junho de 2010. As séries históricas compreenderam os dados diários de precipitação de oito estações operadas pela CPRM - Serviço Geológico do Brasil.

Inicialmente foram selecionadas treze estações pluviométricas, mas no momento em que o estudo foi realizado, apenas oito possuíam dados de junho de 2010, mês em que ocorreram as catástrofes. As séries históricas de precipitação foram obtidas na página da ANA - Agência Nacional de Águas, através do Hidroweb. Para confecção do mapa e delimitação das bacias foi utilizado o Programa ArcGis 10 e algumas shapes utilizadas no Atlas Pluviométrico do Brasil, da CPRM - Serviço Geológico do Brasil. Suas altitudes variam de 10 a 300 metros.

Tabela 31 - Relação das oito estações pluviométricas do Vale do Mundaú e Paraíba e, AL

\begin{tabular}{|l|c|c|c|c|c|c|c|}
\hline Código & Estação & $\begin{array}{c}\text { Bacia } \\
\text { (Sub-bacia) }\end{array}$ & Latitude & Longitude & $\begin{array}{c}\text { Alt. } \\
(\mathbf{m})\end{array}$ & Município & Dados \\
\hline $\mathbf{9 3 5 0 1 2}$ & Murici - Ponte & 39 (Mundaú) & $-09^{\circ} 18^{\prime} 49^{\prime \prime}$ & $-35^{\circ} 56^{\prime} 59^{\prime \prime}$ & 82 & Murici & $\begin{array}{c}\mathrm{jan} / 63 \mathrm{a} \\
\mathrm{mar} / 12\end{array}$ \\
\hline $\mathbf{9 3 5 0 5 6}$ & $\begin{array}{c}\text { Fazenda Boa } \\
\text { Fortuna }\end{array}$ & 39 (Mundaú) & $-09^{\circ} 28^{\prime} 03^{\prime \prime}$ & $-35^{\circ} 51^{\prime} 23^{\prime \prime}$ & 42 & Rio Largo & $\begin{array}{c}\mathrm{ago} / 89 \mathrm{a} \\
\mathrm{fev} / 12\end{array}$ \\
\hline $\mathbf{9 3 5 0 5 7}$ & $\begin{array}{c}\text { Marechal } \\
\text { Deodoro }\end{array}$ & 39 & $-09^{\circ} 42^{\prime} 59^{\prime \prime}$ & $-35^{\circ} 53^{\prime} 30^{\prime \prime}$ & 10 & $\begin{array}{c}\text { Marechal } \\
\text { Deodoro }\end{array}$ & $\begin{array}{c}\mathrm{out} / 90 \mathrm{a} \\
\mathrm{mar} / 12\end{array}$ \\
\hline $\mathbf{9 3 6 1 1 0}$ & Atalaia & 39 (Paraíba) & $-09^{\circ} 30^{\prime} 26^{\prime \prime}$ & $-36^{\circ} 01^{\prime} 24^{\prime \prime}$ & 54 & Atalaia & $\begin{array}{c}\mathrm{ago} / 89 \mathrm{a} \\
\mathrm{mar} / 12\end{array}$ \\
\hline $\mathbf{9 3 6 1 1 1}$ & Viçosa & 39 (Paraíba) & $-09^{\circ} 22^{\prime} 45^{\prime \prime}$ & $-36^{\circ} 14^{\prime} 57^{\prime \prime}$ & 300 & Viçosa & $\begin{array}{c}\mathrm{j} \mathrm{jan} / 89 \mathrm{a} \\
\mathrm{jan} / 12\end{array}$ \\
\hline $\mathbf{9 3 6 1 1 2}$ & $\begin{array}{c}\text { São José da } \\
\text { Laje }\end{array}$ & 39 (Mundaú) & $-09^{\circ} 00^{\prime} 15^{\prime \prime}$ & $-36^{\circ} 03^{\prime} 04^{\prime \prime}$ & 268 & $\begin{array}{c}\text { São José da } \\
\text { Laje }\end{array}$ & $\begin{array}{c}\text { out/90 a } \\
\mathrm{mar} / 12\end{array}$ \\
\hline $\mathbf{9 3 6 1 1 4}$ & $\begin{array}{c}\text { Santana do } \\
\text { Mundaú }\end{array}$ & 39 (Mundaú) & $-09^{\circ} 10^{\prime} 08^{\prime \prime}$ & $-36^{\circ} 13^{\prime} 11^{\prime \prime}$ & 220 & $\begin{array}{c}\text { Santana do } \\
\text { Mundaú }\end{array}$ & $\begin{array}{c}\mathrm{out} / 90 \mathrm{a} \\
\mathrm{mar} / 12\end{array}$ \\
\hline $\mathbf{9 3 6 1 1 5}$ & Quebrangulo & 39 (Paraíba) & $-09^{\circ} 19^{\prime} 13^{\prime \prime}$ & $-36^{\circ} 29^{\prime} 31^{\prime \prime}$ & 220 & Quebrangulo & $\begin{array}{c}\text { out/90 a } \\
\mathrm{ma} / 11\end{array}$ \\
\hline
\end{tabular}

Dentre as estações selecionadas, quatro delas estão localizadas na bacia do Mundaú, nos municípios de São José da Laje, Santana do Mundaú, Murici e Rio Largo três na bacia do Paraíba, nas cidades Quebrangulo, Viçosa e Atalaia. A estação Marechal Deodoro, localizada na lagoa Manguaba, também foi utilizada. 


\subsubsection{Análise estatística dos dados de chuva}

Os volumes mensais precipitados no ano de 2010 foram analisados, principalmente em relação ao total mensal precipitado no mês de junho, quando ocorreu a catástrofe nas bacias do Mundaú e Paraíba, e os meses que antecedem o evento, uma vez que podem indicar o estado antecedente de umidade do solo nessas bacias e ter relação com o processo de formação das cheias.

\subsubsection{Meses que antecedem os eventos}

Foram analisados os totais mensais dos meses que antecedem os eventos críticos ocorridos em junho de 2010. As médias mensais das séries históricas de cada uma das estações foram calculadas e plotadas nos gráficos da Figura 38, que contém também os totais mensais nos anos de 2010 e 2011.

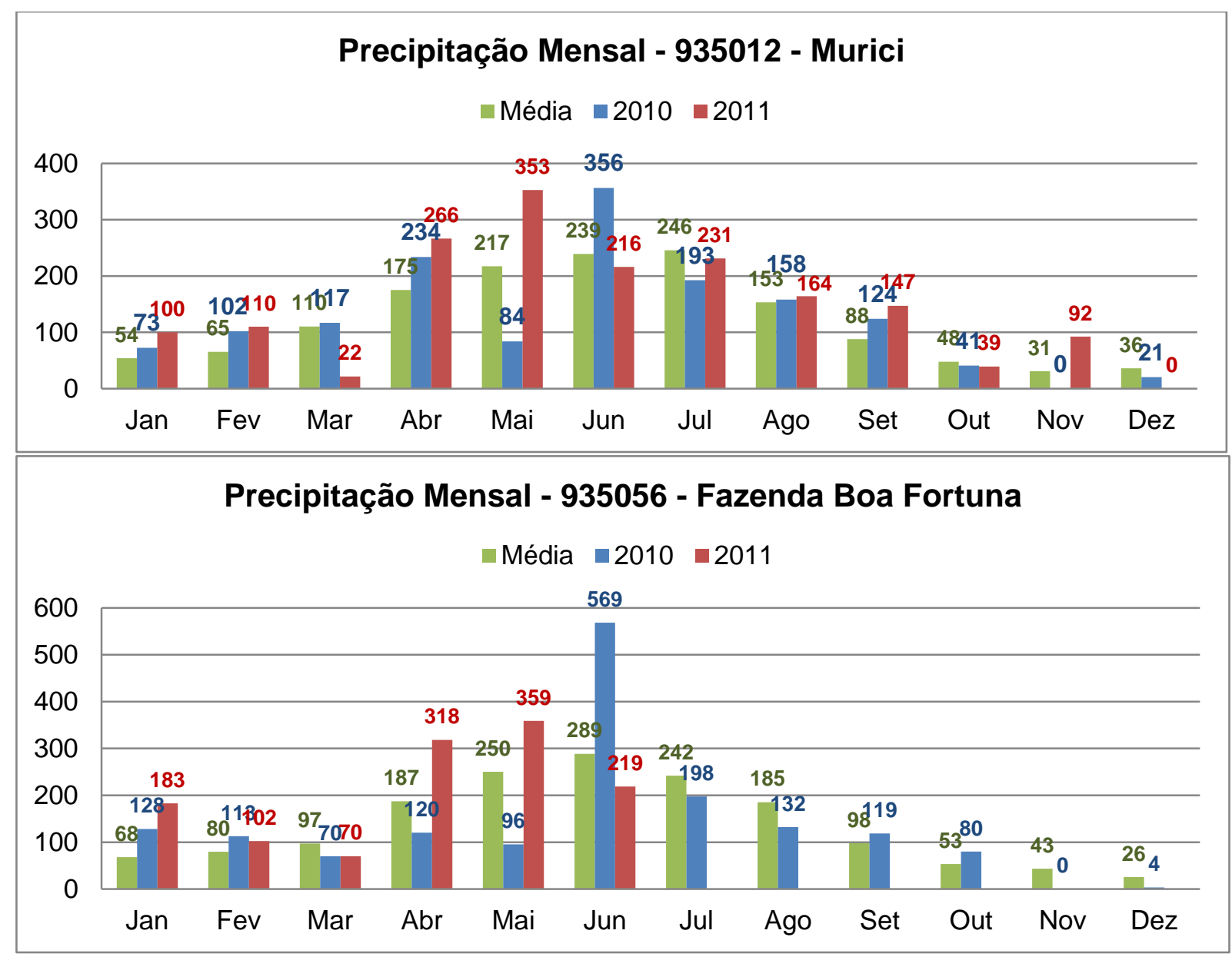

Figura 38 - Totais mensais dos anos 2008 e 2011 e média mensal histórica (continua) 


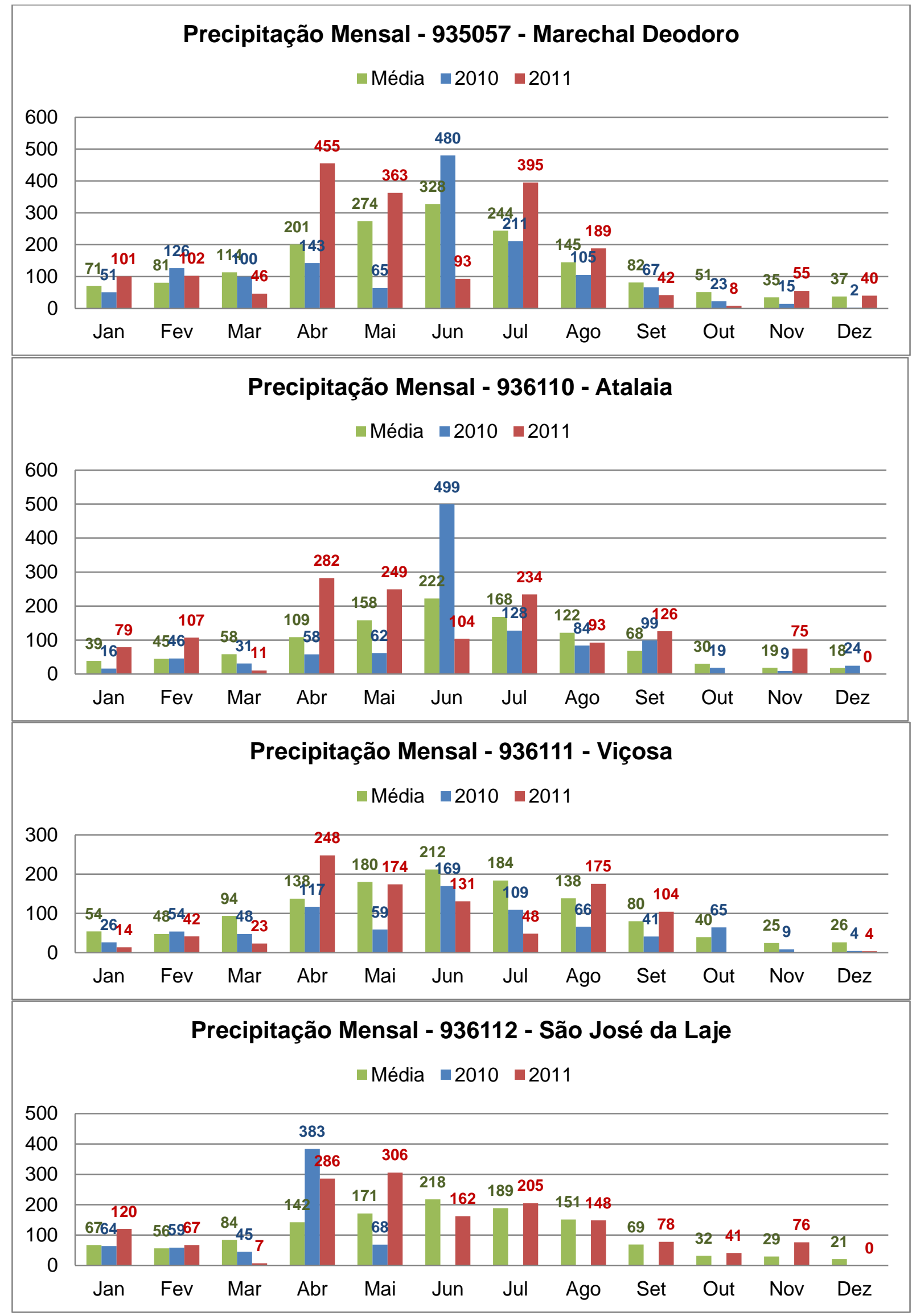

Figura 38 - Totais mensais dos anos 2008 e 2011 e média mensal histórica (continua) 


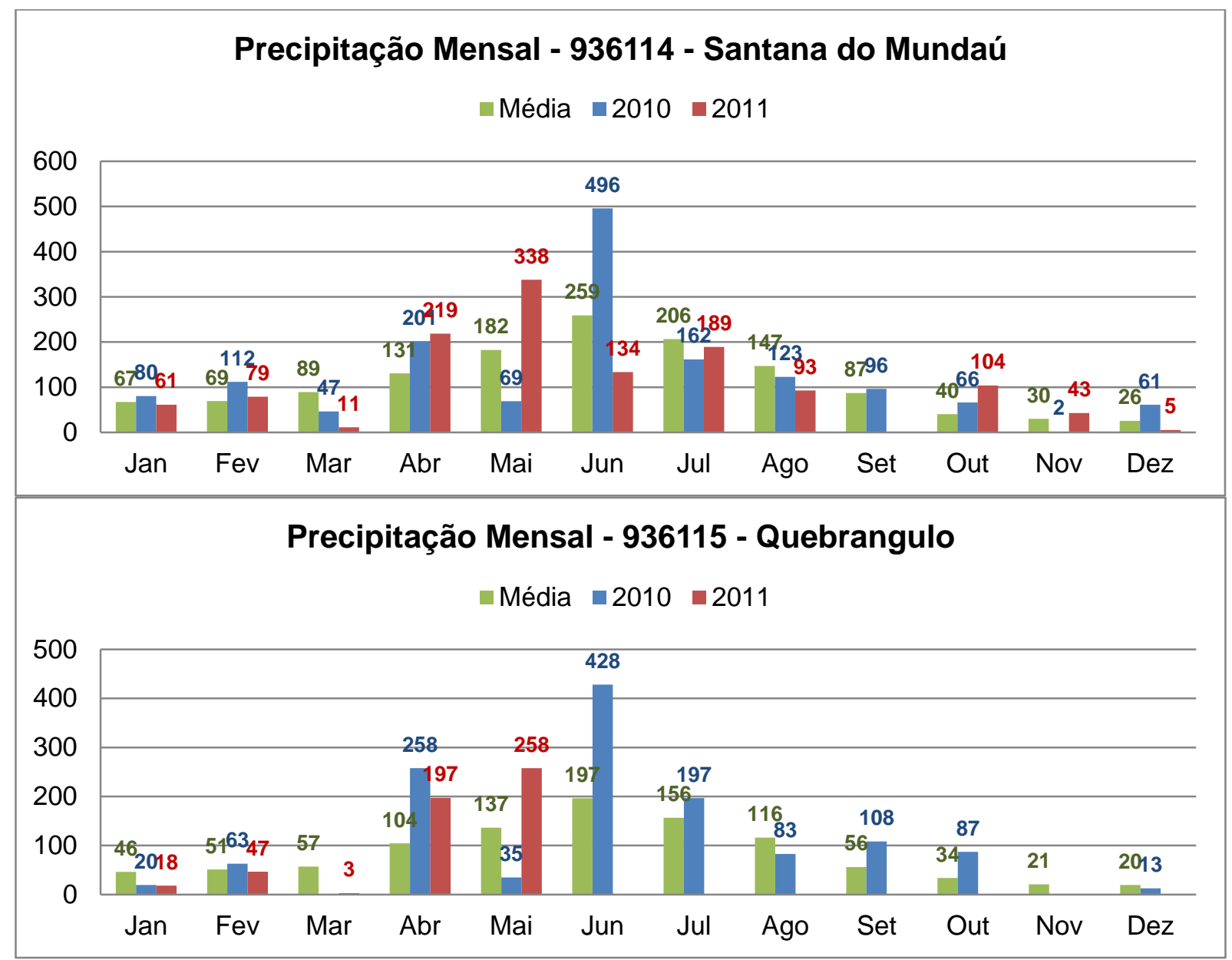

Figura 38 - Totais mensais dos anos 2008 e 2011 e média mensal histórica

Abril de 2010 foi chuvoso em quatro das oito estações. O mês de maio de 2010, que antecede as inundações ocorridas em junho, foi pouco chuvoso, com totais mensais abaixo da média em todas as estações. O mês de junho de 2010 foi de chuvas elevadas, com volumes acumulados acima de $400 \mathrm{~mm}$ na maioria das estações, chegando a $569 \mathrm{~mm}$, na estação Fazenda Boa Fortuna, localizada no município Rio Largo. Em São José da Laje não foi contabilizado o total mensal de junho de 2010, pois a partir do dia 18 até o dia 13 de dezembro não havia dados diários dessa estação no banco da ANA. A chuva acumulada do dia 1 até o dia 18 de junho foi $338,7 \mathrm{~mm}$.

\subsubsection{Estatísticas básicas}

Para entender a magnitude dos eventos, foram calculadas algumas estatísticas básicas: como a precipitação máxima diária no mês em que o evento 
ocorreu, neste caso o mês de junho de 2010, $\left(P_{\max }\right.$ jun/10); o dia da máxima; o total

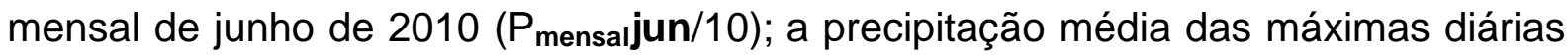
anuais ( $P_{\text {med }}$ max); a precipitação média mensal de junho ( $P_{\text {med }}$ mensal jun) e a precipitação média anual ( $\mathrm{P}_{\text {med }}$ anual). Os dados constam na Tabela 32.

Tabela 32 - Chuvas de junho de 2010, médias das máximas e médias mensais e anuais das estações do Vale do Mundaú e Paraíba

\begin{tabular}{|l|c|c|c|c|c|c|c|}
\hline Código & Estação & $\begin{array}{c}\mathbf{P}_{\max } \\
\text { jun/10 }\end{array}$ & $\begin{array}{c}\text { Dia da } \\
\max \end{array}$ & $\begin{array}{c}\mathbf{P}_{\text {mensal }} \\
\text { jun/10 }\end{array}$ & $\begin{array}{c}\mathbf{P}_{\text {med das }} \\
\max \end{array}$ & $\begin{array}{c}\mathbf{P}_{\text {med mensal }} \\
\text { jun }\end{array}$ & $\mathbf{P}_{\text {med }}$ anual \\
\hline $\mathbf{9 3 5 0 1 2}$ & Murici - Ponte & 68,9 & 5 & 356,4 & 77,7 & 239 & 1465 \\
\hline $\mathbf{9 3 5 0 5 6}$ & Fazenda Boa Fortuna & $\mathbf{2 0 3 , 7}$ & 5 & 568,6 & 101 & 289 & 1608 \\
\hline $\mathbf{9 3 5 0 5 7}$ & Marechal Deodoro & $\mathbf{1 7 7 , 1}$ & 5 & 480,1 & 105 & 327,9 & 1.661 \\
\hline $\mathbf{9 3 6 1 1 0}$ & Atalaia & $\mathbf{2 0 0}$ & 5 & 499,3 & 72,3 & 222,4 & 1057 \\
\hline $\mathbf{9 3 6 1 1 1}$ & Viçosa & 41,8 & 19 & 169,4 & 64,3 & 211,7 & 1229 \\
\hline $\mathbf{9 3 6 1 1 2}$ & São José da Laje & $\mathbf{1 2 0}$ & 5 & 338,7 & 78,9 & 217,5 & 1227 \\
\hline $\mathbf{9 3 6 1 1 4}$ & Santana do Mundaú & 98,1 & 19 & 495,7 & 76,7 & 259 & 1340 \\
\hline $\mathbf{9 3 6 1 1 5}$ & Quebrangulo & $\mathbf{1 1 6 , 7}$ & 5 & 428,0 & 63,2 & 196,5 & 969 \\
\hline
\end{tabular}

As chuvas máximas diárias de junho de 2010 foram maiores que média das máximas na maioria das estações, exceto em Murici e Viçosa. Em Atalaia e Rio Largo choveu 200 mm e 203,5 mm no dia 5 de junho. Em Santana do Mundaú a máxima de $98,1 \mathrm{~mm}$ foi registrada no dia 19 de junho, dia em que ocorreram as inundações na bacia.

\subsubsection{Análise do mês em que ocorre a chuva catastrófica}

Em seguida foram analisados os eventos críticos de junho de 2010. As chuvas diárias de todas as estações foram plotadas no gráfico da Figura 39. 


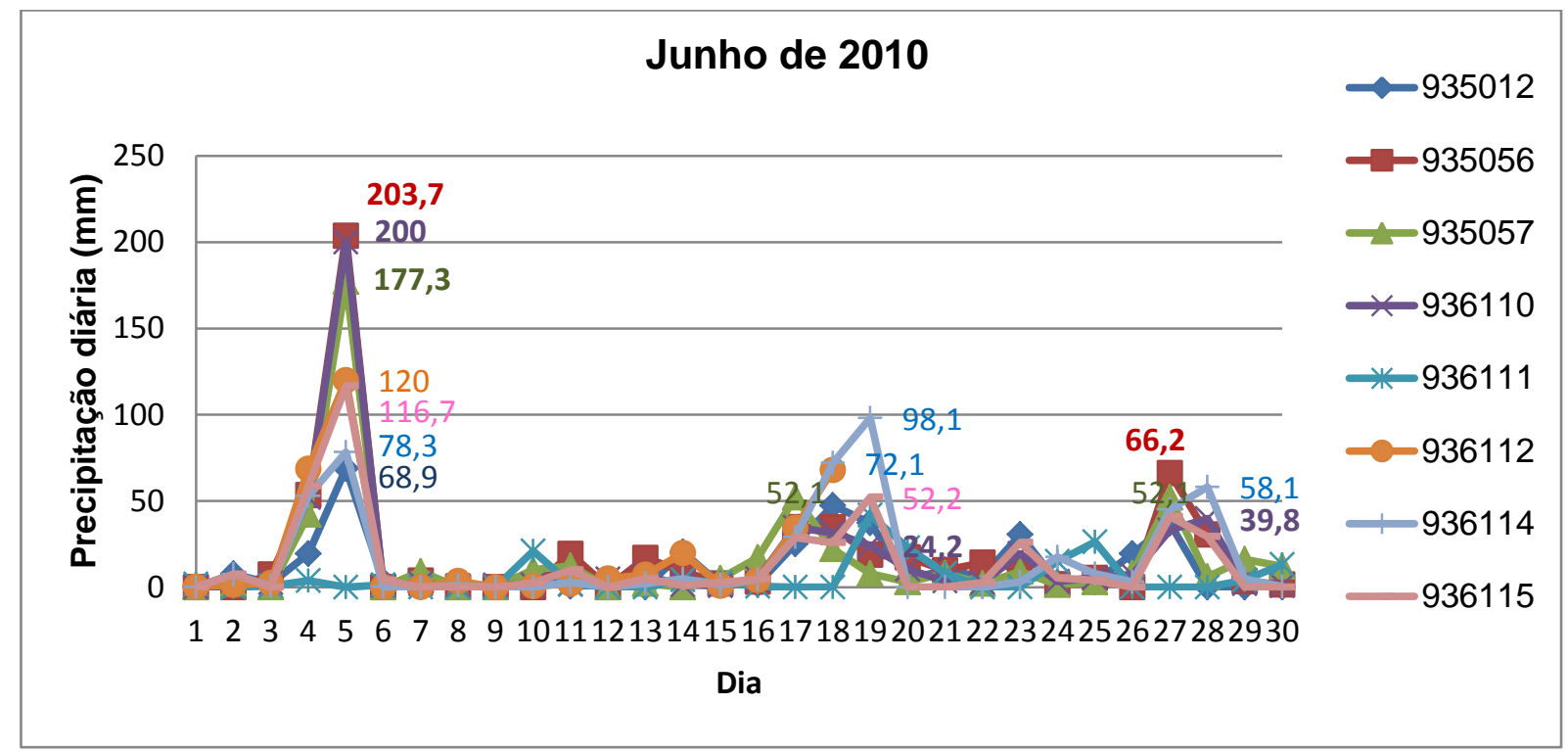

Figura 39 - Precipitação diária de junho de 2010

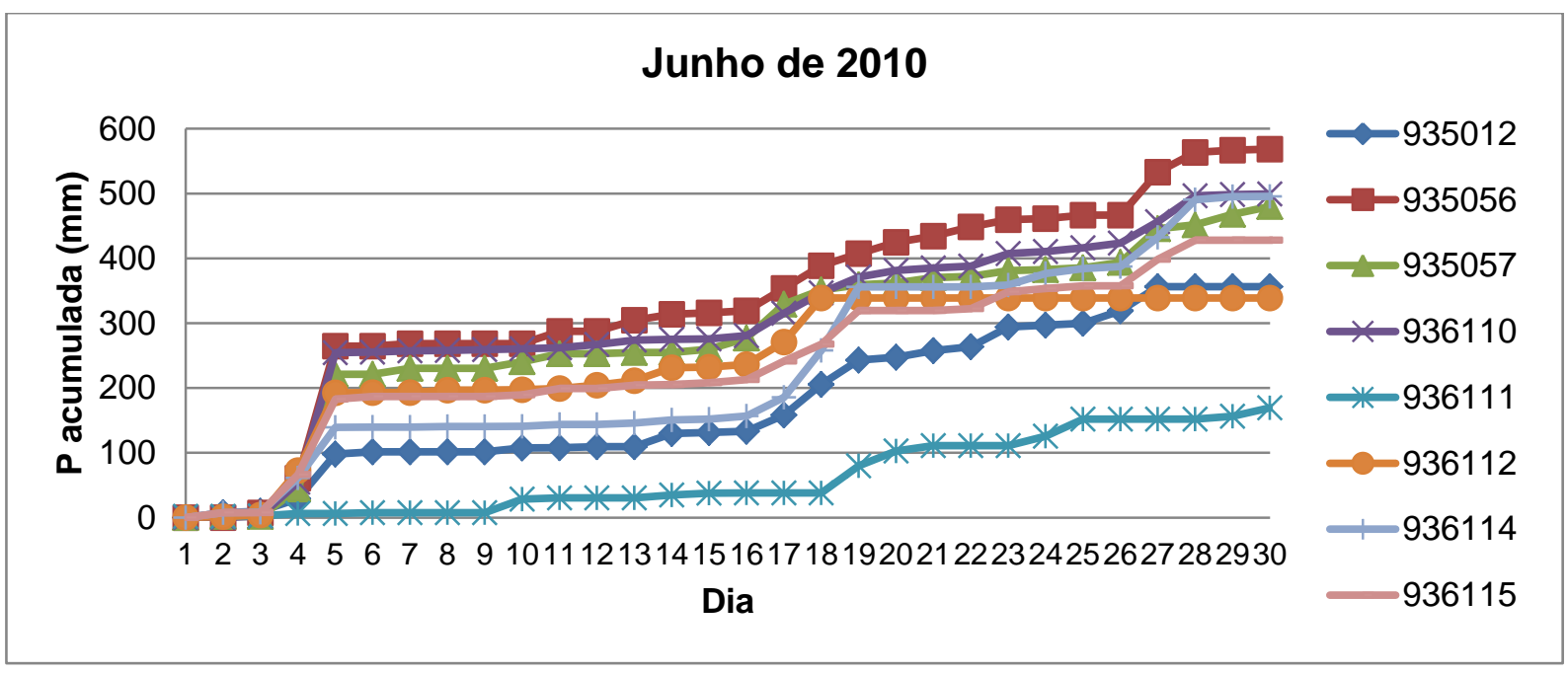

Figura 40 - Precipitação acumulada diária de junho de 2010

Destacam-se os volumes precipitados nos dias 4 e 5 e 17, 18 e 19 de junho de 2010, atingindo valores acima de $200 \mathrm{~mm}$ no dia $5 \mathrm{em}$ algumas estações. Em Rio Largo choveu 203,7 mm, seguido de $200 \mathrm{~mm}$ em Atalaia, 177,3 mm em Marechal Deodoro, $120 \mathrm{~mm}$ em São José da Laje e $117 \mathrm{~mm}$ em Quebrangulo. Certamente as chuvas elevadas dos dias 4 e 5 , combinados com outros valores acima de $50 \mathrm{~mm}$ nos dias 17, 18 e 19 contribuíram para a saturação do solo e para as inundações ocorridas no dia 19 nos municípios estudados. O volume acumulado até o dia 17 atingiu valores acima de $300 \mathrm{~mm}$ em algumas estações. 


\subsubsection{Distribuições adotadas e períodos de retorno (Tr)}

Foram calculadas as posições de plotagem das séries de chuvas máximas diárias, através da fórmula de Cunnane, os períodos de retorno e então foram ajustadas as distribuições Log-Normal e Gumbel para todas as estações. O resumo dos parâmetros estimados de cada distribuição encontra-se na Tabela 33.

Tabela 33 - Resumo dos parâmetros estimados de cada distribuição

\begin{tabular}{|c|c|c|c|c|}
\hline \multirow{2}{*}{ Estação } & \multirow{2}{*}{$\begin{array}{l}\text { Parâmetros } \\
\text { Estimados }\end{array}$} & \multicolumn{3}{|c|}{ Distribuição } \\
\hline & & Empírica & Log-Normal & Gumbel \\
\hline \multirow{3}{*}{935012} & Média $\mu$ & 77,7 & 77,8 & 77,4 \\
\hline & Desvio-padrão $\sigma$ & 28,2 & 30,4 & 27,2 \\
\hline & Assimetria y & 0,5 & 1,0 & 0,9 \\
\hline \multirow{3}{*}{935056} & $\mu$ & 101,1 & 100,2 & 100,3 \\
\hline & $\sigma$ & 47,6 & 43,5 & 44,9 \\
\hline & $\mathrm{Y}$ & 1,1 & 1,0 & 0,8 \\
\hline \multirow{3}{*}{935057} & $\mu$ & 108,9 & 108,8 & 108,3 \\
\hline & $\sigma$ & 32,3 & 32,9 & 30,3 \\
\hline & $\mathrm{Y}$ & 0,3 & 0,7 & 0,8 \\
\hline \multirow{3}{*}{936110} & $\mu$ & 81,2 & 80,2 & 80,4 \\
\hline & $\sigma$ & 42,6 & 37,1 & 40,0 \\
\hline & $\mathrm{Y}$ & 1,5 & 1,0 & 0,8 \\
\hline \multirow{3}{*}{936111} & $\mu$ & 64,3 & 63,9 & 63,9 \\
\hline & $\sigma$ & 26,1 & 23,7 & 24,7 \\
\hline & $\mathrm{Y}$ & 1,2 & 0,9 & 0,8 \\
\hline \multirow{3}{*}{936112} & $\mu$ & 71,2 & 71,2 & 70,9 \\
\hline & $\Sigma$ & 21,1 & 21,8 & 19,8 \\
\hline & $\mathrm{Y}$ & 0,5 & 0,7 & 0,8 \\
\hline \multirow{3}{*}{936114} & $\mu$ & 80,0 & 79,8 & 79,5 \\
\hline & $\sigma$ & 27,4 & 27,2 & 25,7 \\
\hline & $\mathrm{Y}$ & 0,6 & 0,8 & 0,8 \\
\hline \multirow{3}{*}{936115} & $\mu$ & 63,2 & 63,1 & 62,8 \\
\hline & $\sigma$ & 22,9 & 23,5 & 21,6 \\
\hline & $\mathrm{Y}$ & 0,4 & 0,8 & 0,8 \\
\hline
\end{tabular}

Os gráficos contendo as distribuições empíricas e as distribuições ajustadas para cada estação podem ser visualizados na Figura 41. 


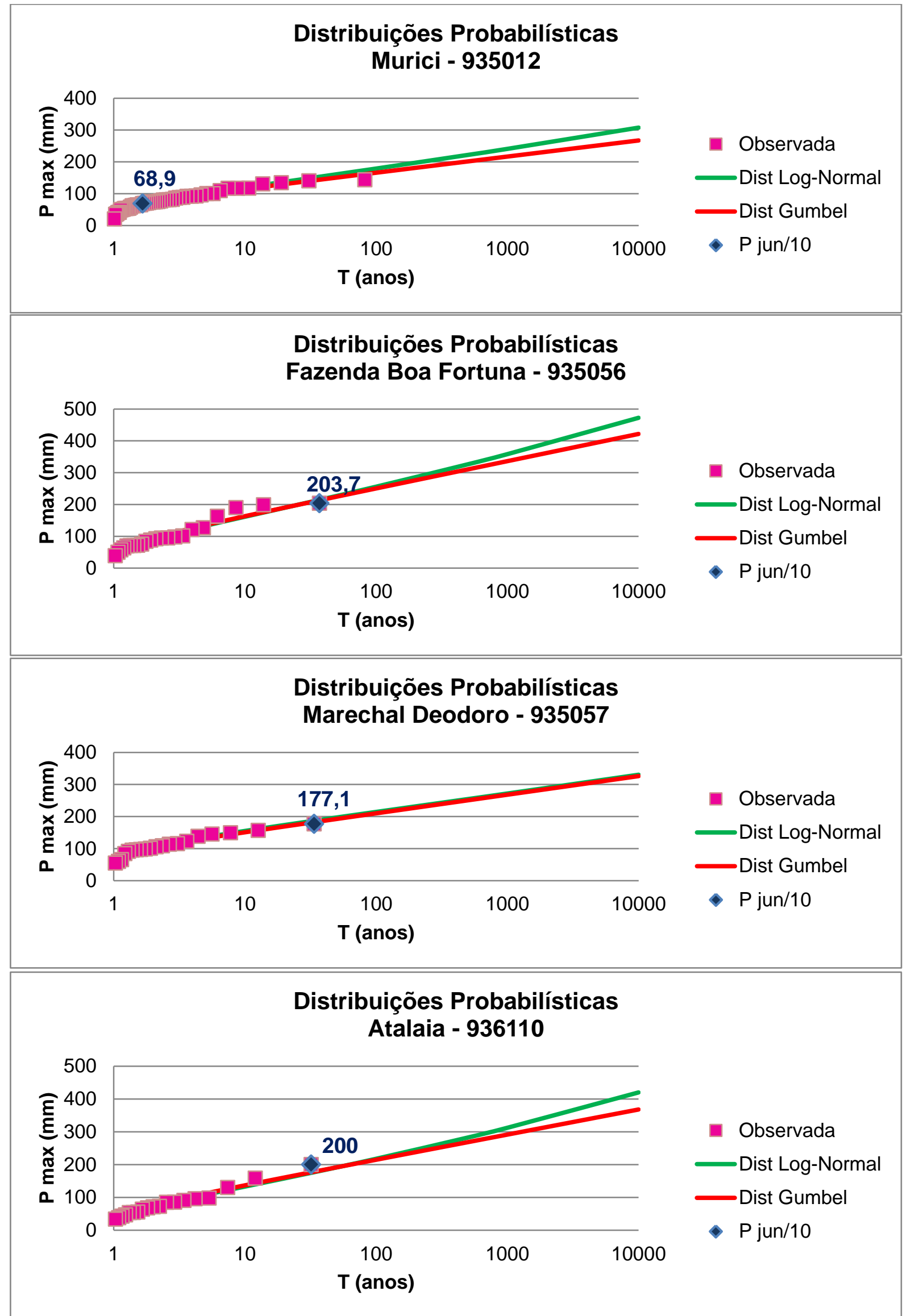

Figura 41- Relação entre Tr e precipitações máximas para 1 dia de duração (continua) 


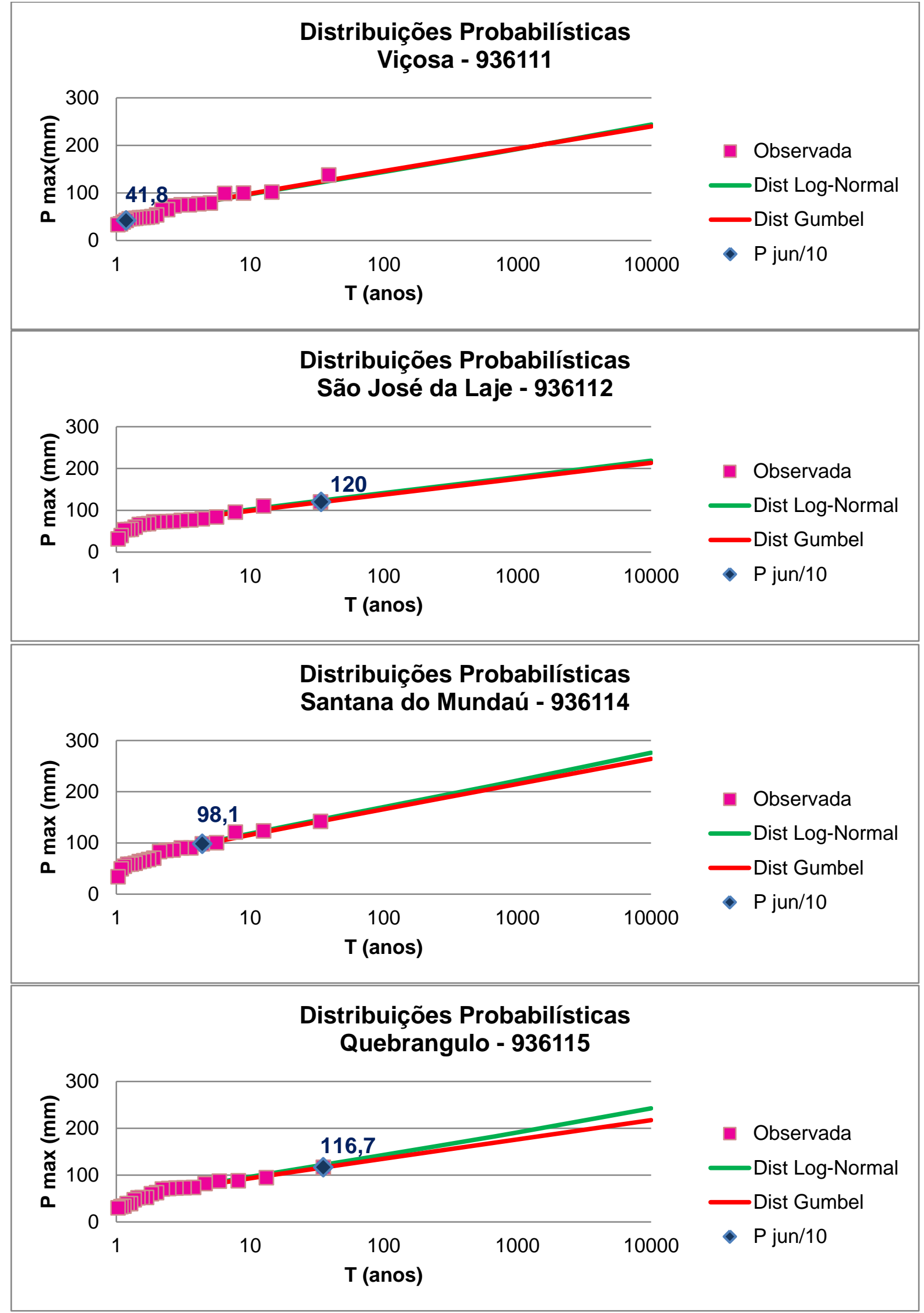

Figura 41 - Relação entre Tr e precipitações máximas para 1 dia de duração 
Através dos gráficos das distribuições, nota-se que a precipitação de junho de 2010 foi a máxima chuva já registrada em cinco das oito estações: Fazenda Boa Fortuna e São José da Laje, localizadas na bacia do Mundaú, Atalaia e Quebrangulo, na bacia do Paraíba, e Marechal Deodoro, na Lagoa Manguaba.

Foram estimados os períodos de retorno das chuvas ocorridas em junho de 2010 para as distribuições de probabilidade Log-Normal e Gumbel. Os resultados se encontram na Tabela 34.

Tabela 34 - Períodos de retorno estimados para as máximas chuvas diárias

\begin{tabular}{|c|c|c|c|c|}
\hline Estação & $\begin{array}{c}\mathbf{P} \text { max } \\
\text { junho de 2008 } \\
\text { (mm) }\end{array}$ & $\begin{array}{c}\text { Tr } \\
\text { Empírica } \\
\text { (anos) } \\
\text { Cunnane }\end{array}$ & $\begin{array}{c}\text { Tr } \\
\text { Log-Normal } \\
\text { (anos) }\end{array}$ & $\begin{array}{c}\mathbf{T r} \\
\text { Gumbel } \\
\text { (anos) }\end{array}$ \\
\hline 935012 & 68,9 & 2 & 2 & 2 \\
\hline 935056 & $\mathbf{2 0 3 , 7}$ & $\mathbf{3 7}$ & $\mathbf{2 8}$ & $\mathbf{2 9}$ \\
\hline 935057 & $\mathbf{1 7 7 , 1}$ & $\mathbf{3 4}$ & $\mathbf{2 3}$ & $\mathbf{2 8}$ \\
\hline 936110 & $\mathbf{2 0 0}$ & $\mathbf{3 2}$ & $\mathbf{6 3}$ & $\mathbf{6 4}$ \\
\hline 936111 & 41,8 & 1 & 2 & 2 \\
\hline 936112 & $\mathbf{1 2 0}$ & $\mathbf{3 4}$ & $\mathbf{2 8}$ & $\mathbf{3 4}$ \\
\hline 936114 & 98,1 & 4 & 5 & 5 \\
\hline 936115 & $\mathbf{1 1 6 , 7}$ & $\mathbf{3 5}$ & $\mathbf{2 7}$ & $\mathbf{3 5}$ \\
\hline
\end{tabular}

Nas estações onde as chuvas foram as máximas históricas, os períodos de retorno ficaram em torno de 28 a 64 anos, estimados pela distribuição de Gumbel. Os períodos de retorno estimados através das distribuições Log-Normal e Gumbel estão bem coerentes com os estimados através das séries empíricas em praticamente todas as estações.

$\mathrm{Na}$ estação Atalaia, os períodos de retorno calculados através das distribuições Log-Normal e Gumbel, 63 e 64 anos, foram um pouco maiores que o estimado através da empírica, 32 anos.

Na maioria das estações os Trs calculados não foram discrepantes entre si.

Nas estações onde as chuvas foram menos elevadas, os períodos de retorno estimados variaram entre 1 e 5 anos. 


\subsubsection{Teste de aderência de Kolmogorov-Smirnov (KS)}

Os resultados do teste de KS, adotado para o nível de significância de $\alpha=$ $10 \%$, que são apresentados na Tabela 35 , indicam que as duas distribuições foram aderentes em todas as estações.

Tabela 35 - Resultados do Teste de KS para N variando de 20 a 49 e $\alpha=10 \%$

\begin{tabular}{|c|c|c|c|c|}
\hline \multicolumn{3}{|c|}{ Distribuição } & Log-Normal & Gumbel \\
\hline \multicolumn{5}{|c|}{935012} \\
\hline \multicolumn{3}{|c|}{ Estatística do teste $\mathrm{D}$ max } & 0,0565 & 0,0483 \\
\hline $\mathrm{N}$ & & 49 & \multicolumn{2}{|c|}{ Decisão } \\
\hline Região Crítica para & $10 \%$ & 0,1742 & Aceito $\mathrm{HO}$ & Aceito $\mathrm{HO}$ \\
\hline \multicolumn{5}{|c|}{935056} \\
\hline \multicolumn{3}{|c|}{ Estatística do teste $\mathrm{D} \max$} & 0,1416 & 0,1570 \\
\hline $\mathrm{N}$ & & 22 & \multicolumn{2}{|c|}{ Decisão } \\
\hline Região Crítica para & $10 \%$ & 0,2530 & Aceito $\mathrm{HO}$ & Aceito $\mathrm{HO}$ \\
\hline \multicolumn{5}{|c|}{935057} \\
\hline \multicolumn{3}{|c|}{ Estatística do teste D max } & 0,0845 & 0,1067 \\
\hline $\mathrm{N}$ & & 21 & \multicolumn{2}{|c|}{ Decisão } \\
\hline Região Crítica para & $10 \%$ & 0,2590 & Aceito $\mathrm{HO}$ & Aceito $\mathrm{HO}$ \\
\hline \multicolumn{5}{|c|}{936110} \\
\hline \multicolumn{3}{|c|}{ Estatística do teste D max } & 0,1049 & 0,1289 \\
\hline $\mathrm{N}$ & & 22 & \multicolumn{2}{|c|}{ Decisão } \\
\hline Região Crítica para & $10 \%$ & 0,2530 & Aceito $\mathrm{HO}$ & Aceito $\mathrm{HO}$ \\
\hline \multicolumn{5}{|c|}{936111} \\
\hline \multicolumn{3}{|c|}{ Estatística do teste D max } & 0,1622 & 0,1564 \\
\hline $\mathrm{N}$ & & 23 & \multicolumn{2}{|c|}{ Decisão } \\
\hline Região Crítica para & $10 \%$ & 0,2470 & Aceito $\mathrm{HO}$ & Aceito $\mathrm{HO}$ \\
\hline \multicolumn{5}{|c|}{936112} \\
\hline \multicolumn{3}{|c|}{ Estatística do teste D max } & 0,1762 & 0,1492 \\
\hline $\mathrm{N}$ & & 20 & \multicolumn{2}{|c|}{ Decisão } \\
\hline Região Crítica para & $10 \%$ & 0,2650 & Aceito $\mathrm{HO}$ & Aceito $\mathrm{HO}$ \\
\hline \multicolumn{5}{|c|}{936114} \\
\hline \multicolumn{3}{|c|}{ Estatística do teste D max } & 0,0852 & 0,0893 \\
\hline $\mathrm{N}$ & & 21 & \multicolumn{2}{|c|}{ Decisão } \\
\hline Região Crítica para & $10 \%$ & 0,2590 & Aceito $\mathrm{HO}$ & Aceito $\mathrm{HO}$ \\
\hline \multicolumn{5}{|c|}{936115} \\
\hline \multicolumn{3}{|c|}{ Estatística do teste D max } & 0,1026 & 0,1252 \\
\hline $\mathrm{N}$ & & 21 & \multicolumn{2}{|c|}{ Decisão } \\
\hline Região Crítica para & $10 \%$ & 0,2590 & Aceito $\mathrm{HO}$ & Aceito $\mathrm{HO}$ \\
\hline
\end{tabular}




\subsubsection{Chuvas máximas históricas da região}

Os dados de chuva máximas diárias de todas as estações foram plotados em conjunto para verificar a magnitude das máximas na região do Mundaú e Paraíba, como mostra a Figura 42.

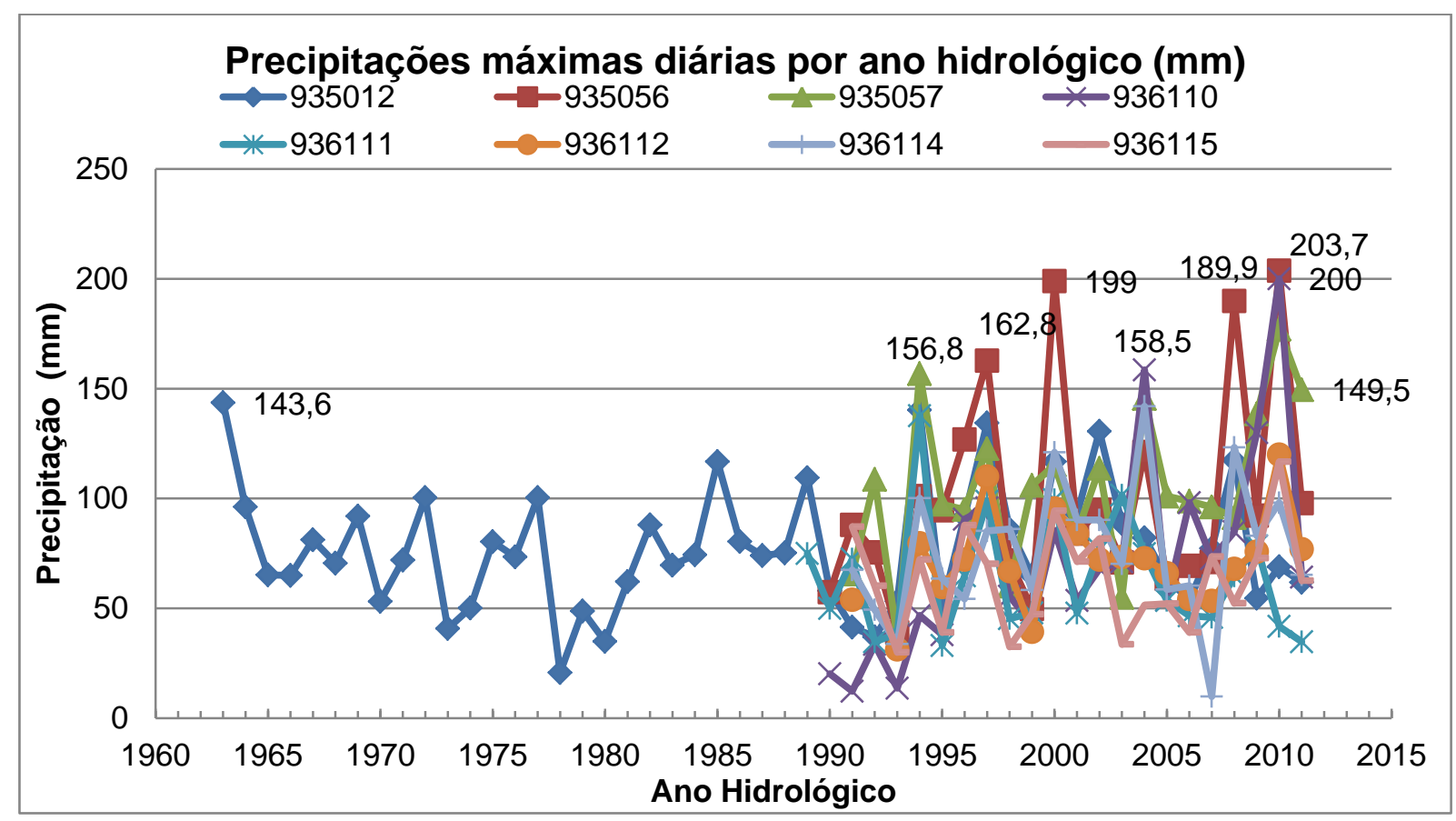

Figura 42 - Precipitações máximas diárias do Vale do Mundaú e Paraíba

A chuva de junho de 2010, de 203,7 mm, coletada na estação Fazenda Boa Fortuna, no município de Rio Largo, foi o maior valor observado desde que se iniciaram as leituras nas estações utilizadas. Em Atalaia também foi registrado um valor elevadíssimo, de $200 \mathrm{~mm}$ e em Marechal Deodoro, 177,3 mm. No ano 2011 foi observado 149,5 mm em Marechal Deodoro e nos demais postos as chuvas máximas diárias ficaram abaixo de $100 \mathrm{~mm}$.

Além do alto volume precipitado no mês de junho de 2010, outros valores elevados já haviam sido observados em anos anteriores. Destaca-se a estação localizada em Rio Largo. Em 1997, foi registrado 162,5 mm nessa estação, 199 mm no ano 2000 e 189,9 mm em 2008. No ano 1994, observou-se 156,8 mm em Marechal Deodoro. Na estação Atalaia choveu $158,5 \mathrm{~mm}$ em 2004. Portanto os eventos de 2010, apesar de elevados, são característicos da bacia.

Foi feito um resumo dos cinco maiores eventos de chuvas diárias observados em cada posto e os anos hidrológicos em que ocorreram, como mostra a Tabela 36. 
Tabela 36 - Os cinco maiores eventos diários de precipitação $(\mathrm{em} \mathrm{mm}$ ) registrados em cada estação do Vale do Mundaú e Paraíba

\begin{tabular}{|c|c|c|c|c|c|c|c|}
\hline Ano & P max diária & Ano & P max diária & Ano & P max diária & Ano & P max diária \\
\hline \multicolumn{2}{|c|}{$\mathbf{9 3 5 0 1 2}$} & \multicolumn{2}{|c|}{$\mathbf{9 3 5 0 5 6}$} & \multicolumn{2}{|c|}{$\mathbf{9 3 5 0 5 7}$} & \multicolumn{2}{|c|}{$\mathbf{9 3 6 1 1 0}$} \\
\hline 1963 & 143,6 & 2010 & 203,7 & 2010 & 177,1 & 2010 & 200 \\
\hline 1994 & 140,3 & 2000 & 199 & 1994 & 156,8 & 2004 & 158,5 \\
\hline 1997 & 134,4 & 2008 & 189,9 & 2011 & 149,5 & 2009 & 130 \\
\hline 2002 & 130,6 & 1997 & 162,8 & 2004 & 145,5 & 2006 & 98,1 \\
\hline 2008 & 117,4 & 1996 & 126,9 & 2009 & 138,5 & 1997 & 95,8 \\
\hline \multicolumn{2}{|c|}{$\mathbf{9 3 6 1 1 1}$} & \multicolumn{9}{|c|}{$\mathbf{9 3 6 1 1 2}$} & \multicolumn{2}{|c|}{$\mathbf{9 3 6 1 1 4}$} & \multicolumn{2}{|c|}{$\mathbf{9 3 6 1 1 5}$} \\
\hline 1994 & 137,7 & 2010 & 120 & 2004 & 142 & 2010 & 116,7 \\
\hline 2003 & 101,5 & 1997 & 110 & 2008 & 123,3 & 2000 & 94,4 \\
\hline 2000 & 99,5 & 2000 & 95,5 & 2000 & 121 & 1996 & 87,8 \\
\hline 1997 & 98,7 & 2001 & 84 & 1994 & 100,2 & 1991 & 87,1 \\
\hline 2009 & 78,4 & 1994 & 79,6 & 2010 & 98,1 & 2002 & 81,7 \\
\hline
\end{tabular}

Existe coerência entre os dados das máximas diárias anuais, principalmente nos anos de 1994, 1997, 2000, 2008 e 2010.

As grandes cheias de 1914, 1941, 1969, 1988 e 1989 não puderam ser avaliadas através dos dados das máximas diárias, pois em sete estações as leituras começaram a partir de 1989 e 1990, provavelmente devido à necessidade de monitoramento das chuvas e níveis na bacia após as inundações. Na estação Viçosa, as leituras tiveram início em janeiro de 1989, mas os dados de abril e maio desse ano estão em branco, portando a máxima também não pode ser confirmada. $\mathrm{Na}$ estação Murici, que possui dados desde 1961, as máximas chuvas não coincidem com as inundações, mas são coerentes com as chuvas das demais estações a partir de 1990.

A cheia de 2000 foi também relevante considerando as elevadas precipitações em cinco das estações analisadas, sendo a segunda máxima em duas delas. As chuvas de 2010 foram as máximas históricas registradas em 5 das 8 estações monitoradas. 


\subsubsection{Precipitações Máximas Acumuladas para diferentes durações}

Foram acumuladas as máximas chuvas para as durações de 1 a 10 dias, 15, 20, 30 e 45 dias. O cálculo foi feito com a acumulada móvel e o intervalo considerado foi 0 ano hidrológico. Em seguida, as séries das máximas para as diferentes durações foram plotadas nos gráficos da Figura 43.

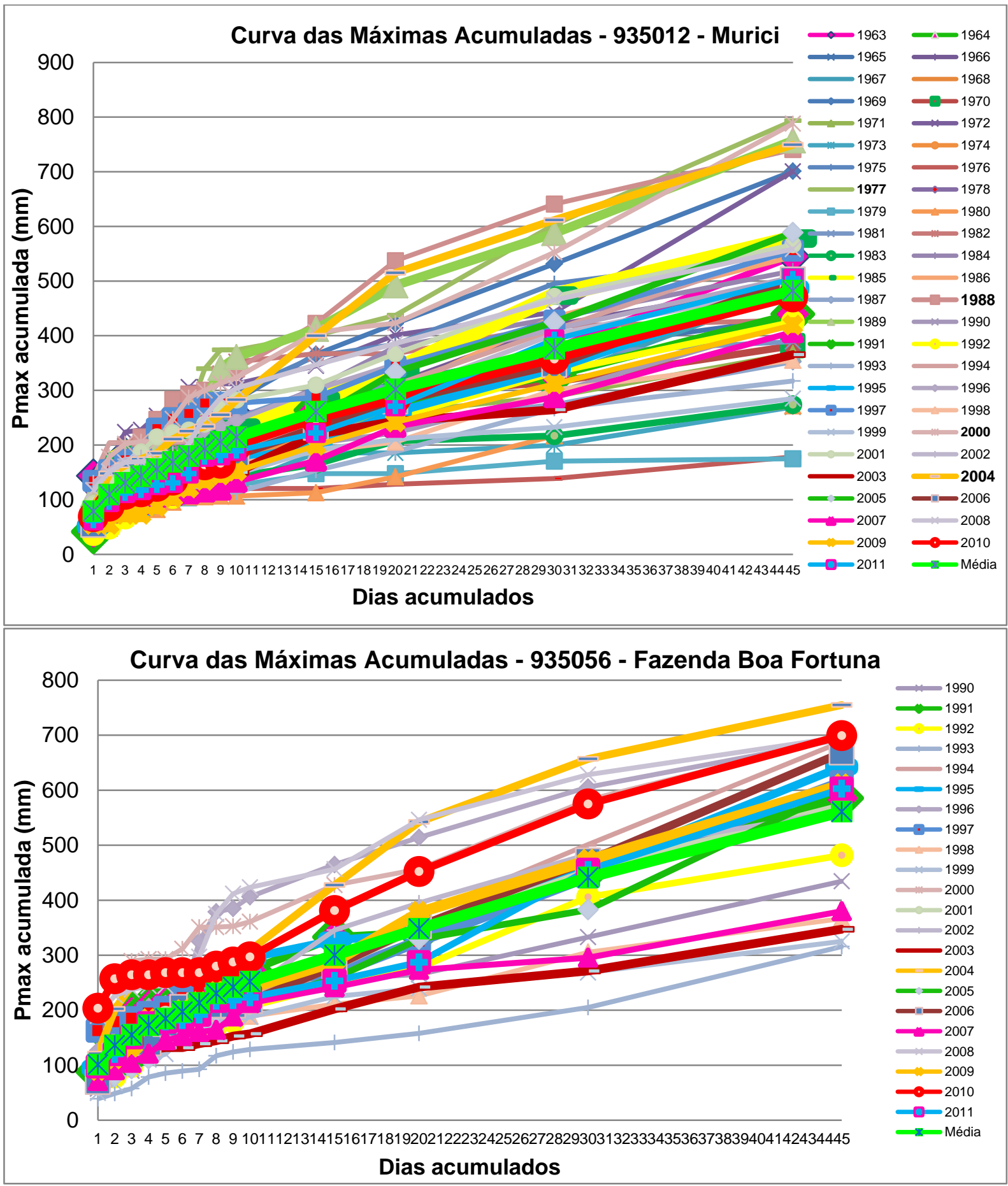

Figura 43 - Curvas das máximas acumuladas para as durações de 1 a 10 dias, 15, 20, 30 e 45 dias (continua) 


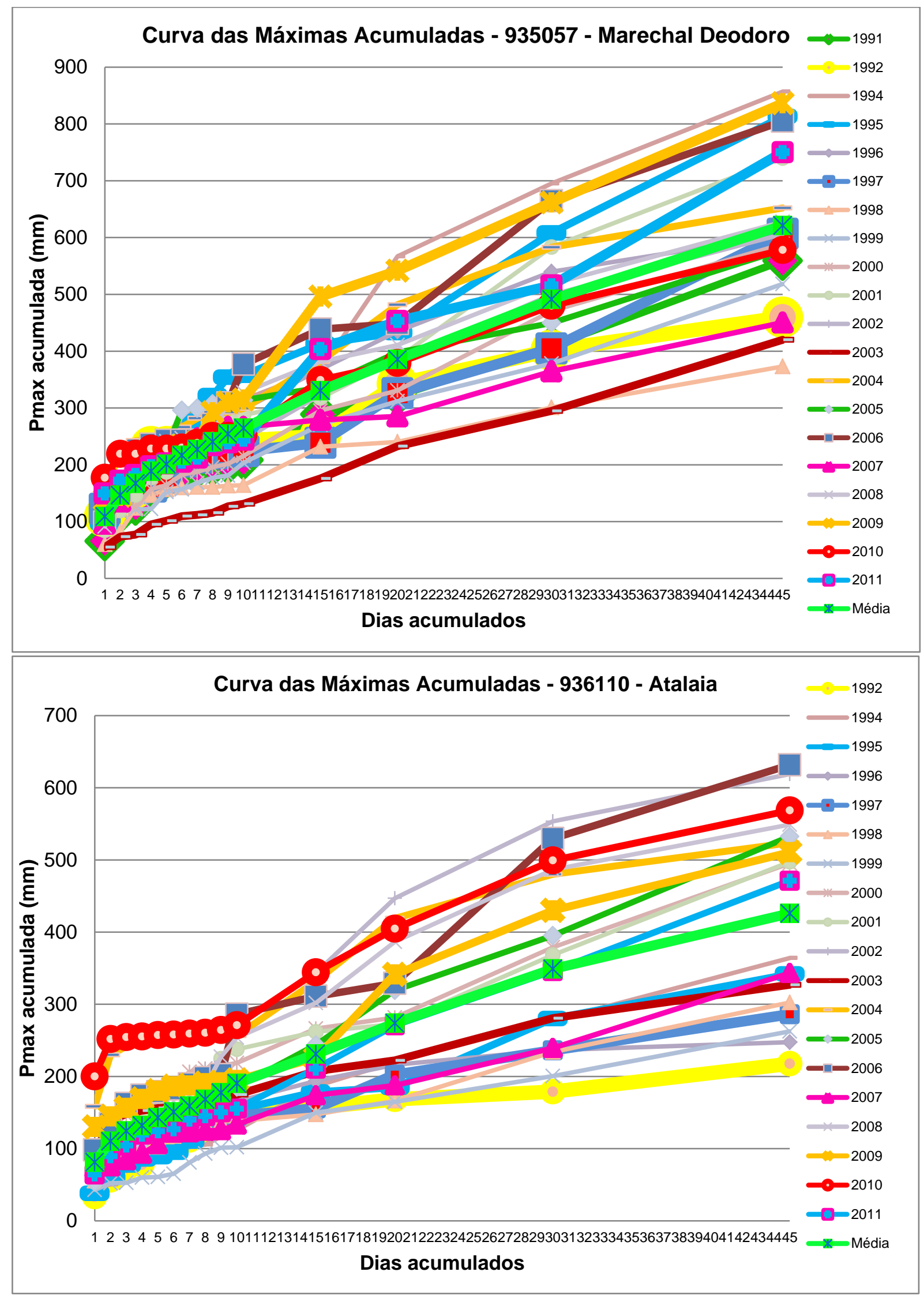

Figura 43 - Curvas das máximas acumuladas para as durações de 1 a 10 dias, 15, 20, 30 e 45 dias (continua) 


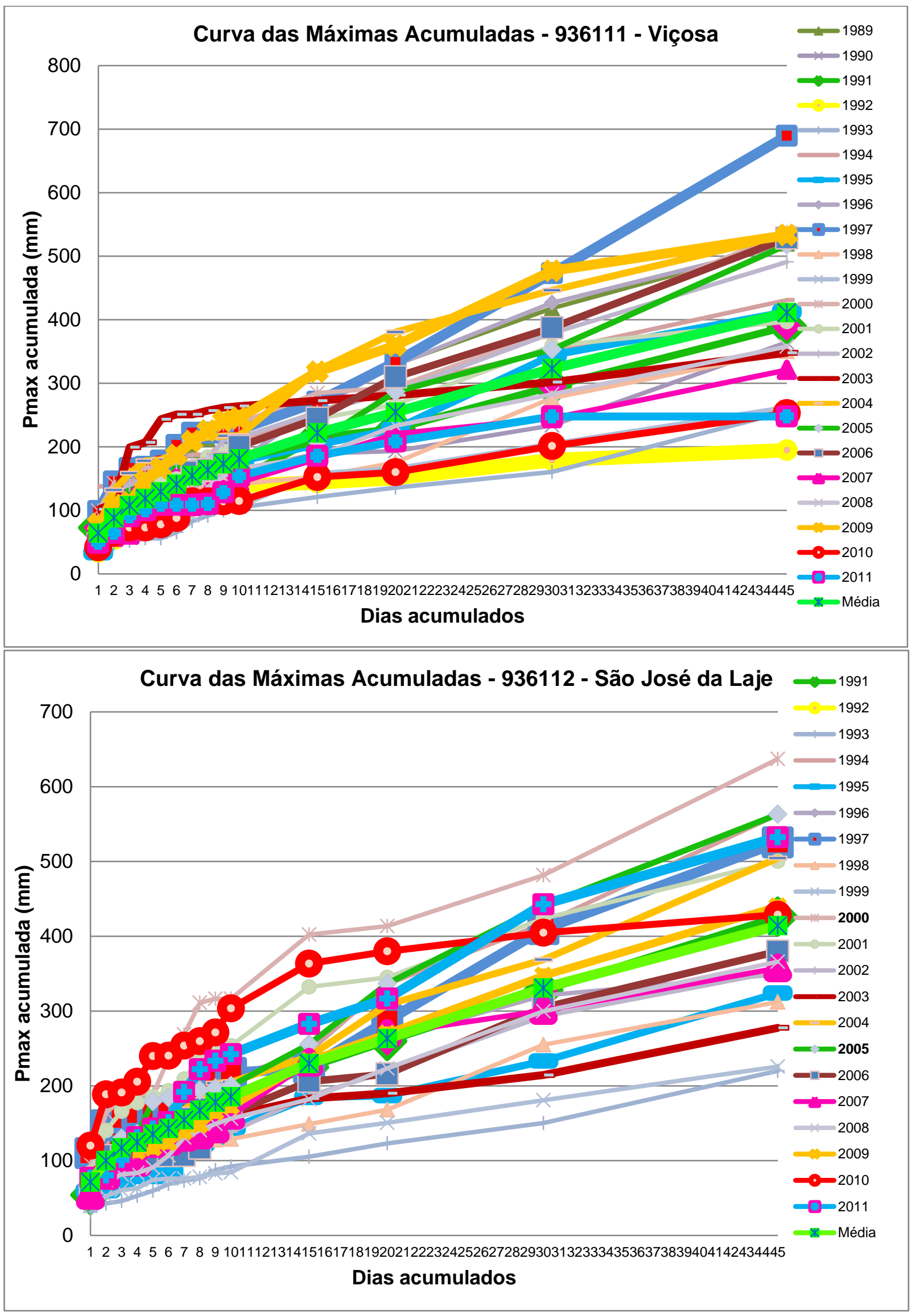

Figura 43 - Curvas das máximas acumuladas para as durações de 1 a 10 dias, 15, 20, 30 e 45 dias (continua) 


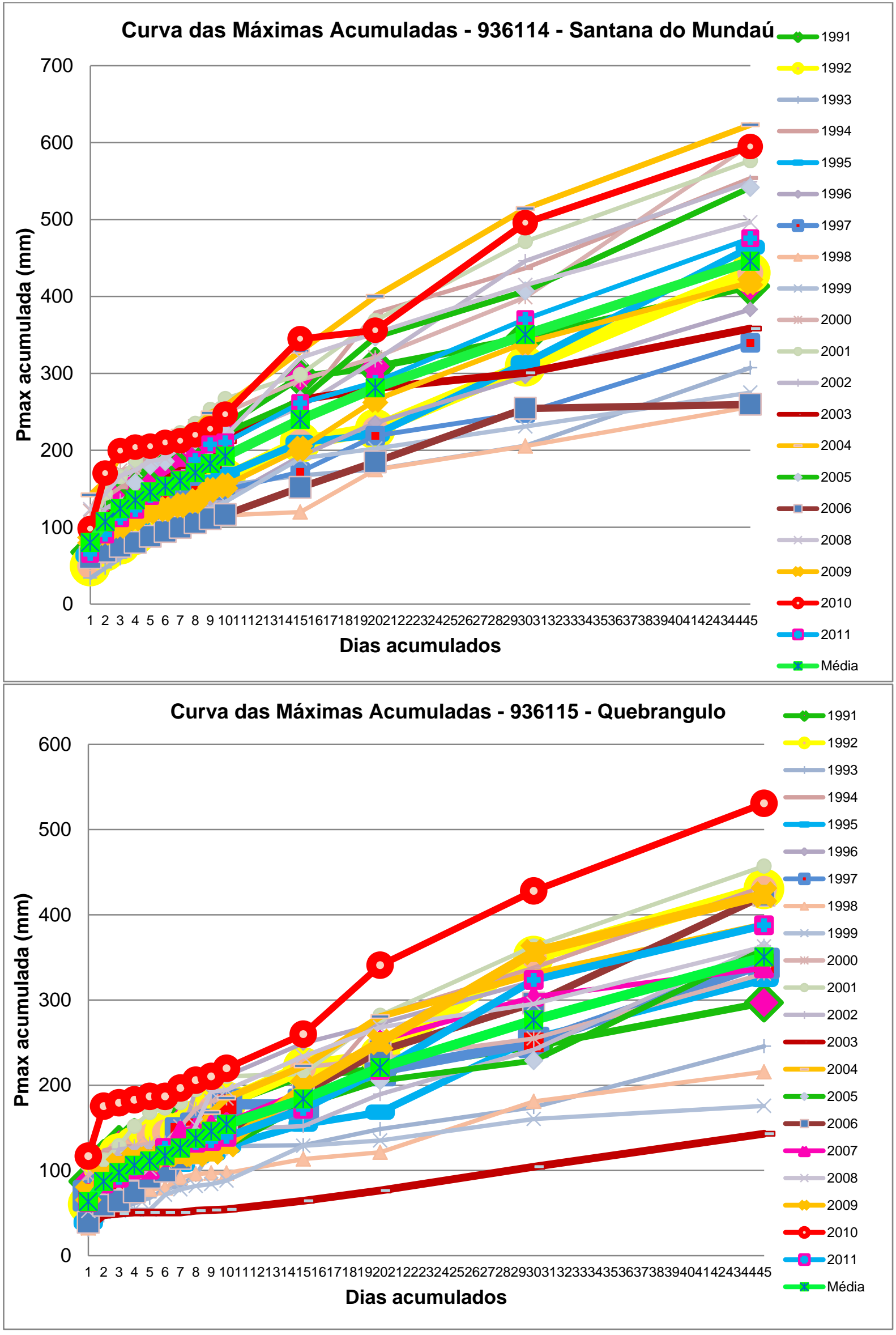

Figura 43 - Curvas das máximas acumuladas para as durações de 1 a 10 dias, 15, 20, 30 e 45 dias 
Através dos gráficos das curvas acumuladas, nota-se que o ano de 2010 foi de chuvas elevadas na maioria das estações, com volumes acumulados bastante expressivos.

Destaca-se o volume acumulado para diferentes durações nas estações: Fazenda Boa Fortuna, Atalaia, Santana do Mundaú e Quebrangulo, com valores acumulados variando de 530 a $700 \mathrm{~mm}$ em apenas 45 dias.

A cheia de 2000 pode ser observada com destaque na estação São José da Laje.

\subsubsection{Classificação das chuvas utilizando o SPI}

O cálculo dos limiares de precipitação foi realizado para cada uma das estações pluviométricas, adotando-se a distribuição de probabilidades de Gumbel, ajustada para as chuvas máximas com diferentes durações.

As séries históricas com intervalos de duração de 1 dia, 2, 3, 4 e 5 dias, calculadas por ano hidrológico foram utilizadas.

A seguir estão ilustrados, através de Tabelas e Figuras, os limiares para a duração de 1 dia. Os limiares para as demais durações estão no Anexo IV.

Tabela 37 - 935012 - Murici - Chuvas máximas anuais com duração de 1 dia

\begin{tabular}{|c|c|c|c|c|c|c|}
\hline Classe de PMDA & \multicolumn{2}{|c|}{ SPI } & p (inf.) & p (sup.) & T (anos) & P 1 dia (mm) \\
\hline Chuva Fraca (CF) & & 0 & & 0,500 & $\leq 2$ & $\leq 73,0$ \\
\hline Chuva Leve (CL) & 0 & 1 & 0,500 & 0,841 & $2<\mathrm{T} \leq 6,3$ & $73,0<\mathrm{T} \leq 103,5$ \\
\hline Chuva Moderada (CM) & 1 & 1,5 & 0,841 & 0,933 & $6,3<\mathrm{T} \leq 15$ & $103,5<\mathrm{T} \leq 123,7$ \\
\hline Chuva Severa (CS) & 1,5 & 2 & 0,933 & 0,977 & $15<\mathrm{T} \leq 44$ & $123,7<\mathrm{T} \leq 147,8$ \\
\hline Chuva Extrema (CE) & 2 & & 0,977 & & $>44$ & $>147,8$ \\
\hline
\end{tabular}




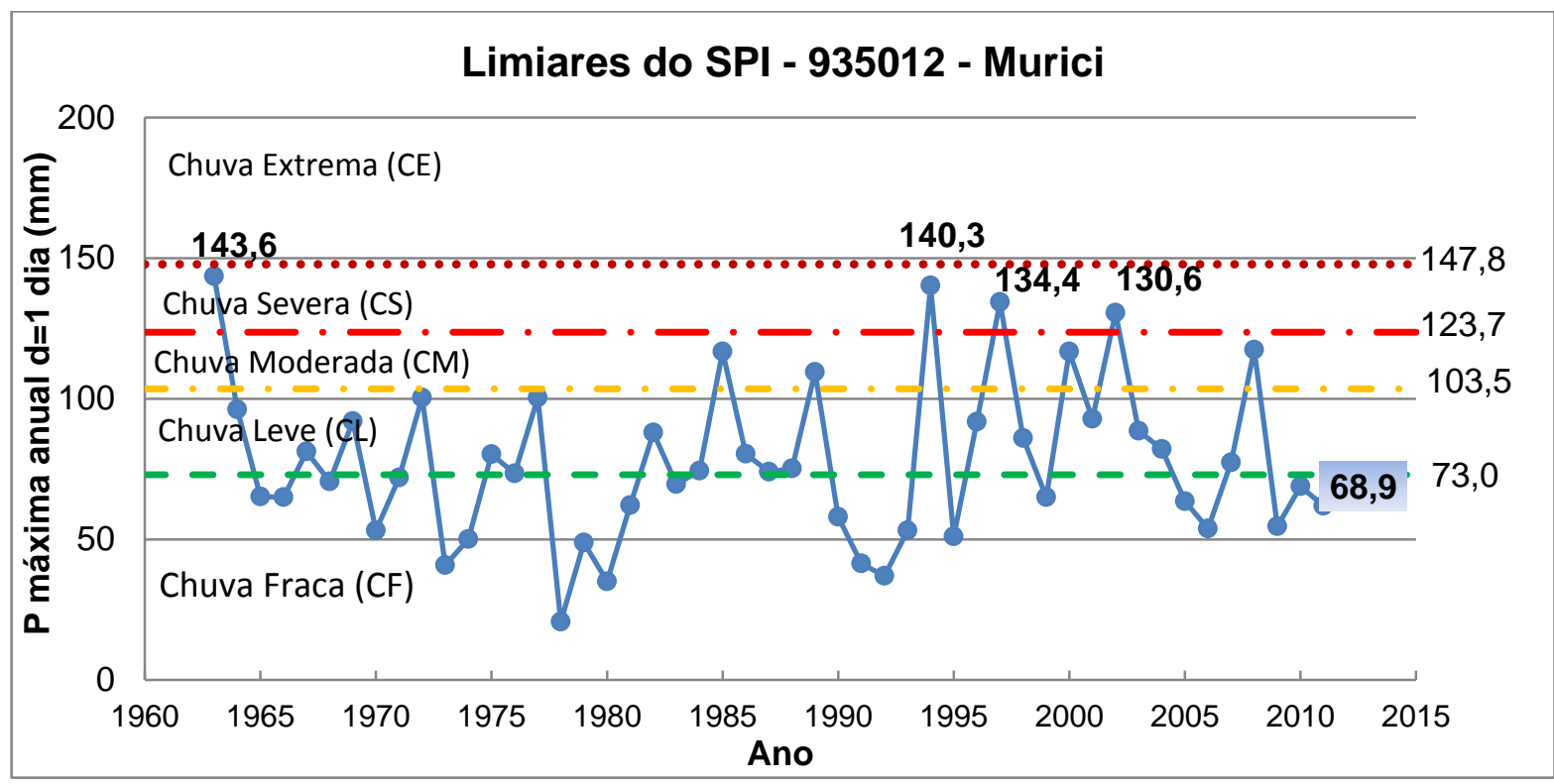

Figura 44 - Classificação das chuvas máximas de duração de 1 dia - 935012 - Murici

Tabela 38 - SPI - 935056 - Fazenda Boa Fortuna - Chuvas máximas anuais com duração de 1 dia

\begin{tabular}{|c|c|c|c|c|c|c|}
\hline Classe de PMDA & \multicolumn{2}{|c|}{ SPI } & p (inf.) & p (sup.) & T (anos) & P 1 dia (mm) \\
\hline Chuva Fraca (CF) & & 0 & & 0,500 & $\leq 2$ & $\leq 93,3$ \\
\hline Chuva Leve (CL) & 0 & 1 & 0,500 & 0,841 & $2<\mathrm{T} \leq 6,3$ & $93,3<\mathrm{T} \leq 144,8$ \\
\hline Chuva Moderada (CM) & 1 & 1,5 & 0,841 & 0,933 & $6,3<\mathrm{T} \leq 15$ & $144,8<\mathrm{T} \leq 178,9$ \\
\hline Chuva Severa (CS) & 1,5 & 2 & 0,933 & 0,977 & $15<\mathrm{T} \leq 44$ & $178,9<\mathrm{T} \leq 219,8$ \\
\hline Chuva Extrema (CE) & 2 & & 0,977 & & $>44$ & $>219,8$ \\
\hline
\end{tabular}

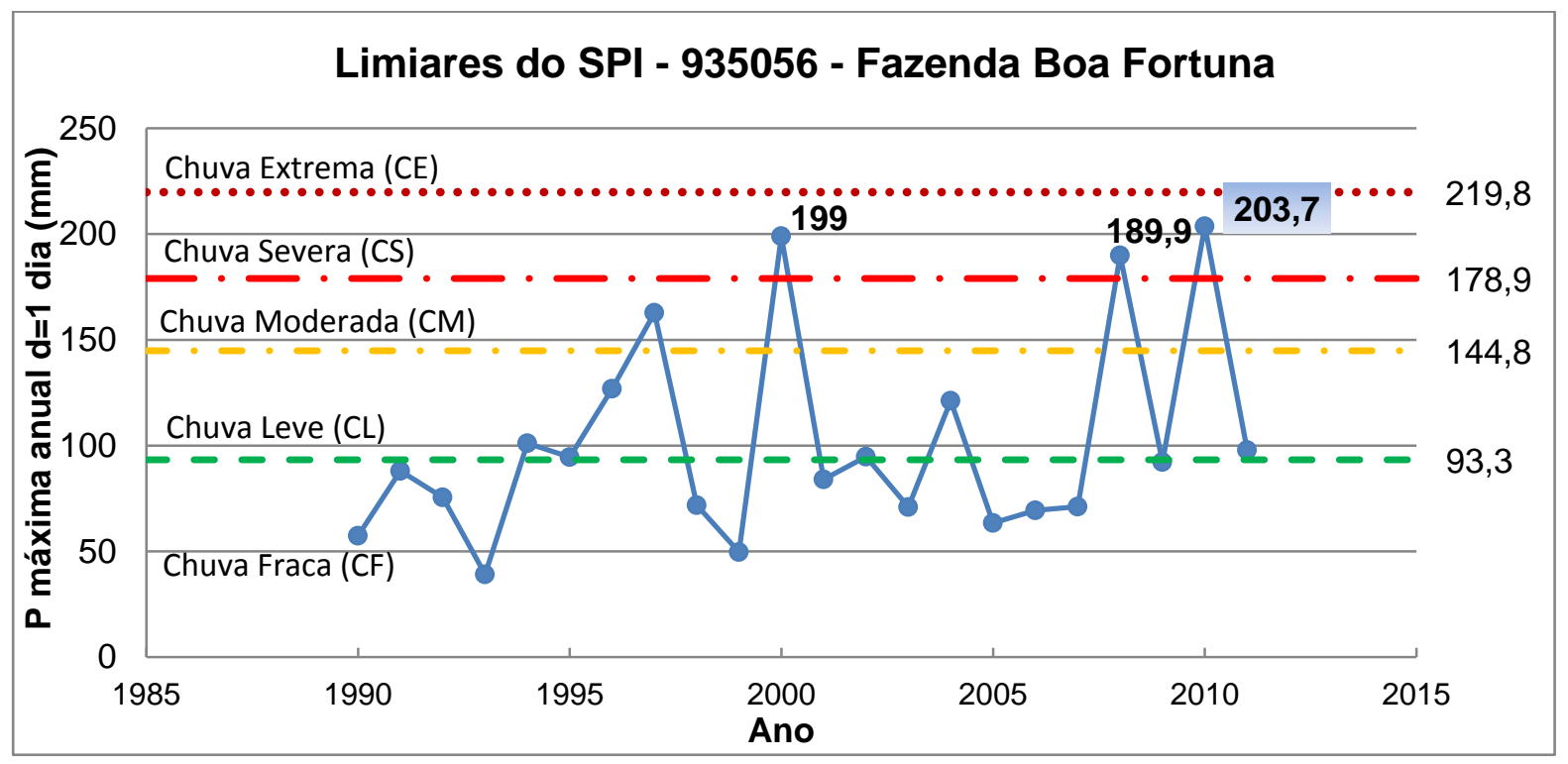

Figura 45 - Classificação das chuvas máximas de duração de 1 dia - 935056 - Fazenda Boa Fortuna 
Tabela 39 - SPI - 935057 - Marechal Deodoro - chuvas máximas anuais com duração de 1 dia

\begin{tabular}{|c|c|c|c|c|c|c|}
\hline Classe de PMDA & \multicolumn{2}{|c|}{ SPI } & p (inf.) & $\mathbf{p}$ (sup.) & T (anos) & P 1 dia (mm) \\
\hline Chuva Fraca (CF) & & 0 & & 0,500 & $\leq 2$ & $\leq 103,6$ \\
\hline Chuva Leve (CL) & 0 & 1 & 0,500 & 0,841 & $2<\mathrm{T} \leq 6,3$ & $103,6<\mathrm{T} \leq 138,6$ \\
\hline Chuva Moderada (CM) & 1 & 1,5 & 0,841 & 0,933 & $6,3<\mathrm{T} \leq 15$ & $138,6<\mathrm{T} \leq 161,7$ \\
\hline Chuva Severa (CS) & 1,5 & 2 & 0,933 & 0,977 & $15<\mathrm{T} \leq 44$ & $161,7<\mathrm{T} \leq 189,3$ \\
\hline Chuva Extrema (CE) & 2 & & 0,977 & & $>44$ & $>189,3$ \\
\hline
\end{tabular}

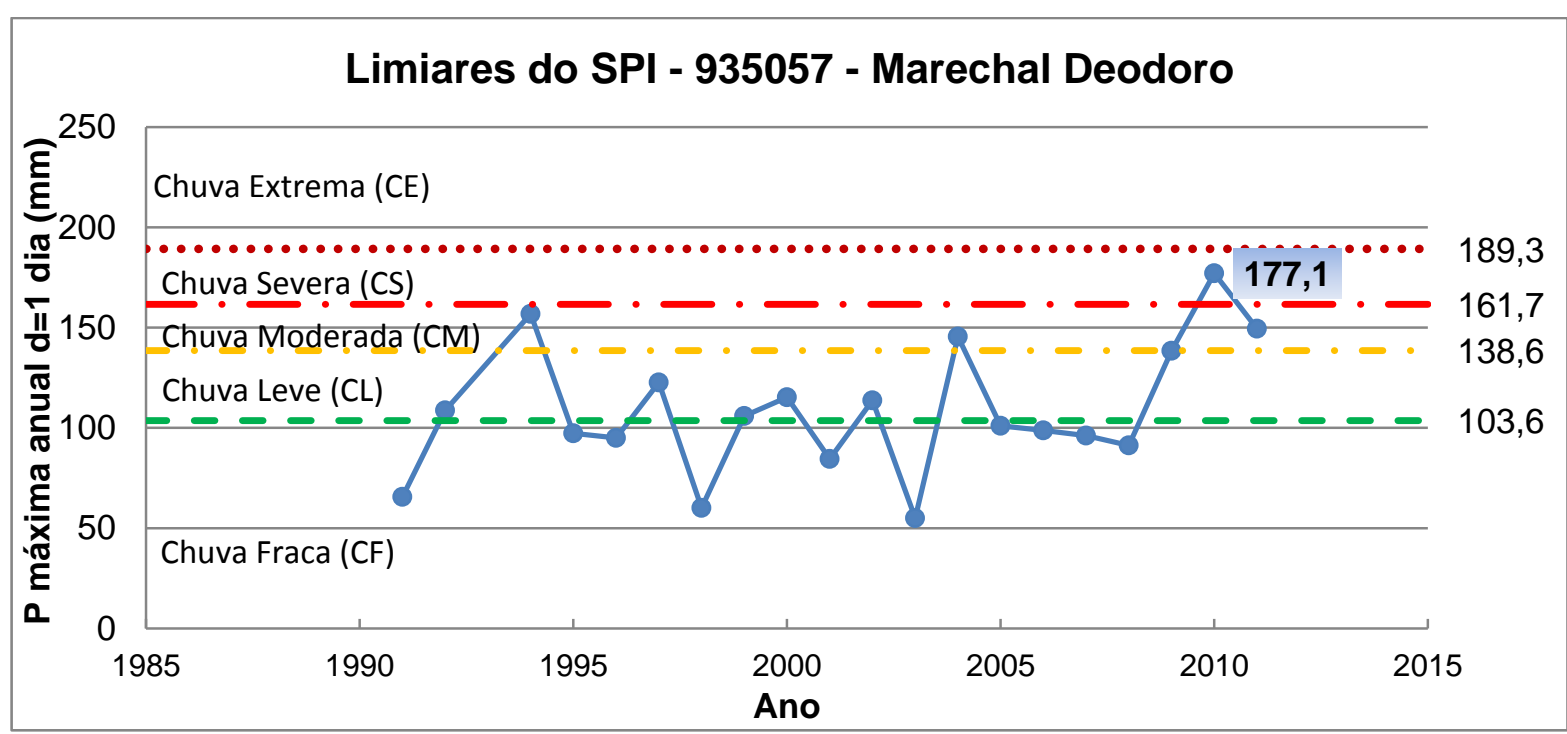

Figura 46 - Classificação das chuvas máximas de duração de 1 dia - 935057 - Marechal Deodoro

Tabela 40 - SPI - 936110 - Atalaia - chuvas máximas anuais com duração de 1 dia

\begin{tabular}{|c|c|c|c|c|c|c|}
\hline Classe de PMDA & \multicolumn{2}{|c|}{ SPI } & p (inf.) & $\mathbf{p}$ (sup.) & T (anos) & P 1 dia (mm) \\
\hline Chuva Fraca (CF) & & 0 & & 0,500 & $\leq 2$ & $\leq 74,2$ \\
\hline Chuva Leve (CL) & 0 & 1 & 0,500 & 0,841 & $2<\mathrm{T} \leq 6,3$ & $74,2<\mathrm{T} \leq 120,4$ \\
\hline Chuva Moderada (CM) & 1 & 1,5 & 0,841 & 0,933 & $6,3<\mathrm{T} \leq 15$ & $120,4<\mathrm{T} \leq 150,9$ \\
\hline Chuva Severa (CS) & 1,5 & 2 & 0,933 & 0,977 & $15<\mathrm{T} \leq 44$ & $150,9<\mathrm{T} \leq 187,4$ \\
\hline Chuva Extrema (CE) & 2 & & 0,977 & & $>44$ & $>187,4$ \\
\hline
\end{tabular}




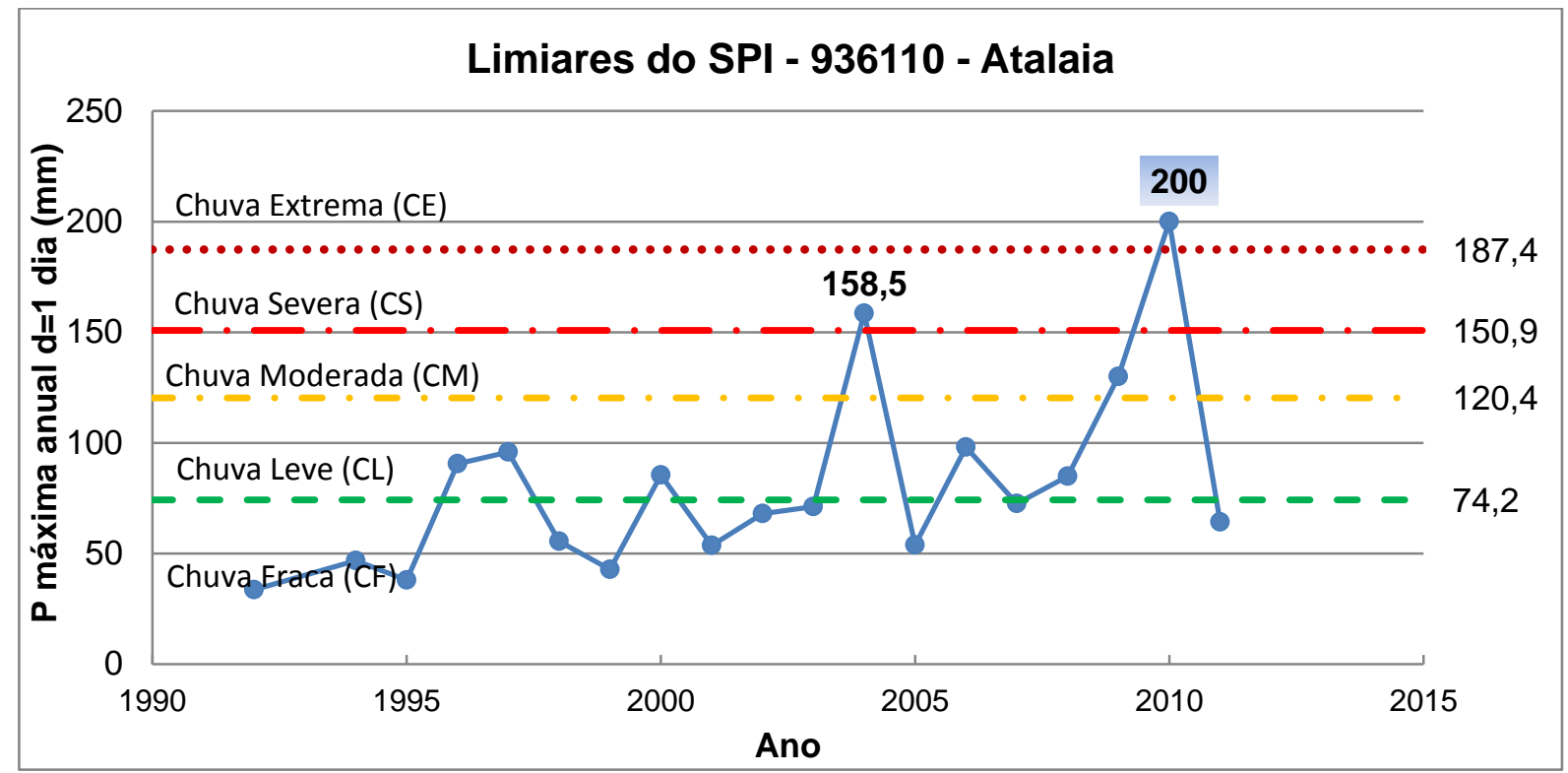

Figura 47 - Classificação das chuvas máximas de duração de 1 dia - 2242024 - 936110 - Atalaia

Tabela 41 - SPI - 936111 - Viçosa - Chuvas máximas anuais com duração de 1 dia

\begin{tabular}{|c|c|c|c|c|c|c|}
\hline Classe de PMDA & \multicolumn{2}{|c|}{ SPI } & p (inf.) & p (sup.) & T (anos) & P 1 dia (mm) \\
\hline Chuva Fraca (CF) & & 0 & & 0,500 & $\leq 2$ & $\leq 60,0$ \\
\hline Chuva Leve (CL) & 0 & 1 & 0,500 & 0,841 & $2<\mathrm{T} \leq 6,3$ & $60,0<\mathrm{T} \leq 88,2$ \\
\hline Chuva Moderada (CM) & 1 & 1,5 & 0,841 & 0,933 & $6,3<\mathrm{T} \leq 15$ & $88,2<\mathrm{T} \leq 106,9$ \\
\hline Chuva Severa (CS) & 1,5 & 2 & 0,933 & 0,977 & $15<\mathrm{T} \leq 44$ & $106,9<\mathrm{T} \leq 129,3$ \\
\hline Chuva Extrema (CE) & 2 & & 0,977 & & $>44$ & $>129,3$ \\
\hline
\end{tabular}

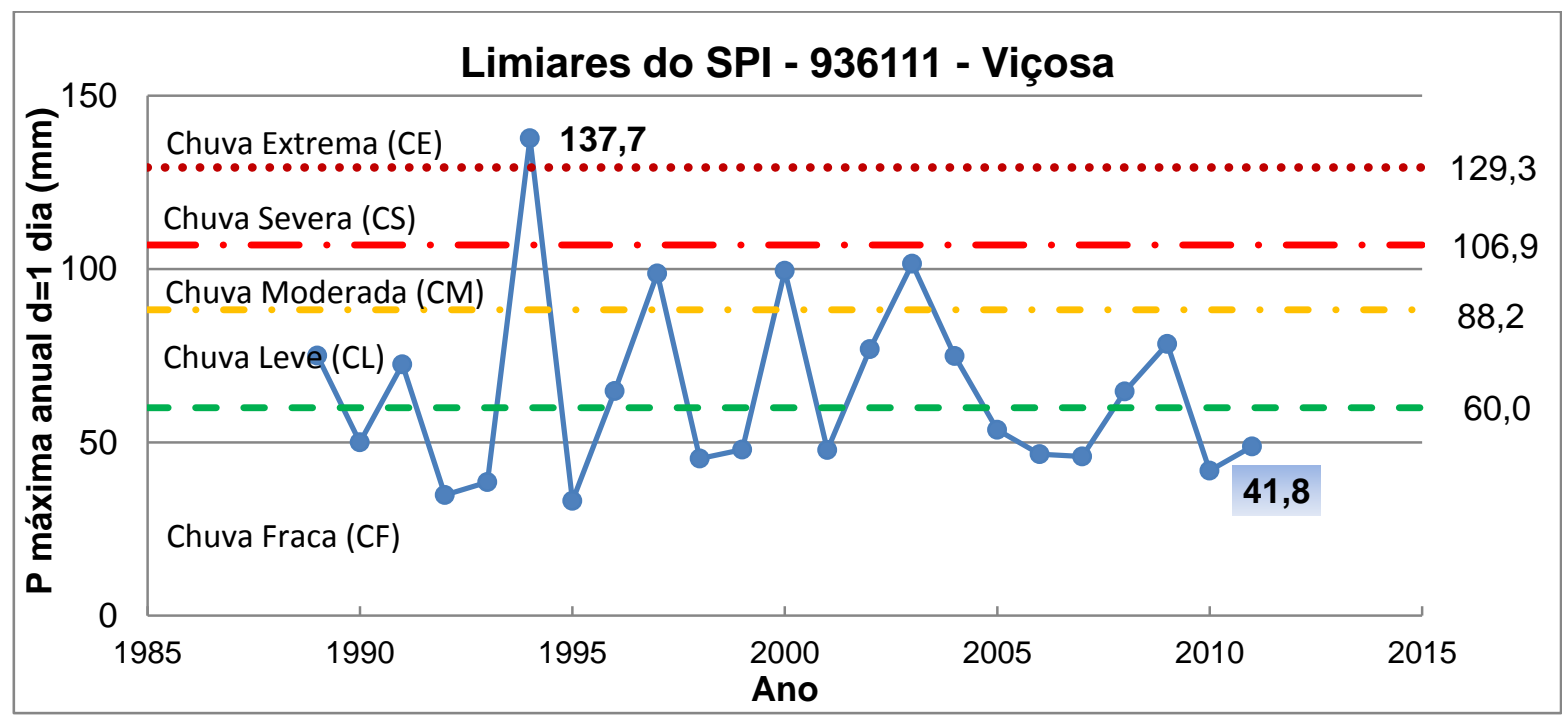

Figura 48 - Classificação das chuvas máximas de duração de 1 dia - 936111 - Viçosa 
Em Viçosa a chuva foi classificada como chuva fraca.

Tabela 42 - SPI - 936112 - São José da Laje - Chuvas máximas anuais com duração de 1 dia

\begin{tabular}{|c|c|c|c|c|c|c|}
\hline Classe de PMDA & \multicolumn{2}{|c|}{ SPI } & p (inf.) & p (sup.) & T (anos) & P 1 dia (mm) \\
\hline Chuva Fraca (CF) & & 0 & & 0,500 & $\leq 2$ & $\leq 67,8$ \\
\hline Chuva Leve (CL) & 0 & 1 & 0,500 & 0,841 & $2<\mathrm{T} \leq 6,3$ & $67,8<\mathrm{T} \leq 90,7$ \\
\hline Chuva Moderada (CM) & 1 & 1,5 & 0,841 & 0,933 & $6,3<\mathrm{T} \leq 15$ & $90,7<\mathrm{T} \leq 105,8$ \\
\hline Chuva Severa (CS) & 1,5 & 2 & 0,933 & 0,977 & $15<\mathrm{T} \leq 44$ & $105,8<\mathrm{T} \leq 123,9$ \\
\hline Chuva Extrema (CE) & 2 & & 0,977 & & $>44$ & $>123,9$ \\
\hline
\end{tabular}

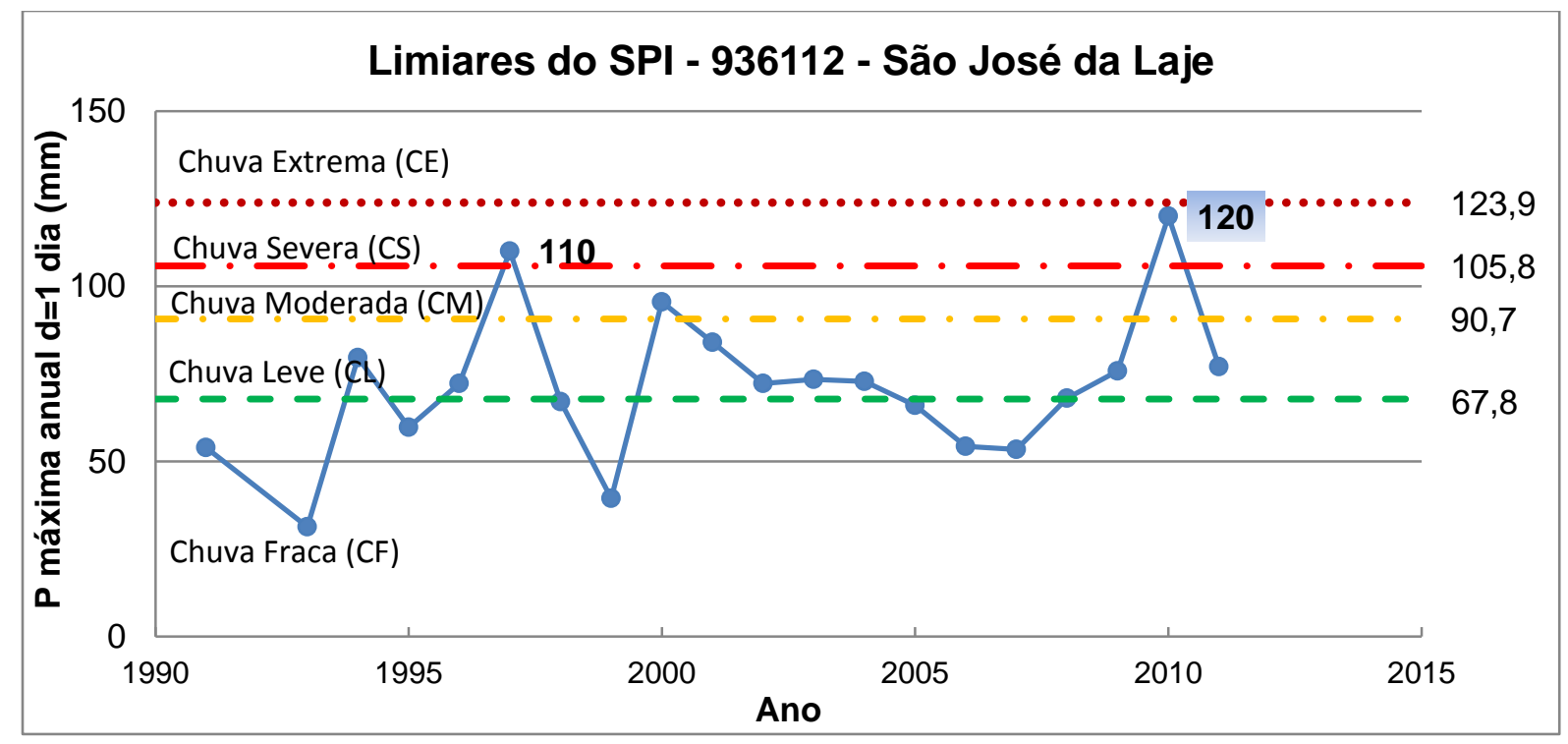

Figura 49 - Classificação das chuvas máximas de duração de 1 dia - 936112 - São José da Laje

Tabela 43 - SPI - 936114 - Santana do Mundaú - Chuvas máximas anuais com duração de 1 dia

\begin{tabular}{|c|c|c|c|c|c|c|}
\hline Classe de PMDA & \multicolumn{2}{|c|}{ SPI } & p (inf.) & $\mathbf{p}$ (sup.) & T (anos) & P 1 dia (mm) \\
\hline Chuva Fraca (CF) & & 0 & & 0,500 & $\leq 2$ & $\leq 75,5$ \\
\hline Chuva Leve (CL) & 0 & 1 & 0,500 & 0,841 & $2<\mathrm{T} \leq 6,3$ & $75,5<\mathrm{T} \leq 105,1$ \\
\hline Chuva Moderada (CM) & 1 & 1,5 & 0,841 & 0,933 & $6,3<\mathrm{T} \leq 15$ & $105,1<\mathrm{T} \leq 124,7$ \\
\hline Chuva Severa (CS) & 1,5 & 2 & 0,933 & 0,977 & $15<\mathrm{T} \leq 44$ & $124,7<\mathrm{T} \leq 148,1$ \\
\hline Chuva Extrema (CE) & 2 & & 0,977 & & $>44$ & $>148,1$ \\
\hline
\end{tabular}




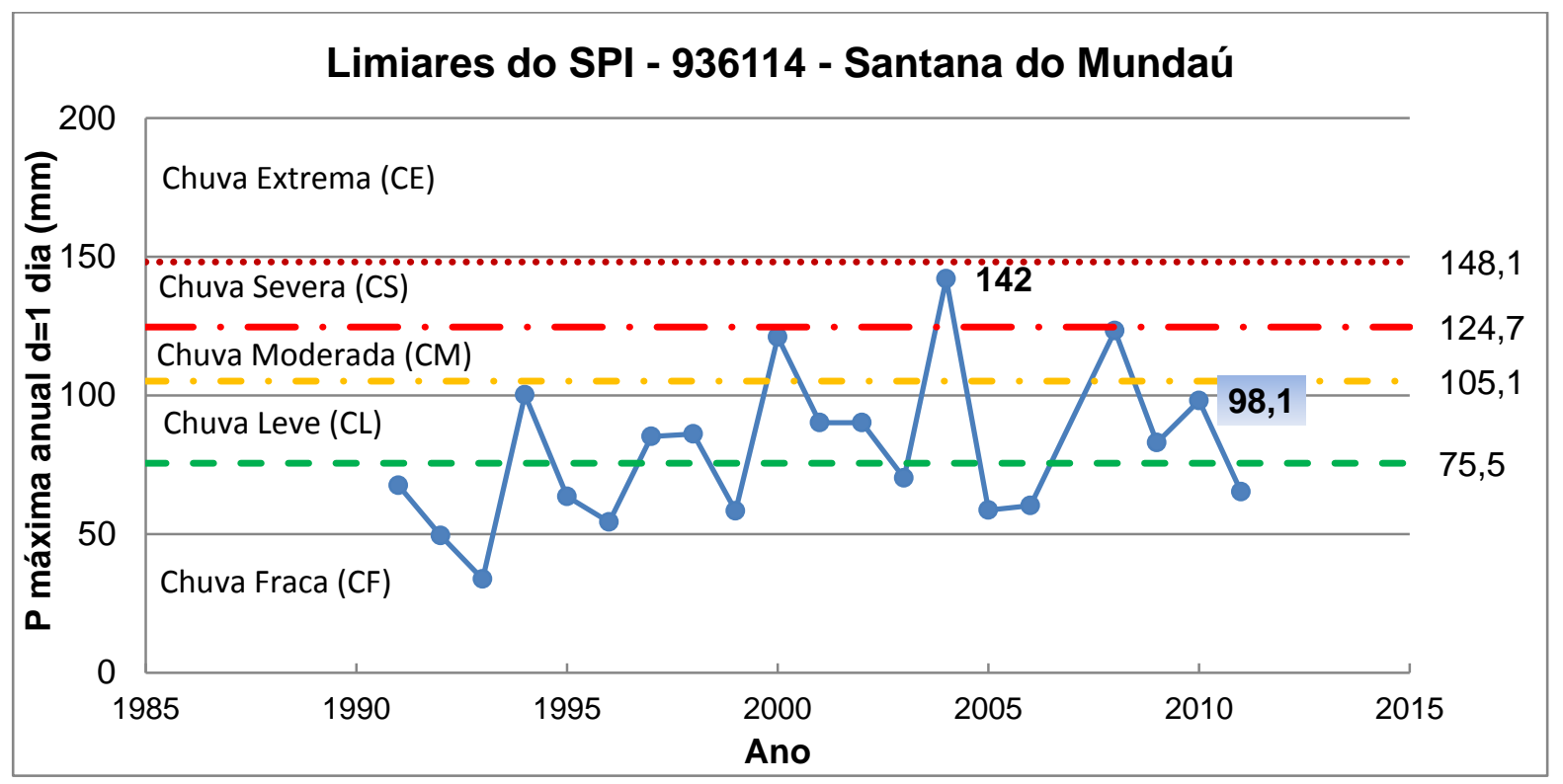

Figura 50 - Classificação das chuvas máximas de duração de 1 dia - 936114 - Santana do Mundaú

Tabela 44 - SPI - 936115 - Quebrangulo - Chuvas máximas anuais com duração de 1 dia

\begin{tabular}{|c|c|c|c|c|c|c|}
\hline Classe de PMDA & \multicolumn{2}{|c|}{ SPI } & p (inf.) & p (sup.) & T (anos) & P 1 dia (mm) \\
\hline Chuva Fraca (CF) & & 0 & & 0,500 & $\leq 2$ & $\leq 59,5$ \\
\hline Chuva Leve (CL) & 0 & 1 & 0,500 & 0,841 & $2<\mathrm{T} \leq 6,3$ & $59,5<\mathrm{T} \leq 84,2$ \\
\hline Chuva Moderada (CM) & 1 & 1,5 & 0,841 & 0,933 & $6,3<\mathrm{T} \leq 15$ & $84,2<\mathrm{T} \leq 100,6$ \\
\hline Chuva Severa (CS) & 1,5 & 2 & 0,933 & 0,977 & $15<\mathrm{T} \leq 44$ & $100,6<\mathrm{T} \leq 120,2$ \\
\hline Chuva Extrema (CE) & 2 & & 0,977 & & $>44$ & $>120,2$ \\
\hline
\end{tabular}

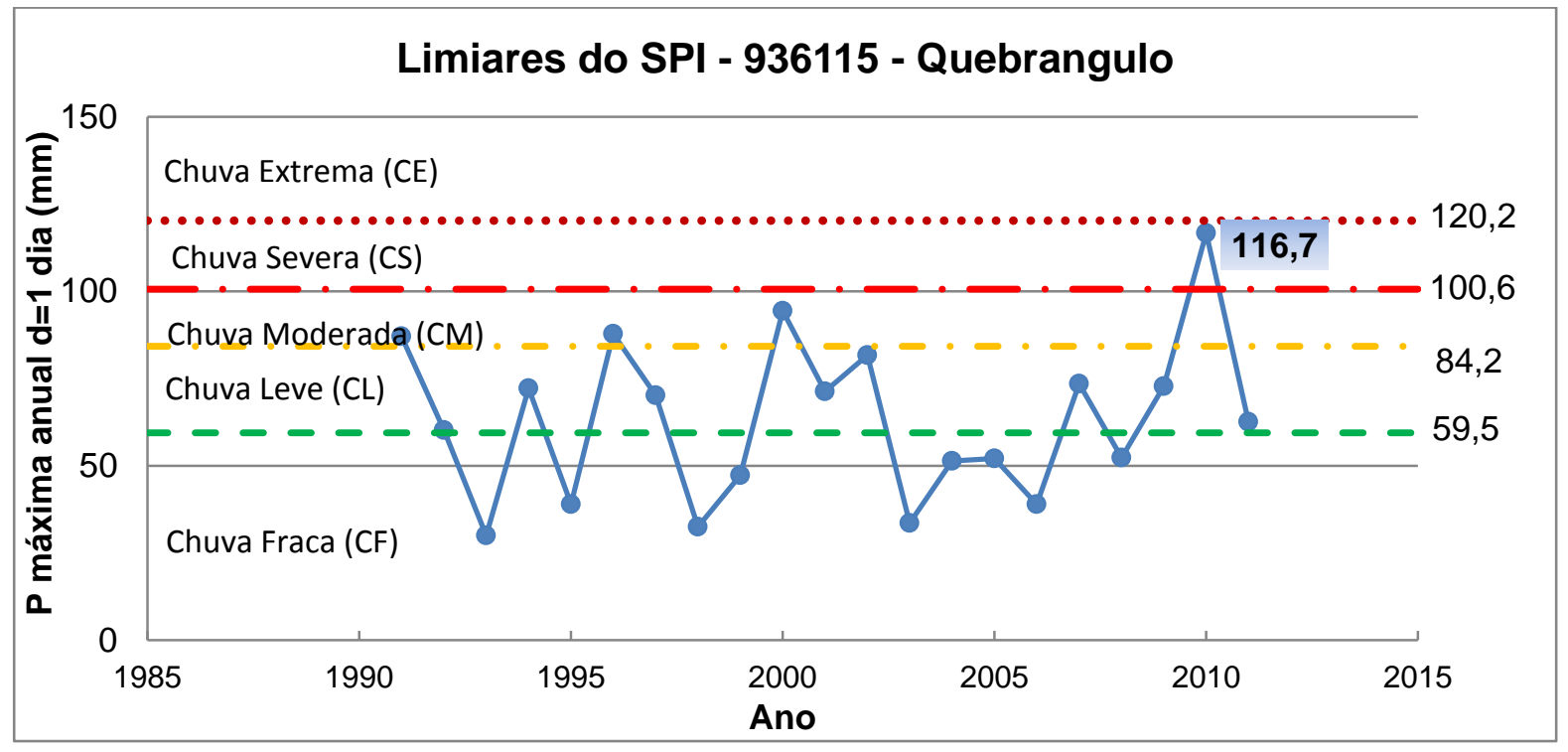

Figura 51 - Classificação das chuvas máximas de duração de 1 dia - 936115 - Quebrangulo 
$\mathrm{Na}$ estação Atalaia, a chuva observada em junho de 2010 foi classificada como chuva extrema. Em quatro estações as chuvas de 2010 foram classificadas como chuvas severas: Fazenda Boa Fortuna, Marechal Deodoro, São José da Laje e Quebrangulo. Em Santana do Mundaú a chuva foi classificada de chuva leve e nas demais estações, Murici e Viçosa, como chuva fraca.

\subsubsection{Conclusões}

No ano de 2010, as chuvas máximas diárias observadas no mês de junho foram acima da média na maioria das estações, sendo as máximas registradas em cinco das oito estações analisadas desde que se iniciaram as leituras. Nas estações localizadas em Atalaia e Rio Largo choveu 200 mm e 203,7 mm no dia 5 de junho, valor muito acima da média, que corresponde a $72,3 \mathrm{~mm}$ e $101 \mathrm{~mm}$ nas duas estações. Acredita-se que a catástrofe de 2010 tenha sido desencadeada pelo elevado volume precipitado no dia 5 , combinado com o período chuvoso nos dias 17,18 e 19 desse mesmo mês, quando ocorreram as inundações. As inundações nessas estações ocorreram no dia 19.

Nas estações onde as chuvas foram as máximas históricas, os períodos de retorno, estimados através da distribuição de Gumbel, variaram de 28 a 64 anos. Nas estações Fazenda Boa Fortuna, Marechal Deodoro, São José da Laje e Quebrangulo, os Trs foram bem parecidos, variando de 28 a 35 anos. Em Atalaia, o $\operatorname{Tr}$ foi 64 anos. Portanto, estas chuvas não são raras, possuem períodos de retorno relativamente baixos.

Os volumes acumulados nos meses anteriores ao evento não foram elevados, ficando acima da média no mês de abril em algumas estações.

Portanto, as inundações podem ter sido causadas principalmente pelas chuvas diárias elevadas no mês de junho de 2010. A ocupação das planícies de inundação contribuiu para a catástrofe observada nas bacias dos rios Mundaú e Paraíba. 
Apesar das chuvas de 2010 serem elevadas, outros valores elevados já foram registrados nessas estações, como ilustrado na Figura 42, indicando que esses eventos são característicos da região.

De acordo com a classificação através do SPI, na maioria das estações as chuvas foram classificadas como chuvas severas ou extremas. Em quatro estações as chuvas de 2010 foram classificadas como chuvas severas: Fazenda Boa Fortuna, Marechal Deodoro, São José da Laje e Quebrangulo. Na estação Atalaia, a chuva observada em junho de 2010 foi classificada como chuva extrema.

Em Santana do Mundaú a chuva foi classificada de chuva leve e nas estações, Murici e Viçosa, como chuva fraca.

Apesar da severidade das chuvas, estas ocorrem com certa frequência na região. Neste caso, o desastre está relacionado à ocupação desordenada das planícies de inundação. 


\subsection{REGIÃO SERRANA DO RIO DE JANEIRO}

Em janeiro de 2011 as chuvas que atingiram a Região Serrana do Estado do Rio de Janeiro foram responsáveis por uma das maiores tragédias ocorridas no Brasil. Várias cidades foram atingidas como Nova Friburgo, Petrópolis, Teresópolis, Bom Jardim, São José do Vale do Rio Preto, Sumidouro, dentre outras. Houve escorregamento de encostas, enchentes, rolamento de blocos de pedras que soterraram bairros inteiros, deixando inúmeras vítimas e várias pessoas desabrigadas. As chuvas elevadas e o relevo íngreme da região contribuíram para o cenário de destruição (MEDEIROS; BARROS, 2011).

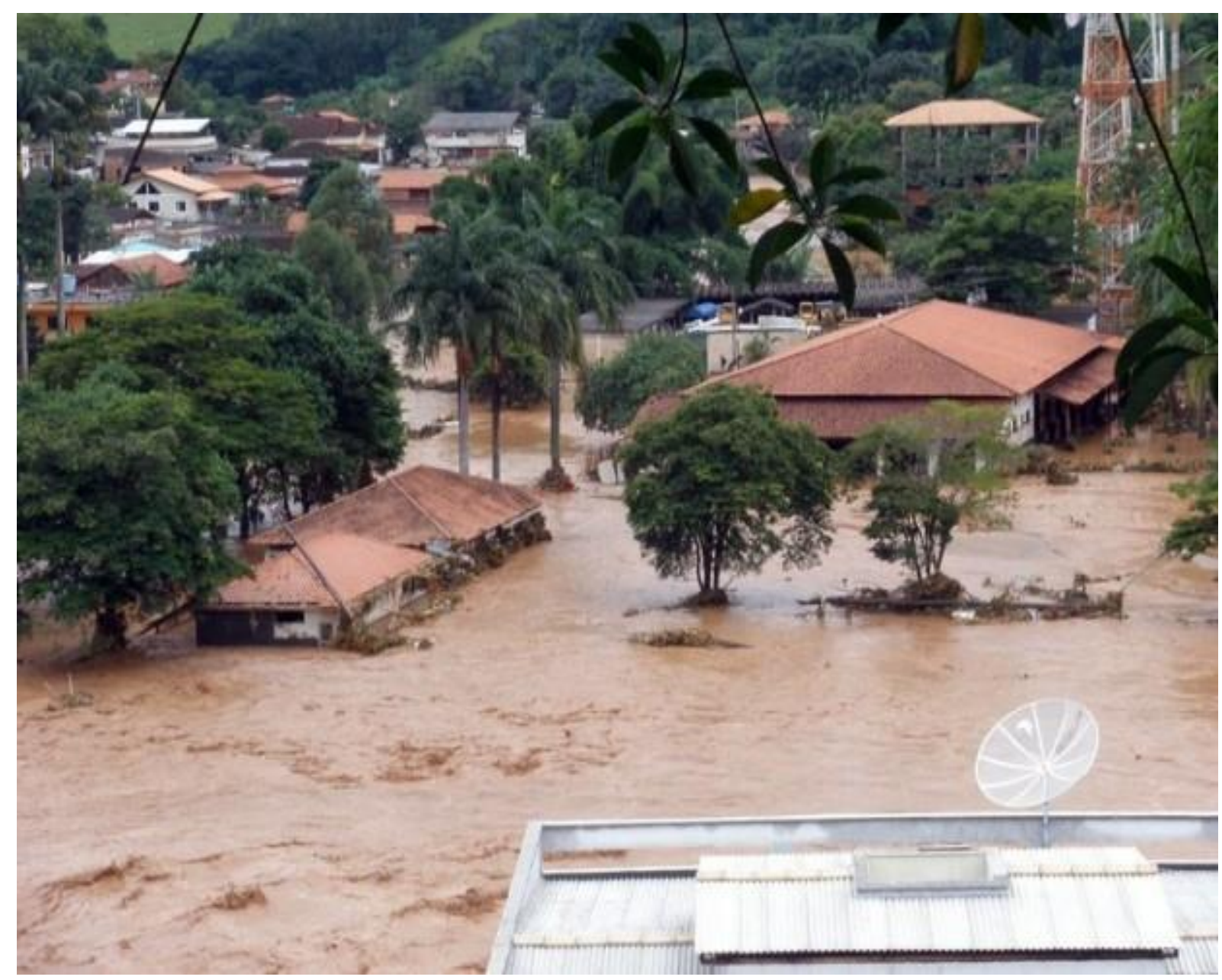

Figura 52 - Município de Bom Jardim na Região Serrana do Rio de Janeiro (Fonte: VEJA, Foto: Ana Amélia Erthal) 


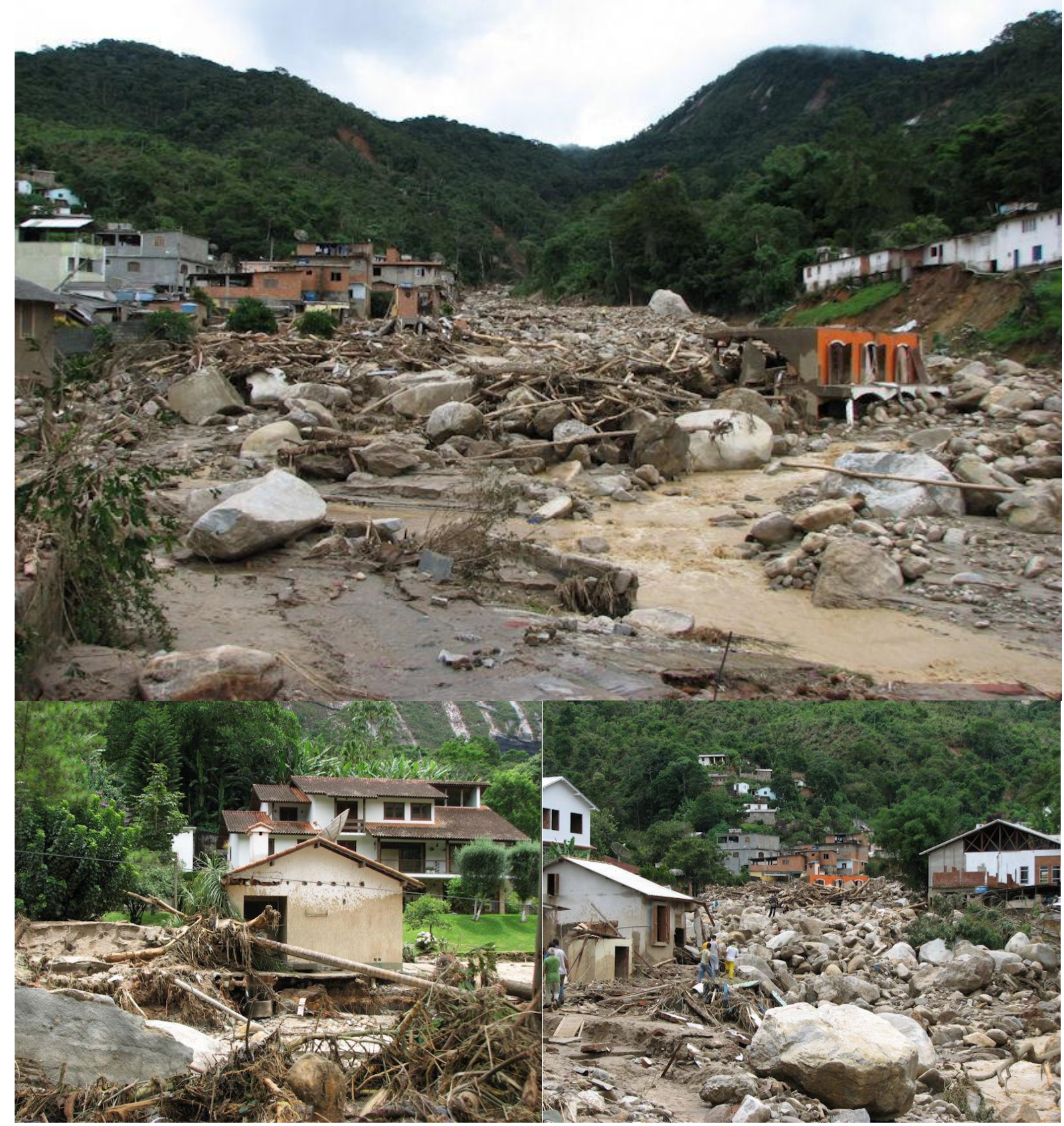

Figura 53 - Comunidade de Campo Grande localizada no bairro Posse, município de Teresópolis (Fonte: Tragédia em Teresópolis, 2011, Fotos: Flavio Morgado)

Os escorregamentos ocorridos próximos à Nova Friburgo foram impressionantes, atingindo enormes áreas, soterrando bairros inteiros. As "cicatrizes" deixadas na região podem ser visualizadas nas imagens do Google. Áreas que antes eram totalmente cobertas de mata verde ficaram com o solo aparente nos lugares onde ocorreram os escorregamentos. 

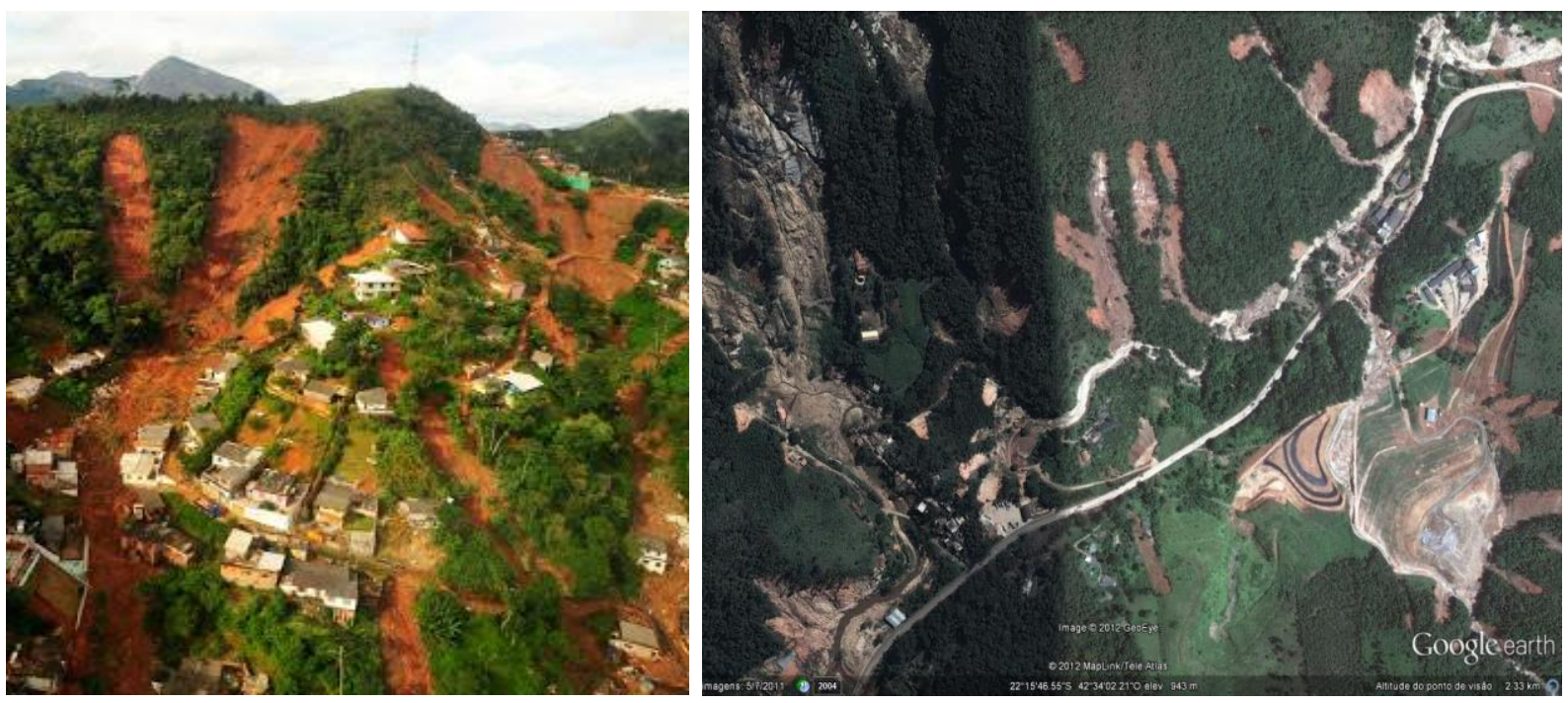

Figura 54 - Cicatrizes em Nova Friburgo e na Imagem do Google

(Fonte: Foto de Marino Azevedo/ Governo do Estado do Rio de Janeiro; Imagem do Google Earth)

De acordo com dados do boletim infoclima de janeiro de 2011, do INPE e CPTEC, os eventos extremos que se observaram em meados de janeiro de 2011, na Região Sudeste do Brasil, foram causados: pela atuação da Zona de Convergência do Atlântico Sul (ZCAS), que costuma ocorrer nos meses de verão, e também foram modulados pelo sinal da Oscilação Intrassazonal Madden-Julian (OMJ). O sinal favorável desta oscilação persistiu até meados de janeiro, intensificando a ZCAS e, consequentemente, as chuvas no sul da Região Sudeste.

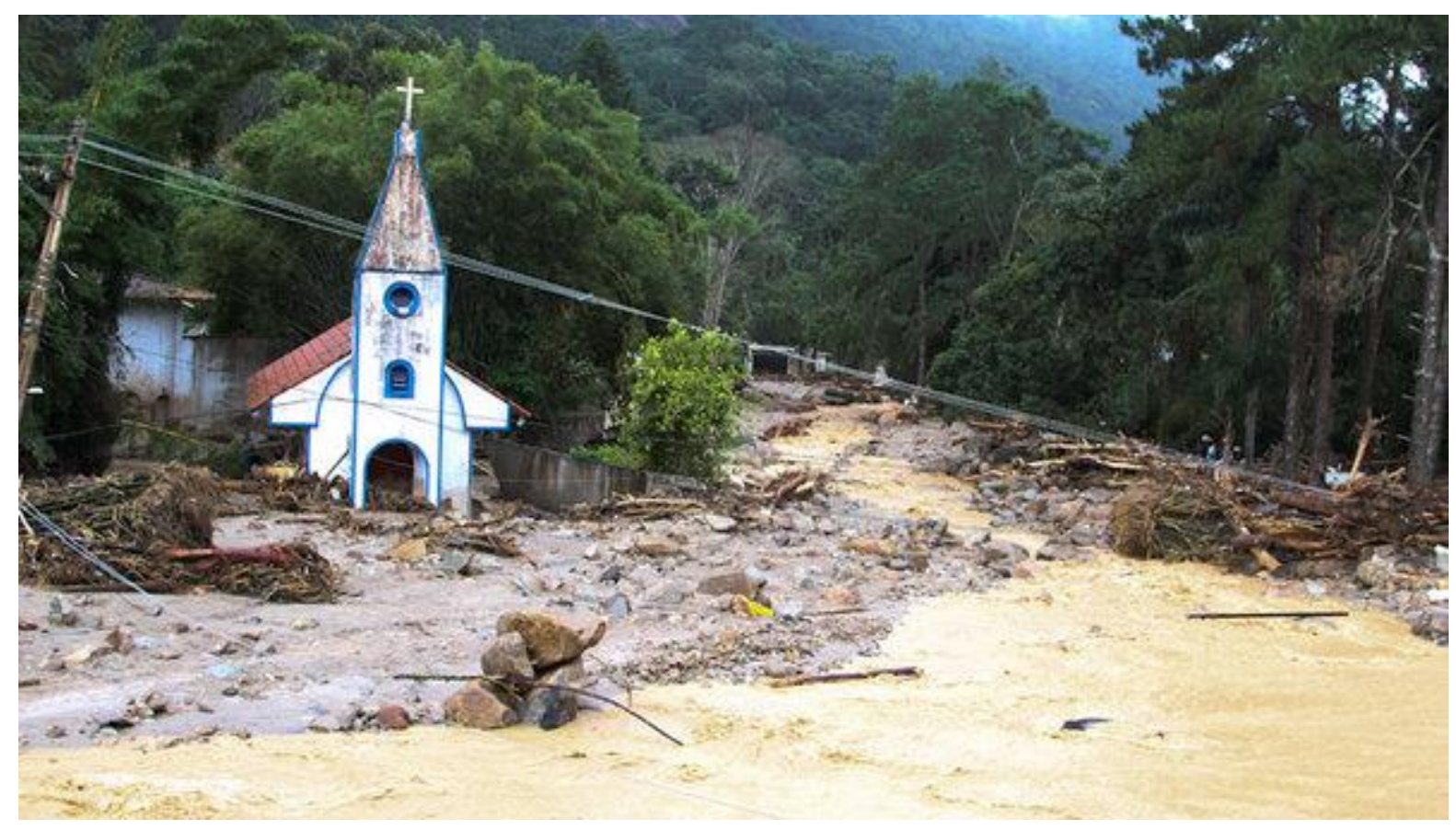

Figura 55 - Igreja do bairro Posse em Teresópolis

(Fonte: Tragédia em Teresópolis, 2011, Foto: Marcos Michel) 


\subsubsection{Descrição da área de estudo e estações pluviométricas utilizadas}

A Região Serrana do Rio de Janeiro está localizada na Serra do Mar, que particularmente recebe o nome de Serra dos Órgãos no entorno das cidades de Nova Friburgo, Petrópolis e Teresópolis, onde o estudo foi realizado. Possui relevo acentuado e escarpado, com altitudes que variam de 650 metros até 1.100 metros nos locais onde foram feitas as leituras de chuva, podendo atingir mais de 2.200 metros em alguns pontos turístico da região, como a Pedra do Sino, localizada no município de Teresópolis (MEDEIROS; BARROS, 2011).

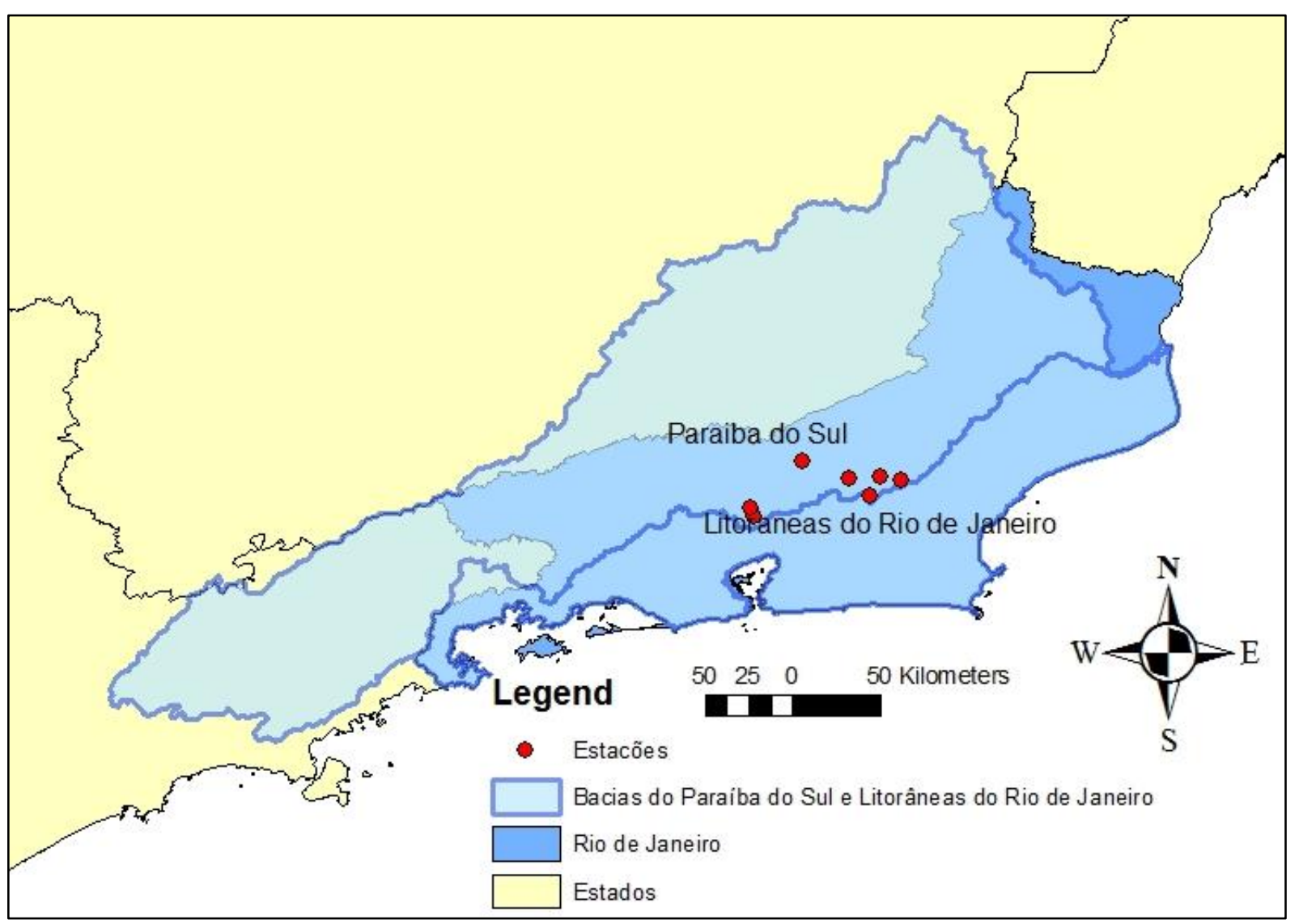

Figura 56 - Localização da Bacia do Paraíba do Sul e postos utilizados no estudo da Região Serrana do Rio de Janeiro

Muitas moradias estão localizadas em encostas de morros ou áreas ripárias. A vulnerabilidade da região é elevada, com alto risco de ocorrência de inundações e escorregamentos de encostas, principalmente no verão, onde as chuvas são mais intensas. 
O clima da região é classificado, segundo Köppen, como Subtropical de Altitude (Cwb), que tem como características verões chuvosos e invernos mais frios e secos. As temperaturas são mais amenas que nas regiões de menor altitude.

As estações da Região Serrana fluminense, utilizadas nesse estudo, fazem parte da bacia do Paraíba do Sul, que banha os Estados de São Paulo, Rio de Janeiro e Minas Gerais. Suas altitudes variam de 650 e 1100 metros e estão localizadas próximas à divisa com a bacia das litorâneas do Rio de Janeiro. As precipitações médias anuais ficam em torno de $1500 \mathrm{~mm}$ na maioria dos postos utilizados no estudo, chegando a $3200 \mathrm{~mm}$ em uma das estações localizadas em Nova Friburgo e os meses mais chuvosos são dezembro e janeiro.

Foram selecionadas sete estações pluviométricas operadas pela CPRM Serviço Geológico do Brasil, localizadas nos municípios de Nova Friburgo, Petrópolis e Teresópolis. A seleção foi feita de acordo com dados disponíveis, pois em algumas estações as chuvas destruíram até mesmo os pluviômetros, que tiveram que ser reinstalados.

$\mathrm{Na}$ Tabela 45 estão relacionadas as estações pluviométricas selecionadas na Região Serrana, que fazem parte da bacia hidrográfica do rio Paraíba do Sul (58).

Tabela 45 - Relação das sete estações pluviométricas da Região Serrana do RJ

\begin{tabular}{|c|c|c|c|c|c|c|c|}
\hline Código & Estação & Bacia & Latitude & Longitude & $\begin{array}{c}\text { Alt. } \\
(\mathbf{m})\end{array}$ & $\begin{array}{c}\text { Esta } \\
\text { do }\end{array}$ & Município \\
\hline 2242019 & Vargem Alta & 58 & $-22,3080$ & $-42,4000$ & 1.100 & RJ & $\begin{array}{c}\text { Nova } \\
\text { Friburgo }\end{array}$ \\
\hline 2242020 & $\begin{array}{c}\text { Vargem } \\
\text { Grande }\end{array}$ & 58 & $-22,2770$ & $-42,5022$ & 680 & RJ & $\begin{array}{c}\text { Nova } \\
\text { Friburgo }\end{array}$ \\
\hline 2242022 & $\begin{array}{c}\text { Fazenda } \\
\text { Mendes }\end{array}$ & 58 & $-22,2858$ & $-42,6600$ & 1.010 & RJ & $\begin{array}{c}\text { Nova } \\
\text { Friburgo }\end{array}$ \\
\hline 2242024 & $\begin{array}{c}\text { Teodoro de } \\
\text { Oliveira }\end{array}$ & 58 & $-22,3789$ & $-42,5542$ & 1.100 & RJ & $\begin{array}{c}\text { Nova } \\
\text { Friburgo }\end{array}$ \\
\hline 2242027 & $\begin{array}{c}\text { Fazenda } \\
\text { Sobradinho }\end{array}$ & 58 & $-22,2011$ & $-42,9000$ & 650 & RJ & Teresópolis \\
\hline 2243010 & Itamarati - SE & 58 & $-22,4853$ & $-43,1492$ & 1.085 & RJ & Petrópolis \\
\hline 2243011 & $\begin{array}{c}\text { Rio da } \\
\text { Cidade }\end{array}$ & 58 & $-22,4381$ & $-43,1703$ & 704 & RJ & Petrópolis \\
\hline
\end{tabular}




\subsubsection{Análise estatística dos dados de chuva}

\subsubsection{Meses que antecedem os eventos}

Foram analisados os totais mensais dos meses que antecedem o evento crítico de janeiro de 2011. As médias mensais de cada série histórica foram calculadas e plotadas nos gráficos da Figura 57, que contém também os totais mensais do ano de 2010 e dos meses disponíveis de 2011.

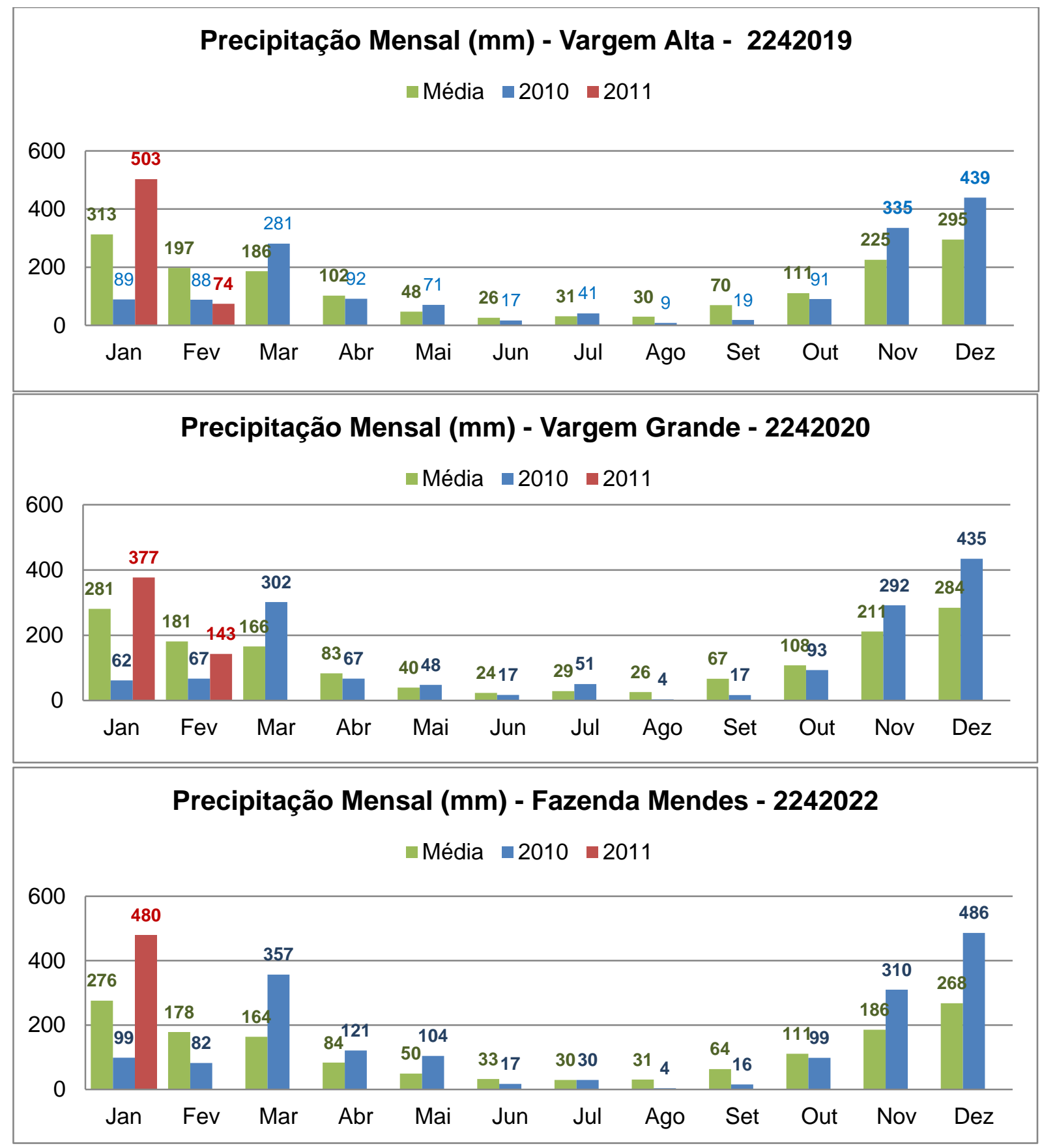

Figura 57 - Totais mensais dos anos 2010 e 2011 e média mensal histórica (continua) 


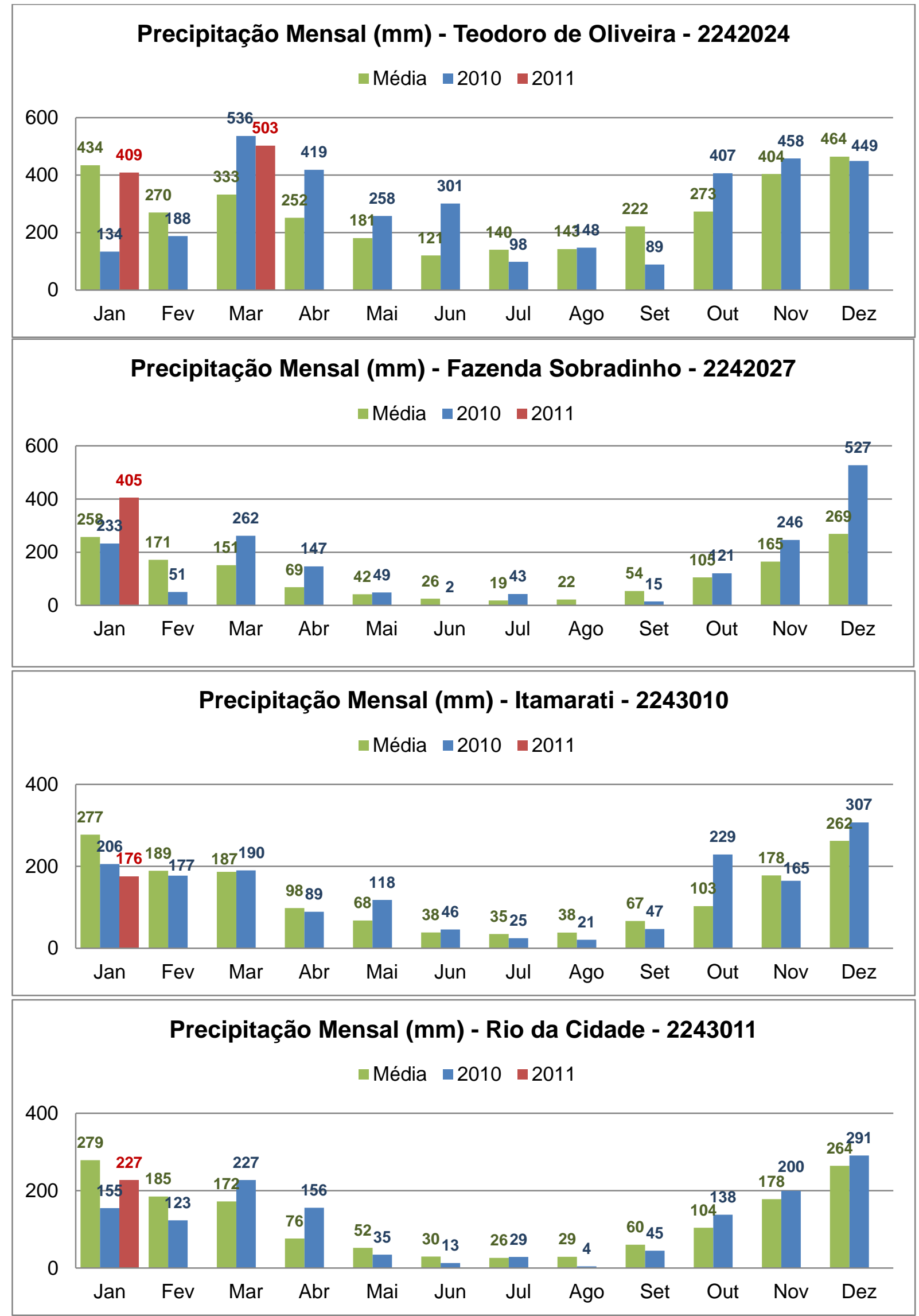

Figura 57 - Totais mensais dos anos 2010 e 2011 e média mensal histórica 
Percebe-se que os meses de novembro e dezembro de 2010, que antecedem os eventos críticos de janeiro de 2011, foram bastante chuvosos. Na maioria das estações choveu mais que a média nesses meses.

\subsubsection{Estatísticas básicas}

Para entender a magnitude dos eventos, foram calculadas algumas estatísticas básicas como: a precipitação máxima diária no mês em que o evento ocorreu, neste caso o mês de janeiro de 2011, ( $P_{\max }$ jan/11); o dia da máxima; a precipitação média das máximas diárias anuais $\left(P_{\text {med }} \max \right)$; o total mensal de janeiro

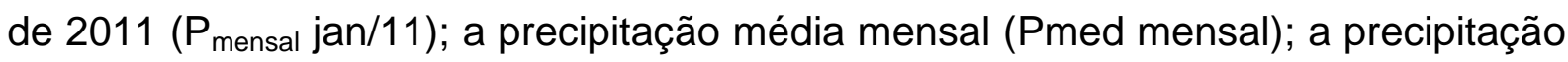
média anual (Pmed anual). Os dados são ilustrados na Tabela 46.

Tabela 46 - Chuvas de janeiro de 2011, médias das máximas e médias mensais e anuais das estações da Região Serrana

\begin{tabular}{|c|c|c|c|c|c|c|c|c|}
\hline Código & Estação & Dados & $\begin{array}{r}P_{\max } \\
\text { jan/11 } \\
(\mathrm{mm})\end{array}$ & $\begin{array}{c}\text { Dia } \\
\text { da } \\
\text { max }\end{array}$ & $\begin{array}{c}P_{\text {med }} \\
\text { das } \\
\text { max } \\
(\mathrm{mm})\end{array}$ & $\begin{array}{c}P \\
\text { mensal } \\
\text { jan/11 } \\
(\mathrm{mm})\end{array}$ & $\begin{array}{c}P_{\text {me }} \\
d \\
\text { mens } \\
\text { al }(m \\
m) \\
\end{array}$ & $\begin{array}{l}P_{\text {med }} \\
\text { anual } \\
(\mathrm{mm})\end{array}$ \\
\hline 2242019 & Vargem Alta & dez/65 a fev/11 & 271,5 & 12 & 90,3 & 503 & 313 & 1.627 \\
\hline 2242020 & Vargem Grande & dez/65 a fev/11 & 183,5 & 12 & 77,5 & 377 & 281 & 1.499 \\
\hline 2242022 & Fazenda Mendes & jul/49 a jan/11 & 225,4 & 12 & 74,6 & 480 & 276 & 1.478 \\
\hline 2242024 & Teodoro de Oliveira & $\mathrm{dez} / 65$ a mar/11 & 112,4 & 11 & 112,2 & 409 & 434 & 3.235 \\
\hline 2242027 & Fazenda Sobradinho & mai/36 a jan/11 & 145,5 & 12 & 77 & 405 & 258 & 1.342 \\
\hline 2243010 & Itamarati - SE & jul/38 a jan/11 & 45,7 & 12 & 89,2 & 176 & 277 & 1.541 \\
\hline 2243011 & Rio da Cidade & ago/38 a jan/11 & 60,4 & 12 & 86,2 & 227 & 279 & 1.455 \\
\hline
\end{tabular}

Nota-se que em quatro das sete estações, as chuvas máximas diárias de janeiro de 2011 foram bem acima da média das máximas.

\subsubsection{Análise do mês em que ocorre a chuva catastrófica}

Em seguida foram analisados os eventos críticos de janeiro de 2011. 
As chuvas diárias de todas as estações foram plotadas no gráfico da Figura 58.

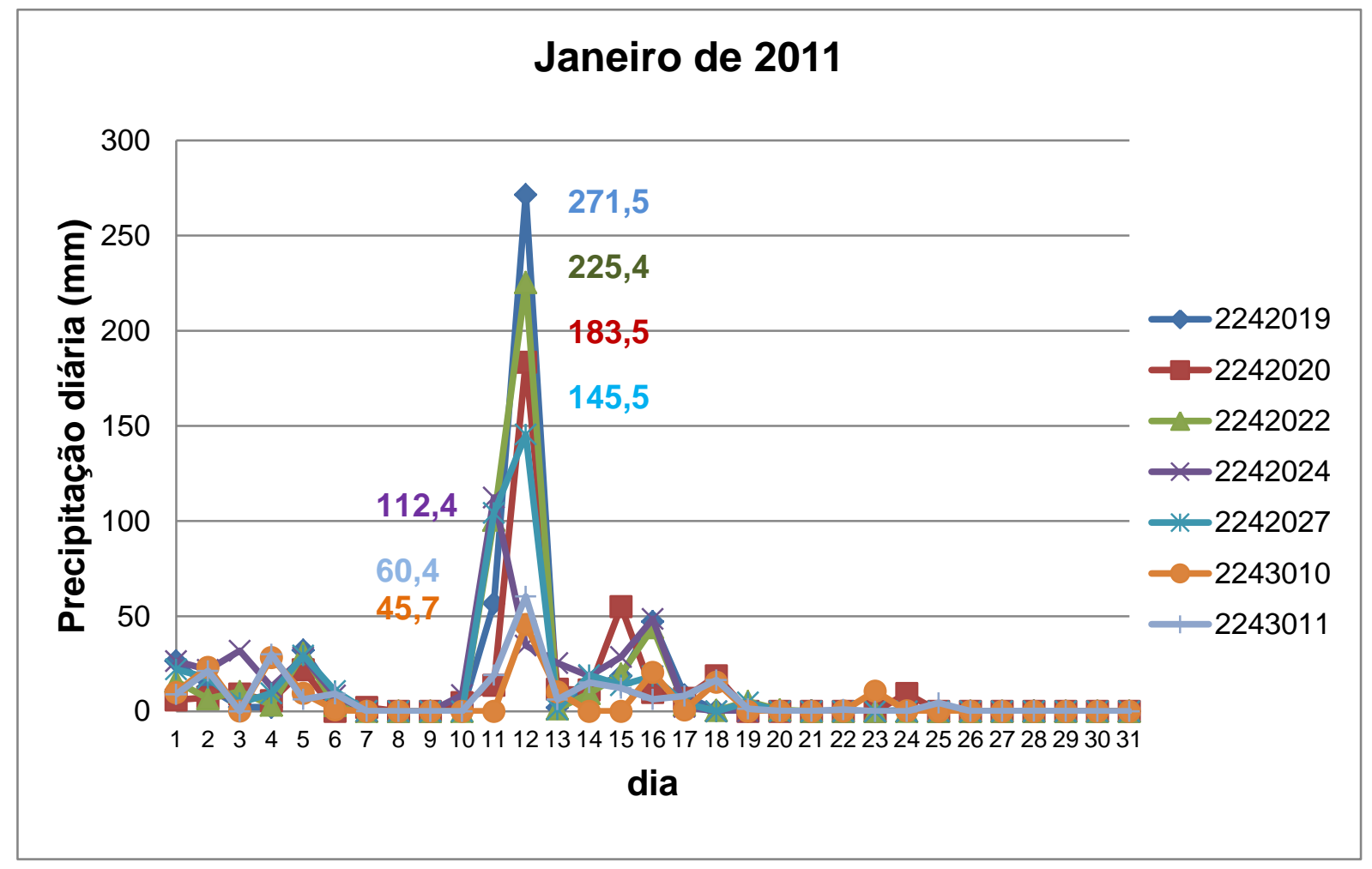

Figura 58 - Precipitação diária de janeiro de 2011

Em todas as estações as chuvas foram elevadas nos dias 11 ou 12 de janeiro de 2011.

Destaca-se o volume precipitado na estação Vargem Alta, que atingiu 271,5 mm, seguido de 225,4 mm em Fazenda Mendes e 183,5 mm em Vargem Grande localizadas no município de Nova Friburgo. Em Teodoro de Oliveira, no mesmo município, o volume precipitado foi um pouco menor, de 112,4 mm.

Na estação Fazenda Sobradinho, no município de Teresópolis, choveu 145,5 $\mathrm{mm}$ no dia 12 e 104,3 mm no dia 11 , somando um volume de $249,8 \mathrm{~mm}$ nos dois dias.

Nas estações Rio da Cidade e Itamarati, localizadas em Petrópolis, as chuvas não foram de magnitude tão elevada, atingindo $60,4 \mathrm{~mm}$ e $45,7 \mathrm{~mm}$, bem abaixo das médias das máximas dessas estações, que ficam em torno de $89 \mathrm{~mm}$ (Tabela 5).

A estação Vargem Alta possui pluviógrafo, que registrou a chuva das sete horas da manhã do dia 11 de janeiro de 2011 às sete horas da manhã do dia 12. A 
chuva acumulada neste período, de acordo com a leitura do gráfico, foi de aproximadamente $270,8 \mathrm{~mm}$, valor muito semelhante ao encontrado no pluviômetro, que foi de $271,5 \mathrm{~mm}$.

O pluviograma de Vargem Alta, visualizado na Figura 59, é uma figura histórica para a Hidrologia Brasileira.

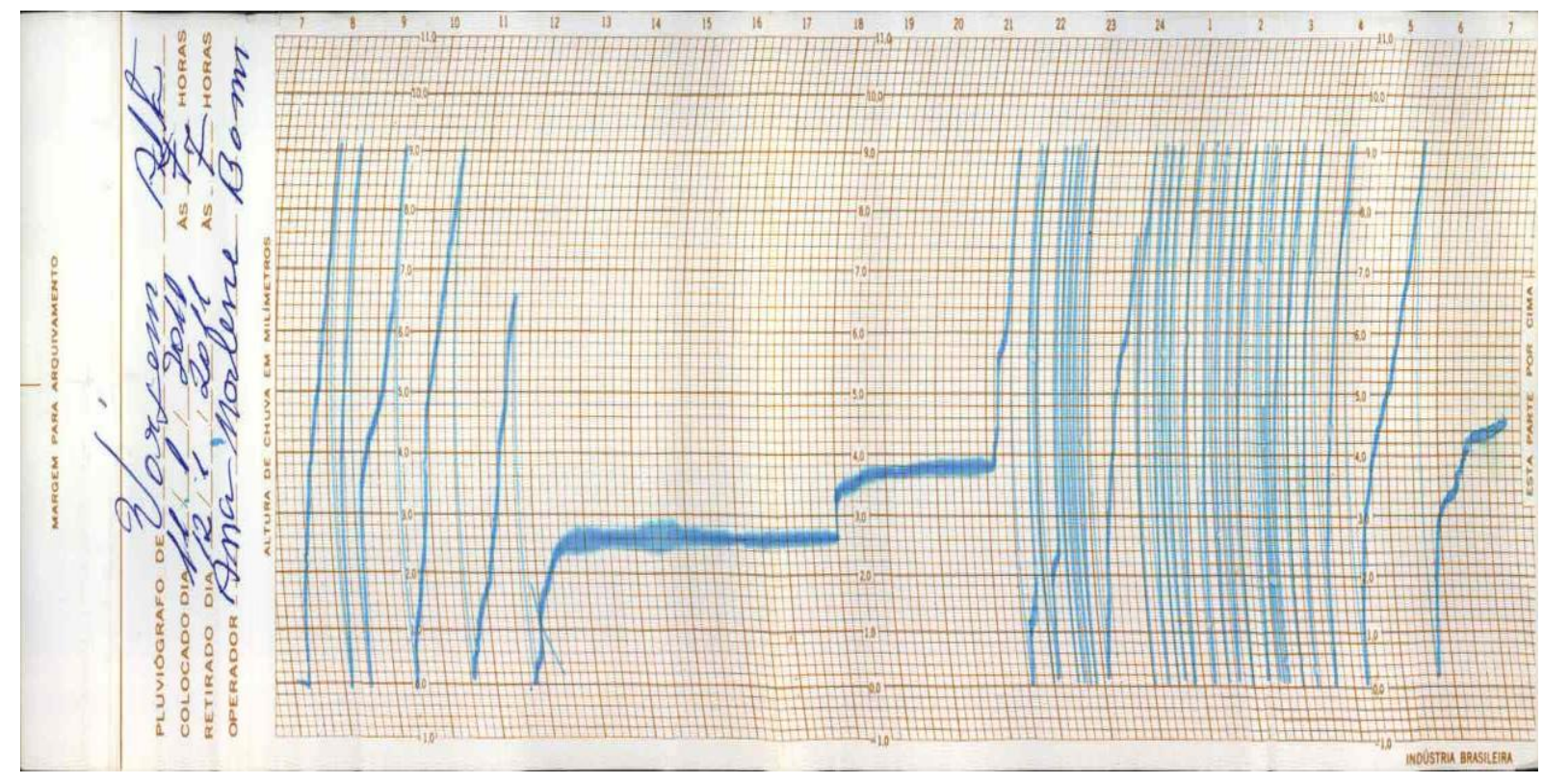

Figura 59 - Pluviograma da estação Vargem Alta das $7 \mathrm{~h}$ do dia 11 de janeiro de 2011 às $7 \mathrm{~h}$ do dia 12 de janeiro de 2011 (Fonte: CPRM)

Outro fato que chama a atenção no pluviograma é o volume de chuva precipitado no período das $21 \mathrm{~h} 30 \mathrm{~min}$ da noite às $07 \mathrm{~h} 00 \mathrm{~min}$ da manhã. $\mathrm{O}$ gráfico registra um volume acumulado elevadíssimo, de aproximadamente 219,2 mm durante a noite e o início da manhã.

\subsubsection{Distribuições adotadas e períodos de retorno (Tr)}

Foram calculadas as posições de plotagem das séries de chuvas máximas diárias, através da fórmula de Cunnane, os períodos de retorno e depois ajustadas as distribuições Log-Normal e Gumbel para todas as estações.

A Tabela 47 mostra o resumo dos parâmetros estimados de cada distribuição. 
Tabela 47 - Resumo dos parâmetros estimados de cada distribuição

\begin{tabular}{|c|c|c|c|c|}
\hline \multirow{2}{*}{ Estação } & \multirow{2}{*}{$\begin{array}{l}\text { Parâmetros } \\
\text { Estimados }\end{array}$} & \multicolumn{3}{|c|}{ Distribuição } \\
\hline & & Empírica & Log-Normal & Gumbel \\
\hline \multirow{3}{*}{2242019} & Média $\mu$ & 90,3 & 89,5 & 90,0 \\
\hline & Desvio-padrão $\sigma$ & 36,4 & 27,5 & 35,1 \\
\hline & Assimetria Y & 3,3 & 0,8 & 0,9 \\
\hline \multirow{3}{*}{2242020} & $\mu$ & 77,5 & 77,2 & 77,2 \\
\hline & $\sigma$ & 29,5 & 27,5 & 28,4 \\
\hline & Y & 1,6 & 0,9 & 0,9 \\
\hline \multirow{3}{*}{2242022} & $\mu$ & 74,6 & 74,5 & 74,4 \\
\hline & $\sigma$ & 30,4 & 29,4 & 29,5 \\
\hline & $\mathrm{Y}$ & 2,0 & 1,0 & 0,9 \\
\hline \multirow{3}{*}{2242024} & $\mu$ & 112,2 & 112,0 & 111,9 \\
\hline & $\sigma$ & 30,5 & 29,2 & 29,4 \\
\hline & $\mathrm{Y}$ & 0,9 & 0,7 & 0,9 \\
\hline \multirow{3}{*}{2242027} & $\mu$ & 77,0 & 76,9 & 76,8 \\
\hline & $\sigma$ & 22,7 & 21,9 & 22,1 \\
\hline & Y & 0,9 & 0,8 & 0,9 \\
\hline \multirow{3}{*}{2243010} & $\mu$ & 89,2 & 89,0 & 89,0 \\
\hline & $\sigma$ & 27,9 & 26,5 & 27,2 \\
\hline & $\mathrm{Y}$ & 1,1 & 0,8 & 0,9 \\
\hline \multirow{3}{*}{2243011} & $\mu$ & 86,2 & 85,9 & 86,0 \\
\hline & $\sigma$ & 27,2 & 25,1 & 26,5 \\
\hline & $\mathrm{y}$ & 1,3 & 0,8 & 0,9 \\
\hline
\end{tabular}

Os gráficos contendo as distribuições empíricas e as ajustadas para cada estação podem ser visualizados na Figura 60.

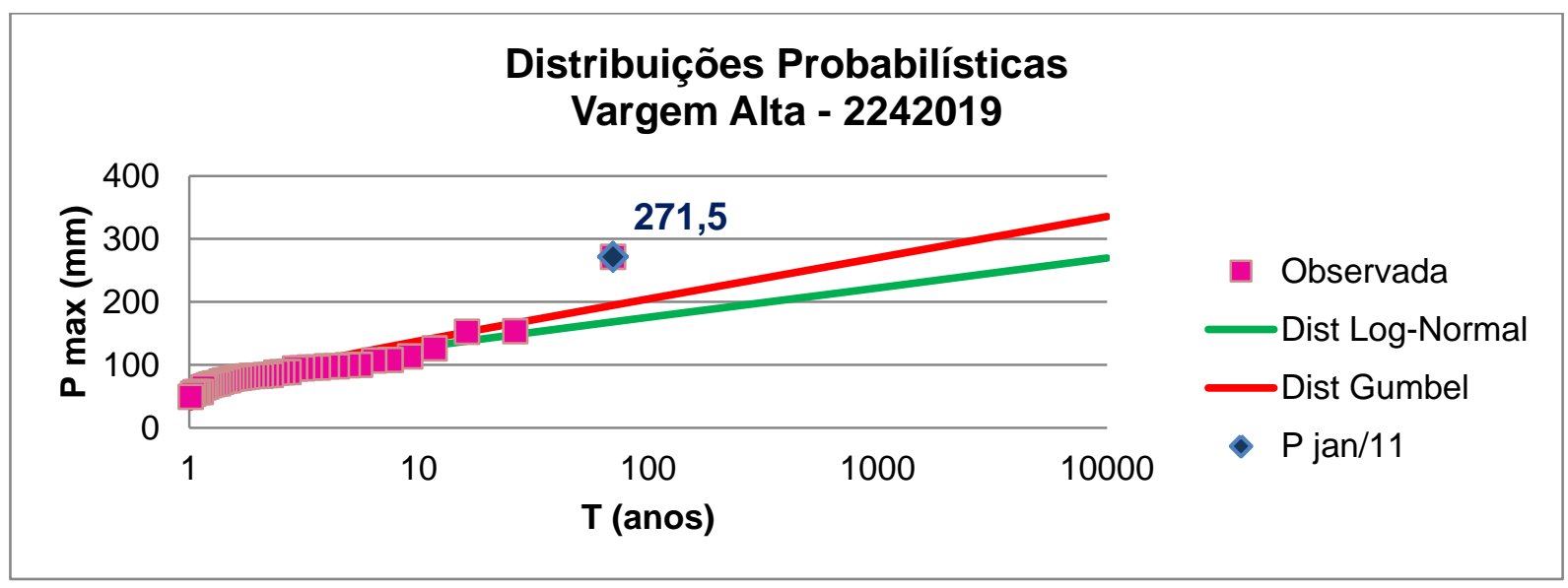

Figura 60 - Relação entre Tr e precipitações máximas para 1 dia de duração (continua) 


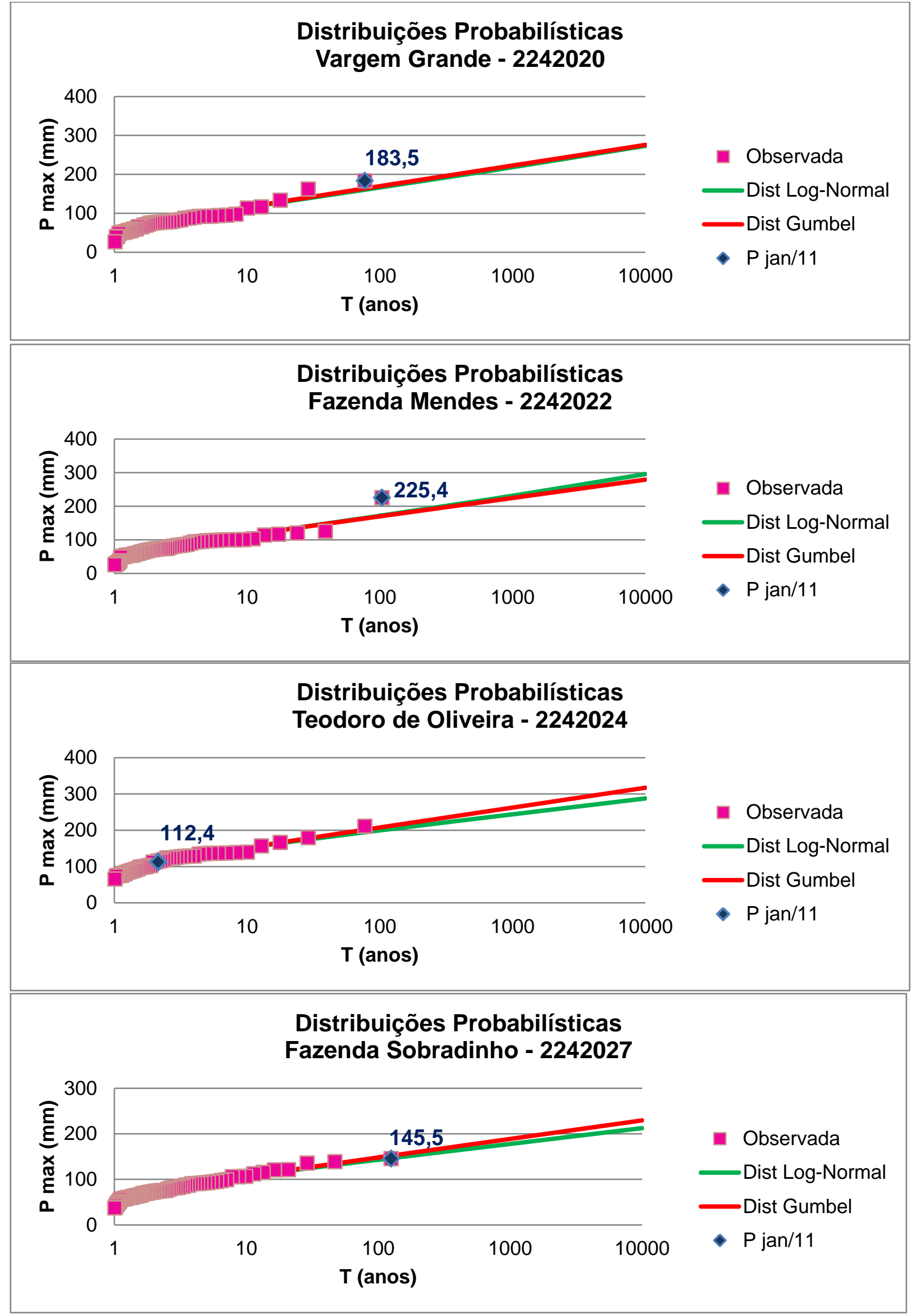

Figura 60 - Relação entre Tr e precipitações máximas para 1 dia de duração (continua) 


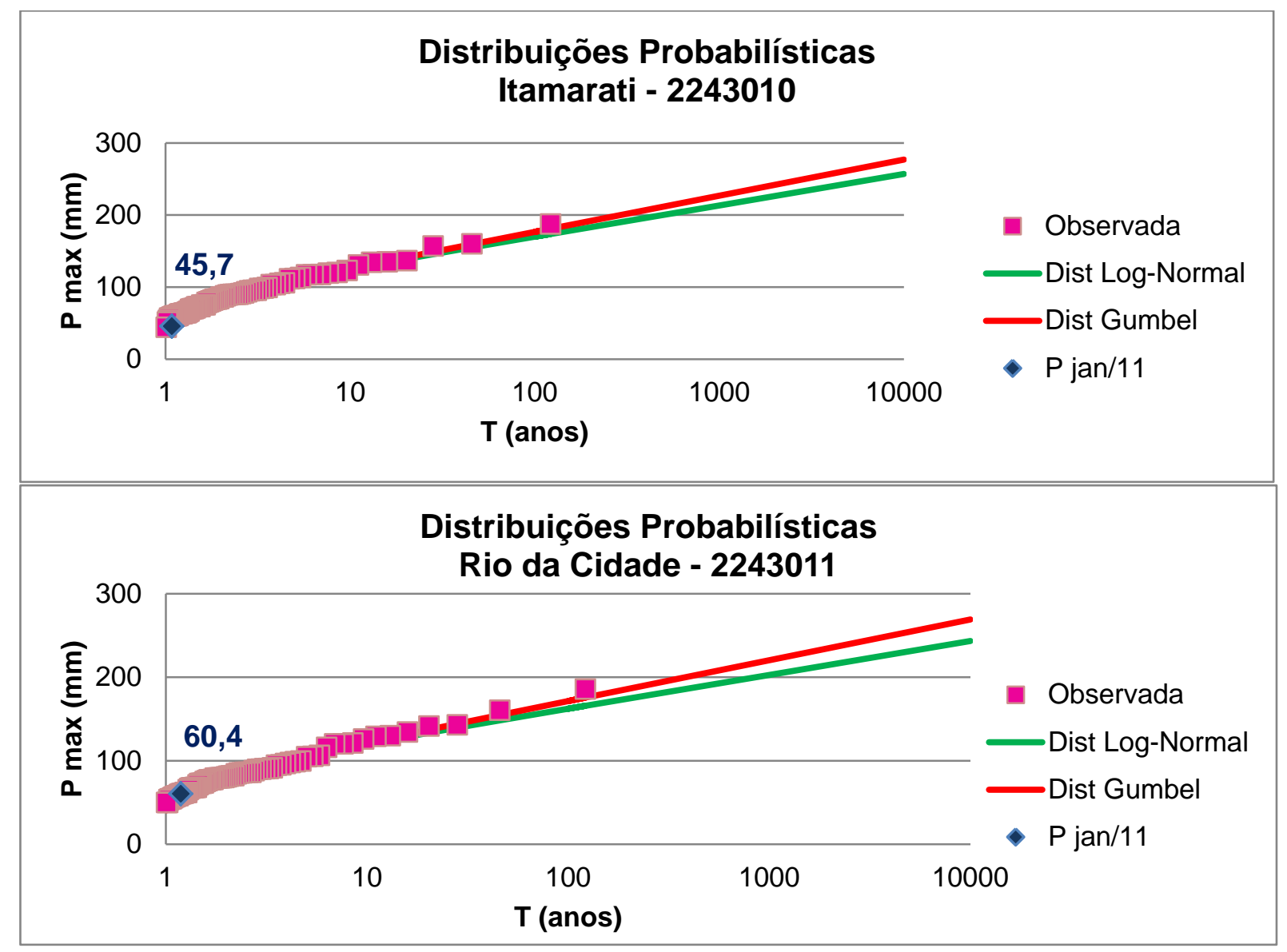

Figura 60 - Relação entre Tr e precipitações máximas para 1 dia de duração

Através dos gráficos das distribuições, nota-se que a precipitação de janeiro de 2011 foi a máxima já registrada na maioria das estações. Apenas nas estações Teodoro de Oliveira, localizada em Nova Friburgo, que possui magnitude de chuvas máximas mais elevadas que as demais estações, e nos postos Itamarati e Rio da Cidade, localizados em Petrópolis, as chuvas não são as máximas históricas. Em Teodoro de Oliveira, a máxima histórica do ano hidrológico 2009/2010 ocorreu em novembro de 2009 e corresponde ao valor $114,8 \mathrm{~mm}$. A chuva de 112,4 mm ocorrida no dia 11 de janeiro de 2010 não é a máxima deste ano.

Foram estimados os períodos de retorno das chuvas ocorridas em janeiro de 2011 para as distribuições de probabilidade Log-Normal e Gumbel. Os resultados dos valores estimados podem ser vistos na Tabela 48 . 
Tabela 48 - Períodos de retorno estimados para as chuvas diárias

\begin{tabular}{|c|c|c|c|c|}
\hline Estação & $\begin{array}{c}\mathbf{P} \text { max } \\
\text { janeiro de 2011 } \\
\text { (mm) }\end{array}$ & $\begin{array}{c}\text { Tr } \\
\text { Empírica } \\
\text { (anos) } \\
\text { Cunnane }\end{array}$ & $\begin{array}{c}\text { Tr } \\
\text { Log-Normal } \\
\text { (anos) }\end{array}$ & $\begin{array}{c}\text { Tr } \\
\text { Gumbel } \\
\text { (anos) }\end{array}$ \\
\hline 2242019 & 271,5 & $\mathbf{7 0}$ & 11.000 & 1.050 \\
\hline 2242020 & 183,5 & $\mathbf{7 7}$ & 210 & 180 \\
\hline 2242022 & 225,4 & $\mathbf{1 0 4}$ & 802 & 1.035 \\
\hline 2242024 & 112,4 & $\mathbf{2}$ & 2 & 2 \\
\hline 2242027 & 145,5 & $\mathbf{1 2 5}$ & 117 & 87 \\
\hline 2242010 & 45,7 & $\mathbf{1}$ & 1 & 1 \\
\hline 2242011 & 60,4 & $\mathbf{1}$ & 1 & 1 \\
\hline
\end{tabular}

$\mathrm{Na}$ estação Vargem Alta, nota-se que o $\mathrm{Tr}$ calculado através da fórmula de Cunanne é de 70 anos e o $\operatorname{Tr}$ calculado para as distribuições de Gumbel é de 1.050 anos e da Distribuição Log-Normal é superior a 10.000 anos. Isso acontece, pois o dado da chuva de 2011 pode ser considerado um outlier, que faz com que as estimativas do $\mathrm{Tr}$ através das distribuições ajustadas sejam bem mais elevadas. Analisando graficamente, a Log-Normal nesta estação está bem abaixo da curva da Gumbel para valores elevados de Tr. Os valores de Tr são superestimados para essa distribuição.

Na estação Fazenda Mendes, onde a chuva de 2011 está bem acima da curva das distribuições adotadas, o Tr do evento de janeiro, calculado pela distribuição de Gumbel, é bem próximo ao de Vargem Alta, em torno de 1.000 anos. O Tr da LogNormal é um pouco menor, mas ainda bem mais elevados que os calculados pela distribuição empírica.

Em Vargem Grande, O Tr calculado pela Gumbel e Log-Normal não difere tanto, ficando entre 180 a 210 anos.

Na estação Fazenda Sobradinho, os Trs estimados através das distribuições ajustadas são de 87 e 117 anos, menores que o calculado através da distribuição empírica, de 125 anos.

As chuvas ocorridas nas demais estações são comuns e acontecem em média todo ano ou a cada dois anos. Nestes casos o período de retorno é o mesmo em todas as distribuições. 


\subsubsection{Teste de aderência de Kolmogorov-Smirnov (KS)}

Os resultados do teste de $\mathrm{KS}$, adotado para o nível de significância de $\alpha=$ $10 \%$, que são apresentados na Tabela 49, indicam que as duas distribuições foram aderentes em todas as estações.

Tabela 49 - Resultados do Teste de KS para N > 40 e $\alpha=10 \%$

\begin{tabular}{|c|c|c|c|}
\hline \multicolumn{2}{|l|}{ Distribuição } & Log-Normal & Gumbel \\
\hline \multicolumn{4}{|c|}{2242019} \\
\hline \multicolumn{2}{|c|}{ Estatística do teste D max } & 0,1408 & 0,1628 \\
\hline $\mathrm{N}$ & 42 & \multicolumn{2}{|c|}{ Decisão } \\
\hline \begin{tabular}{|l|l|} 
Região Crítica para $\alpha$ & $10 \%$ \\
\end{tabular} & 0,1883 & Aceito $\mathrm{HO}$ & Aceito $\mathrm{HO}$ \\
\hline \multicolumn{4}{|c|}{2242020} \\
\hline \multicolumn{2}{|c|}{ Estatística do teste D max } & 0,0968 & 0,1008 \\
\hline $\mathrm{N}$ & 46 & \multicolumn{2}{|c|}{ Decisão } \\
\hline \begin{tabular}{|l|l|} 
Região Crítica para $\alpha$ & $10 \%$ \\
\end{tabular} & 0,1799 & Aceito $\mathrm{HO}$ & Aceito $\mathrm{HO}$ \\
\hline \multicolumn{4}{|c|}{2242022} \\
\hline \multicolumn{2}{|c|}{ Estatística do teste D max } & 0,0732 & 0,0769 \\
\hline $\mathrm{N}$ & 62 & \multicolumn{2}{|c|}{ Decisão } \\
\hline \begin{tabular}{|l|l|} 
Região Crítica para $\alpha$ & $10 \%$ \\
\end{tabular} & 0,1549 & Aceito $\mathrm{HO}$ & Aceito $\mathrm{HO}$ \\
\hline \multicolumn{4}{|c|}{2242024} \\
\hline \multicolumn{2}{|c|}{ Estatística do teste D max } & 0,0968 & 0,1008 \\
\hline $\mathrm{N}$ & 46 & \multicolumn{2}{|c|}{ Decisão } \\
\hline \begin{tabular}{|l|l|} 
Região Crítica para $\alpha$ & $10 \%$ \\
\end{tabular} & 0,1799 & Aceito $\mathrm{HO}$ & Aceito $\mathrm{HO}$ \\
\hline \multicolumn{4}{|c|}{2242027} \\
\hline \multicolumn{2}{|c|}{ Estatística do teste D max } & 0,1065 & 0,0927 \\
\hline $\mathrm{N}$ & 75 & \multicolumn{2}{|c|}{ Decisão } \\
\hline \begin{tabular}{|l|l|} 
Região Crítica para $\alpha$ & $10 \%$ \\
\end{tabular} & 0,1409 & Aceito $\mathrm{HO}$ & Aceito $\mathrm{HO}$ \\
\hline \multicolumn{4}{|c|}{2242010} \\
\hline \multicolumn{2}{|c|}{ Estatística do teste D max } & 0,0695 & 0,0681 \\
\hline $\mathrm{N}$ & 73 & \multicolumn{2}{|c|}{ Decisão } \\
\hline \begin{tabular}{l|l|} 
Região Crítica para a & $10 \%$ \\
\end{tabular} & 0,1428 & Aceito $\mathrm{HO}$ & Aceito $\mathrm{HO}$ \\
\hline \multicolumn{4}{|c|}{2242011} \\
\hline \multicolumn{2}{|c|}{ Estatística do teste D max } & 0,0936 & 0,0865 \\
\hline $\mathrm{N}$ & 73 & \multicolumn{2}{|c|}{ Decisão } \\
\hline $10 \%$ & 0,1428 & Aceito $\mathrm{HO}$ & Aceito $\mathrm{HO}$ \\
\hline
\end{tabular}




\subsubsection{Chuvas máximas históricas da região}

Os dados de chuva máximas diárias de todas as estações estão plotados em conjunto na Figura 61.

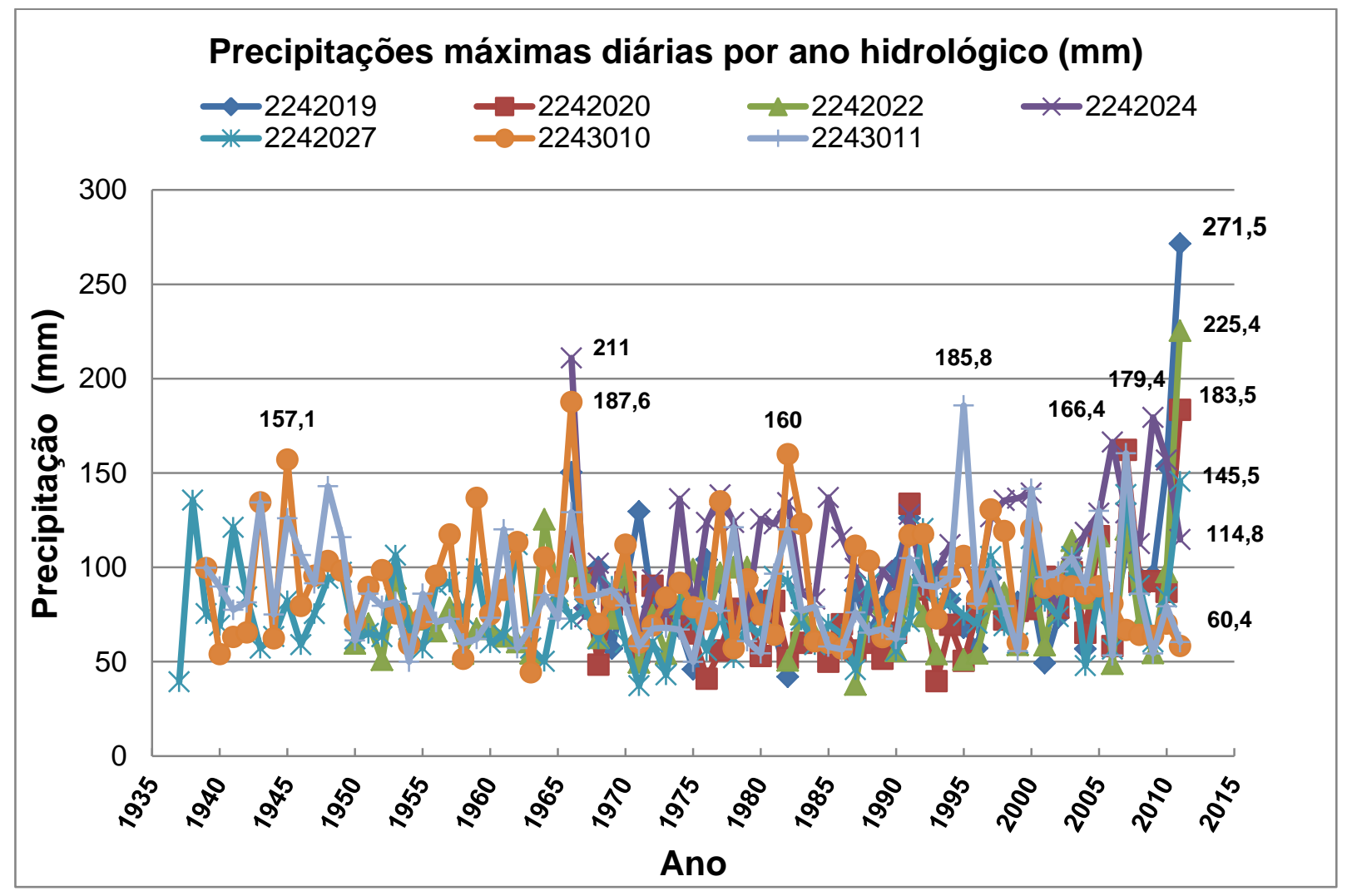

Figura 61 - Precipitações máximas diárias da Região Serrana

Nota-se que as chuvas registradas nas estações Vargem Alta e Fazenda Mendes no ano de 2011, além de serem as máximas históricas registradas nessas estações, são maiores que todos os eventos já registradas nas demais estações desde que se iniciaram as leituras.

A terceira máxima foi registrada na estação Teodoro de Oliveira, no ano de 1966, localizada em Nova Friburgo e corresponde ao valor de $211 \mathrm{~mm}$. Neste mesmo ano chuvas elevadas foram registradas em Itamarati, localizada em Petrópolis e em Vargem Alta, também localizada em Nova Friburgo.

Nas estações Itamarati e Rio da Cidade, localizadas em Petrópolis, apesar das chuvas de 2011 não serem muito elevadas, outros eventos elevados já foram registrados anteriormente. 
Apesar do alto volume precipitado em janeiro de 2011, nota-se na Figura 61 que estes eventos são característicos da região. Muitos valores elevados já foram registrados nos postos utilizados.

Foi feito um resumo das cinco maiores chuvas diárias registradas em cada posto e o ano hidrológico em que ocorreram, como mostra a Tabela 50.

Tabela 50 - Os cinco maiores eventos diários de precipitação (em $\mathrm{mm}$ ) registrados em cada estação da Região Serrana

\begin{tabular}{|c|c|c|c|c|c|c|c|}
\hline Ano & P max diária & Ano & P max diária & Ano & P max diária & Ano & P max diária \\
\hline \multicolumn{2}{|c|}{2242019} & \multicolumn{2}{|r|}{2242020} & \multicolumn{2}{|r|}{2242022} & \multicolumn{2}{|r|}{2242024} \\
\hline 2011 & 271,5 & 2011 & 183,5 & 2011 & 225,4 & 1966 & 211 \\
\hline 2010 & 153,7 & 2007 & 162,3 & 1964 & 125,4 & 2009 & 179,4 \\
\hline 1979 & 152,6 & 1991 & 133,7 & 2007 & 120,1 & 2006 & 166,4 \\
\hline 1991 & 126,2 & 2005 & 116,5 & 2005 & 116,5 & 2010 & 156,8 \\
\hline 1967 & 113,4 & 1966 & 113,6 & 2003 & 114,1 & 2000 & 139,4 \\
\hline \multicolumn{2}{|c|}{2242027} & \multicolumn{2}{|c|}{2242011} & \multicolumn{2}{|c|}{2242011} & & \\
\hline 2011 & 145,5 & 1966 & 187,6 & 1995 & 185,8 & & \\
\hline 2007 & 138,6 & 1982 & 160 & 2007 & 160,4 & & \\
\hline 1938 & 135,6 & 1945 & 157,1 & 1948 & 143 & & \\
\hline 1941 & 121,2 & 1959 & 136,8 & 2000 & 141,6 & & \\
\hline 1992 & 120,6 & 1977 & 135 & 1943 & 134,3 & & \\
\hline
\end{tabular}

Verifica-se que o ano de 2011 foi o mais chuvoso em quatro das sete estações. O ano de 1966 foi o mais chuvoso em duas estações e 1995 em uma delas.

\subsubsection{Precipitações Máximas Acumuladas para diferentes durações}

Foram acumuladas as máximas chuvas para as durações de 1 a 10 dias, 15, 20, 30 e 45 dias. O cálculo foi feito com a acumulada móvel e o intervalo considerado foi o ano hidrológico. Em seguida, as séries das máximas para as diferentes durações foram plotadas nos gráficos da Figura 62. 


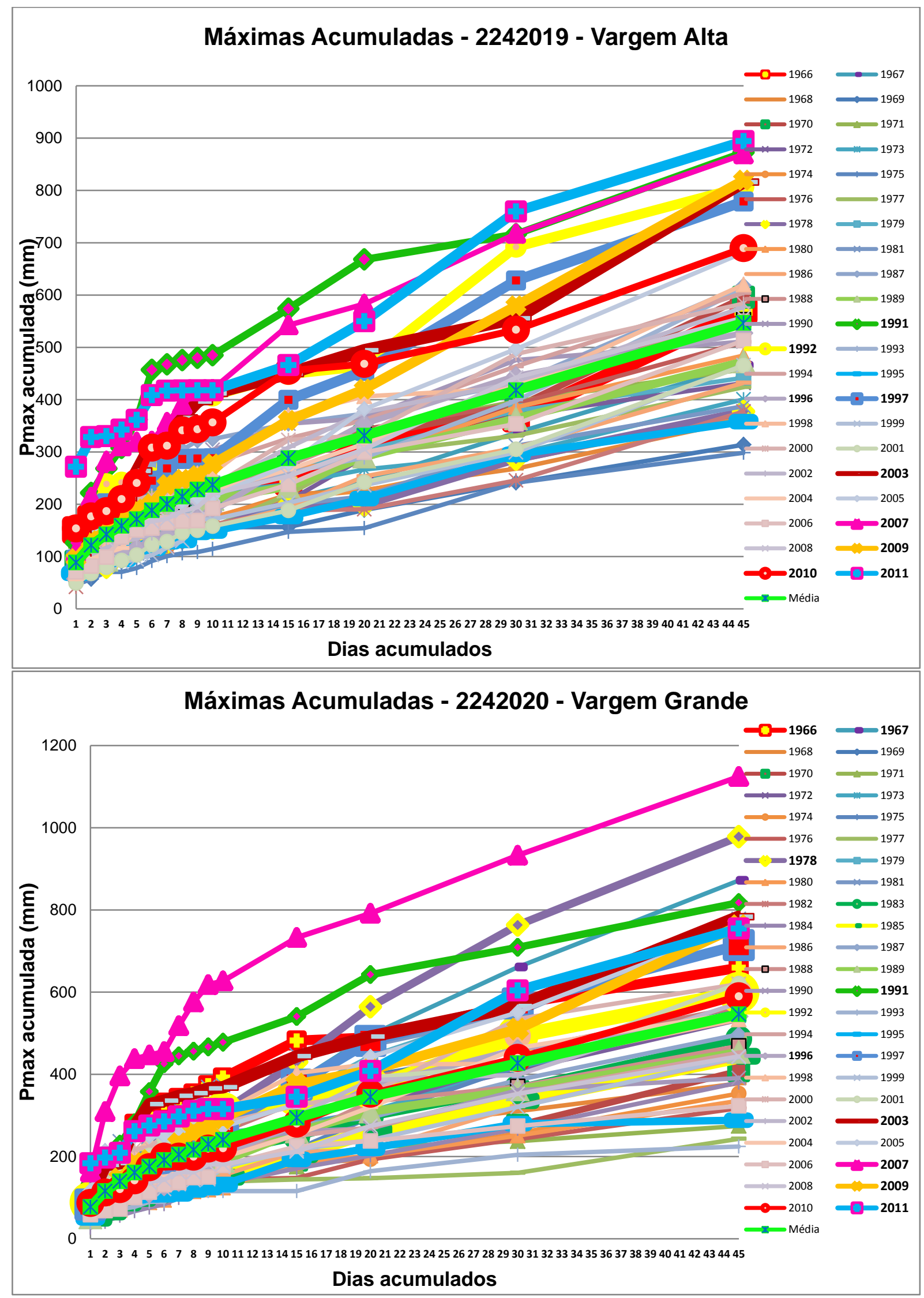

Figura 62 - Curvas das máximas acumuladas para as durações de 1 a 10 dias, 15, 20, 30 e 45 dias (continua) 


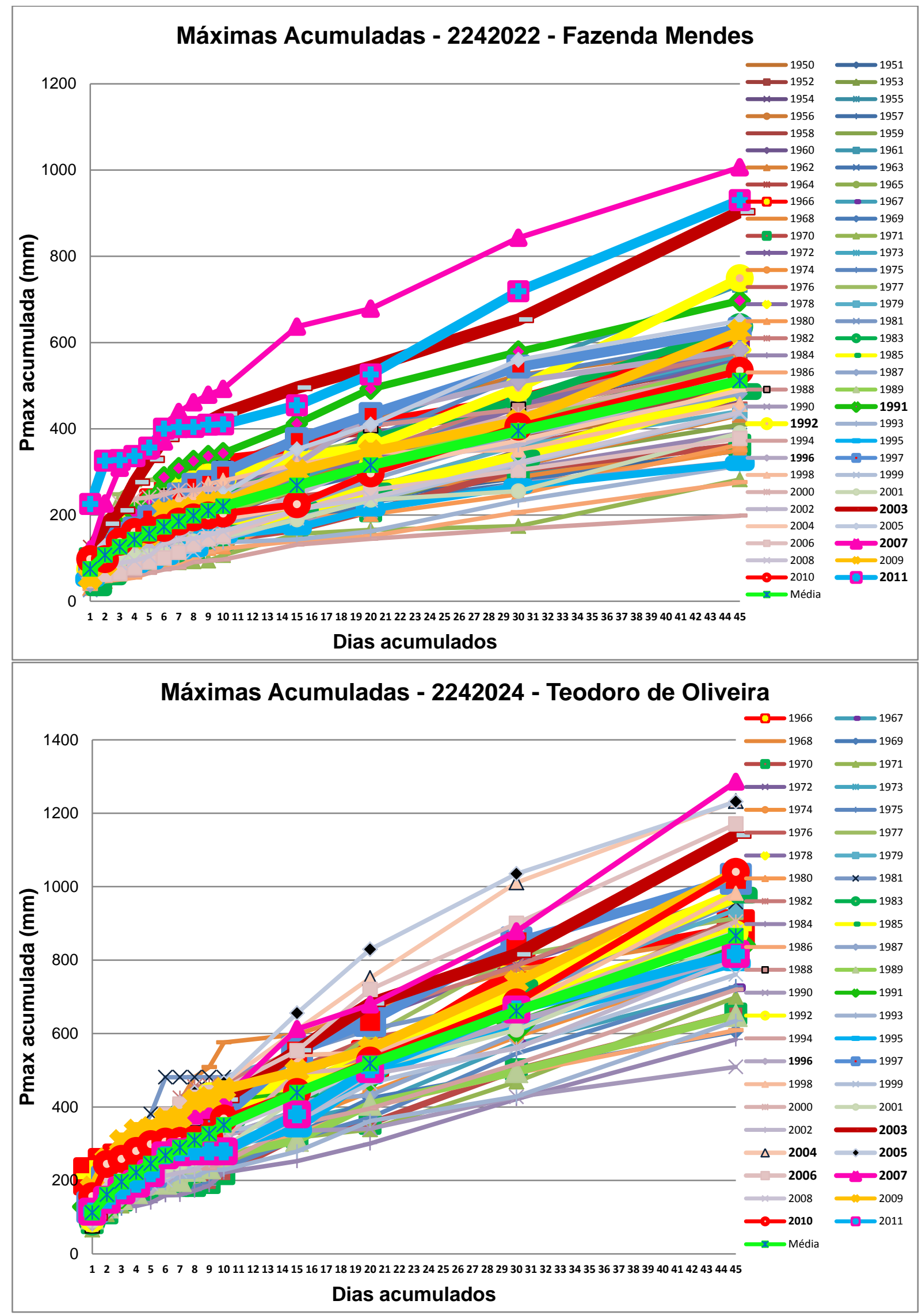

Figura 62 - Curvas das máximas acumuladas para as durações de 1 a 10 dias, 15, 20, 30 e 45 dias (continua) 


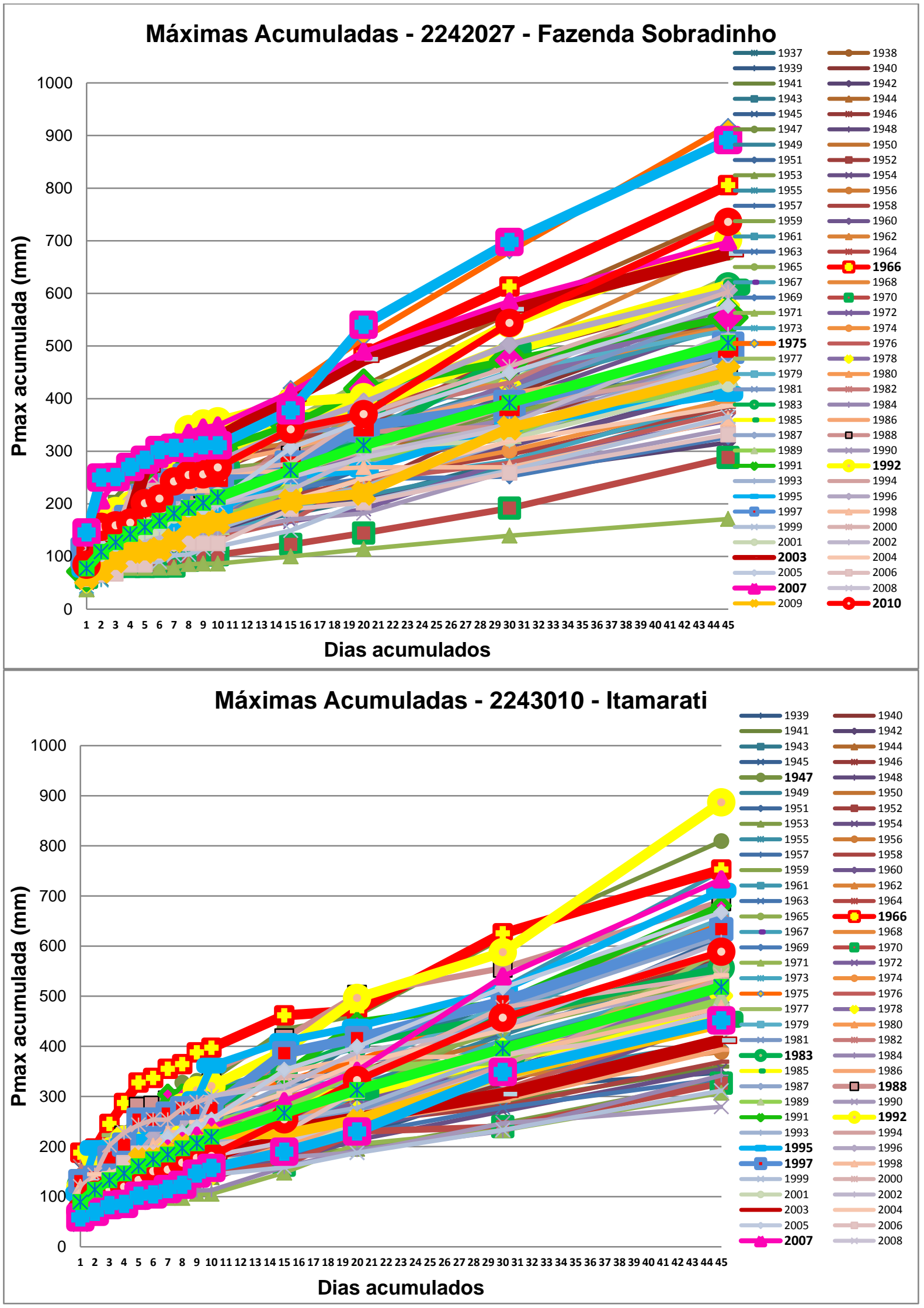

Figura 62 - Curvas das máximas acumuladas para as durações de 1 a 10 dias, 15, 20, 30 e 45 dias (continua) 


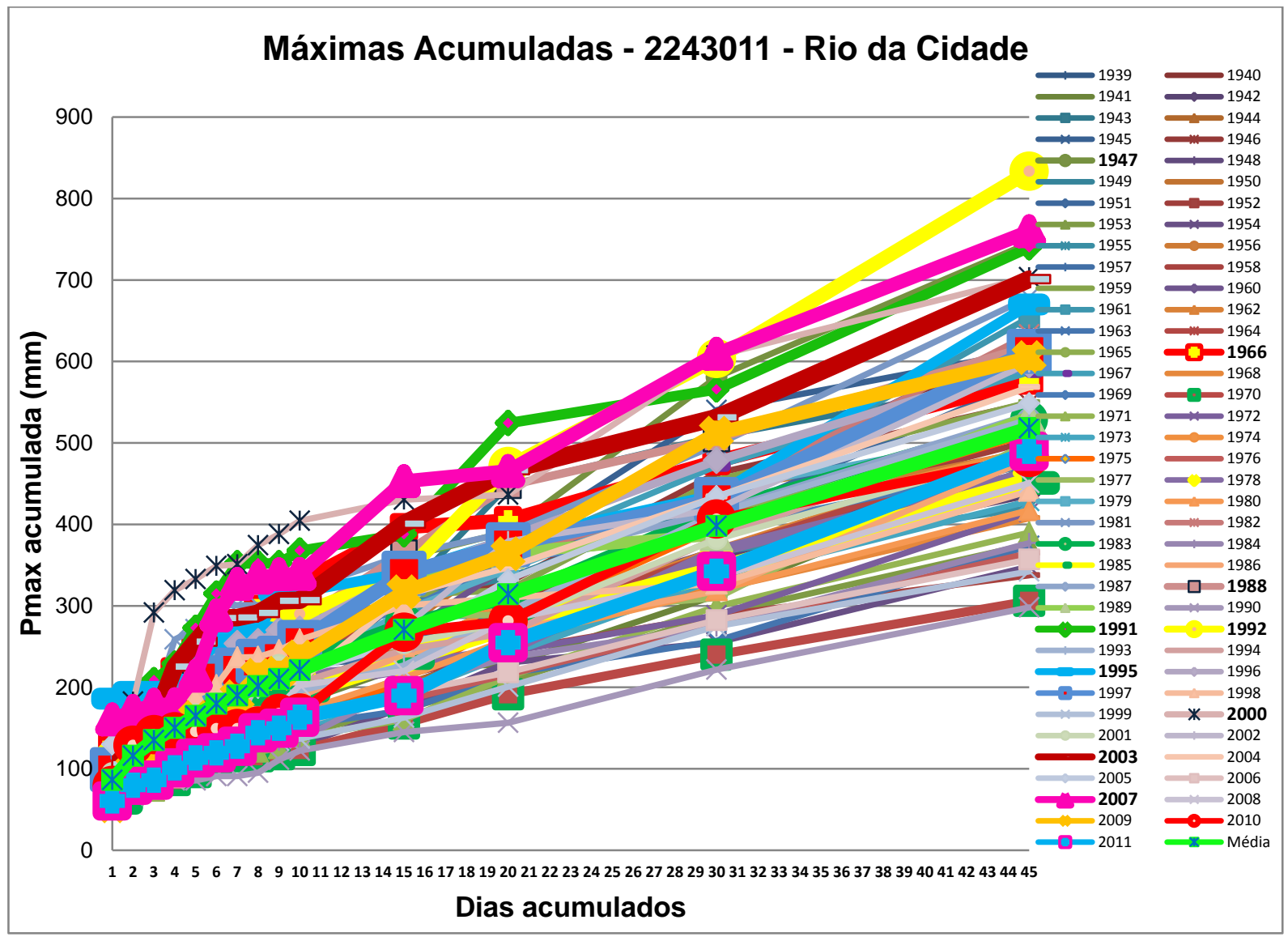

Figura 62 - Curvas das máximas acumuladas para as durações de 1 a 10 dias, 15, 20, 30 e 45 dias

Através dos gráficos das curvas acumuladas, nota-se que o ano de 1966 foi de chuvas elevadas em Fazenda Sobradinho e Itamarati, localizadas em Teresópolis e Petrópolis. Nesse mesmo ano, no Rio de Janeiro, os temporais do dia 2 de janeiro deixaram cerca de 250 mortos e 50 mil desabrigados devido aos escorregamentos.

Em Rio da Cidade e Itamarati, localizadas em Petrópolis, as chuvas acumuladas em 45 dias no ano de 1992 foram as mais elevadas registradas nessas estações desde que se iniciaram as leituras.

As chuvas de 1991, 2003 e 2007 foram bastante elevadas na maioria das estações. Destacam-se os valores acumulados em Nova Friburgo no ano de 2007.

Em Teodoro de Oliveira, localizada em Nova Friburgo, as chuvas acumuladas nos anos 2004, 2005 e 2007 ultrapassaram 1.200 mm.

Os escorregamentos de 1988 em Petrópolis causaram muitas mortes e podem ser notadas nos gráficos de Itamarati e Rio da Cidade. 


\subsubsection{Classificação das chuvas utilizando o SPI}

O cálculo dos limiares de precipitação também foi feito individualmente, para cada uma das estações pluviométricas selecionadas, adotando-se a distribuição de probabilidades de Gumbel ajustada para as séries de chuvas máximas calculadas por ano hidrológico para diferentes durações.

Da mesma forma que nos demais estudos de caso, adotou-se os intervalos de duração de 1 dia, 2, 3, 4 e 5 dias.

A seguir estão ilustrados, através de Tabelas e Figuras, os limiares para a duração de 1 dia. A classificação para as demais durações se encontra no Anexo V.

Tabela 51 - SPI 2242019 - Vargem Alta - Chuvas máximas anuais com duração de 1 dia

\begin{tabular}{|c|c|c|c|c|c|c|}
\hline Classe de PMDA & \multicolumn{2}{|c|}{ SPI } & p (inf.) & $\mathbf{p}$ (sup.) & T (anos) & P 1 dia (mm) \\
\hline Chuva Fraca (CF) & & 0 & & 0,500 & $\leq 2$ & $\leq 84,4$ \\
\hline Chuva Leve $(\mathrm{CL})$ & 0 & 1 & 0,500 & 0,841 & $2<\mathrm{T} \leq 6,3$ & $84,4<\mathrm{T} \leq 123,8$ \\
\hline Chuva Moderada (CM) & 1 & 1,5 & 0,841 & 0,933 & $6,3<\mathrm{T} \leq 15$ & $123,8<\mathrm{T} \leq 149,9$ \\
\hline Chuva Severa (CS) & 1,5 & 2 & 0,933 & 0,977 & $15<\mathrm{T} \leq 44$ & $149,9<\mathrm{T} \leq 181,1$ \\
\hline Chuva Extrema (CE) & 2 & & 0,977 & & $>44$ & $>181,1$ \\
\hline
\end{tabular}

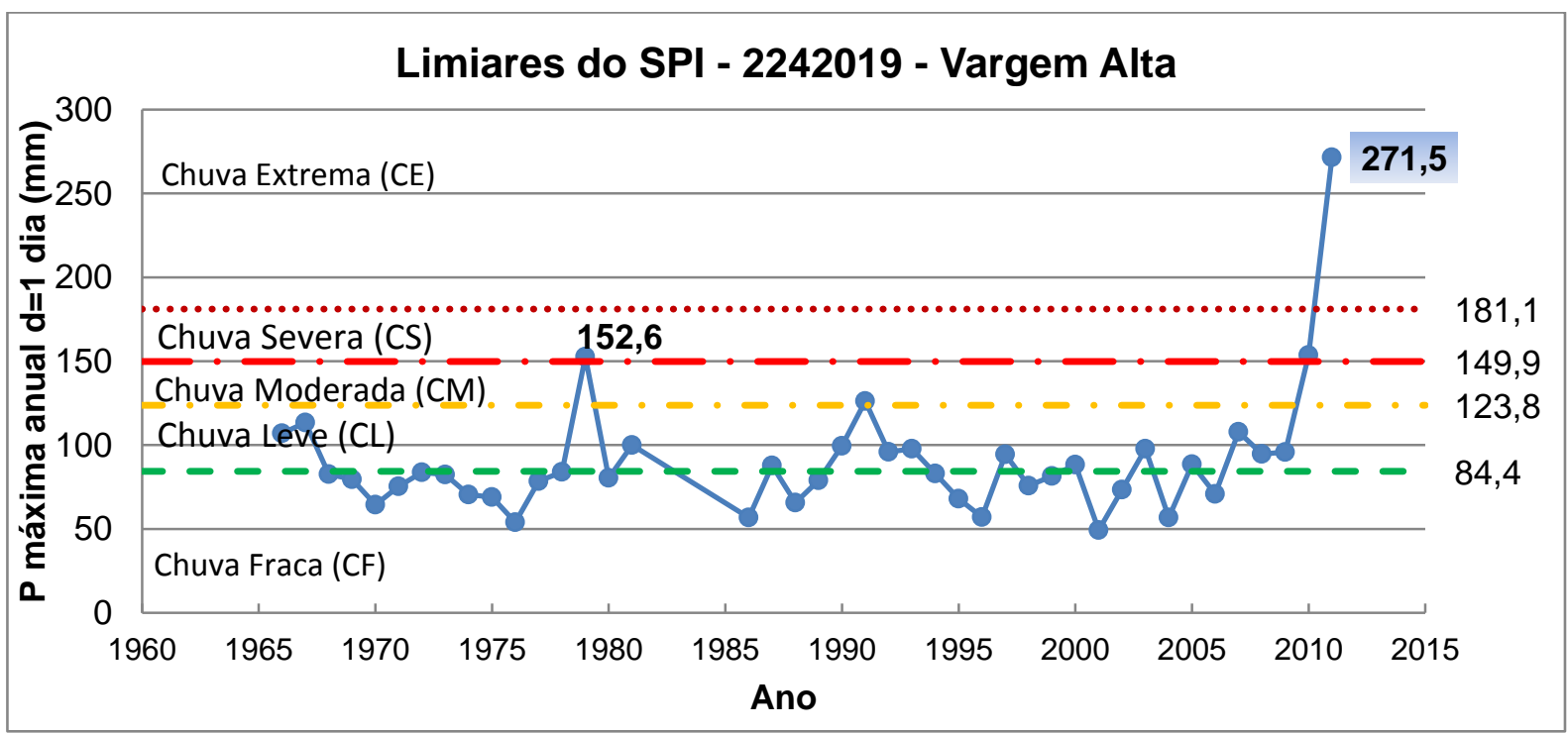

Figura 63 - Classificação das chuvas máximas de duração de 1 dia - 2242019 - Vargem Alta 
Tabela 52 - SPI - 2242020 - Vargem Grande - Chuvas máximas anuais com duração de 1 dia

\begin{tabular}{|c|c|c|c|c|c|c|}
\hline Classe de PMDA & \multicolumn{2}{|c|}{ SPI } & p (inf.) & $\mathbf{p}$ (sup.) & T (anos) & P 1 dia (mm) \\
\hline Chuva Fraca (CF) & & 0 & & 0,500 & $\leq 2$ & $\leq 72,6$ \\
\hline Chuva Leve $(\mathrm{CL})$ & 0 & 1 & 0,500 & 0,841 & $2<\mathrm{T} \leq 6,3$ & $72,6<\mathrm{T} \leq 104,6$ \\
\hline Chuva Moderada $(\mathrm{CM})$ & 1 & 1,5 & 0,841 & 0,933 & $6,3<\mathrm{T} \leq 15$ & $104,6<\mathrm{T} \leq 125,6$ \\
\hline Chuva Severa (CS) & 1,5 & 2 & 0,933 & 0,977 & $15<\mathrm{T} \leq 44$ & $125,6<\mathrm{T} \leq 150,9$ \\
\hline Chuva Extrema (CE) & 2 & & 0,977 & & $>44$ & $>150,9$ \\
\hline
\end{tabular}

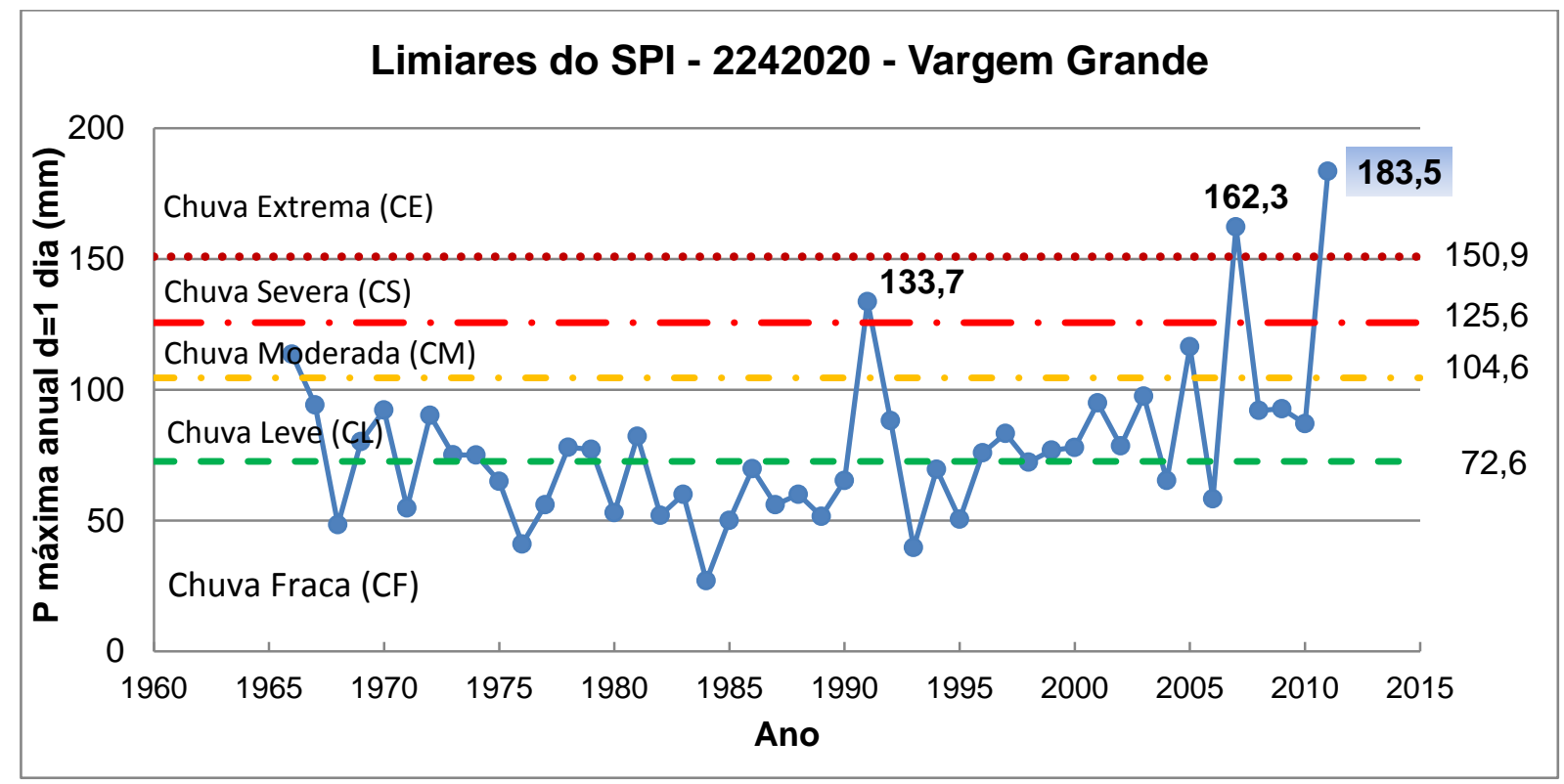

Figura 64 - Classificação das chuvas máximas de duração de 1 dia - 2242020 - Vargem Grande

Tanto na estação Vargem Alta quando em Vargem Grande e em Fazenda Mendes, as chuvas de 2011 foram classificadas como chuvas extremas.

Tabela 53 - SPI - 2242022 - Fazenda Mendes - chuvas máximas anuais com duração de 1 dia

\begin{tabular}{|c|c|c|c|c|c|c|}
\hline Classe de PMDA & \multicolumn{2}{|c|}{ SPI } & p (inf.) & $\mathbf{p}$ (sup.) & T (anos) & P 1 dia (mm) \\
\hline Chuva Fraca (CF) & & 0 & & 0,500 & $\leq 2$ & $\leq 69,6$ \\
\hline Chuva Leve (CL) & 0 & 1 & 0,500 & 0,841 & $2<\mathrm{T} \leq 6,3$ & $69,6<\mathrm{T} \leq 102,5$ \\
\hline Chuva Moderada (CM) & 1 & 1,5 & 0,841 & 0,933 & $6,3<\mathrm{T} \leq 15$ & $102,5<\mathrm{T} \leq 124,3$ \\
\hline Chuva Severa (CS) & 1,5 & 2 & 0,933 & 0,977 & $15<\mathrm{T} \leq 44$ & $124,3<\mathrm{T} \leq 150,3$ \\
\hline Chuva Extrema (CE) & 2 & & 0,977 & & $>44$ & $>150,3$ \\
\hline
\end{tabular}




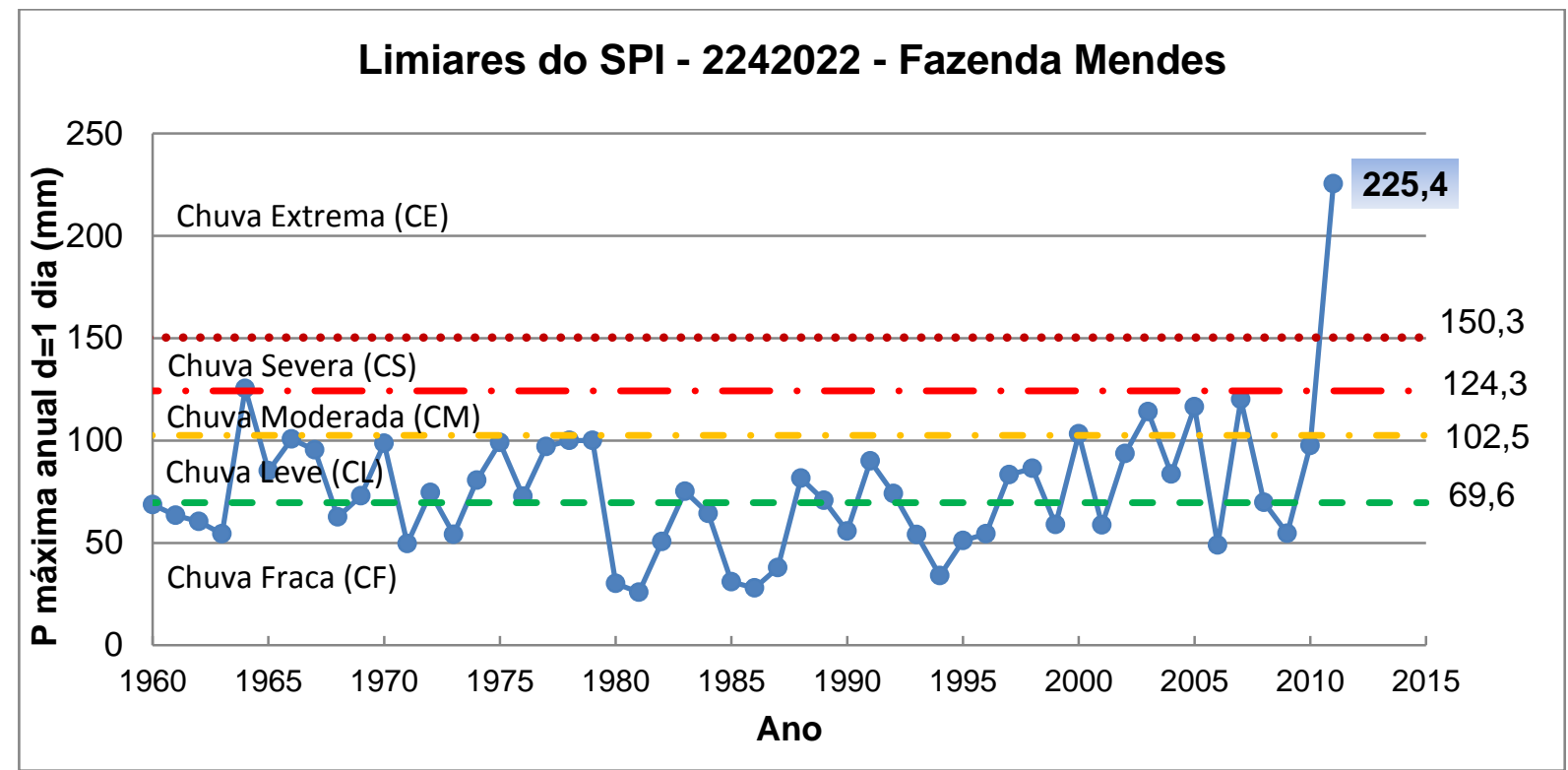

Figura 65 - Classificação das chuvas máximas de duração de 1 dia - 2242022 - Fazenda Mendes

Tabela 54 - SPI - 2242024 - Teodoro de Oliveira - chuvas máximas anuais com duração de 1 dia

\begin{tabular}{|c|c|c|c|c|c|c|}
\hline Classe de PMDA & \multicolumn{2}{|c|}{ SPI } & p (inf.) & $\mathbf{p}$ (sup.) & T (anos) & P 1 dia (mm) \\
\hline Chuva Fraca (CF) & & 0 & & 0,500 & $\leq 2$ & $\leq 107,2$ \\
\hline Chuva Leve (CL) & 0 & 1 & 0,500 & 0,841 & $2<\mathrm{T} \leq 6,3$ & $107,2<\mathrm{T} \leq 140,2$ \\
\hline Chuva Moderada (CM) & 1 & 1,5 & 0,841 & 0,933 & $6,3<\mathrm{T} \leq 15$ & $140,2<\mathrm{T} \leq 162$ \\
\hline Chuva Severa (CS) & 1,5 & 2 & 0,933 & 0,977 & $15<\mathrm{T} \leq 44$ & $162<\mathrm{T} \leq 188,1$ \\
\hline Chuva Extrema (CE) & 2 & & 0,977 & & $>44$ & $>188,1$ \\
\hline
\end{tabular}

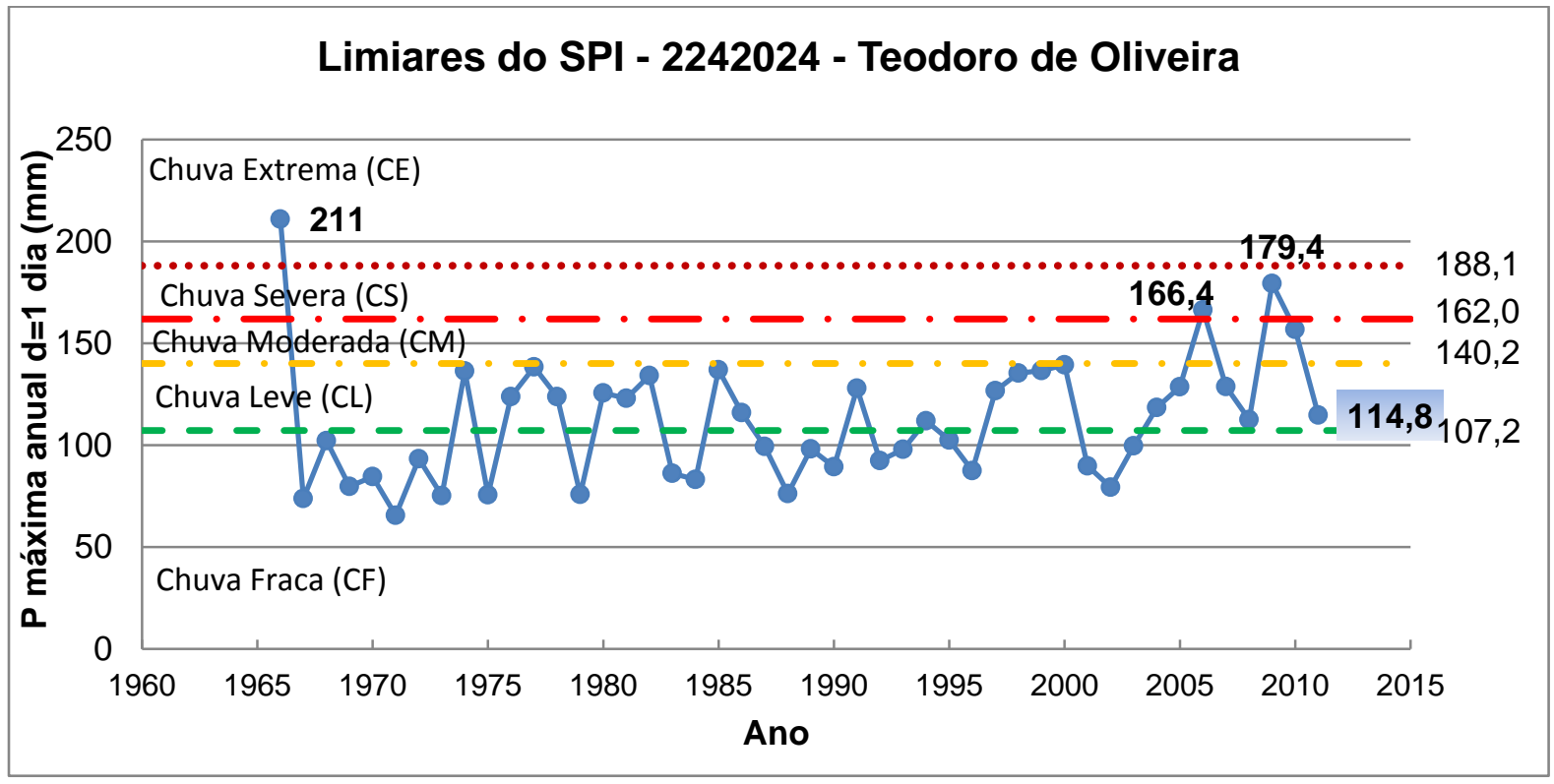

Figura 66 - Classificação das chuvas máximas de duração de 1 dia - 2242024 - Teodoro de Oliveira 
Em Teodoro de Oliveira, a chuva observada em janeiro de 2011 foi classificada como chuva leve.

Tabela 55 - SPI - 2242027 - Fazenda Sobradinho - Chuvas máximas anuais com duração de 1 dia

\begin{tabular}{|c|c|c|c|c|c|c|}
\hline Classe de PMDA & \multicolumn{2}{|c|}{ SPI } & $\mathbf{p}$ (inf.) & $\mathbf{p}$ (sup.) & $\mathbf{T}$ (anos) & P 1 dia (mm) \\
\hline Chuva Fraca (CF) & & 0 & & 0,500 & $\leq 2$ & $\leq 73,3$ \\
\hline Chuva Leve (CL) & 0 & 1 & 0,500 & 0,841 & $2<\mathrm{T} \leq 6,3$ & $73,3<\mathrm{T} \leq 97,8$ \\
\hline Chuva Moderada (CM) & 1 & 1,5 & 0,841 & 0,933 & $6,3<\mathrm{T} \leq 15$ & $97,8<\mathrm{T} \leq 114,0$ \\
\hline Chuva Severa (CS) & 1,5 & 2 & 0,933 & 0,977 & $15<\mathrm{T} \leq 44$ & $114,0<\mathrm{T} \leq 133,4$ \\
\hline Chuva Extrema (CE) & 2 & & 0,977 & & $>44$ & $>133,4$ \\
\hline
\end{tabular}

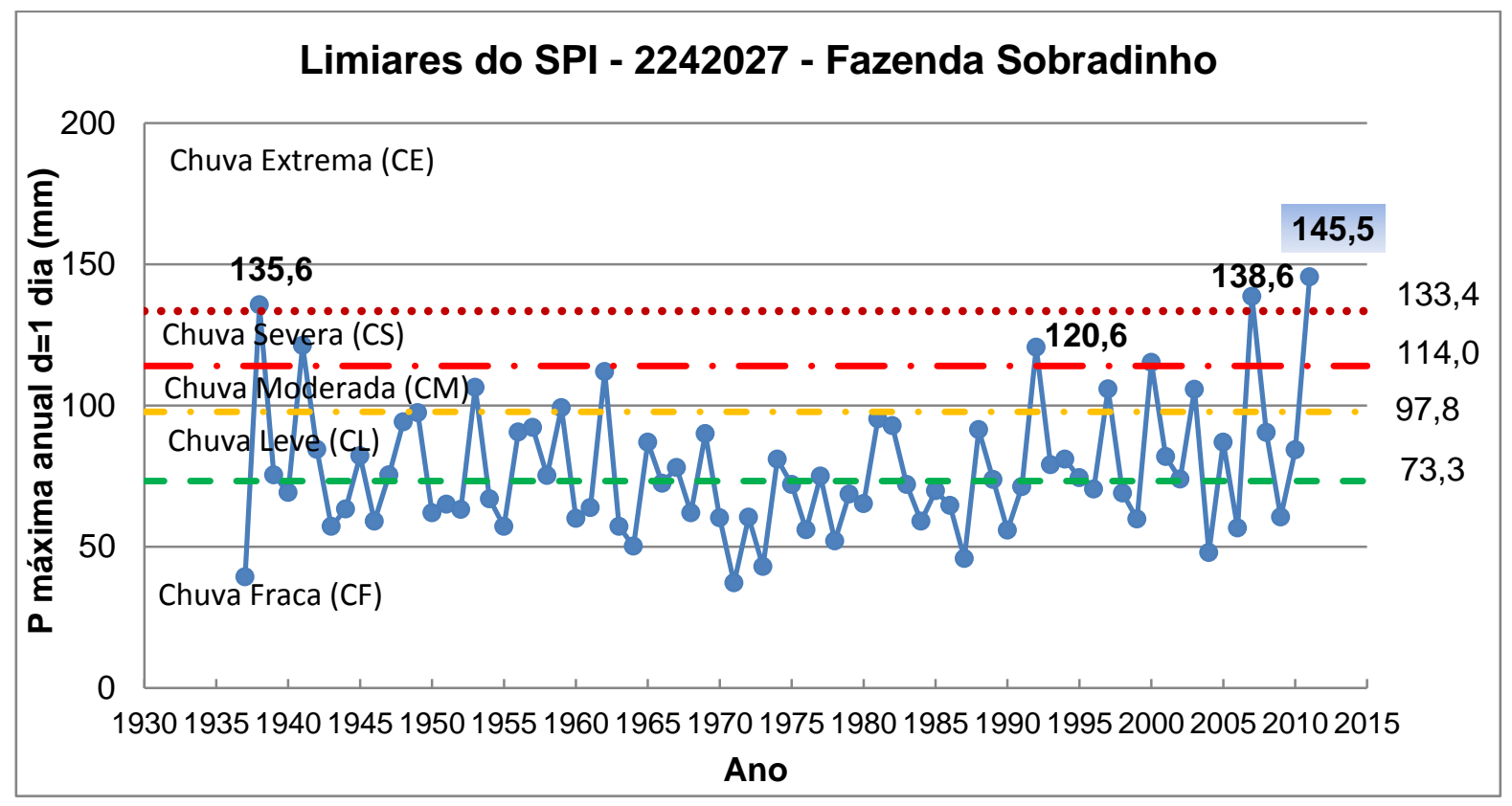

Figura 67 - Classificação das chuvas máximas de duração de 1 dia - 2242027 - Fazenda Sobradinho

Em Fazenda Sobradinho a chuva de 2011 foi classificada como chuva extrema.

Tabela 56 - SPI - 2243010 - Itamarati - Chuvas máximas anuais com duração de 1 dia

\begin{tabular}{|c|c|c|c|c|c|c|}
\hline Classe de PMDA & \multicolumn{2}{|c|}{ SPI } & p (inf.) & p (sup.) & T (anos) & P 1 dia (mm) \\
\hline Chuva Fraca (CF) & & 0 & & 0,500 & $\leq 2$ & $\leq 84,6$ \\
\hline Chuva Leve (CL) & 0 & 1 & 0,500 & 0,841 & $2<\mathrm{T} \leq 6,3$ & $84,6<\mathrm{T} \leq 114,8$ \\
\hline Chuva Moderada (CM) & 1 & 1,5 & 0,841 & 0,933 & $6,3<\mathrm{T} \leq 15$ & $114,8<\mathrm{T} \leq 134,6$ \\
\hline Chuva Severa (CS) & 1,5 & 2 & 0,933 & 0,977 & $15<\mathrm{T} \leq 44$ & $134,6<\mathrm{T} \leq 158,7$ \\
\hline Chuva Extrema (CE) & 2 & & 0,977 & & $>44$ & $>158,7$ \\
\hline
\end{tabular}




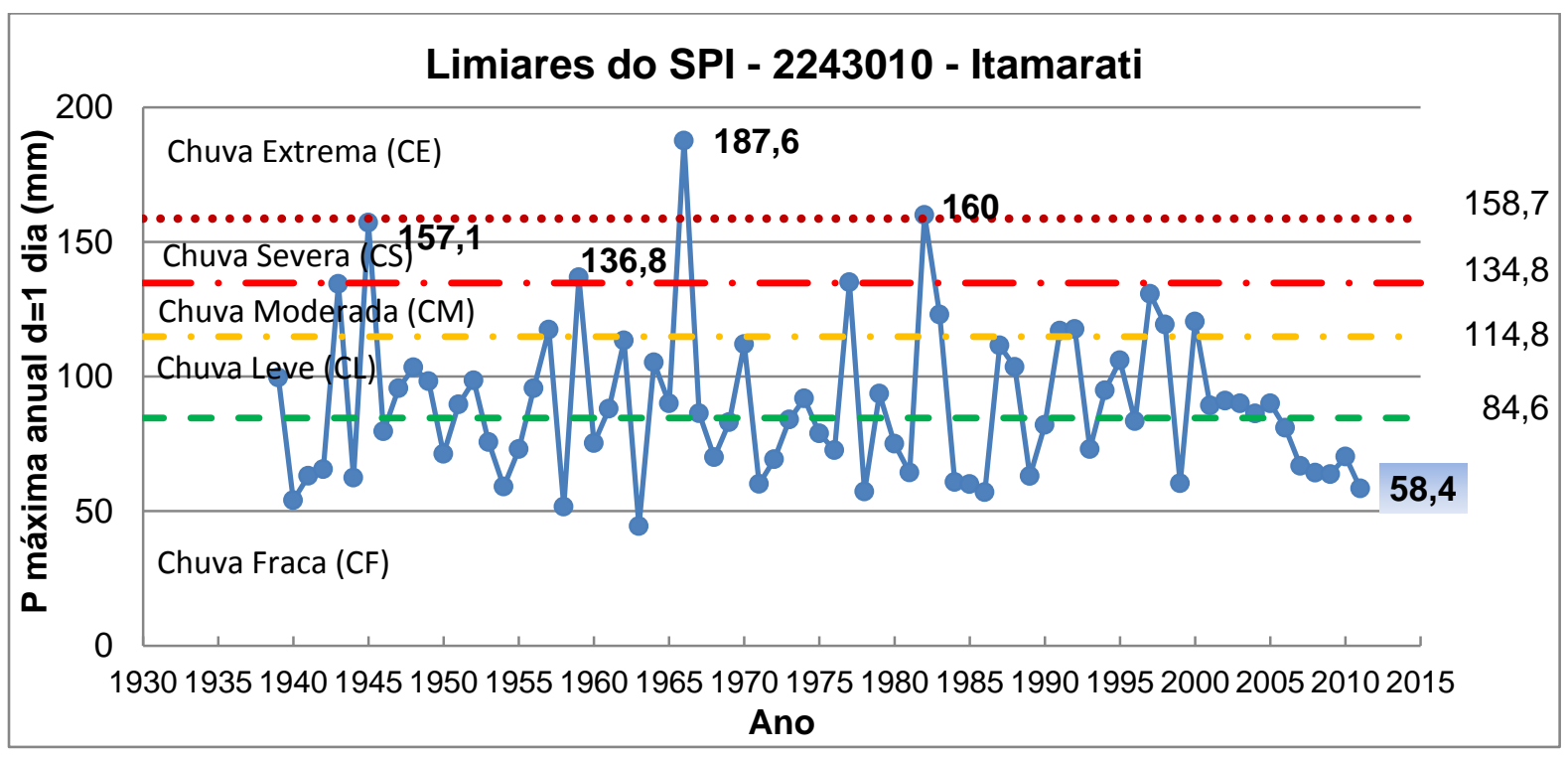

Figura 68 - Classificação das chuvas máximas de duração de 1 dia - 2243010 - Itamarati

Os valores observados em janeiro de 2011 nas estações Itamarati e Rio da Cidade foram classificados como chuvas fracas.

Tabela 57 - SPI - 2243011 - Rio da Cidade - Chuvas máximas anuais com duração de 1 dia

\begin{tabular}{|c|c|c|c|c|c|c|}
\hline Classe de PMDA & \multicolumn{2}{|c|}{ SPI } & p (inf.) & p (sup.) & T (anos) & P 1 dia (mm) \\
\hline Chuva Fraca (CF) & & 0 & & 0,500 & $\leq 2$ & $\leq 81,7$ \\
\hline Chuva Leve (CL) & 0 & 1 & 0,500 & 0,841 & $2<\mathrm{T} \leq 6,3$ & $81,7<\mathrm{T} \leq 111,2$ \\
\hline Chuva Moderada (CM) & 1 & 1,5 & 0,841 & 0,933 & $6,3<\mathrm{T} \leq 15$ & $111,2<\mathrm{T} \leq 130,6$ \\
\hline Chuva Severa (CS) & 1,5 & 2 & 0,933 & 0,977 & $15<\mathrm{T} \leq 44$ & $130,6<\mathrm{T} \leq 153,9$ \\
\hline Chuva Extrema (CE) & 2 & & 0,977 & & $>44$ & $>153,9$ \\
\hline
\end{tabular}

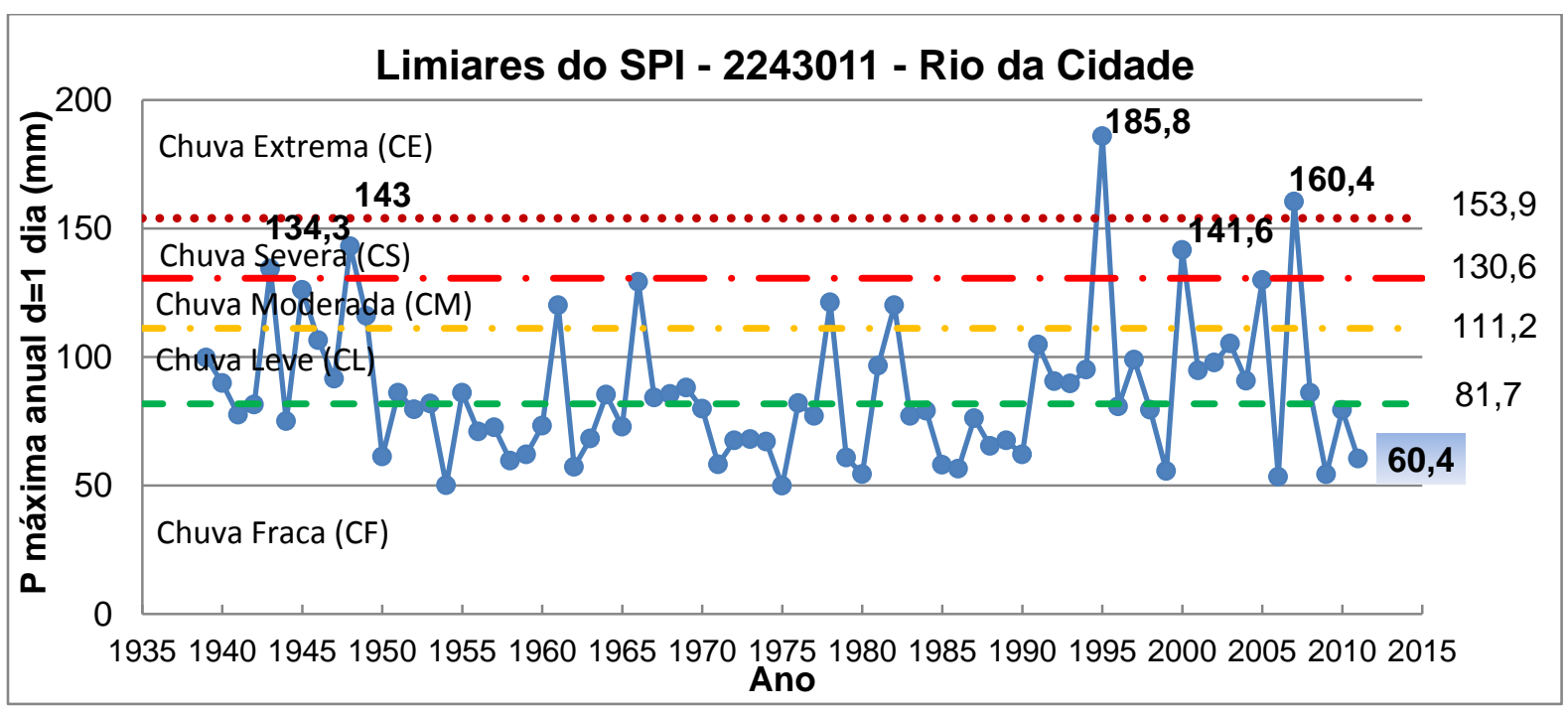

Figura 69 - Classificação das chuvas máximas de duração de 1 dia - 2243011 - Rio da Cidade 


\subsubsection{Conclusões}

A estação mais chuvosa das séries observadas na Região Serrana do Rio de Janeiro é Teodoro de Oliveira, localizada em Nova Friburgo, com altitude de 1.100 metros. A média das máximas diárias nesta estação é $112,5 \mathrm{~mm}$ e a precipitação média anual é $3.235 \mathrm{~mm}$, bem superior às demais estações analisadas. Como está localizada na divisa da bacia, pode ser que as condições do relevo ali existentes façam com que as chuvas sejam intensificadas nesta estação. A segunda estação mais chuvosa é Vargem Alta, localizada na mesma cidade e altitude, onde precipitação média anual de $1.627 \mathrm{~mm}$ e a média das máximas 90,3 mm. Nas demais estações de Nova Friburgo as chuvas médias anuais são 1.478 e 1.499 mm e as médias das máximas são de 74,6 mm e 77,4 mm.

A estação de Teresópolis é a menos chuvosa das estações analisadas, com total anual de $1.342 \mathrm{~mm}$ e média das máximas de $77 \mathrm{~mm}$.

Nas estações de Petrópolis as médias dos totais anuais são $1.455 \mathrm{~mm}$ e $1.541 \mathrm{~mm}$ e a média das máximas $86,2 \mathrm{~mm}$ e $89,2 \mathrm{~mm}$.

Na estação Vargem Alta a melhor distribuição oi a Gumbel, os Trs calculados pela Log-Normal neste posto são superestimados. Nas estações em que as chuvas observadas são outliers, deve-se tomar cuidado ao se estimar o período de retorno desses eventos através das distribuições ajustadas, para que os valores não sejam superestimados.

Os eventos críticos dos dias 11 e 12 de janeiro de 2011 correspondem às máximas chuvas diárias históricas registradas desde que se iniciaram as leituras em quatro dos sete postos utilizados: Vargem Alta, Vargem Grande, Fazenda Mendes e Fazenda Sobradinho, com Trs variando de 70 a 125 anos, estimados pela fórmula de Cunnane. Nos demais postos, os eventos registrados são de alta frequência, com Trs de 1 e 2 anos, indicando que, em média, estes eventos são igualados ou superados a cada ano ou a cada dois anos.

Os meses de novembro e dezembro de 2010 foram chuvosos na maioria das estações, condição que certamente contribuiu para a saturação do solo da bacia e posteriormente para a ocorrência de escorregamentos após as chuvas elevadas de 
11 e 12 de janeiro de 2011. A elevada declividade do relevo da região também foi determinante para os escorregamentos.

A chuva de 11 e 12 de janeiro de 2011 foi de magnitude mais elevada ao redor dos municípios de Nova Friburgo e Teresópolis. Na estação de Vargem Alta, localizada em Nova Friburgo, o volume precipitado foi de $271,5 \mathrm{~mm}$ e pode ser confirmado através do pluviograma recolhido nesta estação, que registrou 270,8 $\mathrm{mm}$. Nos demais postos de Nova Friburgo as chuvas variaram de 225,4 mm, 183,5 mm e 114,8 mm. Em Teresópolis a precipitação foi de 145,5 mm. Nessas estações as chuvas foram classificadas como chuvas extremas, com exceção de Teodoro de Oliveira, onde a chuva foi classificada como chuva leve.

Nas estações localizadas em Petrópolis as chuvas não foram de magnitude tão elevada, com registros de 45,7 mm e $60,4 \mathrm{~mm}$, classificadas através do SPI como chuvas fracas, tanto para a chuva diária quanto para durações de 2 a 5 dias, como ilustra o Anexo V.

De acordo com o Anexo $\mathrm{V}$, as chuvas para durações de 2 a 5 dias permanecem com a classificação de extremas nas estações Fazenda Mendes e Fazenda Sobradinho. Em Vargem Alta, na duração de 5 dias a chuva passa de extrema para severa. Em Vargem Grande, a severidade da chuva diminui para durações superiores a 2 dias, sendo classificada como chuva severa em dois dias e chuva moderada para durações de 3 a 5 dias. Isso indica que o evento diário foi bem mais crítico do que as chuvas acumuladas para as durações de 2 a 5 dias.

Apesar das chuvas 11 e 12 de janeiro de 2011 serem elevadas, outros eventos de magnitude elevada já foram registrados nessas estações pluviométricas (Figura 61). Portanto, estes eventos já ocorreram e são característicos da Região Serrana.

O estudo também mostra a importância da coleta de dados básicos para realização de estudos hidrológicos. Os dados do pluviógrafo confirmaram as chuvas elevadas coletadas no pluviômetro desta estação. O pluviograma do dia 11 para 12 de janeiro de 2011, registrado na estação Vargem Alta, é um dado histórico para a Hidrologia Brasileira. 


\section{CONSIDERAÇÕES FINAIS}

A análise estatística se mostrou adequada para determinar a variabilidade do regime de chuvas de cada uma das regiões estudadas.

$\mathrm{Na}$ análise dos totais mensais, observa-se a variabilidade dos hietogramas para as diferentes regiões do país. Na região Nordeste, onde se encontra o Vale do Mundaú, as chuvas elevadas ocorrem no inverno, entre os meses de abril e julho. $O$ trimestre mais chuvoso é maio, junho e julho, sendo o mês mais chuvoso o mês de junho. Na região Sudeste, observa-se a estação chuvosa no verão, com chuvas elevadas de dezembro a março e janeiro sendo o mês mais chuvoso. Já na região Sul do Brasil, o regime de chuvas não possui sazonalidade bem definida. As chuvas ocorrem durante todo o ano. O mês mais chuvoso no Vale do Itajaí, como na região Sudeste é janeiro.

Analisando as chuvas observadas nas quatro regiões, observa-se que a situação mais crítica ocorreu no Vale do Itajaí. Nos dias 23 e 24 de novembro de 2008, na estação Blumenau choveu $243,5 \mathrm{~mm}$ e $250,9 \mathrm{~mm}$. O volume acumulado em apenas dois dias foi elevadíssimo, de 494,4 mm. O volume acumulado em 45 dias chegou a $1153,9 \mathrm{~mm}$. Em todas as estações, as chuvas foram classificadas como extremas ou severas para as durações de 2 a 5 dias, como mostra o Anexo II.

A chuva diária mais elevada foi observada na estação Vargem Alta, na Região Serrana do Rio de Janeiro. No dia 12 de janeiro de 2011, choveu 271,5 mm. Esse evento corresponde à máxima chuva registrada desde que se iniciaram as leituras nas estações estudadas. Este evento foi classificado, através do SPI, como chuva extrema.

Em Cunha, a chuva observada no dia 1 de janeiro de 2010 na estação Alto da Serra do Mar foi 205,7 mm, também classificado com chuva extrema.

Em Rio Largo, na estação Fazenda Boa Fortuna, na bacia do Mundaú, choveu 203,7 $\mathbf{m m}$ no dia 5 de junho de 2010, classificado como chuva severa.

As chuvas máximas diárias históricas de uma estação podem provocar escorregamentos e inundações, mas estes também podem ser causados por chuvas 
acumuladas em períodos superiores a um dia. Neste caso, quando se estuda somente as máximas diárias, não se tem ideia da magnitude dos eventos acumulados.

No caso do Vale do Itajaí no Vale do Mundaú e na Região Serrana o estudo das máximas diárias já indicaria o evento elevadíssimo que causou as inundações observadas nos anos de 2008, 2010 e 2011 nestas regiões. Em São Luís do Paraitinga, as chuvas máximas diárias de janeiro de 2010 foram de classificadas como chuvas leves. Nesse caso, somente o estudo das máximas diárias dessa estação não seria suficiente para explicar a inundação histórica ocorrida no município. Os gráficos das chuvas acumuladas para diferentes durações auxiliaram na identificação do evento adverso.

No Vale do Itajaí, tanto as chuvas diárias elevadas, quanto as chuvas acumuladas nos meses anteriores contribuíram para a saturação do solo e as posteriores inundações observadas na bacia no ano de 2008. Em 2011, tudo indica que as inundações tenham sido causados pelos volumes acumulados em durações superiores a dois dias.

Em Cunha e em São Luís do Paraitinga, as chuvas extremas ocorridas na cabeceira da bacia e os volumes acumulados nos meses anteriores foram determinantes para causar a inundação histórica e os escorregamentos observados em 2010 no Alto Vale do Paraíba. A análise de outras estações e sua localização na bacia hidrográfica foi importante para caracterizar o evento ocorrido na região.

No Vale do Mundaú e Paraíba, a combinação das chuvas elevadas observadas no dia 5 com as chuvas ocorridas no período de 17 a 19 de junho de 2010, podem ter causado as inundações. A ocupação das planícies de inundação contribuiu para a catástrofe observada nestas bacias. Este evento não foi tão raro, de acordo com os períodos de retorno estimados nas estações. O prejuízo foi causado principalmente pela ocupação do leito do rio nos municípios atingidos pelas inundações.

Na Região Serrana do Rio de Janeiro, vários fatores condicionaram os desastres ocorridos em 2011, dentre eles a saturação do solo devido às chuvas acumuladas nos meses de novembro e dezembro, existência de habitações 
localizadas em áreas de risco (encostas de morros e áreas ripárias), mas principalmente a elevada precipitação ocorrida nos dias 11 e 12 de janeiro. Em Nova Friburgo foi registrado mais de $270 \mathrm{~mm}$ em menos de 24 horas. As chuvas elevadas ocorridas em curto espaço de tempo ocasionam os chamados "flash floods", que são as inundações rápidas, características de regiões de alta declividade e provocadas por chuvas de alta intensidade. Os escorregamentos de encostas aliados à população extremamente vulnerável foi o que causou inúmeras mortes nos municípios atingidos. Segundo Secretaria Nacional da Defesa Civil e Defesa Civil do Rio de Janeiro, foram contabilizadas 865 mortes na região e destas, 420 no município de Nova Friburgo, que teve 99\% de sua população afetada. Na região, mais de 304 mil pessoas foram diretamente afetadas pelo desastre.

A estimativa dos períodos de retorno através das distribuições ajustadas mostrou-se divergente para algumas estações, como, por exemplo, Vargem Alta, quando os eventos são outliers. Por isso deve-se ter cuidado em sua estimativa. Alguns valores, dependendo da distribuição adotada, podem ser superestimados, como mostra a Tabela 48. Portanto, em regiões que sofrem constantemente com os desastres, estes conceitos tem que ser revistos. Talvez a severidade da chuva seja uma alternativa para subsidiar as medidas mitigadoras nestas bacias.

As Figuras 13, 28, 42 e 61, contendo as séries de chuvas máximas diárias de cada uma das regiões, são apropriadas para ilustrar outros eventos de magnitude elevada ocorridos nessas bacias hidrográficas. No Vale do Itajaí, nos anos de 1963 e 1970 choveu 190,8 mm Brusque e 190,4 mm em Blumenau. No Alto Vale do Paraíba, as chuvas elevadas são recorrentes. Em Ponte Alta I, foi registrado 200 mm em 1950, 218,1 mm em 1969, 219 mm em 1963 e 190,1 mm em 2003. No Vale do Mundaú choveu 199 mm no ano 2000 e 189,9 mm na estação Fazenda Boa Fortuna, no município de Rio Largo. Na Região Serrana do Rio de Janeiro, choveu 211 mm em Nova Friburgo e 187,6 mm em Petrópolis no ano de 1966,. Em 1995 choveu 185,9 mm em Petrópolis. Portanto, os eventos extremos são característicos destas regiões.

A classificação das chuvas através do SPI, adaptado por Santos et al. (2013) se mostrou bastante adequada, pois permite uma classificação qualitativa "Chuva Fraca, Chuva Leve, Chuva Moderada, Chuva Severa e Chuva Extrema", dos 
eventos além de estar relacionado à probabilidade de ocorrência e à distribuição teórica. Ao classificamos as chuvas qualitativamente, podemos comparar bacias hidrográficas com diferentes regimes de chuvas, dados de diferentes magnitudes e também padronizar as informações. A classificação das chuvas através do SPI pode ser uma alternativa para os profissionais que planejam sistemas de alerta, auxiliando na definição dos limiares de chuva associados à mudança de estado e também para os profissionais que atuam no tema redução de risco de desastres.

Ao longo desta dissertação procurou-se estudar as chuvas extremas que provocaram desastres naturais importantes no Brasil. Constatou-se que as regiões analisadas estão sujeitas a chuvas extremas com frequência relativamente alta, muito embora tenha se observado, em alguns casos, um certo grau de raridade nesses eventos, como ocorreu com as chuvas no Vale do Itajaí em 2008. Além disso, nas regiões estudadas, observa-se a ocupação desordenada do solo. A população habita as áreas de risco, como as margens dos rios as encostas de morros, suscetíveis à ocorrência de inundações e escorregamentos. Portanto, é necessário aplicar medidas regionais no sentido de disciplinar o uso e ocupação do solo, além de medidas preventivas ou corretivas para diminuir a fragilidade das comunidades que habitam as áreas de risco. É fundamental buscar medidas de adaptação da ocupação, considerando o regime hidrológico dessas regiões. 


\section{RECOMENDAÇÕES PARA ESTUDOS FUTUROS}

Algumas dificuldades surgiram durante a elaboração desta dissertação, como a obtenção de dados referentes aos desastres naturais ocorridos em cada uma das regiões estudadas. Dados mais recentes foram obtidos através dos AVADANs, os relatórios de avaliação de danos, obtidos no site da defesa civil. Outros dados foram obtidos de jornais, de artigos, informação pessoal, como no caso das inundações históricas de São Luís do Paraitinga. Na fase de laboração deste trabalho, ainda não existia um banco de dados único e consolidado no Brasil, como é o caso do banco mundial de desastres naturais EM-DAT, que possui dados desde 1900. Nesse sentido, faz-se necessário sistematizar e criar um banco de dados contendo o cadastro de desastres naturais ocorridos no Brasil. Consta como Instrumento do Plano Nacional de Gestão de Riscos e Resposta a Desastres o Sistema Integrado de Informações sobre Desastres (S2ID). Esta é a primeira iniciativa no país de se criar um banco de dados único, que servirá de fonte oficial de desastres no país. As informações contidas nesse banco serão úteis para compor estudos futuros em temas relacionados a gerenciamento e redução de riscos de desastres no Brasil.

Para os pesquisadores que pretendem dar continuação a estes estudos de caso, sugere-se montar um banco de dados contendo os principais desastres naturais ocorridos nestas bacias hidrográficas, principalmente os escorregamentos e as inundações, que possivelmente poderão ser obtidos mais facilmente com a criação do S2ID. A partir deste banco e com os dados hidrológicos disponíveis, pode-se fazer diversos estudos como: Correlacionar os eventos severos e extremos de precipitação obtidos neste estudo aos desastres ocorridos em cada uma das regiões atingidas; fazer um levantamento apropriado de causa e efeito destes desastres naturais, levando-se em consideração a severidade do evento e as consequências na bacia hidrográfica;

Outros estudos também podem ser realizados, tais como:

Testar outros tipos de distribuições probabilísticas para a estimativa de limiares através do SPI e verificar se estes limiares mudam consideravelmente dependendo da distribuição adotada; 
Caracterizar os eventos críticos a serem considerados para determinação dos níveis de proteção destas bacias hidrográficas. Verificar se os limiares estimados para a classificação das chuvas, através do SPI, para as durações de 1 a 5 dias, nestes estudos de caso, podem ser os mesmos utilizados como limiares para a mudança de estado em sistemas de alerta nestes municípios;

Rever e adaptar os conceitos baseados na estimativa dos períodos de retorno para o dimensionamento de obras hidráulicas em bacias hidrográficas que sofrem frequentemente com desastres. Criar novos conceitos de projeto atendendo os níveis de severidade destes eventos extremos. Adaptar o SPI no dimensionamento de obras de drenagem urbana em locais suscetíveis a ocorrência de inundações e escorregamentos em bacias urbanas. 


\section{BIBLIOGRAFIA}

ABAS - Associação Brasileira de Águas Subterrâneas. Eventos extremos: Fenômenos naturais ou consequência das ações humanas? Disponível em: http://www.abas.org/eventosextremos/ Acesso em: 06 jun. 2011.

ADRC: Asian Disaster Reduction Center e IRP: International Recovery Platform. Great East Japan earthquake: preliminary observations. 2011. Disponível em: http://www.unisdr.org/we/inform/publications/20537. Acesso em: 05 jan. 2011

ALCANTARA-AYALA, I. Geomorphology, natural hazards, vulnerability and prevention of natural disasters in developing countries. Geomorphology, 2002, v. $47, \mathrm{n} 2-4$, p. $107-124$

ALHEIROS, M. M. Contexto histórico e cenário atual da gestão de riscos e desastres no Brasil. In: SIMPÓSIO BRASILEIRO DE DESASTRES NATURAIS E TECNOLÓGICOS, 3, 2011, São Paulo, SP. Anais..., São Paulo: ABGE Associação Brasileira de Geologia de Engenharia e Ambiental, 2011. CD-ROM.

ALMEIDA, M. C. J.; NAKAZAWA, V. A.; TATIZANA, C. Análise da correlação entre chuvas e escorregamentos no município de Petrópolis, RJ. In: CONGRESSO BRASILEIRO DE GEOLOGIA DE ENGENHARIA, 7, Poços de Caldas, SP. Anais... São Paulo: ABGE, 1993. CD-ROM.

AMARAL, R.; RIBEIRO, R. R. Inundações e Enchentes. In: Tominaga, L. K.; Santoro, J.; Amaral, R. (organização). Desastres Naturais: Conhecer para Prevenir. São Paulo: Instituto Geológico, 2009. 160 p.

AMARAL, R.; Gutjahr, M. R. Desastres Naturais. São Paulo: IG/SMA, 2011, 100p.

AMARAL, C.; LIMA, I. F.; VAREJÃO, L. C.; SANTANA, M. Carta de risco remanescente a escorregamentos no município de Teresópolis, após o mega desastre' 11 da Região Serrana. In: CONGRESSO BRASILEIRO DE GEOLOGIA DE ENGENHARIA E AMBIENTAL, 13, 2011, São Paulo, SP. Anais..., São Paulo: ABGE - Associação Brasileira de Geologia de Engenharia e Ambiental, 2011. CDROM.

ANA - Agência Nacional de Águas. Hidroweb: Sistemas de informações Hidrológicas. Disponível em: <http://hidroweb.ana.gov.br>. Acesso em: dez. 2011.

ARAUJO, L. M. N.; MOREIRA, D. M.; MELO, J. S.; MENDEL Jr, A. P.; FERNANDES, N. F.; DAVIS, E. G. Avaliação da distribuição espaço-temporal histórica de eventos chuvosos no Rio de Janeiro In: WORLD WATER CONGRESS, 14, 2011. Porto de Galinhas, PE. Anais... Porto de Galinhas: IWRA - International Water Resources Association, 2011. CD-ROM 
BACK, A. J. Relações entre precipitações intensas de diferentes durações ocorridas no município de Urussanga, SC. Revista Brasileira de Engenharia. Agrícola e Ambiental. 2009, vol.13, n.2, p.170-175

BANCO MUNDIAL, 2012. Avaliação de Perdas e Danos: Inundações e Deslizamentos na Região Serrana do Rio de Janeiro - Janeiro de 2012. Disponível em: http://www.ecapra.org/sites/default/files/documents/DaLA\%20Rio\%20de\%20Janeiro \%20Final\%202\%20Baixa\%20Resolucao_0.pdf Acesso em: fev. 2013

BELL, F. G. Generalized rainfall - duration - frequency relationship, Journal of the Hydraulics Division - ASCE, 1969, V.95, N.HY1, p.311-327

BIZELLI, J. L; ALVES, J. X. S. Gestão em momentos de crise: Programa Unesp para desenvolvimento sustentável de São Luiz do Paraitinga. São Paulo: Cultura Acadêmica, 2011, 208p.

BROLLO, M. J.; FERREIRA, C. J. Indicadores de desastres naturais no Estado de São Paulo. In: SIMPÓSIO DE GEOLOGIA DO SUDESTE, 11, 2009, Águas de São Pedro, SP. Sociedade Brasileira de Geologia. Anais..., Águas de São Pedro, SP p. 125.

BROLLO, M. J.; FERREIRA, C. J.; TOMINAGA, L. K.; VEDOVELLO, R.; SILVA, P. C. F.; ANDRADE, E.; GUEDES, A. C. M. Situação dos desastres e riscos no Estado de São Paulo e instrumentos de gerenciamento. In: CONGRESSO BRASILEIRO DE GEOLOGIA DE ENGENHARIA E AMBIENTAL, 13, 2011, São Paulo, SP. Anais..., São Paulo: ABGE - Associação Brasileira de Geologia de Engenharia e Ambiental, 2011. CD-ROM.

CANHOLI, A. P. Drenagem urbana e controle de enchentes. São Paulo: Oficina de Textos, 2005, $302 \mathrm{p}$.

CASTRO, A. L. C. Manual de desastres: desastres naturais. Brasília: Ministério da Integração Nacional. MIN, 2003, 174 p.

CASTRO, A. L. C. Segurança global da população. Brasília: Ministério da Integração Nacional. MIN, 2007, 64 p.

CAVALCANTI, I. F. A.; FERREIRA, N. J.; JUSTI DA SILVA, M. G. A.; SILVA DIAS, M. A. F. (organizadores). Tempo e Clima no Brasil. São Paulo: Oficina de Textos, 2009. 462p.

CEIVAP - Comitê de Integração da Bacia Hidrográfica do Rio Paraíba do Sul. Bacia do Paraíba do Sul - Dados geoambientais. Disponível em: http://www.ceivap.org.br/bacia_1_2.php Acesso em: agosto de 2012.

CEMADEN - Centro Nacional de Monitoramento e Alerta de Desastres Naturais. Disponível em: http://www.cemaden.gov.br/ Acesso em: janeiro de 2013 
CHEN, C. Rainfall intensity - duration - frequency formulas, Journal of Hydraulics Engineering - ASCE, 1983, V.109, N.12, p.1603-1621

CIRILO, J. A.; DANTAS, C. E. O.; RIBEIRO NETO, A.; SILVA, E. R.; MONTENEGRO, S. M. G. L. Controle e previsão de cheias no Estado de Pernambuco, Brasil: estrutura geral do sistema de suporte à decisão. In: WORLD WATER CONGRESS, 14, 2011. Porto de Galinhas, PE. Anais... Porto de Galinhas: IWRA - International Water Resources Association, 2011. CD-ROM

COUTINHO, S. V. A precipitação e sua influência na movimentação de massa: um estudo de caso. Revista saúde e ambiente. 2002, v.3 p.11-17

CPTEC - ZCAS provoca chuva volumosa e transtornos em MG, RJ e no ES. Disponível em: http://www.cptec.inpe.br/noticias/noticia/20405. Acesso em: 04 jan. 2012.

CPRM - Serviço Geológico do Brasil. Atlas Pluviométrico do Brasil. Versão 2.0, nov. 2011. CD-ROM

DAEE/CETESB. Drenagem urbana - Manual de Projeto. São Paulo: Companhia de Tecnologia e Saneamento Ambiental, 1986, $3^{\mathrm{a}}$ ed. 464p

DANTAS, C. E. O. Previsão e controle de inundações em meio urbano com suporte de informações espaciais de alta resolução. Tese de Doutorado, Faculdade de Engenharia Civil - Universidade Federal de Pernambuco, 2012, 221 p.

DAVIS, E. G; NAGHETTINI, M. C. Estudo de chuvas intensas no Estado do Rio de Janeiro. Belo Horizonte: CPRM, 2001. 140p.

DIAS, M. A. F. S. As chuvas de novembro de 2008 em Santa Catarina: um estudo de caso visando a melhoria do monitoramento e da previsão de eventos extremos. $2009 . \quad$ Disponível em: http://www.ciram.com.br/ciram_arquivos/arquivos/gtc/downloads/NotaTecnica_SC.pd f Acesso em: out. 2012

DI GREGÓRIO, et al. Aplicabilidade dos mapeamentos de suscetibilidade, perigo (hazards) e risco na redução de desastres naturais. In: CONGRESSO BRASILEIRO SOBRE DESASTRES NATURAIS, 2012, Rio Claro, SP. Anais do Congresso Brasileiro sobre Desastres Naturais. Rio Claro: IG, UNESP, CPRM, 2012. CD-ROM

EMBRAPA - $\quad$ Clima. Disponível em http://www.cnpf.embrapa.br/pesquisa/efb/clima.htm Acesso em: outubro de 2012

EM-DAT: The International Disaster Database. OFDA/CRED The Office of US Foreign Disaster Assistance/Centre for Research on the Epidemiology of Disasters Université Catholique de Louvain, Brussels, Belgium. Disponível em: http://www.emdat.be. Acesso em: 16 set. 2011 
EM-DAT: The International Disaster Database. OFDA/CRED The Office of US Foreign Disaster Assistance/Centre for Research on the Epidemiology of Disasters Université Catholique de Louvain, Brussels, Belgium. Disponível em: http://www.emdat.be/classification. Acesso em: 16 nov. 2011

Emergência em Santa Catarina. Tragédia no Vale do Itajaí. Disponível em: http://www.clicrbs.com.br/especial/sc/sos-sc/81,0,523,15573,tragedia-no-vale-doitajai-24-11-2008.html Acesso em: outubro de 2012

Enchente - $\quad$ Ditão Virgílio. Disponível em: http://acervodigital.unesp.br/handle/123456789/40021 Acesso em: fev. 2013

ESRI ArcGIS Desktop 9.3 Help. Disponível em: http://webhelp.esri.com/arcgiSDEsktop/9.3/index.cfm?TopicName=Spline Acesso em: 27 jan. 2012

ESTADÃO. Inundação destrói prédios históricos em São Luís do Paraitinga. Disponível em: http://www.estadao.com.br/noticias/cidades, inundacao-destroipredios-historicos-em-sao-luis-do-paraitinga,489711,0.htm Acesso em: jan. 2013

FALAGUASTA, L. N. Equações de chuvas intensas generalizadas para os Estados de São Paulo e Paraná. Dissertação de Mestrado, Faculdade de Engenharia Civil - Universidade Estadual de Campinas, 2001, 192 p.

FARINACI, J. S.; SEIXAS, C. S.; Resposta a inundações e reorganização de sistemas sócio ecológicos sob a perspectiva da resiliência In: CONGRESSO BRASILEIRO SOBRE DESASTRES NATURAIS, 2012, Rio Claro, SP. Anais do Congresso Brasileiro sobre Desastres Naturais. Rio Claro: IG, UNESP, CPRM, 2012. CD-ROM

FOLHA DE SÃO PAULO. Chuva isola São Luiz do Paraitinga (SP) e deixa quase toda população fora de casa. Disponível em: http://www1.folha.uol.com.br/folha/cotidiano/ult95u673855.shtml Acesso em: jan. 2013

FORÇA VOLUNTÁRIA. O que é um desastre. 2009. Disponível em: http://www.forcavoluntaria.org.br/2009/09/09/91/ Acesso em: 29 fev. 2012

FRAGOSO JR, C. R.; PEDROSA, V. A.; SOUZA, V. C. B. Reflexões sobre a Cheia de Junho de 2010 nas Bacias do Rio Mundaú e Paraíba. In: SIMPÓSIO DE RECURSOS HÍDRICOS DO NORDESTE, 10, 2010, Fortaleza, CE. Anais do X Simpósio de Recursos Hídricos do Nordeste. Porto Alegre: ABRH, 2010. v. 1. CDROM.

FRANK, B.; SAVEGNANI, L. (organizadores). Desastre de 2008 no Vale do Itajaí. Água, Gente e Política. Blumenau: Agência de Água do Vale do Itajaí, 2009. 192 p. 
Disponível em: http://www.comiteitajai.org.br:8080/handle/123456789/1116 Acesso em: 21 mar. 2012

G1 - Conheça como funciona o sistema de monitoramento de chuvas do governo Disponível em : http://g1.globo.com/ciencia-esaude/noticia/2011/12/conheca-como-funciona-o-sistema-de-monitoramento-dechuvas-do-governo.html Acesso em: janeiro de 2012

G1 - Desastre natural na Região Serrana é o maior da história do país. Veja imagens de outras localidades devastadas por temporais. Disponível em: http://g1.globo.com/rio-de-janeiro/chuvas-no-rj/noticia/2011/01/relembre-outrastragedias-causadas-pela-chuva-no-brasil.html Acesso em: 10 jan. 2012

GENOVEZ, A. M. et al. Relação de chuvas intensas de diferentes durações e avaliação das equações de chuvas intensas generalizadas. In: XIV Congresso Latino Americano de Hidráulica, Santiago, Chile, 1994, p.279-290

GENOVEZ, A. M.; ZUFFO, A.C. Chuvas Intensas no Estado de São Paulo: Estudos Existentes e Análise Comparativa, RBRH - Revista Brasileira de Recursos Hídricos, 2000, V.5, N.3, p.45-58

GEIST, E. L.; BILEK, S. L.; ARCAS, D.; TITOV, V. V. Differences in tsunami generation between the December 26, 2004 and March 28, 2005 Sumatra earthquakes. Earth Planets Space, 2006, v. 58, p. 185-193. Disponível em: http://walrus.wr.usgs.gov/tsunami/sumatraEQ/refs.html Acesso em: 18 jan. 2012

GEIST, E. L.; TITOV, V. V.; ARCAS, D.; POLLITZ, F. F.; BILEK, S. L. Implications of the 26 December Sumatra-Andaman earthquake on tsunami forecast and assessment models for great subduction-zone earthquakes: Bulletin of the Seismological Society of America, 2007, v. 97, p. S249-S270 Disponível em: http://walrus.wr.usgs.gov/tsunami/sumatraEQ/refs.html Acesso em: 18 jan. 2012

GUIDICINI, G.; IWASA, O. Y. Ensaio de correlação entre pluviosidade e escorregamentos em meio tropical úmido. São Paulo: IPT, 1972. 48p.

GFDRR; UNISDR; WB. Disaster risk management programs for priority countries - 2nd edition. 2011. 431p. Global Facility for Disaster Reduction and Recovery, the (GFDRR); United Nations International Strategy for Disaster Reduction Secretariat (UNISDR); World Bank, the (WB). Disponível em: http://www.unisdr.org/we/inform/publications/20049 Acesso em: 11 jan. 2012

HALLAK R.; PEREIRA FILHO, A. J. Modelagem numérica da convecção local aplicada à prevenção de desastres naturais associados à precipitação na Região Metropolitana de São Paulo. In: CONGRESSO BRASILEIRO DE GEOLOGIA DE ENGENHARIA E AMBIENTAL, 13, 2011, São Paulo, SP. Anais... São Paulo: ABGE - Associação Brasileira de Geologia de Engenharia e Ambiental, 2011. CD-ROM. 
HEC - The Hydrologic Engineering Center. HEC-HMS. US Army Corps of Engineers. Disponível em: http://www.hec.usace.army.mil/software/hec-hms/ Acesso em: 23 jan. 2012.

HEC - The Hydrologic Engineering Center. HEC-RAS. US Army Corps of Engineers. Disponível em: http://www.hec.usace.army.mil/software/hec-hms/ Acesso em: 23 jan. 2012.

HERNANDEZ, V. Ainda as equações de chuvas intensas - pode-se generalizar? In: SIMPÓSIO BRASILEIRO DE RECURSOS HÍDRICOS, 11, 1991. Rio de Janeiro, RJ. Anais... Rio de Janeiro: ABRH, p.193-203

HERNANDEZ, V. Regionalização dos parâmetros de escala em chuvas intensas. RBRH - Revista Brasileira de Recursos Hídricos, 2008, V.12, N.1, p.91-98 HIDROWEB - Sistema de Informações Hidrológicas - Dados Hidrológicos - Séries Históricas. Disponível em: http://hidroweb.ana.gov.br/ Acesso em: junho de 2012

HUBP, J. L.; INBAR, M. (compiladores) Desastres Naturales en America Latina. México: Fondo de Cultura Economica, 2002, 501 p.

IBGE - Instituto Brasileiro de Geografia e Estatística. Quatro picos brasileiros tem sua altitude alterada. Disponível em: http://www.ibge.gov.br/home/presidencia/noticias/noticia_visualiza.php?id_noticia=21 5\&id_pagina=1 Acesso em: agosto de 2012.

INEA - Instituto Estadual do Ambiente. Disponível em: http://inea.infoper.net/ Acesso em: janeiro de 2012.

INMET - Instituto Nacional de Meteorologia. Disponível em: http://www.inmet.gov.br/html/clima.php Acesso em: janeiro de 2013

Inundação: Mega-desastre em Alagoas e Pernambuco. Disponível em: http://cabana-on.com/Brasil/artigos/artigo28.html Acesso em: junho de 2012

KOBIYAMA, M.; MENDONÇA, M.; MORENO, D. A.; MARCELINO, I. P. V. O.; MARCELINO, E. V.; GONÇALVES, E. F.; BRAZETTI, L. L. P.; GOERL R. F.; MOLLERI G. S. F., RUDORFF F. M. Prevenção de desastres naturais: conceitos básicos. Curitiba: Ed. Organic Trading, 2006. 109p.

LEI 12.608 de abril de 2012. Institui a Política Nacional de Proteção e Defesa Civil PNPDEC; Disponível em: http://www.planalto.gov.br/CCIVIL 03/ Ato20112014/2012/Lei/L12608.htm Acesso em maio de 2013.

LEWIS E. LINK. The anatomy of a disaster, an overview of Hurricane Katrina and New Orleans. Ocean Enginnering, 2010, v.37, n. 1, p. 4-12 
LOBO, G. A.; MAGNI, N. L. G. Estudo sobre proporções de chuvas intensas de diferentes durações. In: SIMPÓSIO BRASILEIRO DE HIDROLOGIA E RECURSOS HÍDRICOS, 7, 1987, Salvador, BA. Anais..., Salvador: ABRH, p.103-114

MAGNI, N. L. G.; MERO, F. Precipitações intensas no Estado de São Paulo. Boletim CTH-DAEE, São Paulo, 1982, 188p.

MAGNI, N.L.G., MARTINEZ J. F. Equações de chuvas intensas no Estado de São Paulo. São Paulo: FCTH-DAEE, 1999, 125p.

MARCELINO, E. V. Desastres Naturais e geotecnologias: conceitos básicos. Santa Maria: INPE, 2008, $38 \mathrm{p}$.

MARTINEZ, A. G.; TAKAHASH, K.; ZUBIETA, R.; OROZCO, R. Extreme meteorological events and risk management in the Andes of Peru In: WORLD WATER CONGRESS, 14, 2011. Porto de Galinhas, PE. Anais... Porto de Galinhas: IWRA - International Water Resources Association, 2011. CD-ROM

McKEE, T.B; DOESKEN, N. J.; KLIEST, J. The relationship of drought frequency and duration to time scales. Eighth Conference on Applied Climatology. American Meteorological Society. Boston. 1993.

MEDEIROS, O. B. Estudo da distribuição na área de chuvas intensas em bacias de médio porte. Dissertação de Mestrado, Faculdade de Engenharia Civil Universidade Estadual de Campinas, 2002, 187 p.

MEDEIROS, V. S.; BARROS, M. T. L. Análise estatística das precipitações ocorridas nas bacias do Mundaú e Paraíba em junho de 2010. In: SIMPÓSIO DE RECURSOS HÍDRICOS DO NORDESTE, 11, 2012, João Pessoa, PB. Anais..., $\mathrm{ABRH}$, 2012. CD-ROM

MEDEIROS, V. S.; BARROS, M. T. L. Análise dos eventos críticos de precipitação ocorridos na Região Serrana do Estado do Rio de Janeiro em 11 e 12 de janeiro de 2011. In: SIMPÓSIO BRASILEIRO DE RECUROS HÍDRICOS, 19, 2011. Maceió, AL. Anais...Maceió: ABRH, 2011. CD-ROM.

MEDEIROS, V. S.; BARROS, M. T. L. Chuvas e desastres naturais ocorridos no Vale do Itajaí em 2008 e 2011. In: CONGRESSO BRASILEIRO SOBRE DESASTRES NATURAIS, 2012, Rio Claro, SP. Anais do Congresso Brasileiro sobre Desastres Naturais. Rio Claro: IG, UNESP, CPRM, 2012. CD-ROM

MEDEIROS, V. S.; BARROS, M. T. L. Estudo da variabilidade de chuvas intensas na Região Metropolitana de São Paulo e sua importância para a drenagem urbana. In: WORLD WATER CONGRESS, 14, 2011. Porto de Galinhas, PE. Anais... Porto de Galinhas: IWRA - International Water Resources Association, 2011. CD-ROM 
MENDONÇA, F.; DANNI-OLIVEIRA, I. M. Climatologia: noções básicas e climas no Brasil. São Paulo: Oficina de Textos, 2007, 206 p.

MICHEL, G. P.; GOERL, R. F.; KOBIYAMA, M.; REIS R. A. Estimativa da quantidade de chuvas para deflagrar escorregamentos. In: SIMPÓSIO BRASILEIRO DE RECUROS HÍDRICOS, 19, 2011. Maceió, AL. Anais...Maceió: $A B R H$, 2011. CD-ROM.

MISHRA, A.K., SINGH, V.P. A review of drought concepts. Journal of Hydrology doi:10.1016/j.jhydrol.2010.07.012.2010

MINISTÉRIO DAS CIDADES. Planos Municipais de Redução de Riscos. 2011. Disponível em: http://www.cidades.gov.br/index.php?option=com_content\&view=article\&id=823:plan os-municipais-de-reducao-de-riscos\&catid $=135 \&$ Itemid $=163$ Acesso em: 17 jan. 2012

NAGHETTINI, M.; PINTO, E. J. de A. Hidrologia Estatística. Belo Horizonte: CPRM, 2007, 561p.

OCCHIPINTI, A.G.; SANTOS, P. M. Análise das máximas intensidades de chuva na cidade de São Paulo. São Paulo: IAG - Instituto de Astronomia, Geofísica e Ciências Atmosféricas da USP - Universidade de São Paulo, 1965, 40p.

OCCHIPINTI, A.G.; SANTOS, P.M. Relação entre as precipitações máximas de "um dia" e de "24 horas" na cidade de São Paulo. In: SIMPÓSIO DE REDES HIDROLÓGICAS, 1, 1966, Belo Horizonte, MG. Anais... São Paulo: IAG - Instituto de Astronomia, Geofísica e Ciências Atmosféricas da USP, 1966

OLIVEIRA, D. L. ; SOUZA, V. C. B. ; FRAGOSO JR., C. R. Análise das precipitações e níveis do evento de junho de 2010 nas bacias dos rios Mundaú e Paraíba, em Alagoas e Pernambuco. In: SIMPÓSIO BRASILEIRO DE RECURSOS HÍDRICOS, 2011, 19, Maceió. Anais do XIX Simpósio Brasileiro de Recursos Hídricos. Porto Alegre : ABRH, 2011. v. 1. CD-ROM

OLIVER-SMITH, A. El gran terremoto del Peru, 1970: el concepto de la vulnerabilidade y el estúdio y la gestión de los desastres em América Latina. In: HUBP, J. L. e INBAR, M. (compiladores) Desastres Naturales en America Latina. México: Fondo de Cultura Economica, 2002, 501 p.

PEREIRA FILHO, A. J.; BARROS, M. T. L.; Hallak, R.; GANDU, A.W. Enchentes na Região Metropolitana de São Paulo: aspectos de mesoescala e avaliação de impactos. In: CONGRESSO BRASILEIRO DE METEOROLOGIA, 13, 2004. Fortaleza, CE. Anais... Fortaleza: CBMET, 2004. CD-ROM.

PFASTETTER, O. Chuvas Intensas no Brasil. DNOS - Departamento de Obras e Saneamento. Rio de Janeiro, RJ. 1957, 419 p. 
PICHLER, E. Aspectos Geológicos dos escorregamentos de Santos. Boletim da Sociedade Brasileira de Geologia. São Paulo, 1957, v.6, n.2, p.69-77.

Plano Nacional de Gestão de Risco e Resposta a Desastres Naturais. Disponível em: http://www.pac.gov.br/pub/up/relatorio/d0d2a5b6f24df2fea75e7f5401c70e0d.pdf Acesso em: janeiro de 2013

POZZOBON, M.; XAVIER, F. F.; CARREIRÃO, H. M. C.; BALEN, A.; PERDONCINI, L. C.; FILHO, G. L.; BARBATO, A. M.; VALÉRIO, J. L. Gerenciamento de áreas de risco geológico: A experiência do município de Blumenau, Santa Catarina. In: CONGRESSO BRASILEIRO DE GEOLOGIA DE ENGENHARIA E AMBIENTAL, 13, 2011, São Paulo, SP. Anais..., São Paulo: ABGE - Associação Brasileira de Geologia de Engenharia e Ambiental, 2011. CD-ROM.

PEREIRA FILHO, A.J., et al. Impactos antrópicos no clima da região metropolitana de São Paulo. Boletim da Sociedade Brasileira de Meteorologia, 2007, V.31, n.1, p48-56

RAMOS, C. L.; BARROS, M. L.; PALOS, J. C. F. Diretrizes básicas para projetos de drenagem urbana no município de São Paulo. São Paulo: FCTH/DAEE e Prefeitura do Município de São Paulo, (Reedição eletrônica 1999), 289p.

REVISTA ISTO É. O Haiti é aqui. Disponível em: http://www.istoe.com.br/reportagens/83502_O+HAITI+E+AQUI Acesso em: junho de 2012

REVISTA VEJA. A Origem do Tsunami que varreu o Nordeste. Disponível em: http://veja.abril.com.br/noticia/brasil/a-origem-do-tsunami-que-varreu-o-nordeste Acesso em: Junho de 2012

REVISTA VEJA. Calamidade. São Luiz do Paraitinga sofre com as chuvas do início de ano. Disponível em: http://vejasp.abril.com.br/materia/sao-luiz-doparaitinga-sofre-com-as-chuvas-do-inicio-de-ano Acesso em: Janeiro de 2013

RODRIGUES-ITURBE, I. R. e MEJIA, J. M. On the Transformation of Point Rainfall to Areal Rainfall. Water Resources Research, 1974, V.10, N.4, p.729-734

RODRIGUES-ITURBE, I. R. e MEJIA, J. M. The Design of Rainfall Networks in Time and Space. Water Resources Research, 1974, V.10, N.4, p.713-728

ROSAL, M. C. F.; MEDEIROS, V. S. Análise das precipitações máximas e dos eventos extremos ocorridos em São Luís do Paraitinga e municípios vizinhos. In : SIMPÓSIO DE RECURSOS HÍDRICOS DO NORDESTE, 11, 2010, Fortaleza, CE, Anais... Fortaleza, 2010. CD-ROM.

SAISP - Sistema de Alerta a Inundações do Estado de São Paulo. Disponível em: http://www.saisp.br/estaticos/sitenovo/produtos.xmlt\#a4 Acesso em: janeiro de 2012 
SAMPAIO, M. V. Espacialização dos coeficientes das equações de chuvas intensas em bacias hidrográficas do Rio Grande do Sul. Tese de doutorado. Universidade Federal de Santa Maria, RS, 2011, 156p.

SANTO, F. E.; LIMA, M. I. P.; RAMOS, A. M. Investigating changes in daily precipitation extremes in Mainland Portugal, 1941-2007 In: WORLD WATER CONGRESS, 14, 2011. Porto de Galinhas, PE. Anais... Porto de Galinhas: IWRA International Water Resources Association, 2011. CD-ROM

SANTOS, P. M. et al. Evolução climática na Região Metropolitana de São Paulo. In: CONGRESSO BRASILEIRO DE METEOROLOGIA, 14, 2006. Florianópolis, SC. Anais... Florianópolis: CBMET2006. CD-ROM.

SANTOS, M. S. et al. A Atuação Secretaria Nacional de Defesa Civil - SEDEC na Gestão de Riscos e Resposta a Desastres Naturais. In: Congresso Consad de Gestão Pública, 6, 2013. Brasília, DF. Anais... Brasília: CD-ROM.

SANTOS, M. S.; PINTO, E. J. A.; MARTINS, L. K. L. A. e PINTO, J. A. O. Definição de limiares de secas e cálculo do índice de precipitação padronizada por meio de análise regional de frequências na bacia do alto São Francisco. Revista Brasileira de Recursos Hídricos - RBRH, 2013, V18, n.2

SEDEC - Secretaria Nacional da Defesa Civil. Novos dados do desastre em Pernambuco e Alagoas são divulgados. 2010. Disponível em: http://www.defesacivil.gov.br/noticias/noticia.asp?id=5105 Acesso em: junho de 2012

SEMARH - Secretaria de Estado do Meio Ambiente e de Recursos Hídricos. 2011. Fortes chuvas elevam os níveis dos rios em norte de Alagoas. Disponível em: http://www.semarh.al.gov.br/noticias/fortes-chuvas-elevam-nivel-dos-rios-no-nortede-alagoas Acesso em: junho de 2012

SEMARH - Secretaria de Estado do Meio Ambiente e de Recursos Hídricos. Sistema de alerta de cheias para as bacias hidrográficas dos rios Mundaú e Paraíba. em: http://www.semarh.al.gov.br/tempo\%20e\%20clima/saladealerta/saladealerta.pdf Acesso em: junho de 2012

SILVA, P. C. F.; ANDRADE, E.; DANNA, L. C. Mapeamento de risco à inundação em municípios do Vale do Paraíba. In: CONGRESSO BRASILEIRO DE GEOLOGIA DE ENGENHARIA E AMBIENTAL, 13, 2011, São Paulo, SP. Anais..., São Paulo: ABGE - Associação Brasileira de Geologia de Engenharia e Ambiental, 2011. CD-ROM.

SILVA, L. J. R. O. B.; MACHADO, M. J. M.; VIEIRA, L. O. M.; PAES, N. M. Resultados do gerenciamento do risco geológico após 25 anos da Fundação GEO Rio. In: CONGRESSO BRASILEIRO DE GEOLOGIA DE ENGENHARIA E 
AMBIENTAL, 13, 2011, São Paulo, SP. Anais..., São Paulo: ABGE - Associação Brasileira de Geologia de Engenharia e Ambiental, 2011. CD-ROM.

SILVEIRA, A.L.L. Abatimento Espacial da Chuva em Porto Alegre, Revista Brasileira de Recursos Hídricos, 2001 V.6, N.2, p.5-13

SINDEC - Sistema Nacional de Defesa Civil. AVADAN - Avaliação de Danos. 01/01/2010. Disponível em: http://150.162.127.14:8080/ged/SP-A-3550001-12302100101.pdf Acesso em: agosto de 2012.

SINDEC - Sistema Nacional de Defesa Civil. AVADAN - Avaliação de Danos. 09/12/2009. Disponível em: http://150.162.127.14:8080/ged/SP-A-3550001-12302091209.pdf Acesso em: agosto de 2012.

SOBREIRA, F. G.; SOUZA, L. A. Cartografia Geotécnica Apliacada ao Planejamento Urbano. Revista Brasileira de Geologia de Engenharia e Ambiental, 2012, v.2, p.79-97

SMYTH, C. G.; STEPHEN, A. R. Urban landslide hazards; incidence e causative factors in Niteroi, Rio de Janeiro State, Brazil. Applied Geography, 2000, v. 20, p.95-117

TATIZANA, C., OGURA, A.T.; CERRI, L.E.S. e ROCHA, M.C.M. Análise de correlação entre chuvas e escorregamentos - Serra do Mar, município de Cubatão. In: CONGRESSO BRASILEIRO DE GEOLOGIA DE ENGENHARIA, 5, 1987, São Paulo. Anais...São Paulo: ABGE, 1987. v. 2, p. 224-236. CD-ROM.

TATIZANA, C., OGURA, A.T.; CERRI, L.E.S. e ROCHA, M. C. M. Modelamento numérico da análise de correlação entre chuvas e escorregamentos - Serra do Mar, município de Cubatão. In: CONGRESSO BRASILEIRO DE GEOLOGIA DE ENGENHARIA, 5, 1987, São Paulo. Anais... São Paulo: ABGE, 1987b. v.2, p. 237248. CD-ROM.

TAVAREZ, C.; SANT'ANNA NETO, J. L.; TOMMASELLI, J. T. G.; PRESSINOTTI, M. M. N.; SANTORO, J. Análise da variabilidade temporal e espacial das chuvas associada aos movimentos de massa no litoral norte paulista. In: SIMPÓSIO BRASILEIRO DE DESASTRES NATURAIS, 1, 2004, Florianópolis, SC. Anais... Florianópolis: GEDN/UFSC, 2004. p. 680-696. CD-ROM.

TOMINAGA, L. K.; SANTORO, J.; AMARAL, R. (organizadores). Desastres Naturais: Conhecer para Prevenir. São Paulo: Instituto Geológico, 2009. 160 p.

TORRICO, J. J. T. Práticas hidrológicas. Rio de Janeiro: Transcon, 1975. 119p.

TUCCI, C.E.M. MARQUES, D. M. L. M. (organizadores). Avaliação e controle da drenagem urbana. Porto Alegre: Editora da Universidade/UFRGS, 2000. 558p. 
TUCCI, C.E.M. Hidrologia ciência e aplicação. ABRH - Associação Brasileira de Recursos Hídricos, 1993. 943p.

TUCCI, C.E.M. Desastres naturais e a fragilidade humana. Disponível em: http://rhama.net/wordpress/?p=191 Acesso em: 04 jan. 2012

TUCCI, C.E.M. Gestão de risco de desastres naturais. Disponível em: http://rhama.net/wordpress/?p=184 Acesso em: 15 nov. 2011

TUCCI, C.E.M. Temporada de inundações e escorregamentos. Disponível em: http://rhama.net/wordpress/?p=183 Acesso em: 04 jan. 2012

UNISDR - The United Nations International Strategy Disaster Reduction. Disponível em: http://www.unisdr.org/. Acesso em: 16 nov. 2011.

USGS - U. S. Geological Survey. Natural Hazards. Disponível em: http://www.usgs.gov/natural_hazards/ Acesso em: 18 jan. 2012

USGS - U. S. Geological Survey. Flood hazards - A national treath. 2006. Disponível em: http://pubs.usgs.gov/fs/2006/3026/2006-3026.pdf Acesso em: 18 jan. 2012

USGS - U. S. Geological Survey. Flood hazards. WaterWatch. Disponível em: http://waterwatch.usgs.gov/new/index.php Acesso em: 18 jan. 2012

VEJA. A explosão vermelha. 1986. p.36-43 Disponível em: http://veja.abril.com.br/acervodigital/?edicao=922\&pg=36 Acesso em: 29 jan. 2012

VEJA. Japão equipara acidente em Fukushima a Chernobyl. 2011.Disponível em: http://veja.abril.com.br/noticia/internacional/japao-equipara-acidente-em-fukushimaa-chernobyl Acesso em: 29 jan. 2012

VEJA. Bom Jardim, uma cidade ilhada. Disponível em: http://veja.abril.com.br/blog/veja-acompanha/a-tragedia-das-enchentes/bom-jardimuma-cidade-ilhada/ Acesso em: fev. 2013

WESCHENFELDER, A. B.; PICKBRENNER, K.; PINTO, E. J. A. Análise da frequência de ocorrência e a classificação das precipitações diárias máximas anuais na região da laguna dos patos (sub-bacia 87) In: SIMPÓSIO BRASILEIRO DE RECUROS HÍDRICOS, 19, 2011. Maceió, AL. Anais... Maceio: ABRH, 2011. CD-ROM.

WEISS, L.L., Ratio of true to fixed-interval maximum rainfall. Journal of Hydraulics Division, ASCE, 1964, V90, N.1, p 77-82

WIKIPEDIA Classificação climática de Köppen-Geiger. Disponível em: http://pt.wikipedia.org/wiki/Classificação_climática_de_Koppen-Geiger Acesso em: janeiro de 2013 
Anexo I - Movimentos de massa ocorridos no Brasil

\begin{tabular}{|c|c|c|}
\hline DATA & LOCAL & FONTE \\
\hline Mar/1928 & Monte Serrat, Santos/SP & VARGAS, 1966 \\
\hline 1942 e 1943 & Ubatuba/SP & CRUZ, 1974 \\
\hline Jul/1946 e Mar/1947 & Usina Henry Borden/SP & FOX, 1964/TERZAGHI, 1967 \\
\hline Jun/1947 & Rodovia Curitiba, Joinville/SC & VARGAS, 1966 \\
\hline Dez/1948 & Sul de Minas Gerais & STERNBERG, 1949 \\
\hline Dez/1948 & Vale do Paraíba/RJ & AUGUSTO FILHO, 1993 \\
\hline 1949 & Ubatuba/SP & CRUZ, 1988 \\
\hline $1949 / 50 / 51$ e 1952 & Via Anchieta, São Paulo/SP & RODRIGUES, 1981/ GUIDICINI e NIEBLE, 1983 \\
\hline 1952 & Escarpas de Massaguaçu/SP & CRUZ, 1974 \\
\hline Jul/1953 & Usina Eloy Chaves, Pinal/SP & VARGAS, 1966 \\
\hline 1953/1955 e 1956 & Usina Euclides da Cunha/SP & VARGAS, 1966 \\
\hline Mar/1956 & Monte Serrat, Santos/SP & PICHLER, 1957 \\
\hline Mar/1956 & Morro da Penha, ligação Via Anchieta a São Vicente/SP & VARGAS, 1966 / VARGAS e PICHLER, 1957 \\
\hline $1957 / 1960 / 1962$ & Rodovia BR-116/SP & GUIDICINI e NIEBLE, 1983 \\
\hline 1964 & Via Anchieta, São Paulo/SP & GUIDICINI e NIEBLE, 1983 \\
\hline Jan./1966 Fev./1967 & Área urbana do Rio de Janeiro & BARATA, 1969 / JONES, 1973 \\
\hline Jan/1967 & Serra de Araras/RJ & JONES, 1973 / NUNES, 1969 \\
\hline Jan/1967 & Estrada do Soberbo/RJ & FERNANDES E AMARAL, 1996 \\
\hline Mar/1967 & Serra de Caraguatatuba/RJ & PETRI e SUGUIO, 1971 / GUIDICINI e NIEBLE, 1983 \\
\hline Set/1968 & Guaratuba/PR & GREHS, 1970 \\
\hline Abr/1971 & Salvador/BA & AUGUSTO FILHO, 1993 \\
\hline Ago/1972 & Vila Albertina, Campos do Jordão/SP & AMARAL e FUCK, 1973 / GUIDICINI e PRANDINI, 1974 \\
\hline 1973 e 1974 & Rodovia Paranaguá-Curitiba/PR & FREIRE, 1965 \\
\hline 1974 & Serra de Maranguape/CE & GUIDICINI e NIEBLE, 1983 \\
\hline 1974 & Vale do Rio Tubarão/SC & GUIDICINI e NIEBLE, 1983 \\
\hline 1975 e 1976 & Rodovia dos Imigrantes/SP & GUIDICINI e IWASA, 1976 \\
\hline Abr/1976 & Serra de Maranguape/CE & GUIDICINI e IWASA, 1976 \\
\hline 1982 & Serra de Teresópolis/RJ & FERNANDES E AMARAL, 1996 \\
\hline Jul./1983 & União da Vitória/PR & LOPES, 1995 \\
\hline 1983/84/1990 e 1992 & Blumenau/SC & AUGUSTO FILHO, 1993 \\
\hline Dez/1984 & Favela Pavão-Pavãozinho/RJ & FERNANDES E AMARAL, 1996 \\
\hline Jan/1985 & Morro do Tabuleiro/ES & MIRANDA, 1992 \\
\hline Jan/1985 & Serra do Mar, próximo a Cubatão/SP & TATIZANA et al, 1987 \\
\hline Dez/1986 & Lavrinhas/SP & AUGUSTO FILHO, 1993 \\
\hline Fev/1988 & Morro da Serrinha/RJ & FERNANDES E AMARAL, 1996 \\
\hline Fev/1988 & Petrópolis/RJ & BARATA, 1992 \\
\hline Fev/1988 & Favela Morro da Formiga/SP & MAIA E PIAIA, 1992 \\
\hline Jun/1989 & Salvador/BA & AUGUSTO FILHO, 1993 \\
\hline Jan/1990 & Ortigueira/PR & LOPES, 1995 \\
\hline Jul/1990 & Recife/PE & AUGUSTO FILHO, 1993 \\
\hline Out/1991 & Palmeira/PR & LOPES, 1995 \\
\hline Mar/1992 & Contagem/MG & AUGUSTO FILHO, 1993 \\
\hline 1992 e 1993 & Almirante Tamandaré/RJ & LOPES, 1995 \\
\hline Fev/1995 & Rio de Janeiro/RJ & AMARAL e BARROS, 1996 \\
\hline Fev/1996 & Jacarepaguá/RJ & FERNANDES e AMARAL, 1996 \\
\hline
\end{tabular}


Anexo II - Limiares do SPI do Vale do Itajaí

\begin{tabular}{|c|c|c|c|c|}
\hline \multicolumn{5}{|c|}{2649004} \\
\hline Classe & P 2 dias (mm) & P 3 dias $(\mathrm{mm})$ & P 4 dias $(\mathrm{mm})$ & P 5 dias $(\mathrm{mm})$ \\
\hline $\mathrm{CF}$ & $\leq 106,4$ & $\leq 121,1$ & $\leq 133,6$ & $\leq 144,7$ \\
\hline $\mathrm{CL}$ & $106,4<\mathrm{T} \leq 143,1$ & $121,1<\mathrm{T} \leq 162,1$ & $133,6<\mathrm{T} \leq 179,7$ & $144,7<\mathrm{T} \leq 193,1$ \\
\hline $\mathrm{CM}$ & $143,1<\mathrm{T} \leq 167,3$ & $162,1<\mathrm{T} \leq 189,3$ & $179,7<\mathrm{T} \leq 210,3$ & $193,1<\mathrm{T} \leq 225,2$ \\
\hline CS & $167,3<\mathrm{T} \leq 196,3$ & $189,3<\mathrm{T} \leq 221,8$ & $210,3<\mathrm{T} \leq 246,8$ & $225,2<\mathrm{T} \leq 263,6$ \\
\hline CE & $>196,3$ & $>221,8$ & $>246,8$ & $>263,6$ \\
\hline \multicolumn{5}{|c|}{2649005} \\
\hline Classe & P 2 dias (mm) & P 3 dias $(\mathrm{mm})$ & P 4 dias (mm) & P 5 dias $(\mathrm{mm})$ \\
\hline $\mathrm{CF}$ & $\leq 97,9$ & $\leq 111,7$ & $\leq 123,1$ & $\leq 131,5$ \\
\hline $\mathrm{CL}$ & $97,9<\mathrm{T} \leq 132,5$ & $111,7<\mathrm{T} \leq 149,6$ & $123,1<\mathrm{T} \leq 167,5$ & $131,5<\mathrm{T} \leq 179,5$ \\
\hline $\mathrm{CM}$ & $132,5<\mathrm{T} \leq 155,3$ & $149,6<\mathrm{T} \leq 174,7$ & $167,5<\mathrm{T} \leq 196,9$ & $179,5<\mathrm{T} \leq 211,5$ \\
\hline CS & $155,3<\mathrm{T} \leq 182,6$ & $174,7<\mathrm{T} \leq 204,7$ & $196,9<\mathrm{T} \leq 232,1$ & $211,5<\mathrm{T} \leq 249,1$ \\
\hline $\mathrm{CE}$ & $>182,6$ & $>204,7$ & $>232,1$ & $>249,1$ \\
\hline \multicolumn{5}{|c|}{2649007} \\
\hline Classe & P 2 dias $(\mathrm{mm})$ & P 3 dias $(\mathrm{mm})$ & P 4 dias $(\mathrm{mm})$ & P 5 dias $(\mathrm{mm})$ \\
\hline $\mathrm{CF}$ & $\leq 109,0$ & $\leq 122,4$ & $\leq 133,1$ & $\leq 144,3$ \\
\hline $\mathrm{CL}$ & $109,0<\mathrm{T} \leq 171,7$ & $122,4<\mathrm{T} \leq 189,1$ & $133,1<\mathrm{T} \leq 206,1$ & $144,3<\mathrm{T} \leq 219,5$ \\
\hline $\mathrm{CM}$ & $171,7<\mathrm{T} \leq 213,1$ & $189,1<\mathrm{T} \leq 233,1$ & $206,1<\mathrm{T} \leq 254,3$ & $219,5<T \leq 269,2$ \\
\hline $\mathrm{CS}$ & $213,1<\mathrm{T} \leq 262,7$ & $233,1<\mathrm{T} \leq 285,9$ & $254,3<\mathrm{T} \leq 312,0$ & $269,2<\mathrm{T} \leq 328,7$ \\
\hline CE & $>262,7$ & $>285,9$ & $>312,0$ & $>328,7$ \\
\hline \multicolumn{5}{|c|}{2649008} \\
\hline Classe & P 2 dias (mm) & P 3 dias $(\mathrm{mm})$ & P 4 dias (mm) & P 5 dias (mm) \\
\hline $\mathrm{CF}$ & $\leq 109,5$ & $\leq 125,7$ & $\leq 139,4$ & $\leq 148,0$ \\
\hline $\mathrm{CL}$ & $109,5<\mathrm{T} \leq 146,2$ & $125,7<\mathrm{T} \leq 188,3$ & $139,4<\mathrm{T} \leq 190,1$ & $148,0<T \leq 200,2$ \\
\hline $\mathrm{CM}$ & $146,2<\mathrm{T} \leq 170,5$ & $188,3<\mathrm{T} \leq 196,5$ & $190,1<\mathrm{T} \leq 223,7$ & $200,2<T \leq 234,8$ \\
\hline CS & $170,5<\mathrm{T} \leq 199,5$ & $196,5<\mathrm{T} \leq 230,1$ & $223,7<\mathrm{T} \leq 263,8$ & $234,8<\mathrm{T} \leq 276,1$ \\
\hline CE & $>199,5$ & $>230,1$ & $>263,8$ & $>276,1$ \\
\hline \multicolumn{5}{|c|}{2649010} \\
\hline Classe & P 2 dias $(\mathrm{mm})$ & P 3 dias $(\mathrm{mm})$ & P 4 dias (mm) & P 5 dias $(\mathrm{mm})$ \\
\hline $\mathrm{CF}$ & $\leq 111,6$ & $\leq 125,6$ & $\leq 138,8$ & $\leq 147,8$ \\
\hline $\mathrm{CL}$ & $111,6<\mathrm{T} \leq 160,5$ & $125,6<\mathrm{T} \leq 178,1$ & $138,8<\mathrm{T} \leq 198,3$ & $147,8<\mathrm{T} \leq 211,4$ \\
\hline $\mathrm{CM}$ & $160,5<\mathrm{T} \leq 192,9$ & $178,1<\mathrm{T} \leq 212,8$ & $198,3<\mathrm{T} \leq 237,6$ & $211,4<T \leq 253,5$ \\
\hline CS & $192,9<\mathrm{T} \leq 231,6$ & $212,8<\mathrm{T} \leq 254,4$ & $237,6<\mathrm{T} \leq 284,6$ & $253,5<\mathrm{T} \leq 303,8$ \\
\hline CE & $>231,6$ & $>254,4$ & $>284,6$ & $>303,8$ \\
\hline \multicolumn{5}{|c|}{2748000} \\
\hline Classe & P 2 dias $(\mathrm{mm})$ & P 3 dias $(\mathrm{mm})$ & P 4 dias (mm) & P 5 dias $(\mathrm{mm})$ \\
\hline CF & $\leq 101,5$ & $\leq 116,9$ & $\leq 131,1$ & $\leq 142,2$ \\
\hline $\mathrm{CL}$ & $101,5<\mathrm{T} \leq 141,3$ & $116,9<\mathrm{T} \leq 161,3$ & $131,1<\mathrm{T} \leq 181,4$ & $142,2<\mathrm{T} \leq 193,4$ \\
\hline $\mathrm{CM}$ & $141,3<\mathrm{T} \leq 167,6$ & $161,3<\mathrm{T} \leq 190,6$ & $181,4<\mathrm{T} \leq 214,7$ & $193,4<\mathrm{T} \leq 227,2$ \\
\hline CS & $167,6<\mathrm{T} \leq 199,1$ & $190,6<\mathrm{T} \leq 225,8$ & $214,7<\mathrm{T} \leq 254,5$ & $227,2<\mathrm{T} \leq 267,7$ \\
\hline CE & $>199,1$ & $>225,8$ & $>254,5$ & $>267,7$ \\
\hline
\end{tabular}




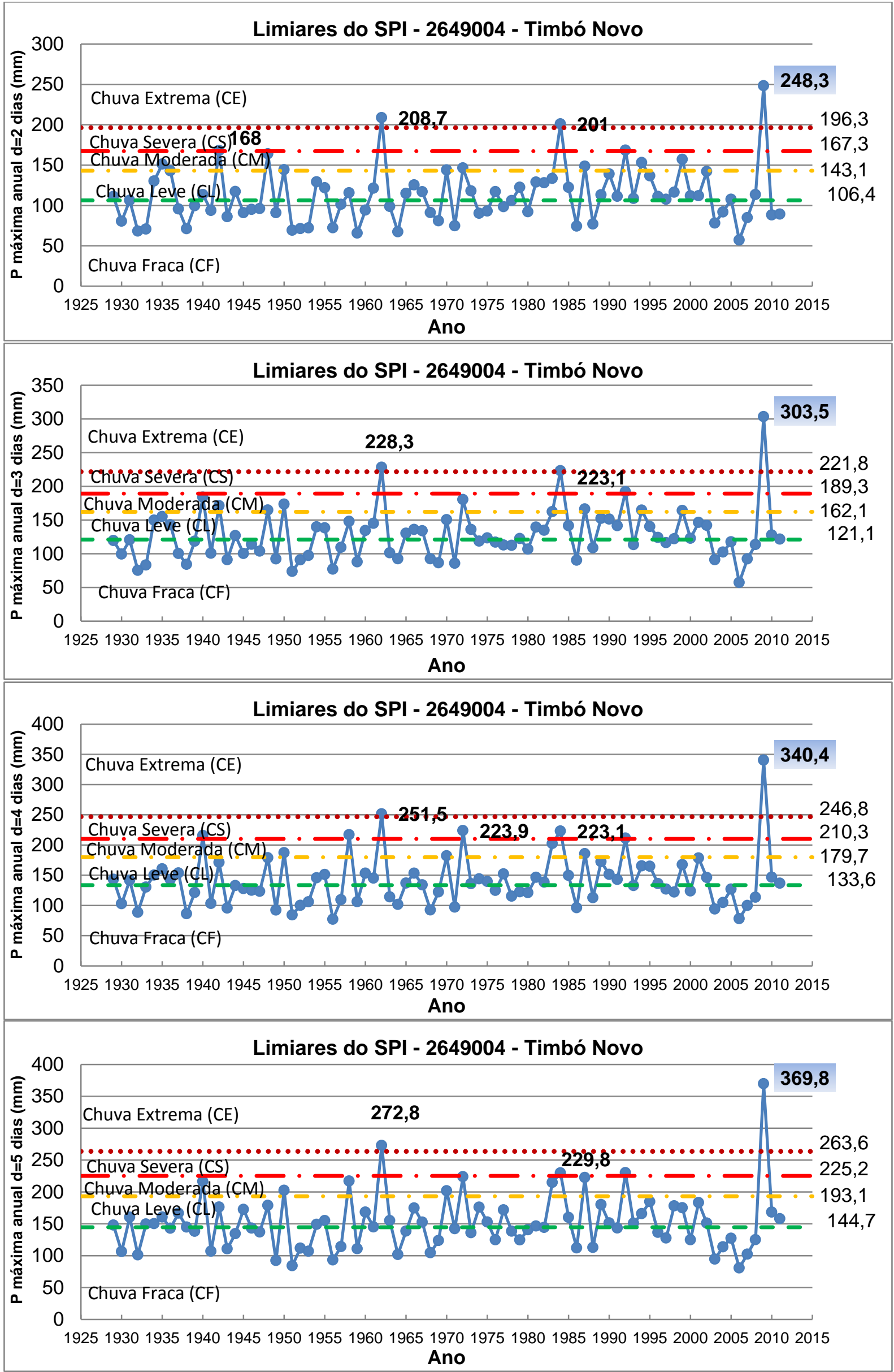




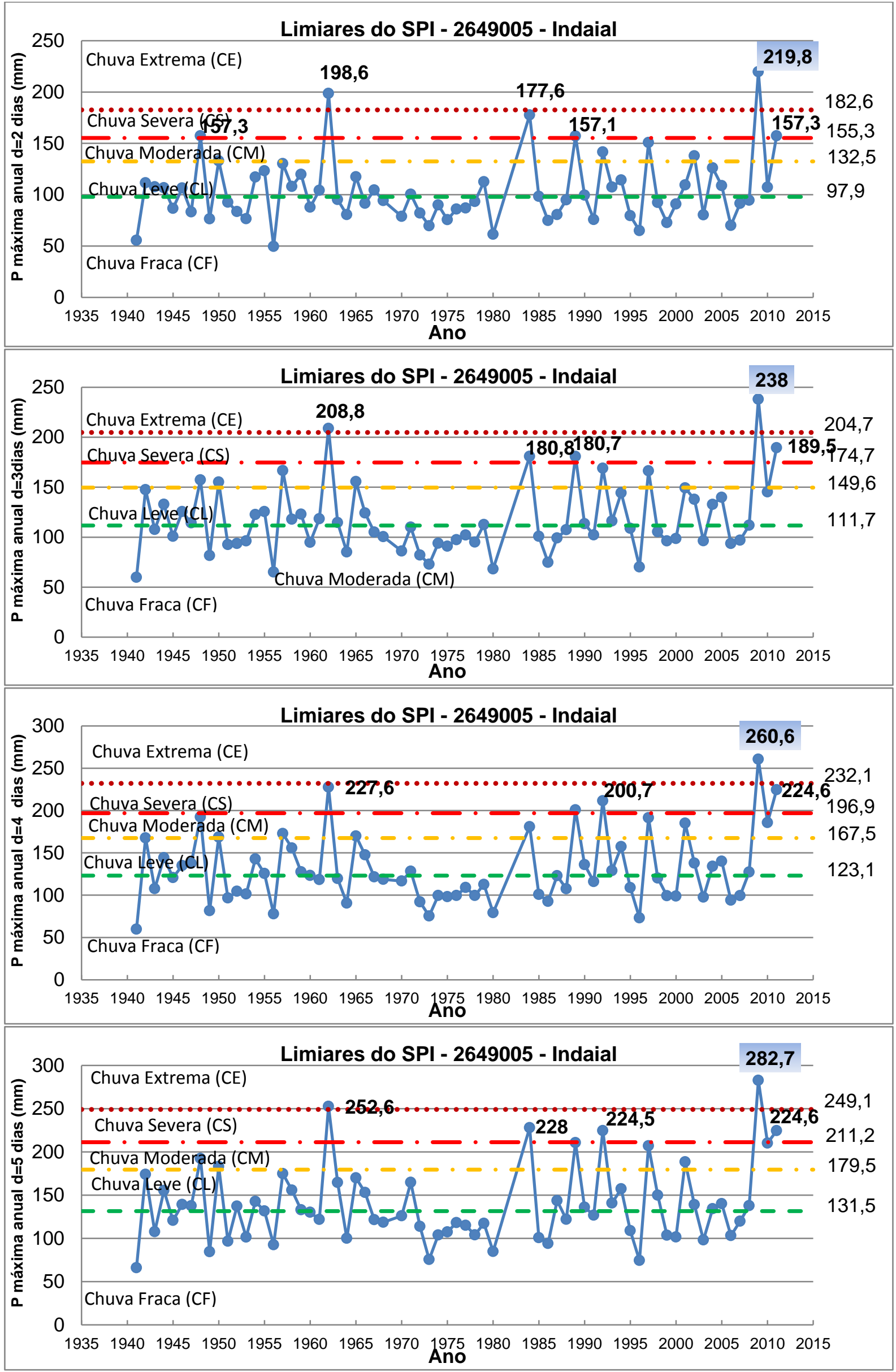




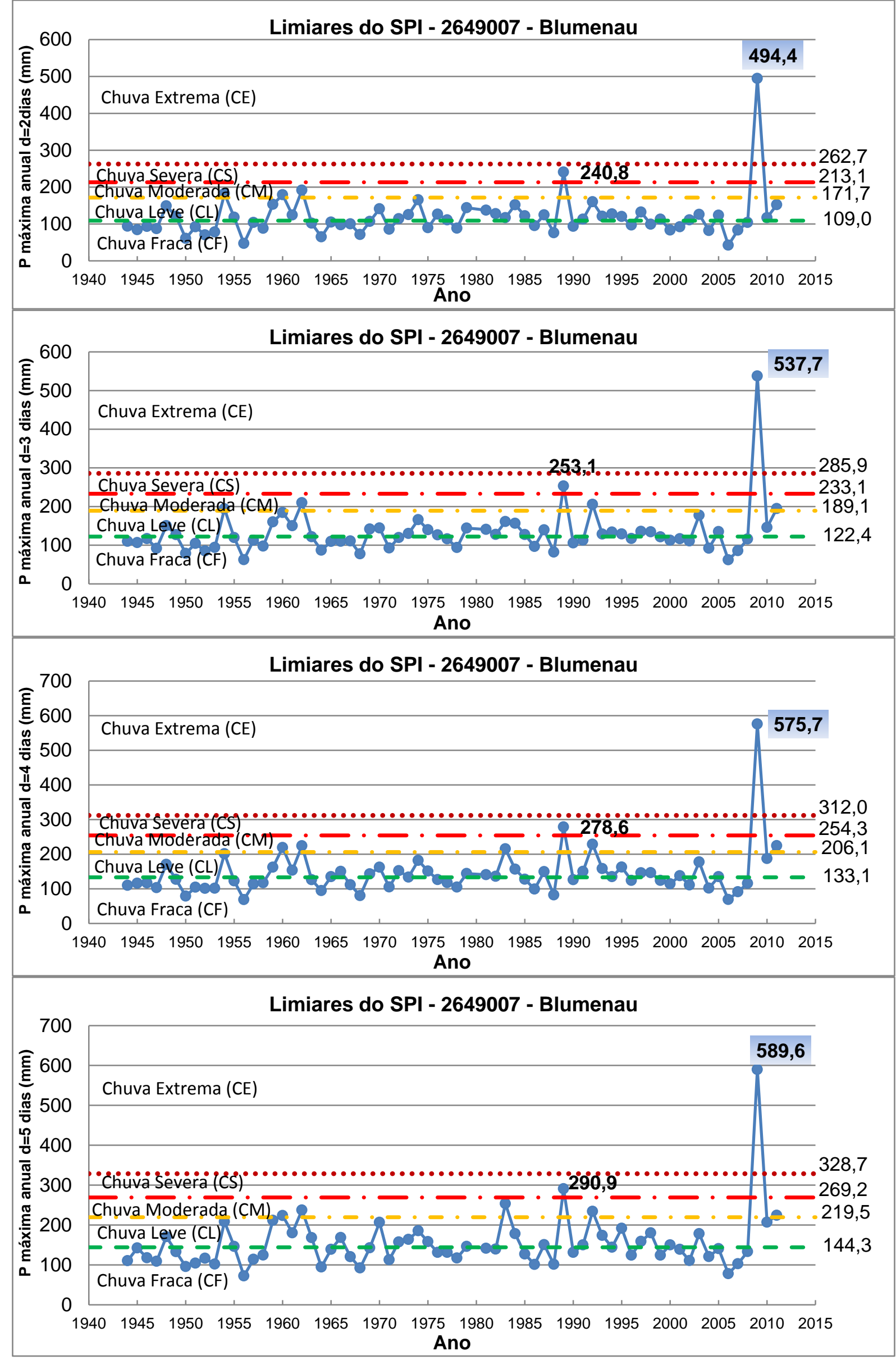




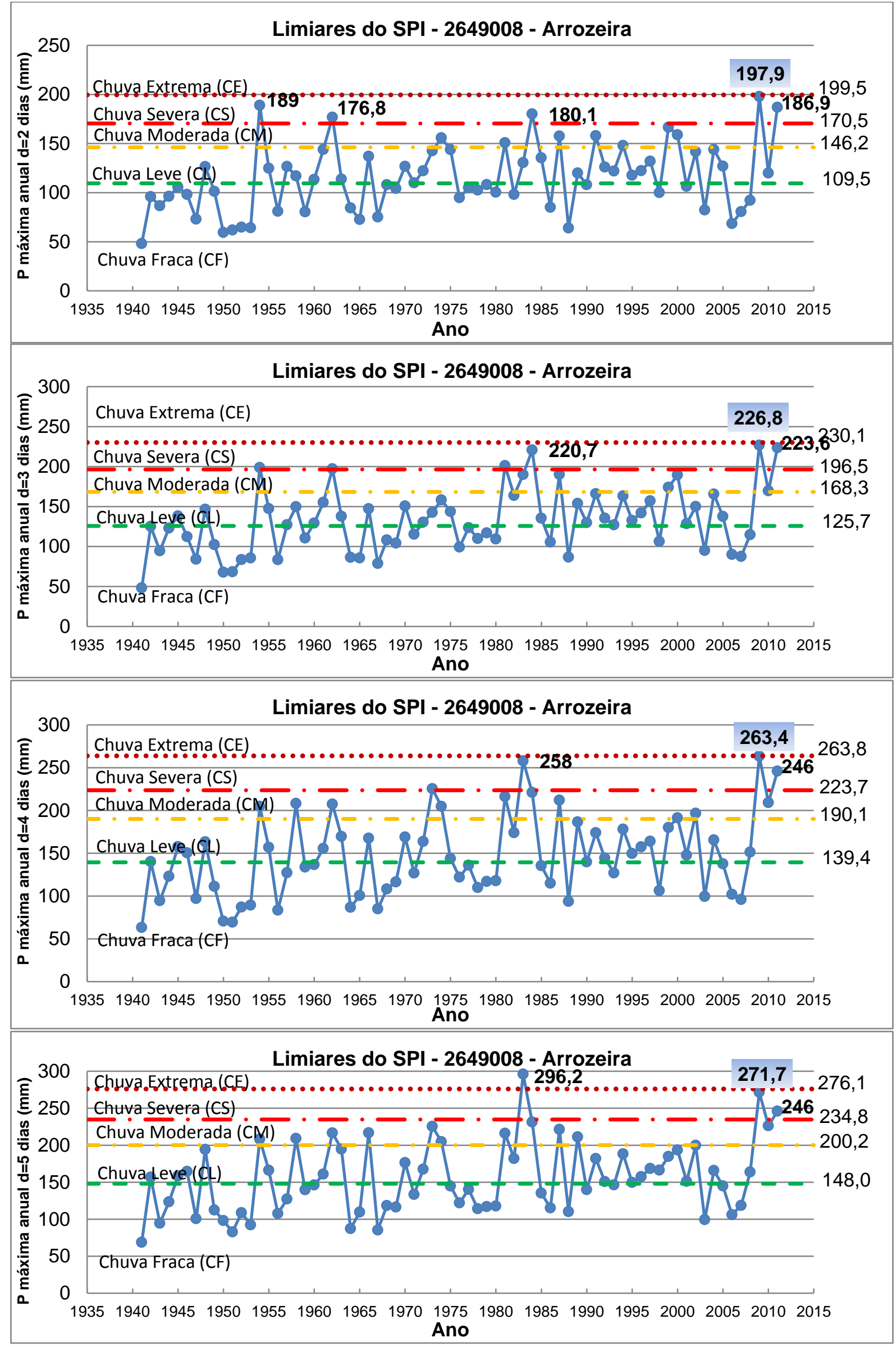




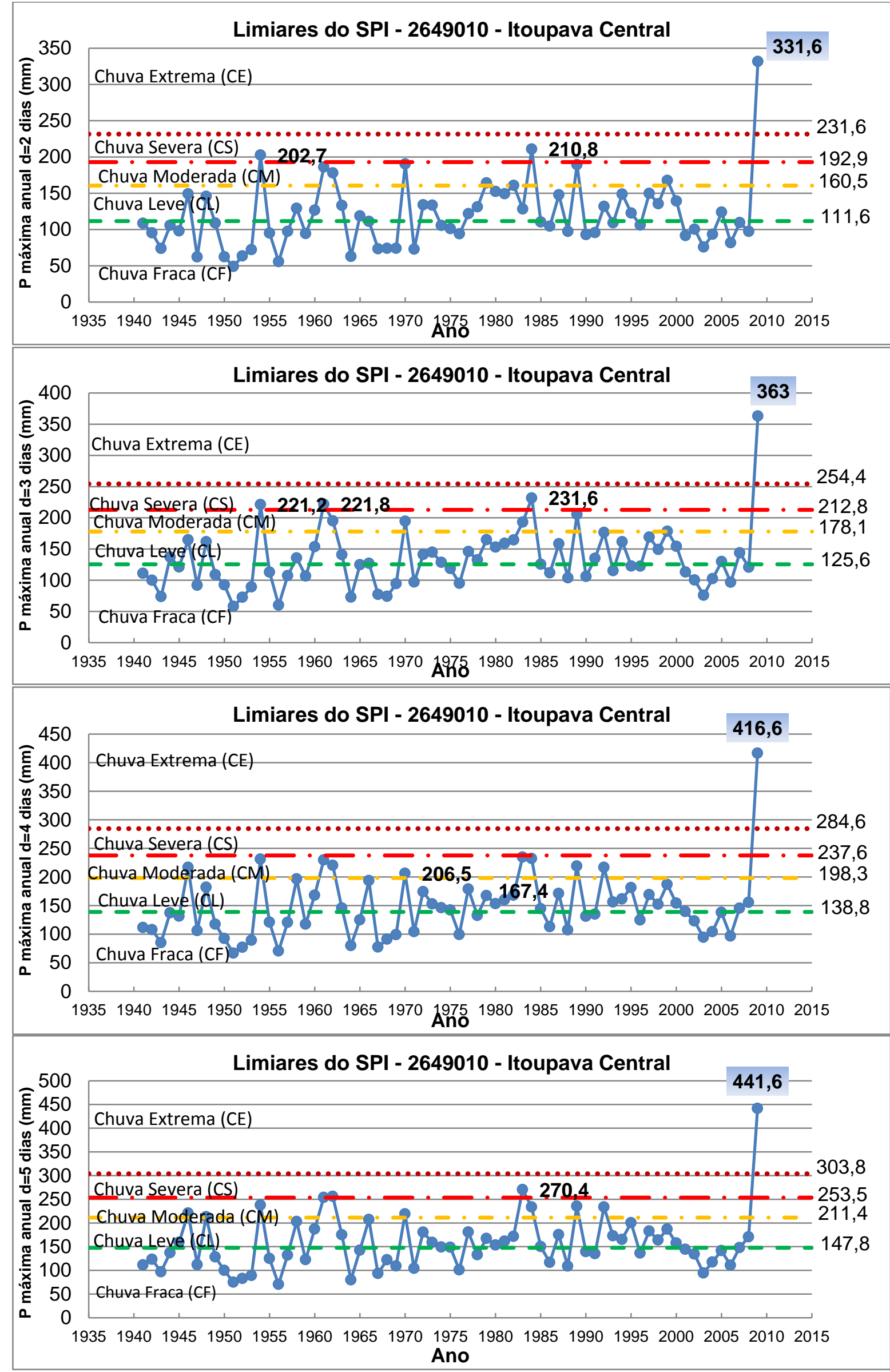



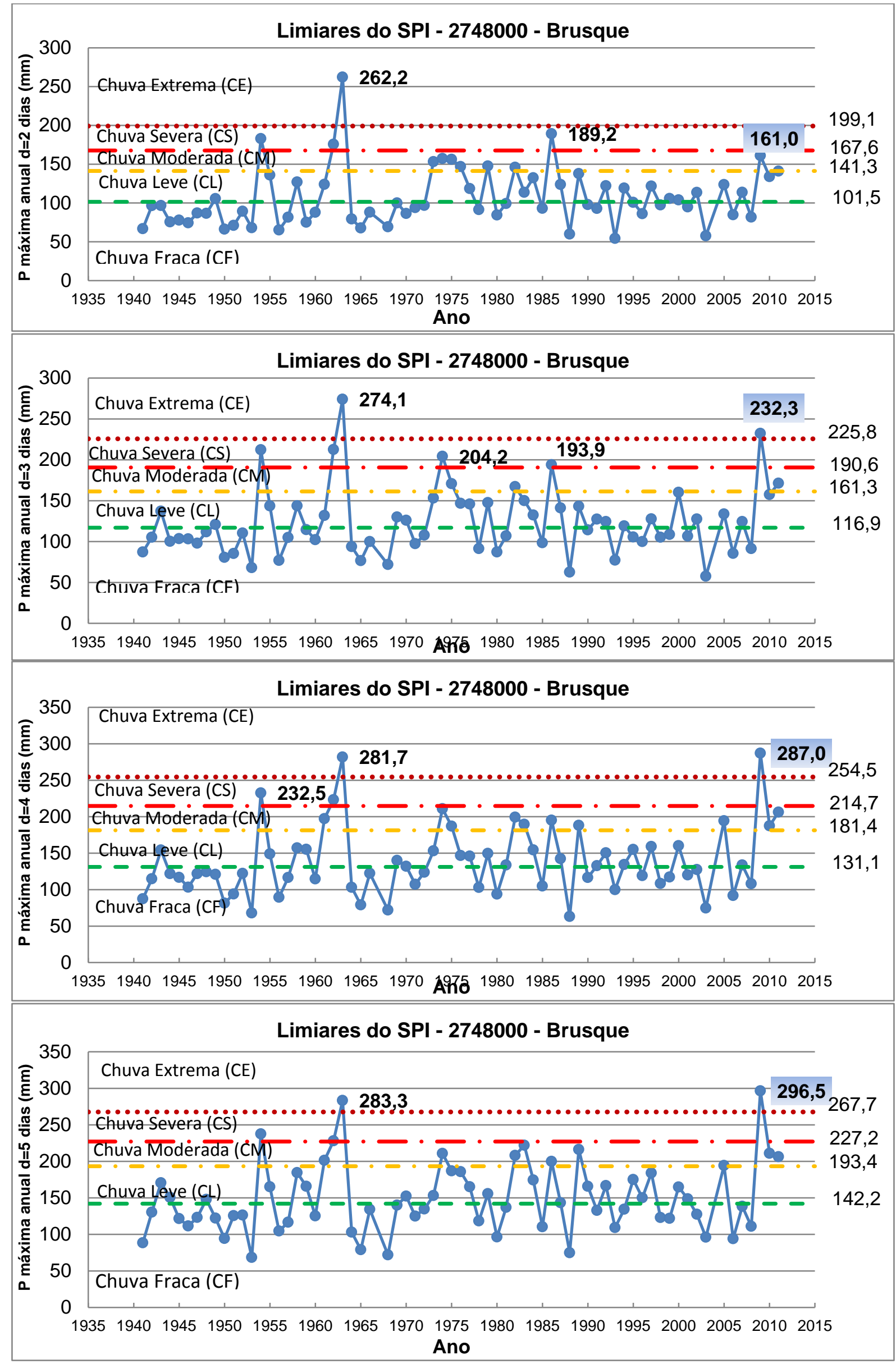
Anexo III - Limiares do SPI de São Luís do Paraitinga e Cunha

\begin{tabular}{|c|c|c|c|c|}
\hline \multicolumn{5}{|c|}{2244048} \\
\hline Classe & P 2 dias (mm) & P 3 dias (mm) & P 4 dias (mm) & P 5 dias $(\mathrm{mm})$ \\
\hline CF & $\leq 86,0$ & $\leq 102,2$ & $\leq 114,9$ & $\leq 125,3$ \\
\hline $\mathrm{CL}$ & $86,0<\mathrm{T} \leq 115,4$ & $102,2<\mathrm{T} \leq 131,7$ & $114,9<\mathrm{T} \leq 144,4$ & $125,3<\mathrm{T} \leq 156,0$ \\
\hline CM & $115,4<\mathrm{T} \leq 134,8$ & $131,7<\mathrm{T} \leq 151,1$ & $144,4<\mathrm{T} \leq 164,0$ & $156,0<\mathrm{T} \leq 176,3$ \\
\hline CS & $134,8<\mathrm{T} \leq 158,0$ & $151,1<\mathrm{T} \leq 174,4$ & $164,0<\mathrm{T} \leq 187,4$ & $176,3<\mathrm{T} \leq 200,6$ \\
\hline CE & $>158,0$ & $>174,4$ & $>187,4$ & $>200,6$ \\
\hline \multicolumn{5}{|c|}{2245055} \\
\hline Classe & P 2 dias $(\mathrm{mm})$ & P 3 dias $(\mathrm{mm})$ & P 4 dias $(\mathrm{mm})$ & P 5 dias $(\mathrm{mm})$ \\
\hline $\mathrm{CF}$ & $\leq 93,9$ & $\leq 109,3$ & $\leq 121,8$ & $\leq 137,3$ \\
\hline $\mathrm{CL}$ & $93,9<\mathrm{T} \leq 123,0$ & $109,3<\mathrm{T} \leq 143,7$ & $121,8<\mathrm{T} \leq 162,9$ & $137,3<\mathrm{T} \leq 184,5$ \\
\hline CM & $123,0<T \leq 142,2$ & $143,7<\mathrm{T} \leq 166,4$ & $162,9<\mathrm{T} \leq 190,0$ & $184,5<\mathrm{T} \leq 215,8$ \\
\hline CS & $142,2<\mathrm{T} \leq 165,2$ & $166,4<\mathrm{T} \leq 193,5$ & $190,0<\mathrm{T} \leq 225,5$ & $215,8<\mathrm{T} \leq 253,2$ \\
\hline CE & $>165,2$ & $>193,5$ & $>225,5$ & $>253,2$ \\
\hline \multicolumn{5}{|c|}{2344009} \\
\hline Classe & P 2 dias (mm) & P 3 dias $(\mathrm{mm})$ & P4 dias $(\mathrm{mm})$ & P 5 dias $(\mathrm{mm})$ \\
\hline CF & $\leq 132,7$ & $\leq 151,5$ & $\leq 164,5$ & $\leq 179,8$ \\
\hline $\mathrm{CL}$ & $132,7<\mathrm{T} \leq 188,9$ & $151,5<\mathrm{T} \leq 212,8$ & $164,5<\mathrm{T} \leq 228,2$ & $179,8<\mathrm{T} \leq 251,7$ \\
\hline CM & $188,9<\mathrm{T} \leq 226,1$ & $212,8<\mathrm{T} \leq 253,3$ & $228,2<\mathrm{T} \leq 270,4$ & $251,7<\mathrm{T} \leq 299,2$ \\
\hline CS & $226,1<\mathrm{T} \leq 270,6$ & $253,3<\mathrm{T} \leq 301,7$ & $270,4<T \leq 320,8$ & $299,2<\mathrm{T} \leq 356,1$ \\
\hline CE & $>270,6$ & $>301,7$ & $>320,8$ & $>356,1$ \\
\hline \multicolumn{5}{|c|}{2345065} \\
\hline Classe & P 2 dias $(\mathrm{mm})$ & P 3 dias $(\mathrm{mm})$ & P 4 dias $(\mathrm{mm})$ & P 5 dias $(\mathrm{mm})$ \\
\hline CF & $\leq 82,2$ & $\leq 100,6$ & $\leq 113,1$ & $\leq 125,7$ \\
\hline $\mathrm{CL}$ & $82,2<\mathrm{T} \leq 104,8$ & $100,6<\mathrm{T} \leq 126,3$ & $113,1<\mathrm{T} \leq 143,0$ & $125,7<\mathrm{T} \leq 158,7$ \\
\hline CM & $104,8<\mathrm{T} \leq 119,7$ & $126,3<\mathrm{T} \leq 143,4$ & $143,0<T \leq 162,8$ & $158,7<\mathrm{T} \leq 180,5$ \\
\hline CS & $119,7<\mathrm{T} \leq 137,6$ & $143,4<\mathrm{T} \leq 163,8$ & $162,8<\mathrm{T} \leq 186,4$ & $180,5<\mathrm{T} \leq 206,7$ \\
\hline CE & $>137,6$ & $>163,8$ & $>186,4$ & $>206,7$ \\
\hline \multicolumn{5}{|c|}{2345067} \\
\hline Classe & P 2 dias $(\mathrm{mm})$ & P 3 dias $(\mathrm{mm})$ & P 4 dias $(\mathrm{mm})$ & P 5 dias $(\mathrm{mm})$ \\
\hline CF & $\leq 154,7$ & $\leq 172,4$ & $\leq 186,1$ & $\leq 198,6$ \\
\hline $\mathrm{CL}$ & $154,7<\mathrm{T} \leq 215,9$ & $172,4<\mathrm{T} \leq 241,1$ & $186,1<\mathrm{T} \leq 256,3$ & $198,6<\mathrm{T} \leq 274,2$ \\
\hline CM & $215,9<T \leq 256,4$ & $241,1<\mathrm{T} \leq 286,6$ & $256,3<\mathrm{T} \leq 302,8$ & $274,2<\mathrm{T} \leq 324,2$ \\
\hline CS & $256,4<\mathrm{T} \leq 304,8$ & $286,6<T \leq 340,9$ & $302,8<\mathrm{T} \leq 358,3$ & $324,2<\mathrm{T} \leq 384,1$ \\
\hline CE & $>304,8$ & $>340,9$ & $>358,3$ & $>384,1$ \\
\hline \multicolumn{5}{|c|}{2345071} \\
\hline Classe & P 2 dias (mm) & P 3 dias $(\mathrm{mm})$ & P 4 dias (mm) & P 5 dias $(\mathrm{mm})$ \\
\hline $\mathrm{CF}$ & $\leq 90,5$ & $\leq 105,7$ & $\leq 117,3$ & $\leq 130,6$ \\
\hline $\mathrm{CL}$ & $90,5<\mathrm{T} \leq 117,5$ & $105,7<T \leq 138,7$ & $117,3<\mathrm{T} \leq 154,0$ & $130,6<\mathrm{T} \leq 170,7$ \\
\hline CM & $117,5<\mathrm{T} \leq 134,9$ & $138,7<\mathrm{T} \leq 160,6$ & $154,0<\mathrm{T} \leq 178,3$ & $170,7<\mathrm{T} \leq 197,2$ \\
\hline CS & $134,9<\mathrm{T} \leq 156,0$ & $160,6<\mathrm{T} \leq 186,7$ & $178,3<\mathrm{T} \leq 207,3$ & $197,2<\mathrm{T} \leq 228,9$ \\
\hline CE & $>156,0$ & $>186,7$ & $>207,3$ & $>228,9$ \\
\hline
\end{tabular}




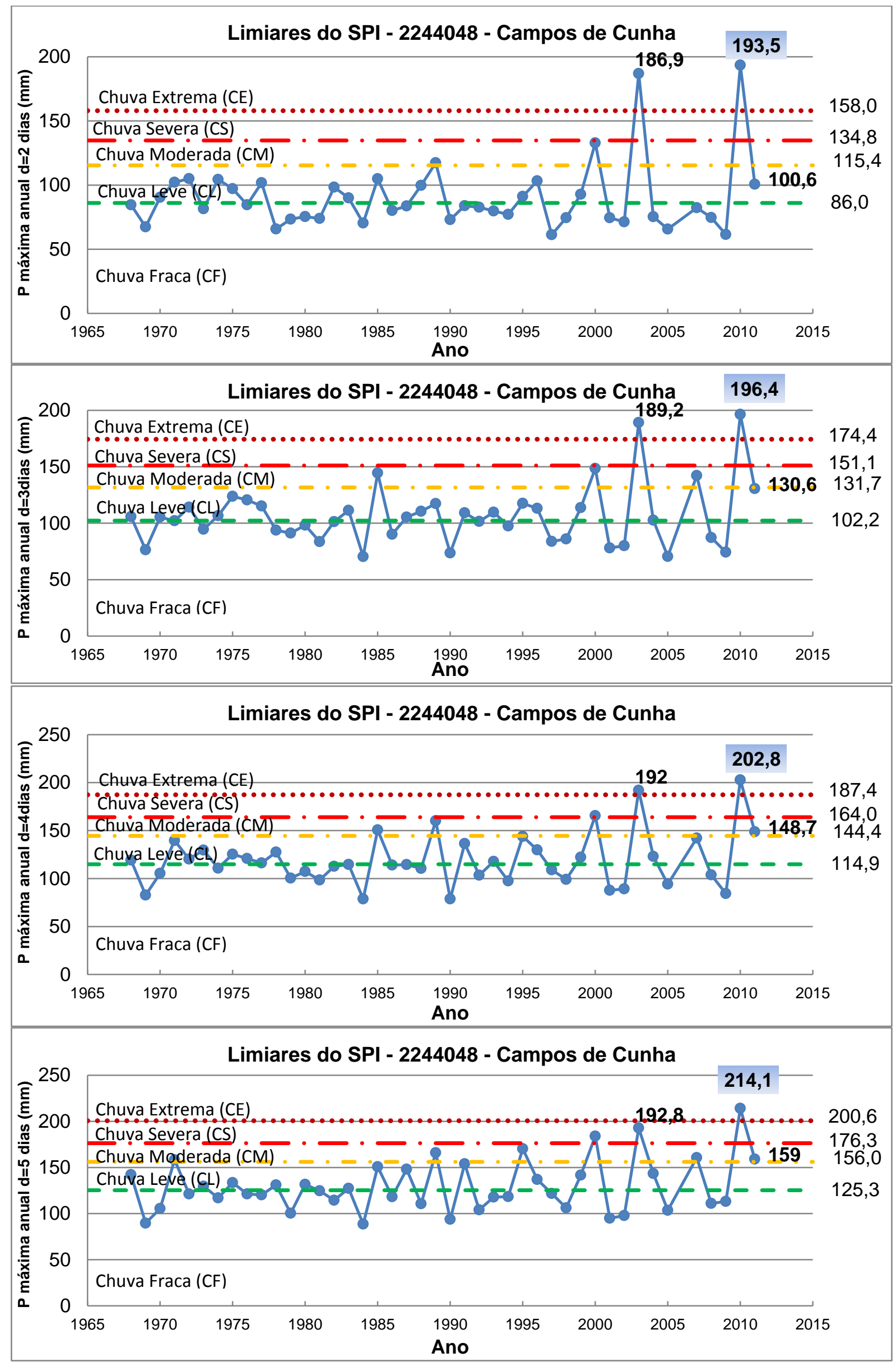




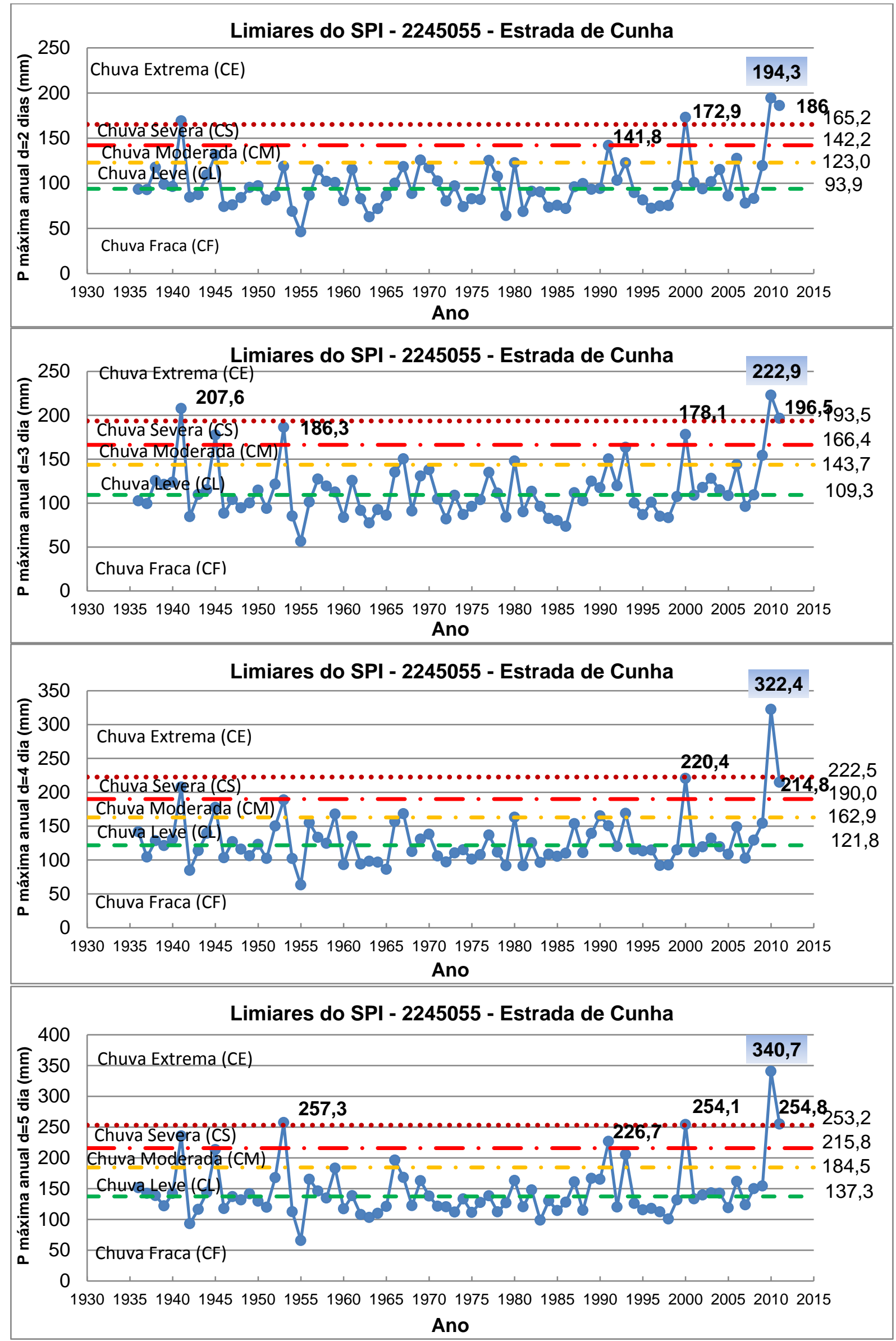




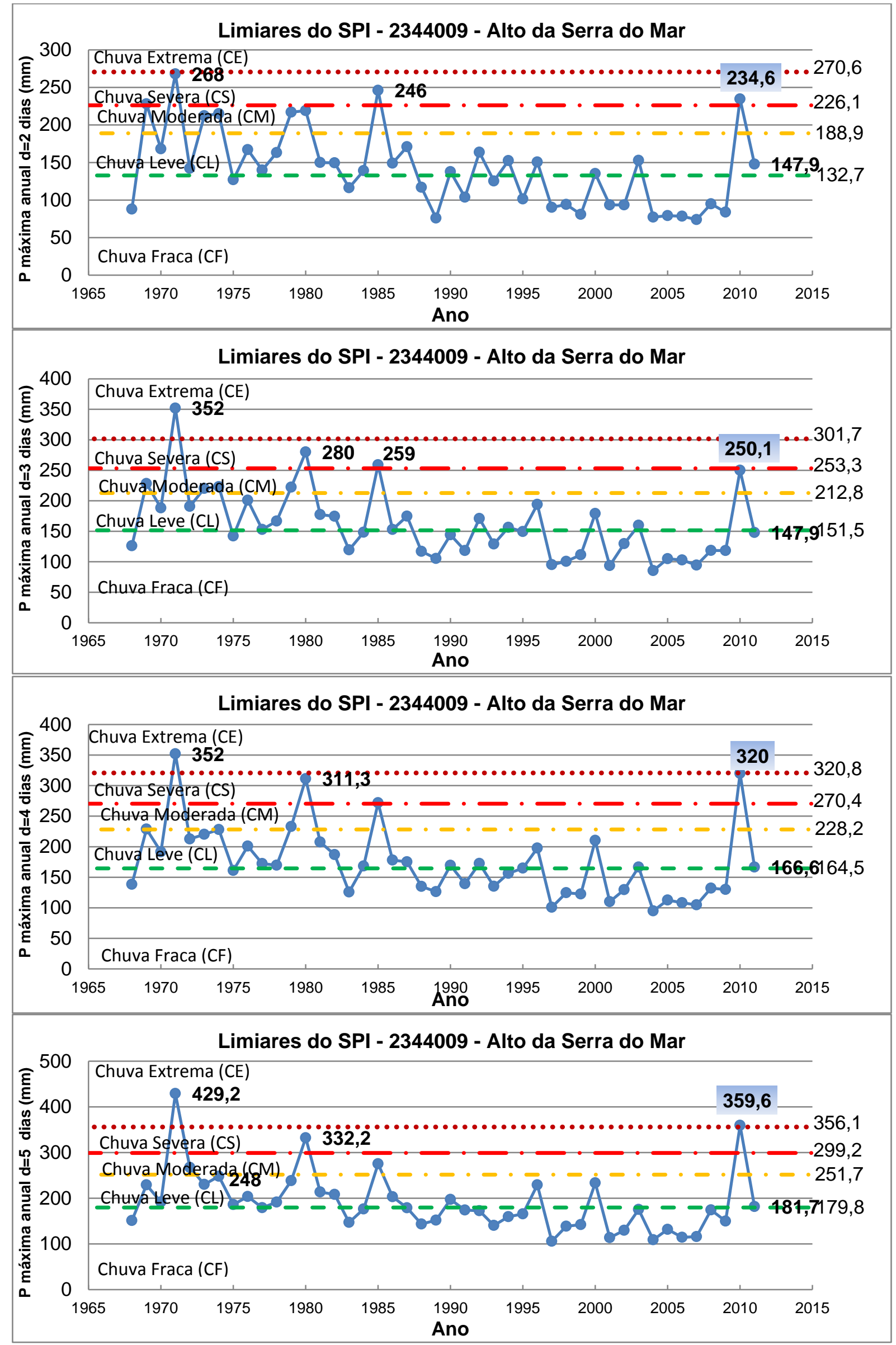




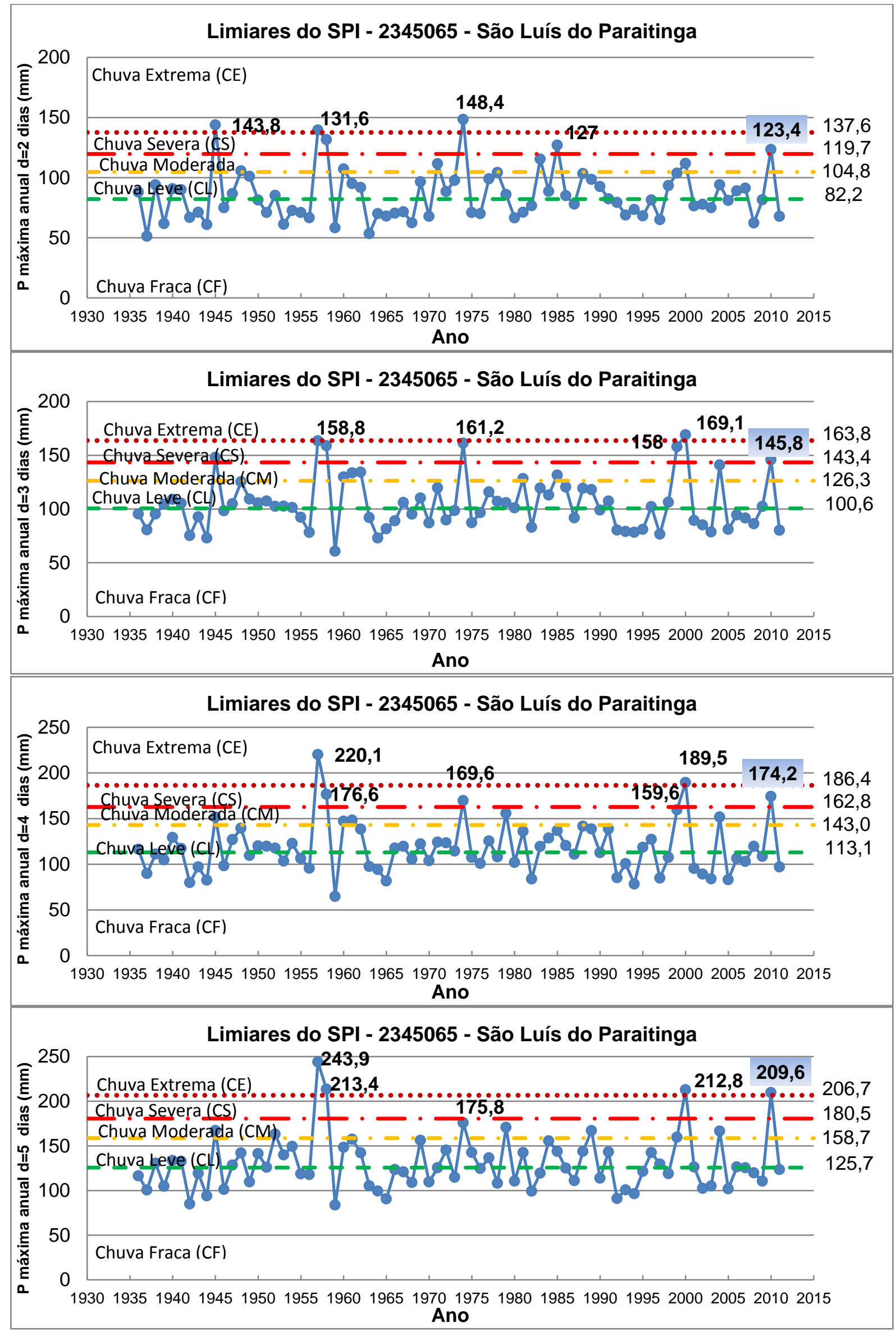




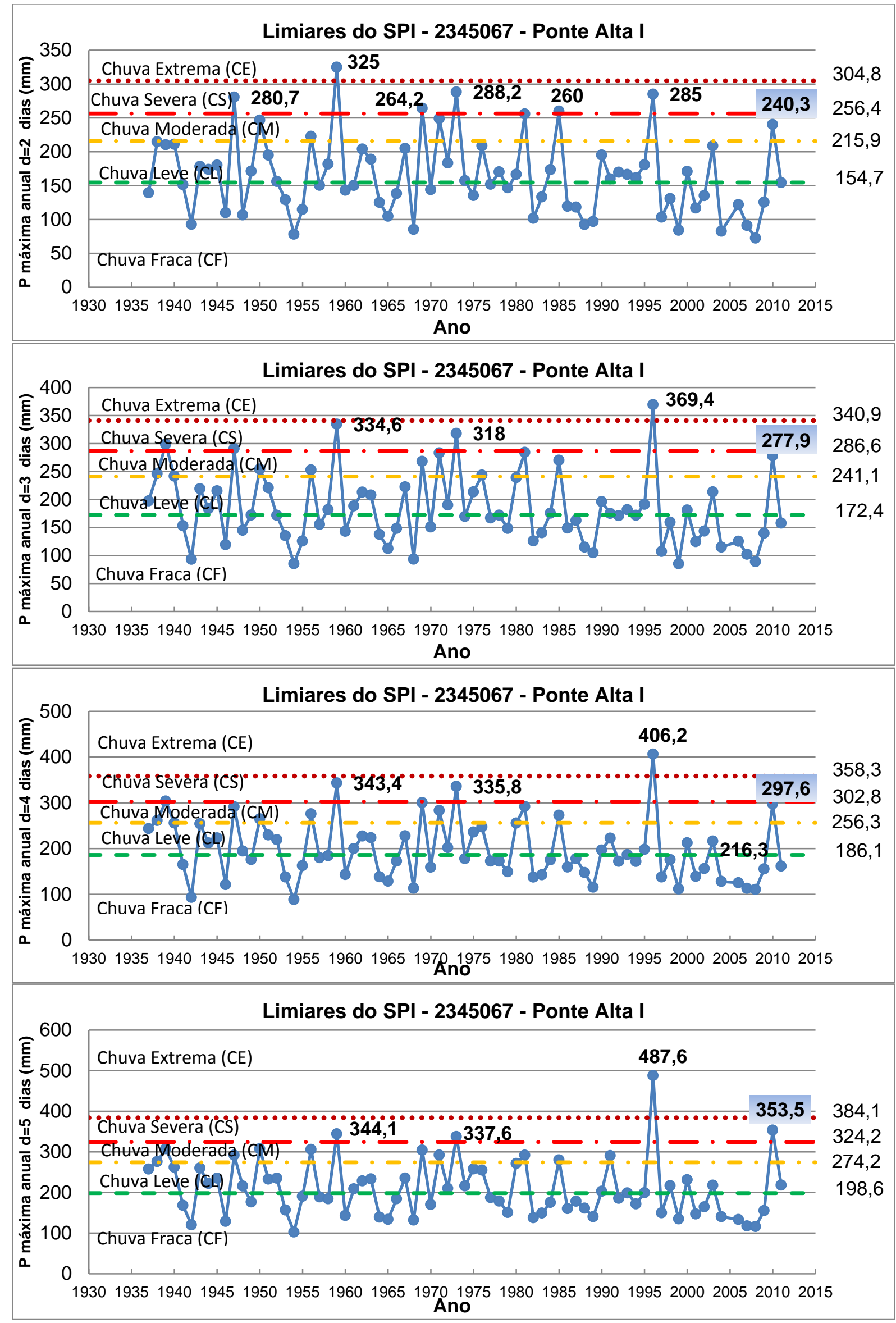




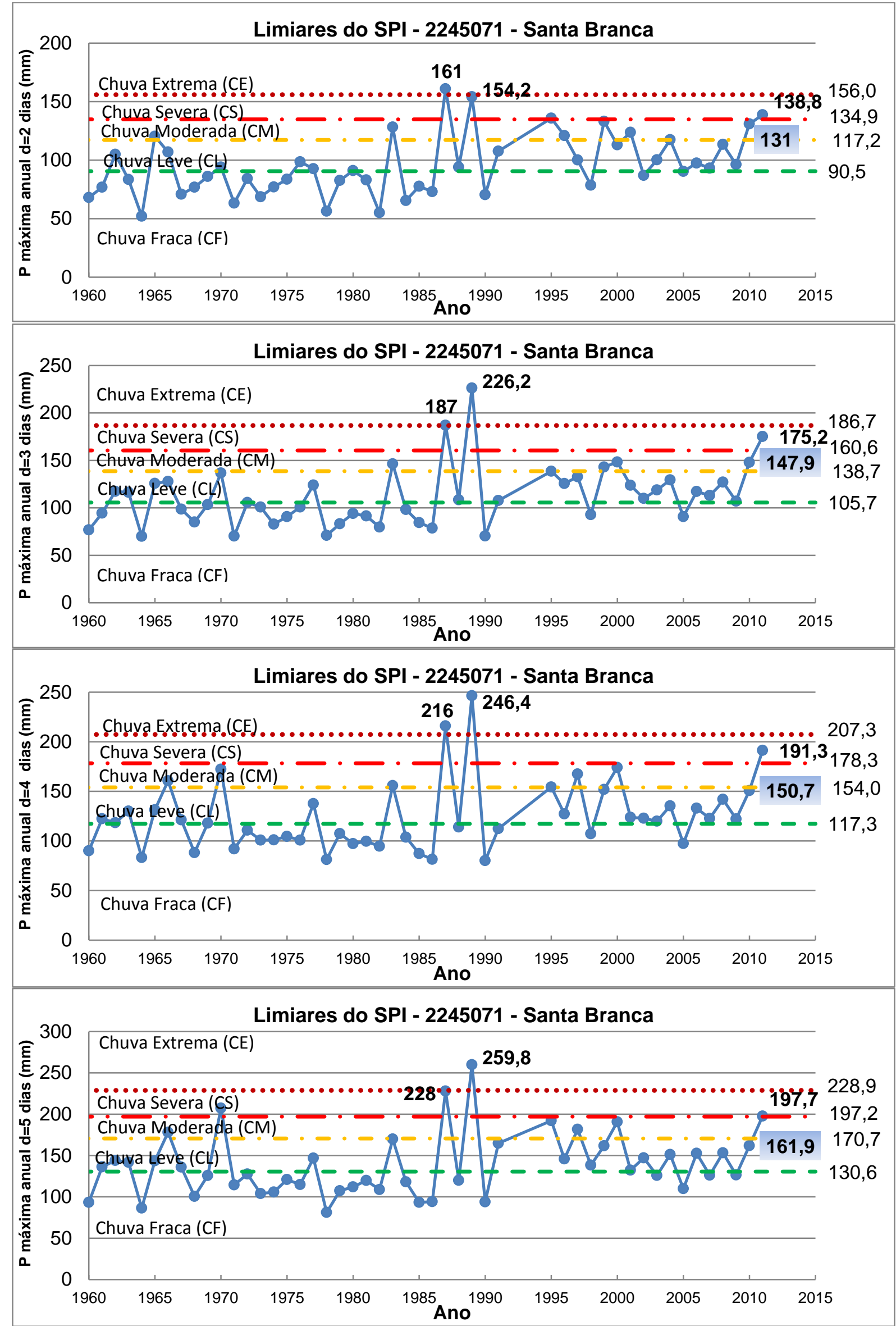




\section{Anexo IV - Limiares do SPI do Vale do Mundaú e Paraíba}

\begin{tabular}{|c|c|c|c|c|}
\hline \multicolumn{5}{|c|}{935012} \\
\hline Classe & P 2 dias (mm) & P 3 dias $(\mathrm{mm})$ & P 4 dias (mm) & P 5 dias (mm) \\
\hline $\mathrm{CF}$ & $\leq 103,4$ & $\leq 124,7$ & $\leq 136,9$ & $\leq 149,4$ \\
\hline $\mathrm{CL}$ & $103,4<\mathrm{T} \leq 144,9$ & $124,7<\mathrm{T} \leq 170,0$ & $136,9<\mathrm{T} \leq 182,0$ & $149,4<\mathrm{T} \leq 198,8$ \\
\hline $\mathrm{CM}$ & $144,9<\mathrm{T} \leq 172,3$ & $170,0<T \leq 200,0$ & $182,0<T \leq 211,8$ & $198,8<\mathrm{T} \leq 231,4$ \\
\hline CS & $172,3<\mathrm{T} \leq 205,2$ & $200,0<\mathrm{T} \leq 235,9$ & $211,8<T \leq 247,4$ & $231,4<\mathrm{T} \leq 270,5$ \\
\hline CE & $>205,2$ & $>235,9$ & $>247,4$ & $>270,5$ \\
\hline \multicolumn{5}{|c|}{935056} \\
\hline Classe & P 2 dias (mm) & P 3 dias (mm) & P 4 dias (mm) & P 5 dias (mm) \\
\hline $\mathrm{CF}$ & $\leq 126,8$ & $\leq 145,1$ & $\leq 163,6$ & $\leq 176,4$ \\
\hline $\mathrm{CL}$ & $126,8<\mathrm{T} \leq 189,7$ & $145,1<\mathrm{T} \leq 211,2$ & $163,6<\mathrm{T} \leq 223,8$ & $176,4<\mathrm{T} \leq 231,6$ \\
\hline $\mathrm{CM}$ & $189,7<\mathrm{T} \leq 231,2$ & $211,2<T \leq 254,9$ & $223,8<T \leq 263,6$ & $231,6<\mathrm{T} \leq 268,0$ \\
\hline CS & $231,2<\mathrm{T} \leq 281,0$ & $254,9<\mathrm{T} \leq 307,3$ & $263,6<\mathrm{T} \leq 311,3$ & $268,0<\mathrm{T} \leq 311,6$ \\
\hline CE & $>281,0$ & $>307,3$ & $>311,3$ & $>311,6$ \\
\hline \multicolumn{5}{|c|}{935057} \\
\hline Classe & P 2 dias (mm) & P 3 dias $(\mathrm{mm})$ & P 4 dias (mm) & P 5 dias $(\mathrm{mm})$ \\
\hline $\mathrm{CF}$ & $\leq 139,6$ & $\leq 160,5$ & $\leq 181,7$ & $\leq 194,5$ \\
\hline $\mathrm{CL}$ & $139,6<\mathrm{T} \leq 185,1$ & $160,5<\mathrm{T} \leq 205,6$ & $181,7<\mathrm{T} \leq 227,6$ & $194,5<\mathrm{T} \leq 236,6$ \\
\hline $\mathrm{CM}$ & $185,1<\mathrm{T} \leq 215,2$ & $205,6<\mathrm{T} \leq 235,4$ & $227,6<\mathrm{T} \leq 258,0$ & $236,6<\mathrm{T} \leq 264,4$ \\
\hline CS & $215,2<T \leq 251,2$ & $235,4<\mathrm{T} \leq 271,1$ & $258,0<\mathrm{T} \leq 294,4$ & $264,4<\mathrm{T} \leq 297,7$ \\
\hline $\mathrm{CE}$ & $>251,2$ & $>271,1$ & $>294,4$ & $>297,7$ \\
\hline \multicolumn{5}{|c|}{936110} \\
\hline Classe & P 2 dias $(\mathrm{mm})$ & P 3 dias $(\mathrm{mm})$ & P 4 dias (mm) & P 5 dias (mm) \\
\hline $\mathrm{CF}$ & $\leq 101,1$ & $\leq 115,8$ & $\leq 123,3$ & $\leq 134,5$ \\
\hline $\mathrm{CL}$ & $101,1<\mathrm{T} \leq 160,1$ & $115,8<\mathrm{T} \leq 172,9$ & $123,3<\mathrm{T} \leq 180,4$ & $134,5<\mathrm{T} \leq 190,3$ \\
\hline CM & $160,1<\mathrm{T} \leq 199,1$ & $172,9<\mathrm{T} \leq 210,7$ & $180,4<T \leq 218,1$ & $190,3<\mathrm{T} \leq 227,2$ \\
\hline CS & $199,1<\mathrm{T} \leq 245,8$ & $210,7<\mathrm{T} \leq 255,9$ & $218,1<\mathrm{T} \leq 263,2$ & $227,2<\mathrm{T} \leq 271,3$ \\
\hline CE & $>245,8$ & $>255,9$ & $>263,2$ & $>271,3$ \\
\hline \multicolumn{5}{|c|}{936111} \\
\hline Classe & P 2 dias $(\mathrm{mm})$ & P 3 dias $(\mathrm{mm})$ & P 4 dias $(\mathrm{mm})$ & P 5 dias $(\mathrm{mm})$ \\
\hline $\mathrm{CF}$ & $\leq 83,2$ & $\leq 101,2$ & $\leq 112,2$ & $\leq 121,9$ \\
\hline $\mathrm{CL}$ & $83,2<\mathrm{T} \leq 116,7$ & $101,2<T \leq 142,0$ & $112,2<\mathrm{T} \leq 153,6$ & $121,9<\mathrm{T} \leq 167,8$ \\
\hline $\mathrm{CM}$ & $116,7<\mathrm{T} \leq 138,9$ & $142,0<\mathrm{T} \leq 169,0$ & $153,6<T \leq 181,0$ & $167,8<\mathrm{T} \leq 198,1$ \\
\hline CS & $138,9<\mathrm{T} \leq 165,4$ & $169,0<\mathrm{T} \leq 201,2$ & $181,0<\mathrm{T} \leq 213,7$ & $198,1<\mathrm{T} \leq 234,4$ \\
\hline CE & $>165,4$ & $>201,2$ & $>213,7$ & $>234,4$ \\
\hline \multicolumn{5}{|c|}{936112} \\
\hline Classe & P 2 dias (mm) & P 3 dias (mm) & P 4 dias (mm) & P 5 dias (mm) \\
\hline $\mathrm{CF}$ & $\leq 93,8$ & $\leq 110,6$ & $\leq 117,6$ & $\leq 127,7$ \\
\hline $\mathrm{CL}$ & $93,8<\mathrm{T} \leq 134,0$ & $110,6<\mathrm{T} \leq 154,0$ & $117,6<\mathrm{T} \leq 162,8$ & $127,7<\mathrm{T} \leq 176,7$ \\
\hline CM & $134,0<T \leq 160,6$ & $154,0<\mathrm{T} \leq 182,7$ & $162,8<\mathrm{T} \leq 192,6$ & $176,7<\mathrm{T} \leq 209,0$ \\
\hline CS & $160,6<\mathrm{T} \leq 192,5$ & $182,7<T \leq 217,0$ & $192,6<\mathrm{T} \leq 228,4$ & $209,0<\mathrm{T} \leq 247,7$ \\
\hline CE & $>192,5$ & $>217,0$ & $>228,4$ & $>247,7$ \\
\hline \multicolumn{5}{|c|}{936114} \\
\hline Classe & P 2 dias (mm) & P 3 dias $(\mathrm{mm})$ & P 4 dias $(\mathrm{mm})$ & P 5 dias $(\mathrm{mm})$ \\
\hline $\mathrm{CF}$ & $\leq 101,1$ & $\leq 117,1$ & $\leq 128,3$ & $\leq 138,5$ \\
\hline $\mathrm{CL}$ & $101,1<\mathrm{T} \leq 140,7$ & $117,1<\mathrm{T} \leq 161,9$ & $128,3<\mathrm{T} \leq 174,4$ & $138,5<\mathrm{T} \leq 186,2$ \\
\hline $\mathrm{CM}$ & $140,7<\mathrm{T} \leq 166,9$ & $161,9<\mathrm{T} \leq 191,5$ & $174,4<T \leq 205,0$ & $186,2<\mathrm{T} \leq 217,7$ \\
\hline CS & $166,9<\mathrm{T} \leq 198,2$ & $191,5<\mathrm{T} \leq 226,9$ & $205,0<T \leq 241,5$ & $217,7<\mathrm{T} \leq 255,5$ \\
\hline CE & $>198,2$ & $>226,9$ & $>241,5$ & $>255,5$ \\
\hline \multicolumn{5}{|c|}{936115} \\
\hline
\end{tabular}




\begin{tabular}{|c|c|c|c|c|}
\hline Classe & P 2 dias (mm) & P 3 dias $(\mathbf{m m})$ & P 4 dias (mm) & P 5 dias (mm) \\
\hline $\mathrm{CF}$ & $\leq 82,0$ & $\leq 92,2$ & $\leq 100,6$ & $\leq 105,5$ \\
\hline $\mathrm{CL}$ & $82,0<\mathrm{T} \leq 115,1$ & $92,2<\mathrm{T} \leq 127,1$ & $100,6<\mathrm{T} \leq 136,0$ & $105,5<\mathrm{T} \leq 142,0$ \\
\hline $\mathrm{CM}$ & $115,1<\mathrm{T} \leq 137,0$ & $127,1<\mathrm{T} \leq 150,1$ & $136,0<\mathrm{T} \leq 159,4$ & $142,0<\mathrm{T} \leq 166,2$ \\
\hline $\mathrm{CS}$ & $137,0<\mathrm{T} \leq 163,2$ & $150,1<\mathrm{T} \leq 177,6$ & $159,4<\mathrm{T} \leq 187,4$ & $166,2<\mathrm{T} \leq 195,1$ \\
\hline $\mathrm{CE}$ & $>163,2$ & $>177,6$ & $>187,4$ & $>195,1$ \\
\hline
\end{tabular}

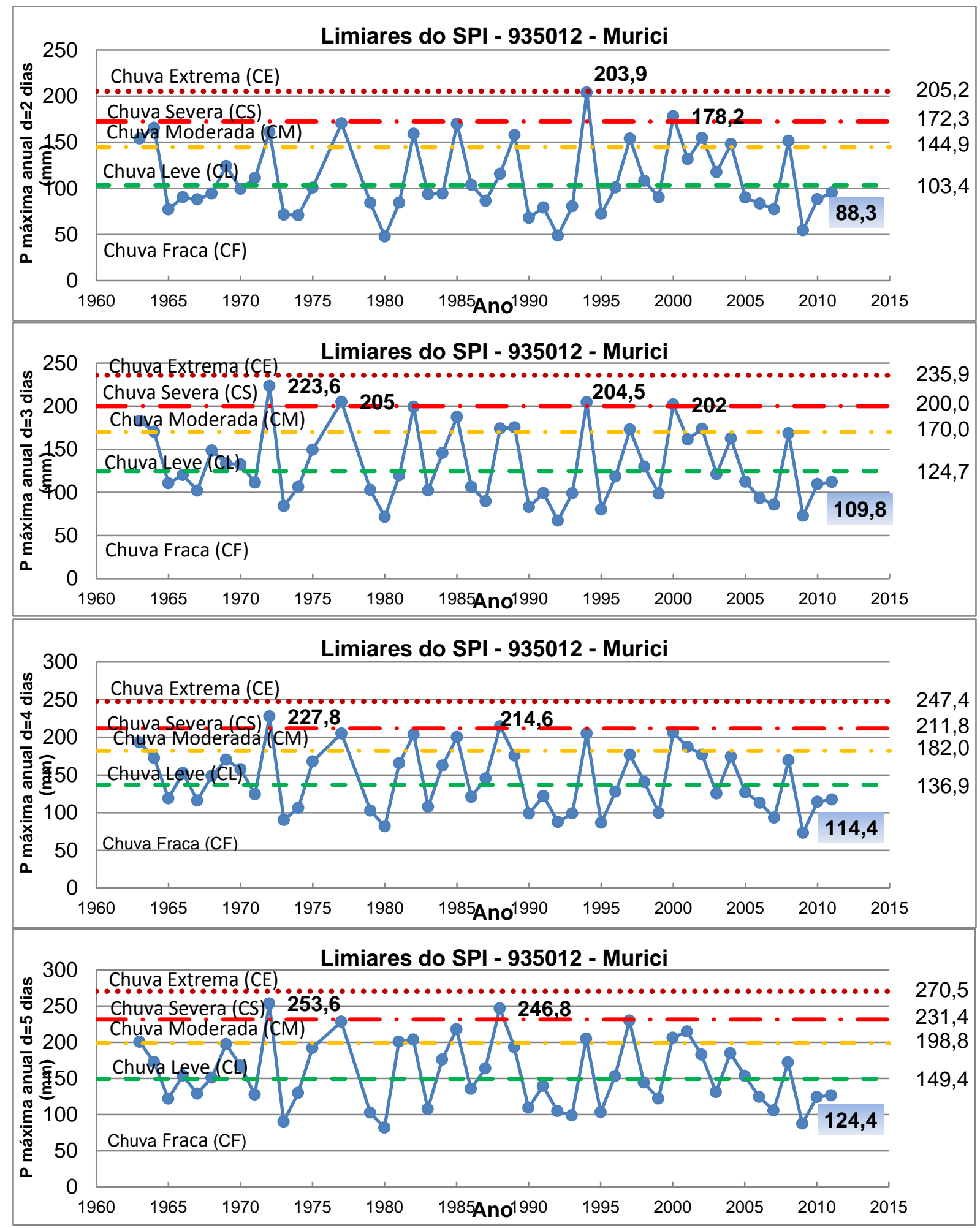




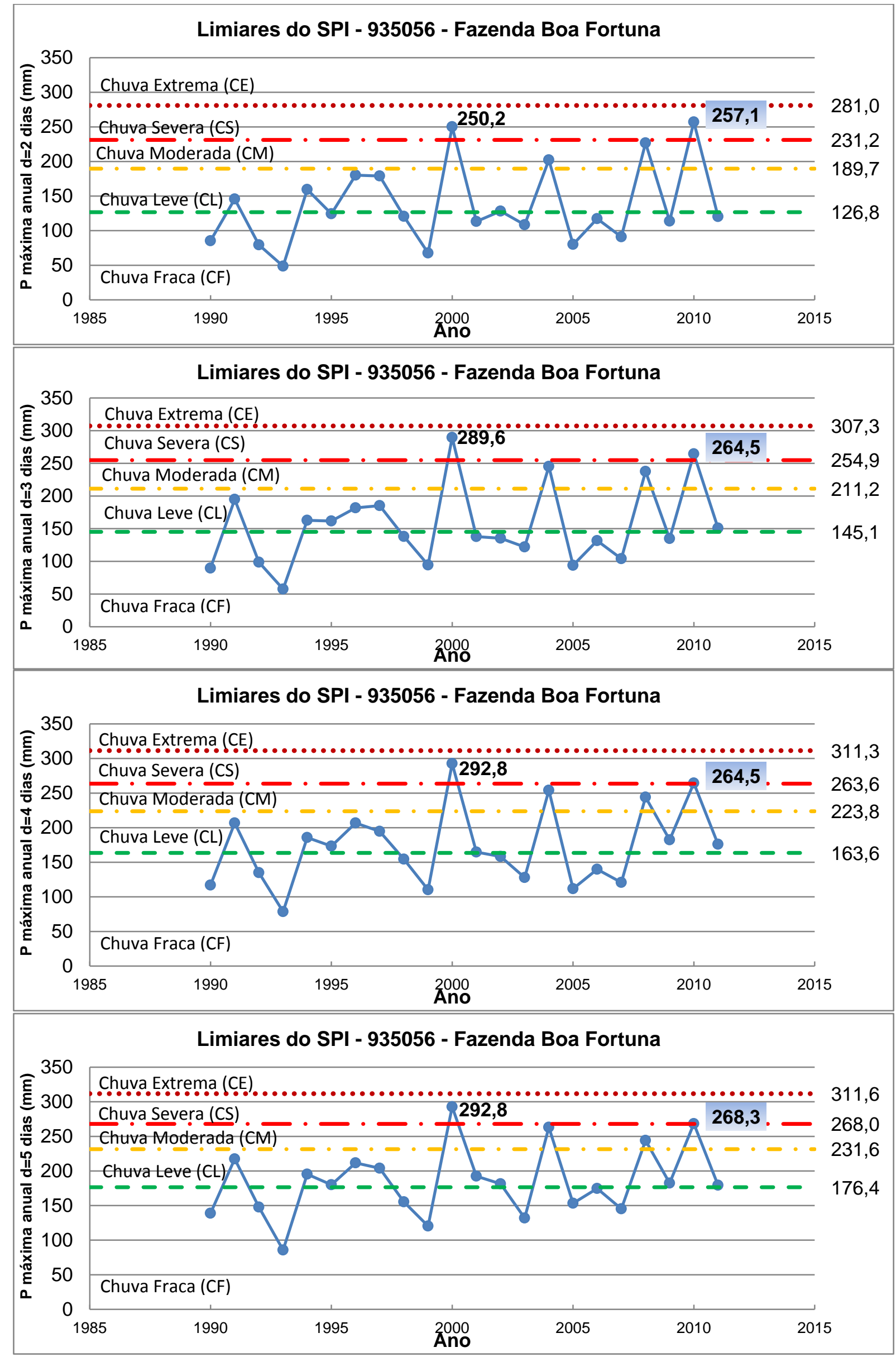




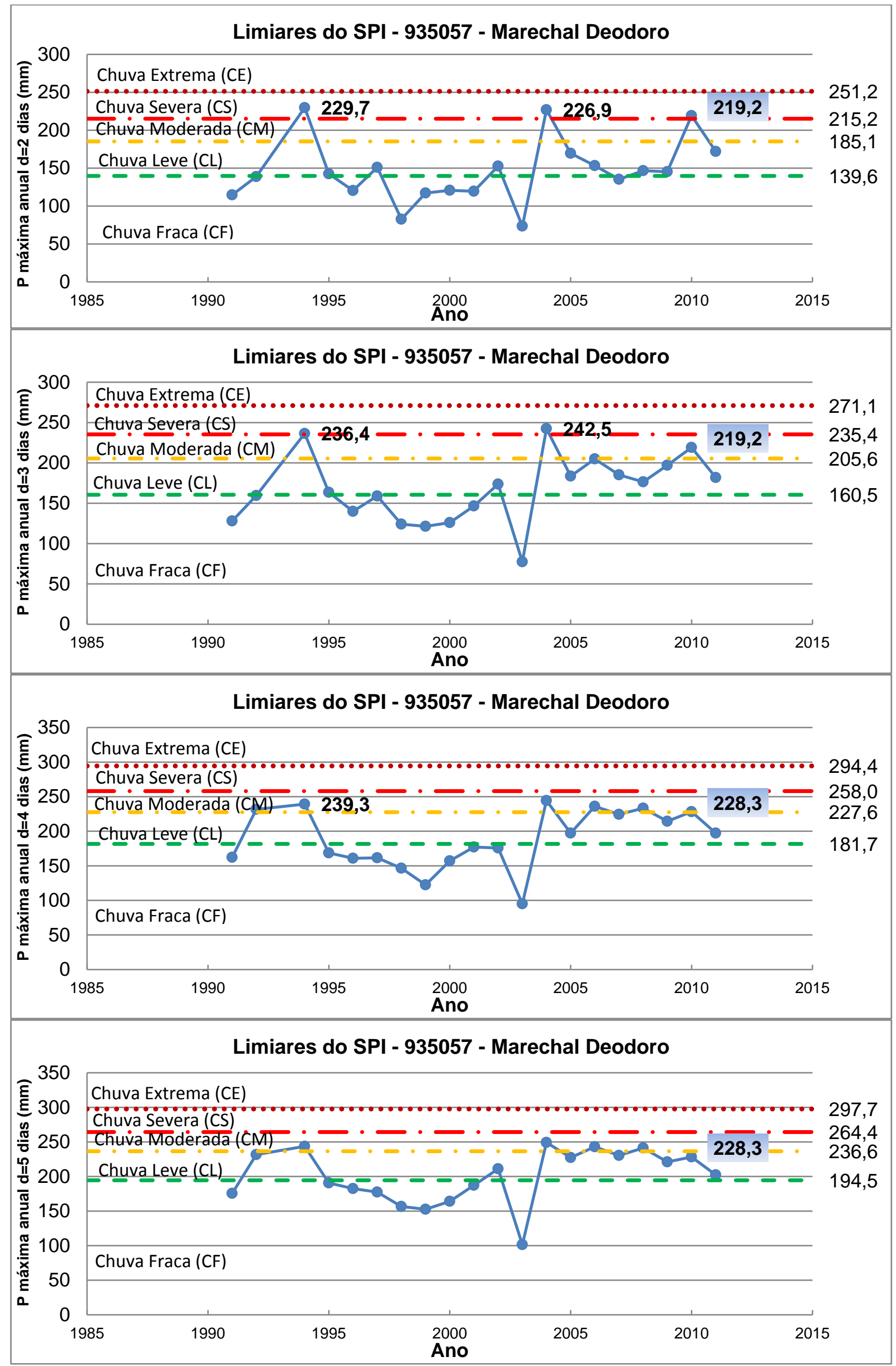




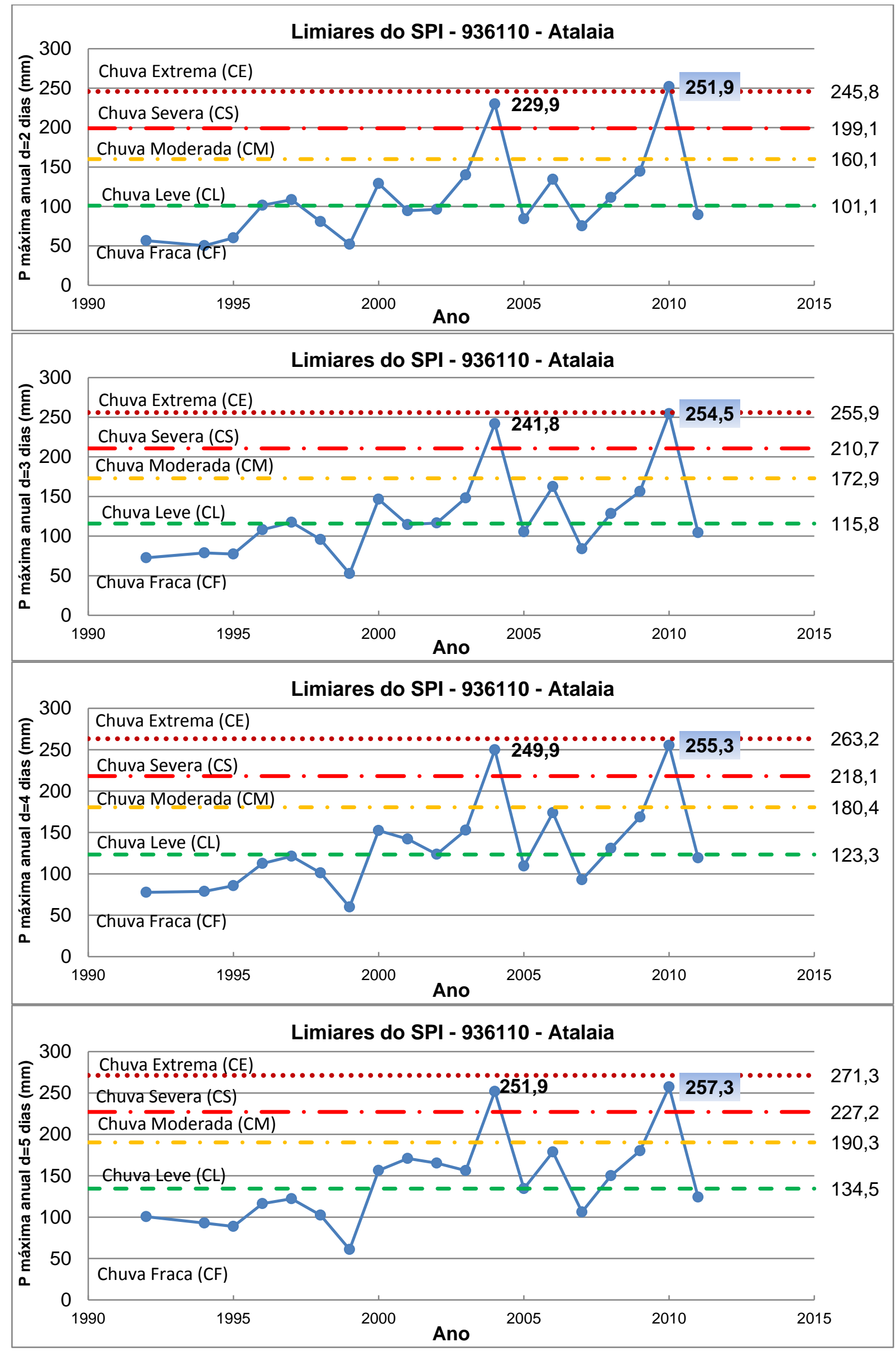




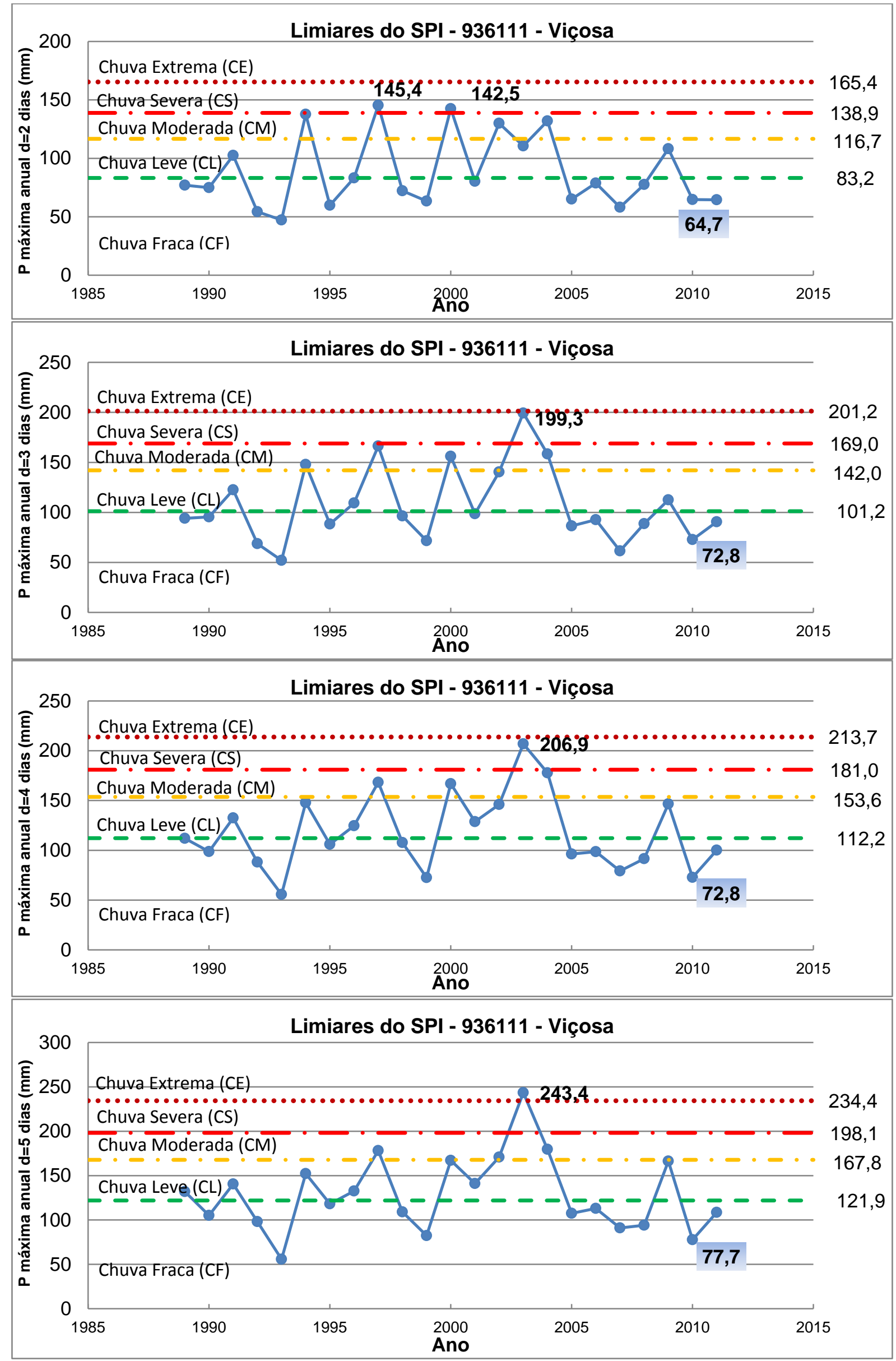




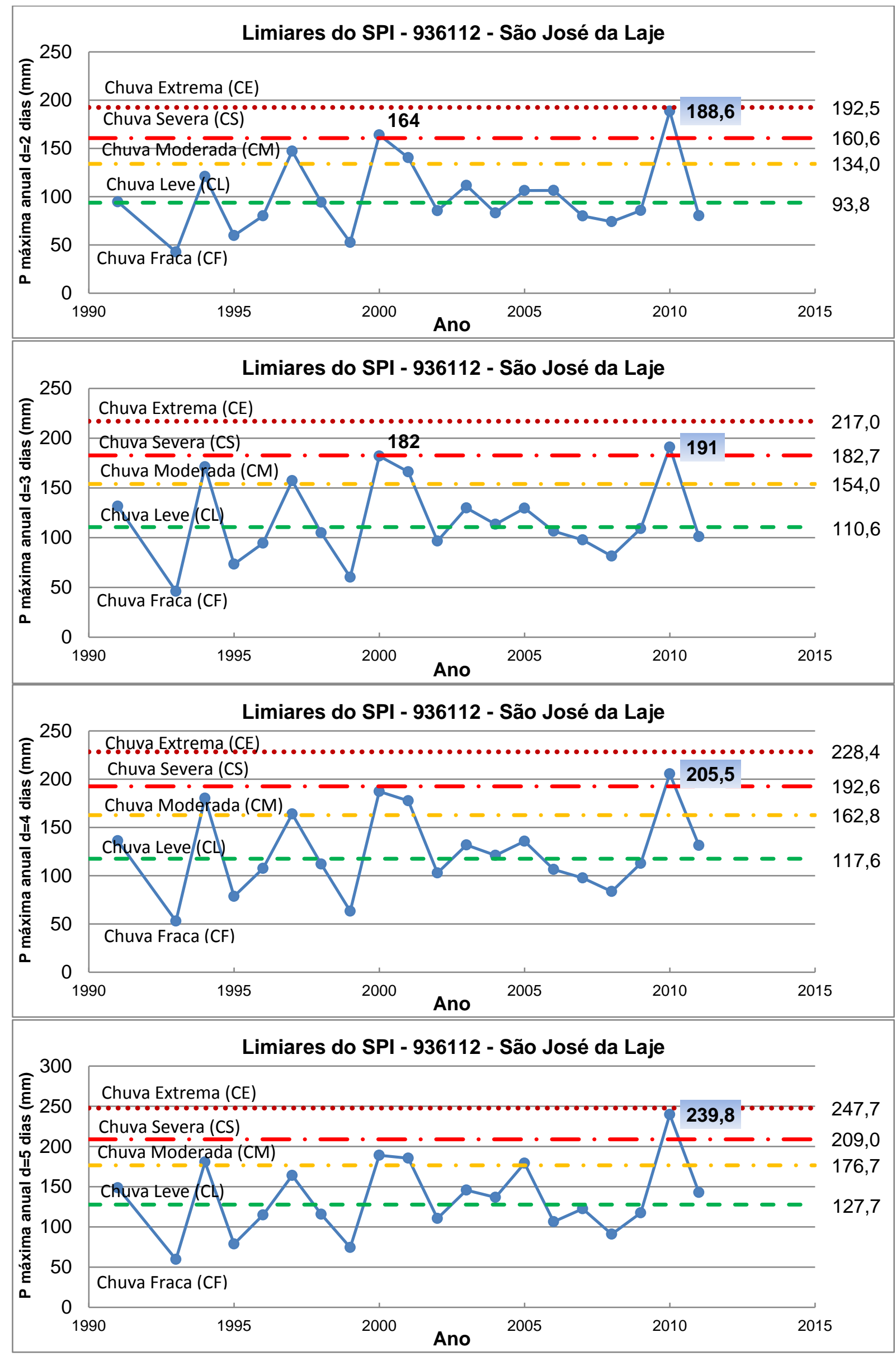



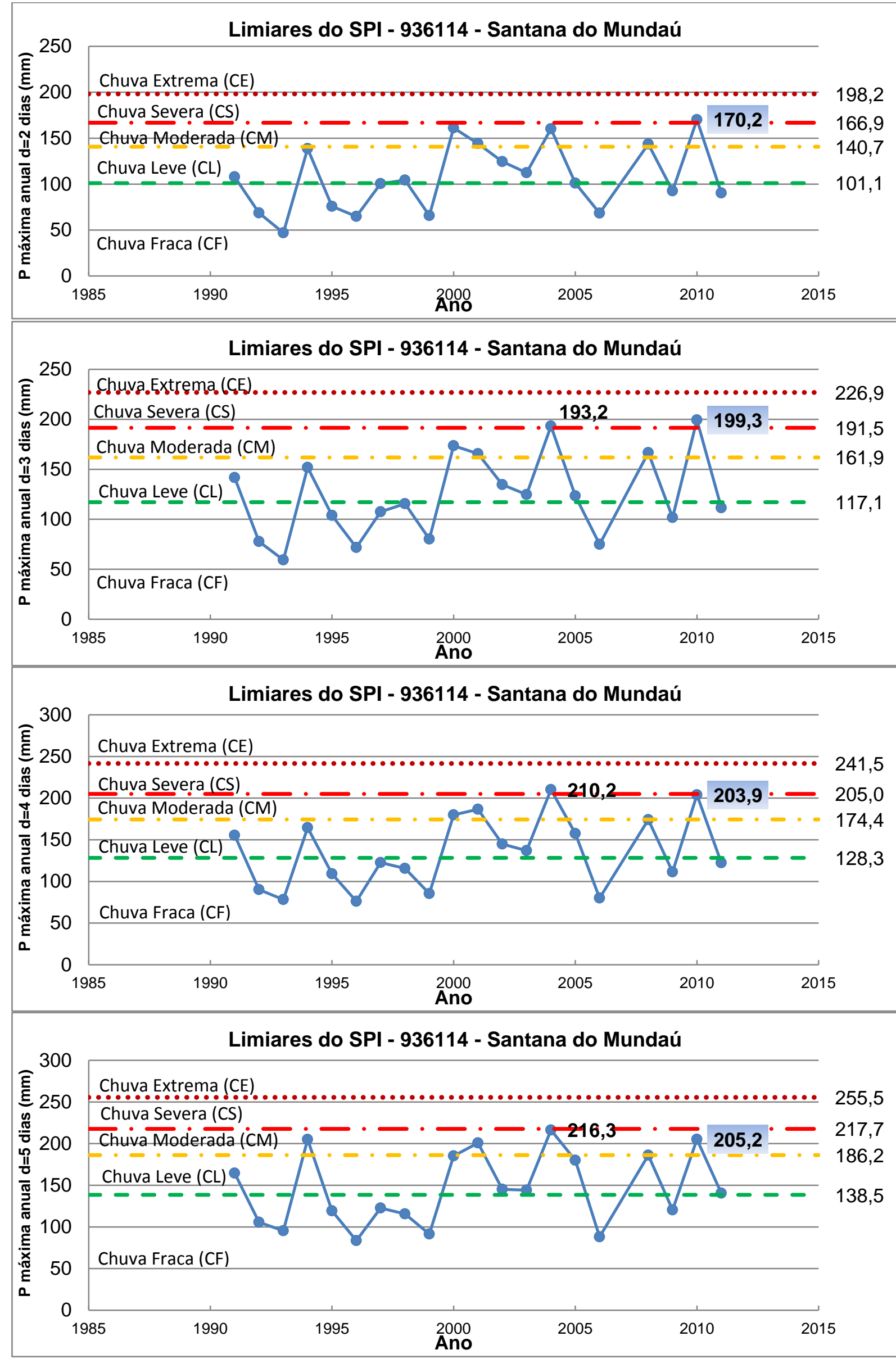


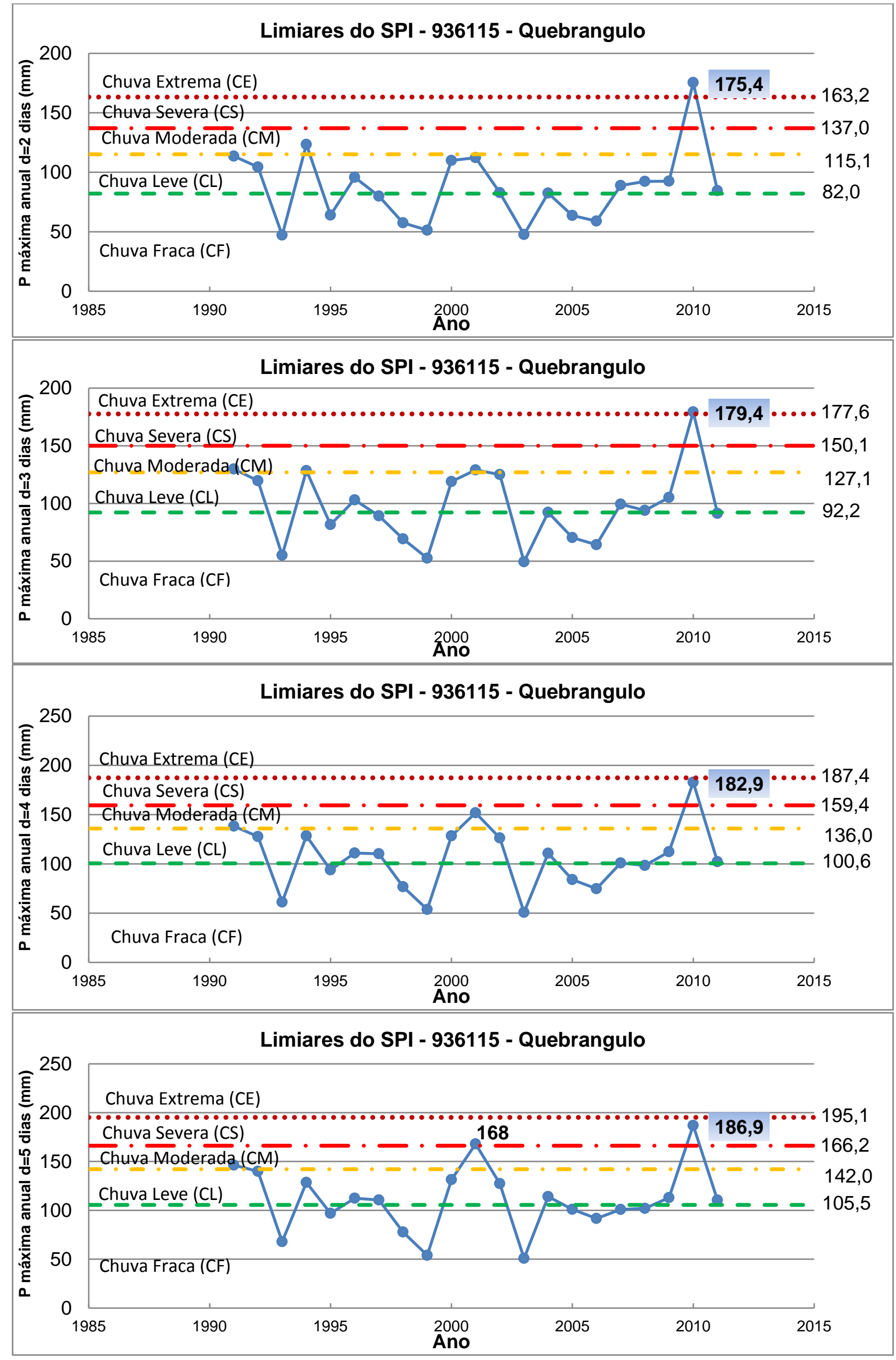




\section{Anexo V - Limiares do SPI da Região Serrana do Rio de Janeiro}

\begin{tabular}{|c|c|c|c|c|}
\hline \multicolumn{5}{|c|}{2242019} \\
\hline Classe & P 2 dias $(\mathrm{mm})$ & P 3 dias $(\mathrm{mm})$ & P 4 dias $(\mathrm{mm})$ & P 5 dias $(\mathrm{mm})$ \\
\hline $\mathrm{CF}$ & $\leq 122,7$ & $\leq 143,1$ & $\leq 162,3$ & $\leq 178,4$ \\
\hline $\mathrm{CL}$ & $122,7<\mathrm{T} \leq 180,2$ & $143,1<\mathrm{T} \leq 207,3$ & $162,3<\mathrm{T} \leq 233,6$ & $178,4<\mathrm{T} \leq 253,6$ \\
\hline $\mathrm{CM}$ & $180,2<\mathrm{T} \leq 218,3$ & $207,3<T \leq 249,8$ & $233,6<T \leq 280,8$ & $253,6<\mathrm{T} \leq 303,4$ \\
\hline CS & $218,3<T \leq 263,8$ & $249,8<T \leq 300,6$ & $280,8<\mathrm{T} \leq 337,2$ & $303,4<\mathrm{T} \leq 362,9$ \\
\hline $\mathrm{CE}$ & $>263,8$ & $>300,6$ & $>337,2$ & $>362,9$ \\
\hline \multicolumn{5}{|c|}{2242020} \\
\hline Classe & P 2 dias (mm) & P 3 dias $(\mathrm{mm})$ & P 4 dias $(\mathrm{mm})$ & P 5 dias $(\mathrm{mm})$ \\
\hline $\mathrm{CF}$ & $\leq 108,0$ & $\leq 129,9$ & $\leq 149,4$ & $\leq 162,9$ \\
\hline $\mathrm{CL}$ & $108,0<T \leq 160,2$ & $129,9<T \leq 193,8$ & $149,4<\mathrm{T} \leq 226,0$ & $162,9<\mathrm{T} \leq 246,7$ \\
\hline $\mathrm{CM}$ & $160,2<\mathrm{T} \leq 194,8$ & $193,8<T \leq 236,0$ & $226,0<\mathrm{T} \leq 276,7$ & $246,7<\mathrm{T} \leq 302,1$ \\
\hline CS & $194,8<\mathrm{T} \leq 236,1$ & $236,0<\mathrm{T} \leq 286,6$ & $276,7<\mathrm{T} \leq 337,3$ & $302,1<\mathrm{T} \leq 368,3$ \\
\hline $\mathrm{CE}$ & $>236,1$ & $>286,6$ & $>337,3$ & $>368,3$ \\
\hline \multicolumn{5}{|c|}{2242022} \\
\hline Classe & P 2 dias $(\mathrm{mm})$ & P 3 dias $(\mathrm{mm})$ & P 4 dias $(\mathrm{mm})$ & P 5 dias $(\mathrm{mm})$ \\
\hline CF & $\leq 99,5$ & $\leq 117,5$ & $\leq 133,2$ & $\leq 146,2$ \\
\hline $\mathrm{CL}$ & $99,5<\mathrm{T} \leq 148,5$ & $117,5<\mathrm{T} \leq 174,7$ & $133,2<\mathrm{T} \leq 156,0$ & $146,2<\mathrm{T} \leq 213,8$ \\
\hline $\mathrm{CM}$ & $148,5<\mathrm{T} \leq 180,9$ & $174,7<\mathrm{T} \leq 212,6$ & $156,0<\mathrm{T} \leq 237,6$ & $213,8<T \leq 258,4$ \\
\hline CS & $180,9<\mathrm{T} \leq 219,7$ & $212,6<\mathrm{T} \leq 257,8$ & $237,6<\mathrm{T} \leq 287,3$ & $258,4<T \leq 311,9$ \\
\hline CE & $>219,7$ & $>257,8$ & $>287,3$ & $>311,9$ \\
\hline \multicolumn{5}{|c|}{2242024} \\
\hline Classe & P 2 dias $(\mathrm{mm})$ & P 3 dias $(\mathrm{mm})$ & P 4 dias (mm) & P 5 dias $(\mathrm{mm})$ \\
\hline $\mathrm{CF}$ & $\leq 154,9$ & $\leq 189,3$ & $\leq 213,2$ & $\leq 236,1$ \\
\hline $\mathrm{CL}$ & $154,9<\mathrm{T} \leq 194,6$ & $189,3<\mathrm{T} \leq 235,5$ & $213,2<\mathrm{T} \leq 266,9$ & $236,1<\mathrm{T} \leq 299,2$ \\
\hline $\mathrm{CM}$ & $194,6<\mathrm{T} \leq 220,8$ & $235,5<\mathrm{T} \leq 266,1$ & $266,9<\mathrm{T} \leq 302,4$ & $299,2<\mathrm{T} \leq 341,0$ \\
\hline $\mathrm{CS}$ & $220,8<\mathrm{T} \leq 252,1$ & $266,1<\mathrm{T} \leq 302,6$ & $302,4<\mathrm{T} \leq 344,9$ & $341,0<\mathrm{T} \leq 391,0$ \\
\hline CE & $>252,1$ & $>302,6$ & $>344,9$ & $>391,0$ \\
\hline \multicolumn{5}{|c|}{2242027} \\
\hline Classe & P 2 dias (mm) & P 3 dias $(\mathrm{mm})$ & P 4 dias $(\mathrm{mm})$ & P 5 dias (mm) \\
\hline $\mathrm{CF}$ & $\leq 103,3$ & $\leq 121,0$ & $\leq 136,0$ & $\leq 148,2$ \\
\hline $\mathrm{CL}$ & $103,3<\mathrm{T} \leq 139,2$ & $121,0<\mathrm{T} \leq 160,3$ & $136,0<\mathrm{T} \leq 179,4$ & $148,2<\mathrm{T} \leq 197,8$ \\
\hline $\mathrm{CM}$ & $139,2<\mathrm{T} \leq 162,9$ & $160,3<\mathrm{T} \leq 186,2$ & $179,4<\mathrm{T} \leq 208,1$ & $197,8<\mathrm{T} \leq 230,6$ \\
\hline CS & $162,9<\mathrm{T} \leq 191,3$ & $186,2<\mathrm{T} \leq 217,3$ & $208,1<\mathrm{T} \leq 242,5$ & $230,6<\mathrm{T} \leq 269,8$ \\
\hline CE & $>191,3$ & $>217,3$ & $>242,5$ & $>269,8$ \\
\hline \multicolumn{5}{|c|}{2243010} \\
\hline Classe & P 2 dias (mm) & P 3 dias $(\mathrm{mm})$ & P 4 dias $(\mathrm{mm})$ & P 5 dias (mm) \\
\hline $\mathrm{CF}$ & $\leq 108,6$ & $\leq 126,6$ & $\leq 139,7$ & $\leq 153,0$ \\
\hline $\mathrm{CL}$ & $108,6<\mathrm{T} \leq 143,3$ & $126,6<\mathrm{T} \leq 166,7$ & $139,7<\mathrm{T} \leq 184,0$ & $153,0<\mathrm{T} \leq 203,7$ \\
\hline $\mathrm{CM}$ & $143,3<\mathrm{T} \leq 166,2$ & $166,7<\mathrm{T} \leq 193,2$ & $184,0<\mathrm{T} \leq 213,4$ & $203,7<\mathrm{T} \leq 237,2$ \\
\hline CS & $166,2<\mathrm{T} \leq 193,6$ & $193,2<T \leq 224,9$ & $213,4<\mathrm{T} \leq 248,4$ & $237,2<\mathrm{T} \leq 277,4$ \\
\hline $\mathrm{CE}$ & $>193,6$ & $>224,9$ & $>248,4$ & $>277,4$ \\
\hline \multicolumn{5}{|c|}{2243011} \\
\hline Classe & P 2 dias $(\mathrm{mm})$ & P 3 dias $(\mathrm{mm})$ & P 4 dias (mm) & P 5 dias $(\mathrm{mm})$ \\
\hline $\mathrm{CF}$ & $\leq 110,6$ & $\leq 128,6$ & $\leq 142,8$ & $\leq 157,0$ \\
\hline $\mathrm{CL}$ & $110,6<\mathrm{T} \leq 144,6$ & $128,6<\mathrm{T} \leq 171,1$ & $142,8<\mathrm{T} \leq 190,6$ & $157,0<\mathrm{T} \leq 208,2$ \\
\hline $\mathrm{CM}$ & $144,6<\mathrm{T} \leq 167,1$ & $171,1<\mathrm{T} \leq 199,2$ & $190,6<\mathrm{T} \leq 222,2$ & $208,2<\mathrm{T} \leq 242,0$ \\
\hline CS & $167,1<\mathrm{T} \leq 194,0$ & $199,2<\mathrm{T} \leq 232,9$ & $222,2<\mathrm{T} \leq 260,0$ & $242,0<\mathrm{T} \leq 282,5$ \\
\hline $\mathrm{CE}$ & $>194,0$ & $>232,9$ & $>260,0$ & $>282,5$ \\
\hline
\end{tabular}




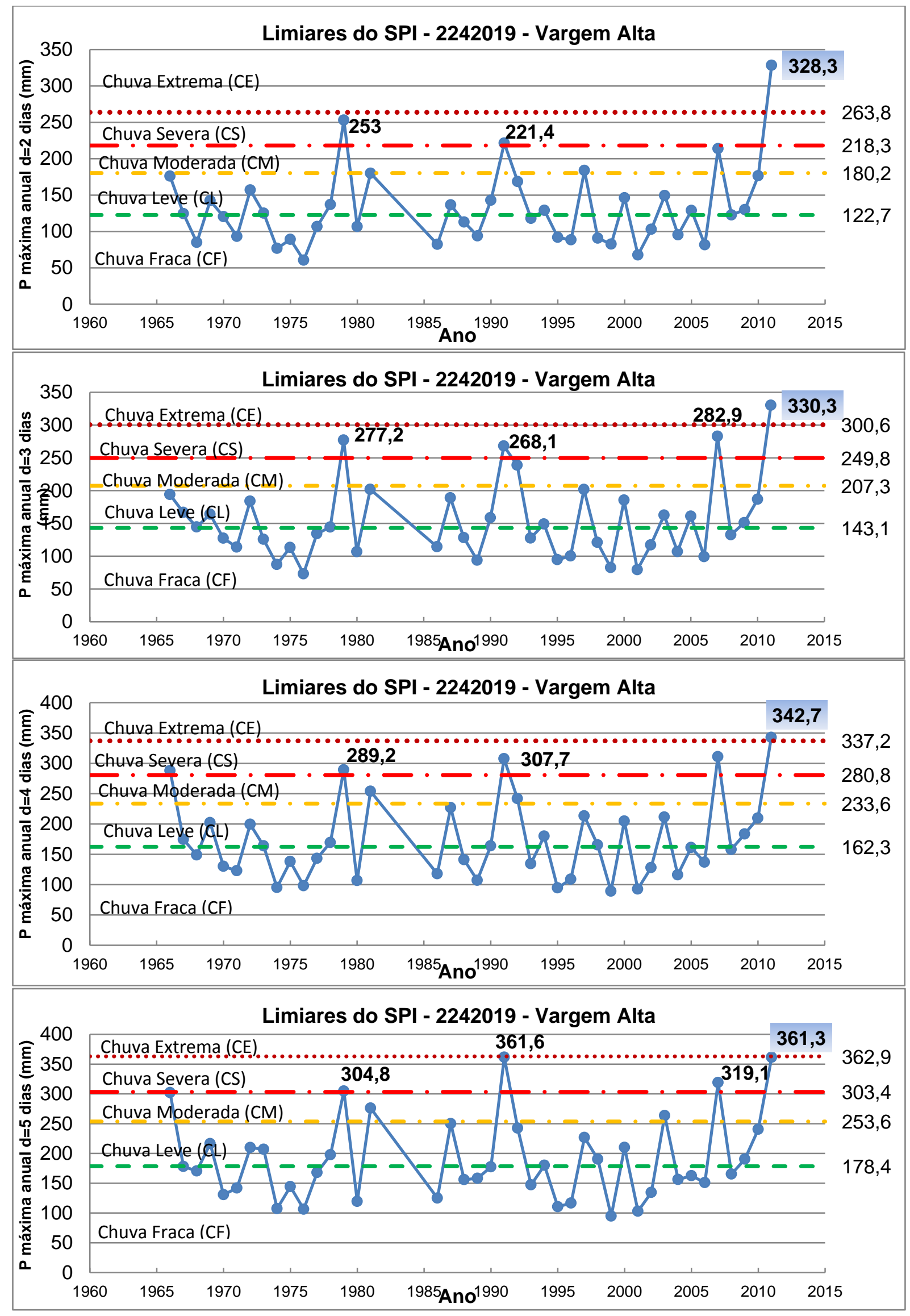




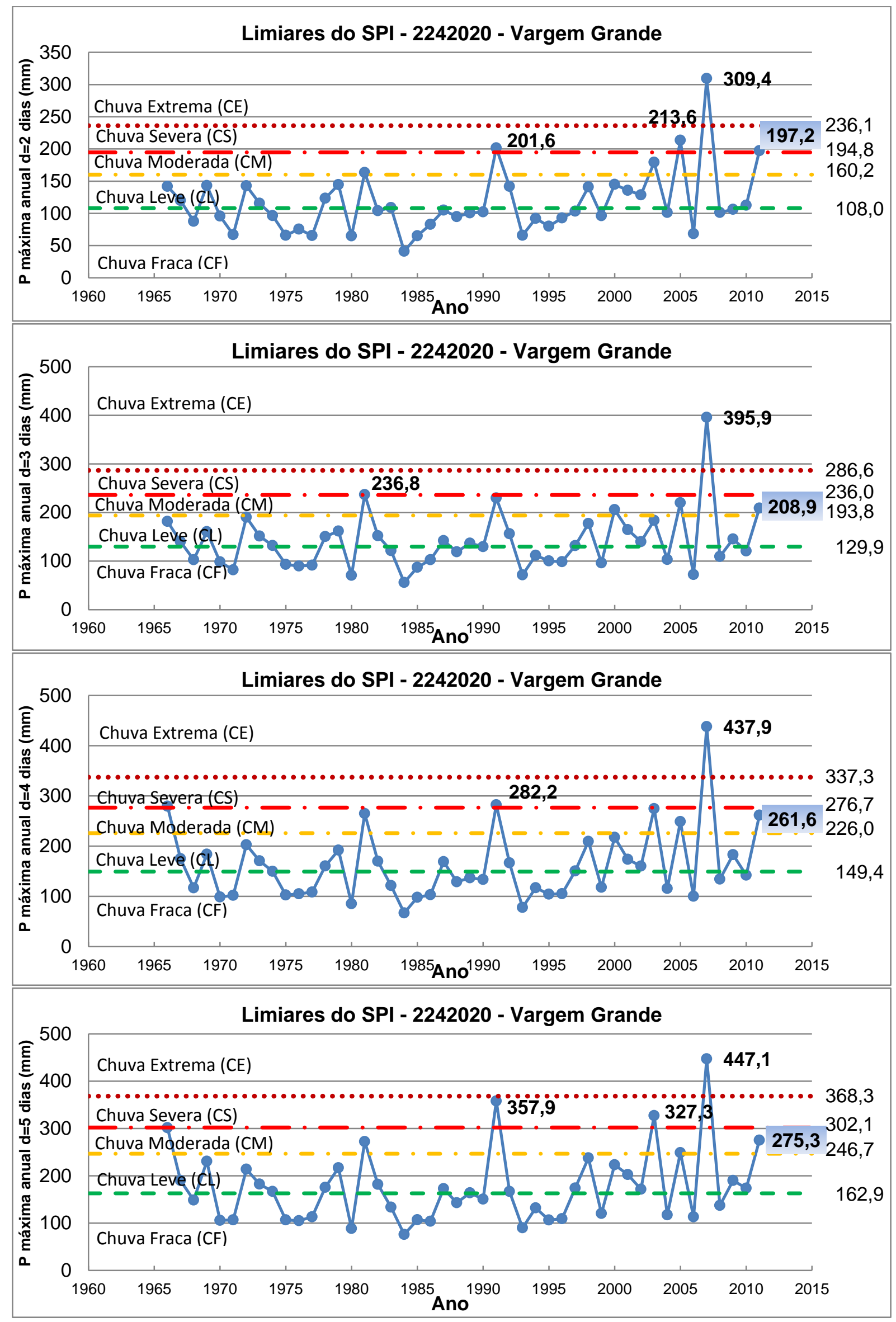




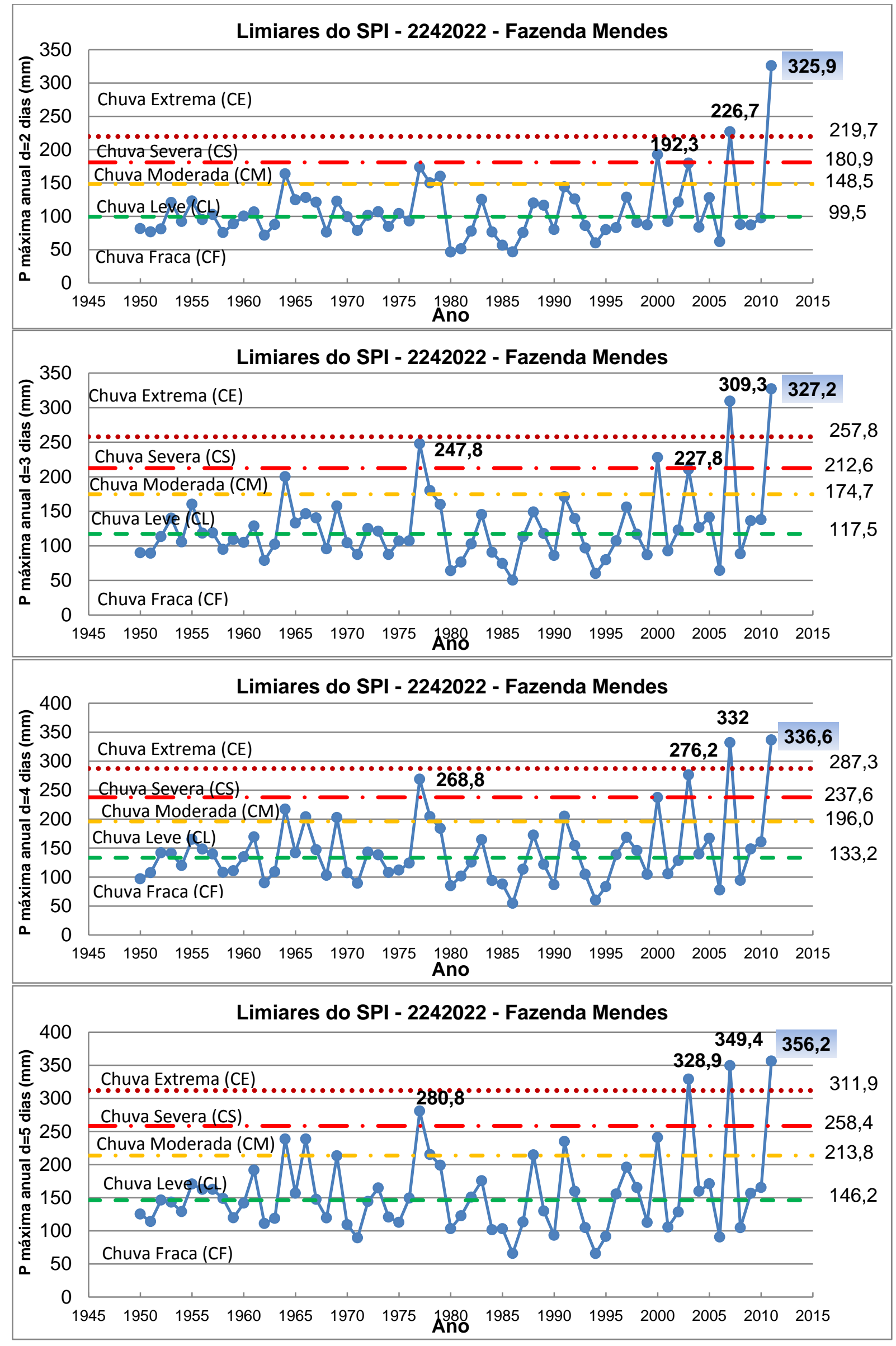




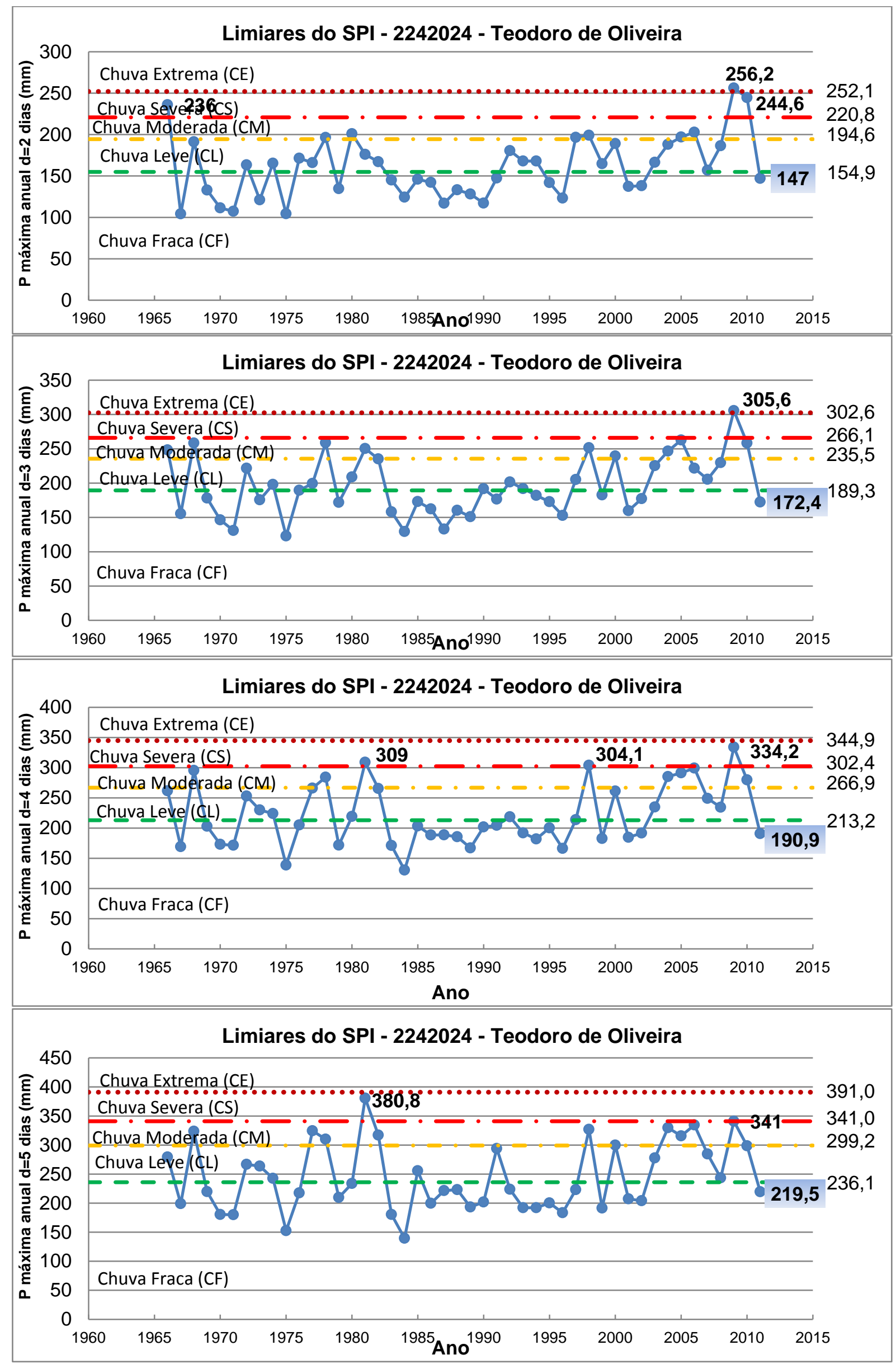




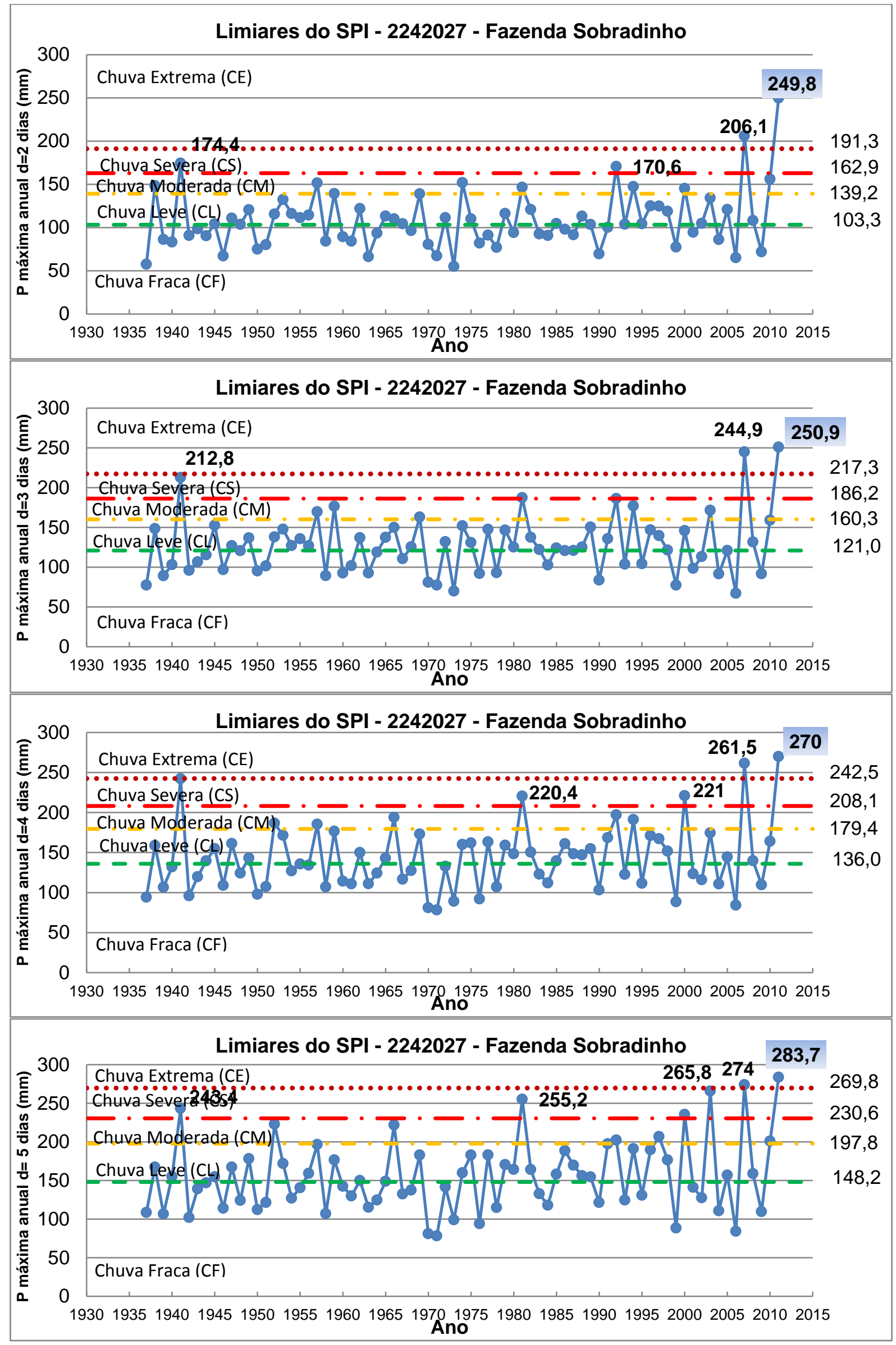




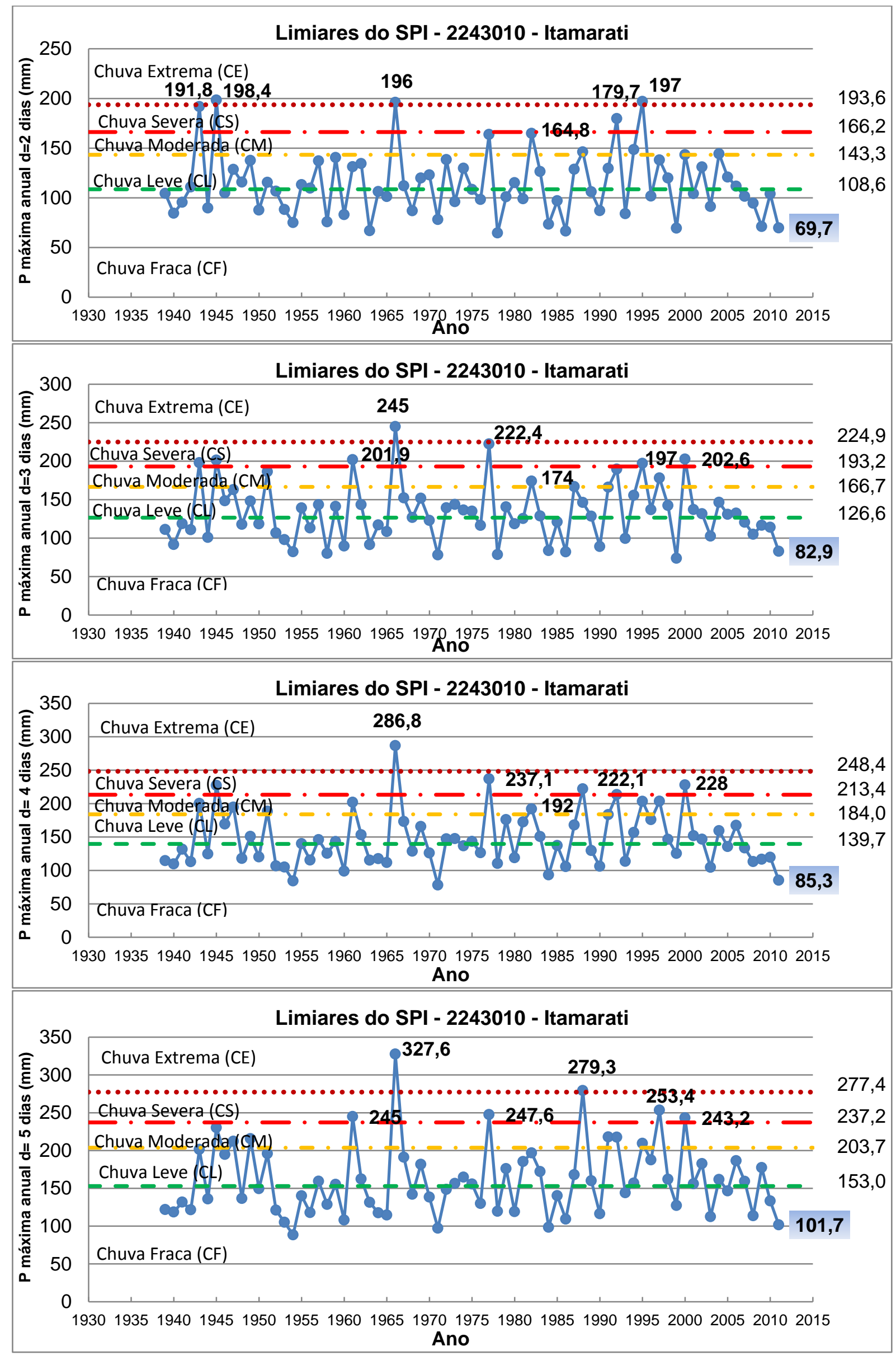




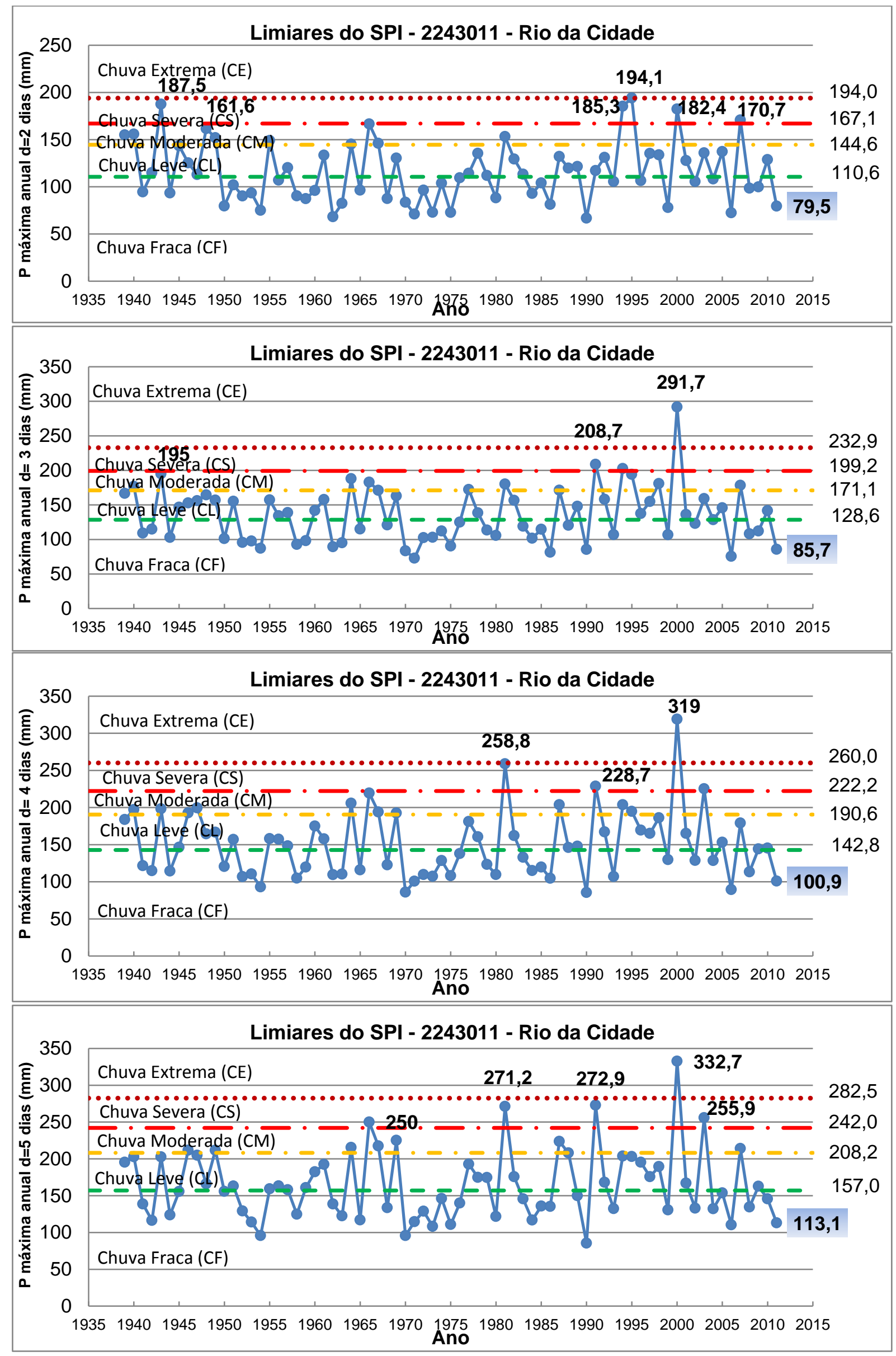

